\title{
Phase 2 THOR Steam Reforming Tests for Sodium- Bearing Waste Treatment
}

\author{
N. R. Soelberg \\ D. W. Marshall \\ S. O. Bates \\ D. D. Taylor
}

January 2004

Idaho National Engineering and Environmental Laboratory Bechtel BWXT Idaho, LLC 


\title{
Phase 2 Steam Reforming Tests for Sodium-Bearing Waste Treatment
}

\author{
Nicholas R. Soelberg \\ Douglas W. Marshall \\ Steven O. Bates \\ Dean D. Taylor
}

January 30, 2004

\section{Idaho National Engineering and Environmental Laboratory Environmental Technology and Engineering Idaho Falls, Idaho 83415}

\author{
Prepared for the \\ U.S. Department of Energy \\ Assistant Secretary for Environmental Management \\ Under DOE Idaho Operations Office \\ Contract DE-AC07-99ID13727
}




\begin{abstract}
About one million gallons of acidic, hazardous, and radioactive sodiumbearing waste is stored in stainless steel tanks at the Idaho Nuclear Technology and Engineering Center (INTEC), which is a major operating facility of the Idaho National Engineering and Environmental Laboratory. Steam reforming is a candidate technology being investigated for converting the waste into a road ready waste form that can be shipped to the Waste Isolation Pilot Plant in New Mexico for interment.

A steam reforming technology patented by Studsvik, Inc., and licensed to THOR Treatment Technologies has been tested in two phases using a Department of Energy-owned fluidized bed test system located at the Science Applications International Corporation (SAIC) Science and Technology Applications Research Center located in Idaho Falls, Idaho. The Phase 1 tests were reported earlier in 2003. The Phase 2 tests are reported here.

For Phase 2, the process feed rate, stoichiometry, and chemistry were varied to identify and demonstrate process operation and product characteristics under different operating conditions. Two test series were performed. During the first series, the process chemistry was designed to produce a sodium carbonate product. The second series was designed to produce a more leachresistant, mineralized sodium aluminosilicate product. The tests also demonstrated the performance of a MACT-compliant off-gas system.
\end{abstract}




\section{EXECUTIVE SUMMARY}

About one million gallons of acidic, hazardous, and radioactive sodium-bearing waste (SBW) is stored in stainless steel tanks at the Idaho Nuclear Technology and Engineering Center (INTEC), which is a major operating facility of the Idaho National Engineering and Environmental Laboratory (INEEL). Steam reforming is a candidate technology being investigated for treatment of the SBW into a road ready waste form that can be shipped to the Waste Isolation Pilot Plant in New Mexico for interment.

A steam reforming technology patented by Studsvik, Inc., and licensed to THOR Treatment Technologies (TTT) was demonstrated on a WM-180 SBW simulant in January of 2003 using a Department of Energy-owned fluidized bed test system. The THOR steam reforming process provides a thermal and reactive environment to evaporate the liquid SBW simulant feed to a dry, granular solid product, and to destroy nitrates in the feed and $\mathrm{NO}_{\mathrm{x}}$ evolved from the nitrates. The Phase 1 tests showed that SBW could be successfully converted into a solid alkali carbonate granule form without serious agglomeration, but the emphasis was on process viability and reliability rather than on production and optimization.

Phase 2 tests were performed in November 2003 to evaluate the THOR process under a wider range of conditions over two 1-week testing periods. During the first week, the process chemistry was designed to produce a sodium carbonate product similar to that of the January 2003 tests. Tests during the second week were designed to produce a more leach-resistant, mineralized sodium aluminosilicate product. The performance of an independent MACT-compliant off-gas system was also demonstrated.

TTT participated in the Phase 2 tests to ensure that the tests emulated the primary features of the THOR technology to the extent possible. During test planning stages, TTT provided recommendations for test system modifications and helped determine test objectives. Under subcontract to the INEEL, TTT personnel observed the test series, provided consultation and recommendations during the tests, and provided a post-test observation report to INEEL.

\section{Carbonate Test Series Results}

Process conditions of the carbonate test series were designed to produce an alkali carbonate product. Several different test conditions were performed to evaluate different solid reductants, provide operating time for process stabilization and bed building, determine maximum and optimum simulant feed rates, and to vary the reductant stoichiometry. All of the test objectives for the carbonate product tests were accomplished.

All carbonate tests produced a sodium carbonate product with no agglomerations. The process conditions and chemistry for producing a carbonate product simultaneously with high $\mathrm{NO}_{\mathrm{x}}$ resulted in stable bed operation, except that the bed particle size grew and was not controlled during the duration of the test series. Several options were identified as possible methods to control the bed particle size growth.

The SBW simulant feed rate exceeded rates achieved during the Phase-1 tests. Operation while processing a SBW simulant that contained synthetic tank heel solids was demonstrated.

The total mass of feed solids and residual unreacted solid carbon partitioned about $53 \%$ to the bed product (including recycled cyclone catch) and $47 \%$ to the filter catch. Heavy metals (excluding $\mathrm{Hg}$ ), halides, and radionuclide surrogates were quantitatively captured/retained in the bed product and filter catch. 
Residual organic carbon content in the products ranged from negligible quantities in both the bed product and filter catch when sugar syrup was the only reductant, up to $10 \mathrm{wt} \%$ in the bed and $53 \mathrm{wt} \%$ in the filter catch when activated carbon addition rates were high. The low carbon content of the products when activated carbon addition was low meets the objective to reduce unreacted carbon levels below what was achieved during Phase-1 tests.

$\mathrm{NO}_{\mathrm{x}}$ destruction during some of the carbonate test conditions averaged as high as $99 \%$. The average $\mathrm{NO}_{\mathrm{x}}$ destruction for all test conditions averaged 93\% for the test series (meeting the goal of $90 \%$ $\mathrm{NO}_{\mathrm{x}}$ destruction), even though some test conditions were designed to evaluate different reductants and lower reductant stoichiometries. Feed nitrate destruction averaged $99.96 \%$, and there was essentially no residual nitrate in the solid products.

Off-gas compliance to the Hazardous Waste Combustor Maximum Achievable Control Technology (HWC MACT) standards was demonstrated for mercury, chlorine, carbon monoxide, and total hydrocarbons. $99.4 \%$ of the $\mathrm{Cl}$ in the feed was retained in the steam reformer solid products. Mercury capture was $99.9 \%$ efficient with a granular activated carbon bed.

\section{Mineralized Test Series Results}

Conditions of the mineralized test series were designed to produce an alkali aluminosilicate product. Kaolin clay was added to combine with $\mathrm{Na}$ and $\mathrm{K}$ in the simulant to produce nepheline-like minerals. All of the objectives were met for the mineralized product.

The feasibility of producing a mineralized product was confirmed. When sufficient mineralizing additive was used, the mineralized product was leach resistant and passing Toxicity Characteristic Leaching Procedure (TCLP) limits for lead, chromium, nickel, and zinc. Product Consistency Test (PCT) leaches were performed on several bed, cyclone, and filter samples, using a modified PCT procedure developed for INEEL waste calcines. The results are still being evaluated and are not available for inclusion in this report.

The bed particle size growth was controlled, but the bed particle and bulk density continued to decrease during the test duration. The range of SBW feed rates was consistent with the ranges shown for the carbonate test series.

The total mass of feed solids and unreacted solid carbon partitioned about $41 \%$ to the bed product (including recycled cyclone catch) and 59\% to the filter catch. Heavy metals (excluding Hg), halides, and radionuclide surrogates were nearly entirely captured and retained in the bed product and filter catch.

Residual organic carbon content in the products ranged from negligible quantities in both the bed product and filter catch when sugar syrup was the only reductant, up to $8 \mathrm{wt} \%$ in the bed and $16 \mathrm{wt} \%$ in the filter catch when activated carbon addition rates were high. The low carbon content of the products when activated carbon addition was low meets the objective to reduce unreacted carbon levels below what was achieved during Phase-1 tests.

$\mathrm{NO}_{\mathrm{x}}$ reduction was generally not as high as observed during the carbonate test series, although $\mathrm{NO}_{\mathrm{x}}$ destruction for at least some of the test conditions reached the goal of $90 \%$. Feed nitrate destruction averaged $99.96 \%$, and there was essentially no residual nitrate in the solid products. The test results suggest that the metals in the SBW simulant or in iron-based additives did not catalyze $\mathrm{NO}_{\mathrm{x}}$ reduction during the mineralized test as much as was apparent in the carbonate tests. 
Off-gas compliance to the Hazardous Waste Combustor Maximum Achievable Control Technology (HWC MACT) standards was demonstrated for mercury, chlorine, carbon monoxide, and total hydrocarbons. At least $68 \%$ of the $\mathrm{Cl}$ in the feed was retained in the steam reformer solid products. Mercury capture was $99.8 \%$ efficient with a granular activated carbon bed.

\section{Recommendations}

Several areas were identified where additional testing and technology development/demonstration. These areas are:

- $\quad$ Control of the carbonate bed particle size growth by incorporation of a particle size management system to produce/introduce seed particles into the bed

- $\quad$ Improving the mineralized product density

- Improved reducing potential and $\mathrm{NO}_{\mathrm{x}}$ destruction while making a mineralized product

- Increasing retention of product in the bed particles and better solid carbon utilization by recycling more fines than were captured and recycled by the cyclone used during the test series

- Improved performance of key system components, including the gas distributor, the bed drain, and the feed nozzle

- Operation for longer periods of time to demonstrate long-term performance 


\section{ACKNOWLEDGMENTS}

Many persons from several organizations contributed to the success of this test program. Under direction from the Idaho National Engineering and Environmental Laboratory (INEEL), Science Applications International Corporation (SAIC) operates the Department of Energy (DOE)-owned fluidized bed test system at the SAIC Science and Technology Research (STAR) Center. Significant modifications to the prior fluidized bed test system were made before this test series. With collaboration from INEEL, SAIC designed, fabricated, and installed the modifications. Several subcontractors and vendors to SAIC also performed specific equipment fabrication and installation.

Many INEEL personnel were involved in the test program. Arlin Olson directed technology development, including steam reformer testing, for SBW treatment. Gary Anderson was the steam reformer test program manager. Richard Boardman provided fluidized bed and steam reforming technical consultation. Doug Marshall, Nick Soelberg, and Steve Bates designed and directed the steam reformer tests. Curtis St. Michel directed the team (Ervin Brubaker, Brad Eldredge of Eldredge Engineering, Jeff Gelner, an independent contractor through Portage Environmental, Del Heward, Desiree Reagan, Von Scholes, Trent Taylor, and John Yadon of Havlovick Engineering,) that designed and operated the process logic controller hardware, software, and related instrumentation. Duane Siemer designed and performed onsite analyses for process control and posttest laboratory analyses. Brad Ward performed onsite data and sample analyses and posttest sample management.

Most SAIC personnel who were involved in the test program also performed multiple roles and were involved in many aspects of equipment design, fabrication, installation, and steam reformer testing. Bart Packer was the SAIC project manager. J. D. Atkinson was the STAR Center director. Troy Thomson was the senior fluidized bed engineer and shift leader. Bryan Bird and Paul Perez were shift leaders. Tim Hertzler and Chad Ross were continuous emission monitoring engineers. Brent Haines, Phuoc Lee, Kurt Marlow, and Roy Woodvine were test engineers.

Personnel from THOR Treatment Technologies, LLC, who provided valuable consultation and test observation, were Brad Mason, Scott Roesener, and Kevin Ryan. Scott Roesener and Kevin Ryan observed the tests. 


\section{CONTENTS}

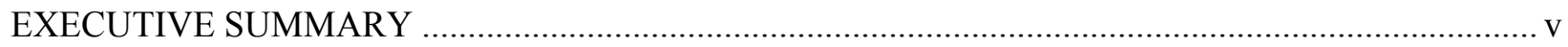

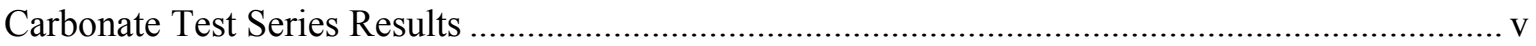

Mineralized Test Series Results ................................................................................................ vi

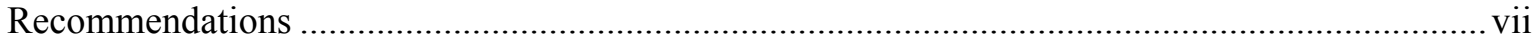

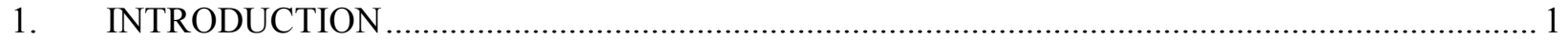

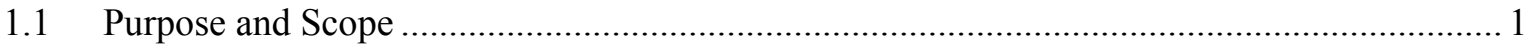

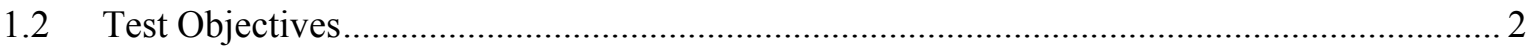

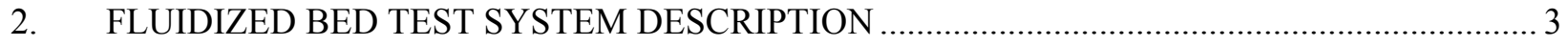

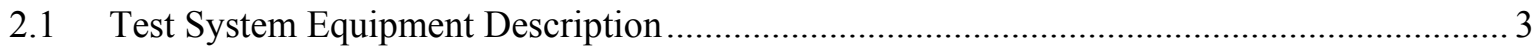

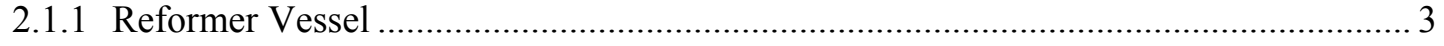

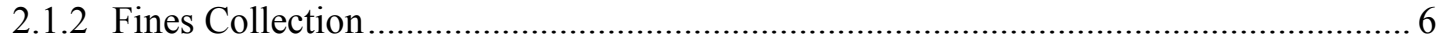

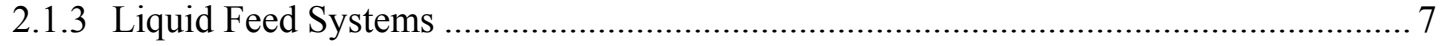

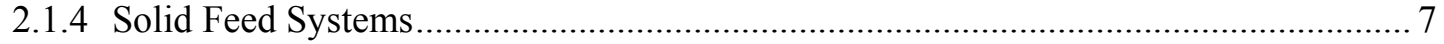

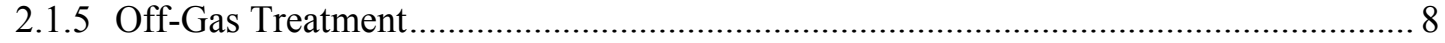

2.1.6 Process Data Acquisition and Control Systems......................................................... 8

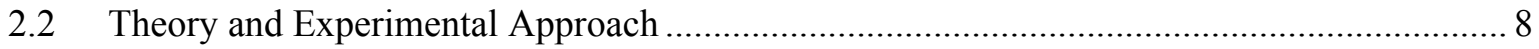

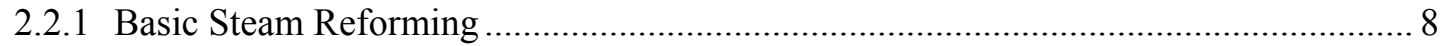

2.2.2 THOR Steam Reforming Technology ……............................................................ 9

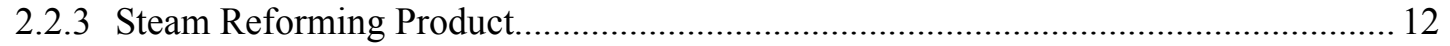

3. MEASUREMENTS, SAMPLE COLLECTION, AND SAMPLE ANALYSIS............................ 13

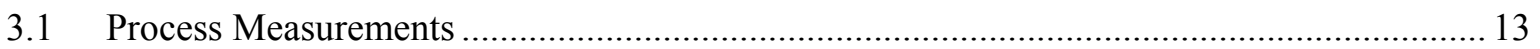

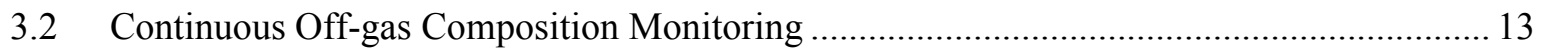

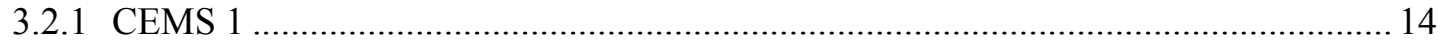

3.2.2 Partial Quench Outlet and Carbon Bed Inlet Hg CEM................................................ 17

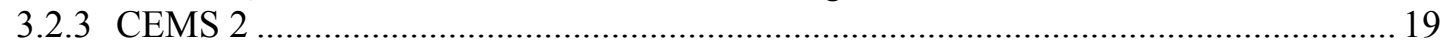

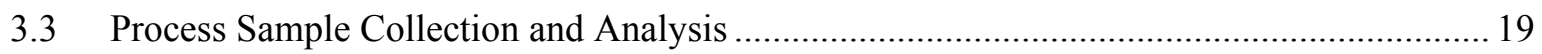

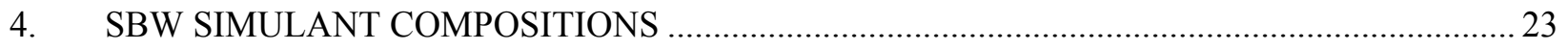

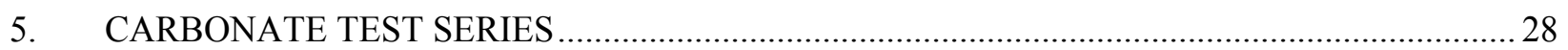

5.1 Test Operating Conditions and Observations .............................................................. 28 


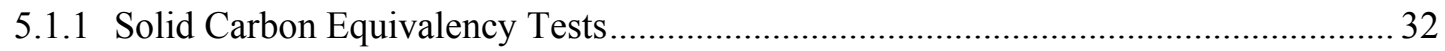

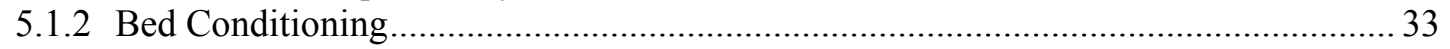

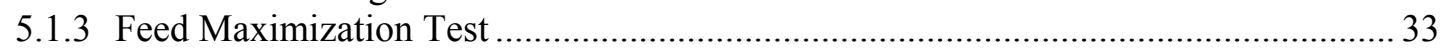

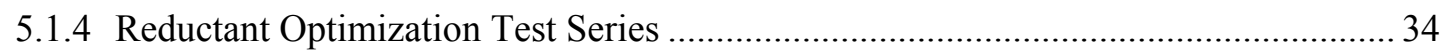

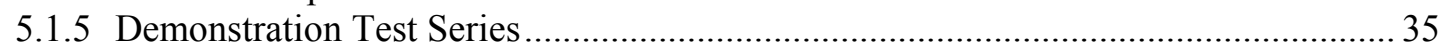

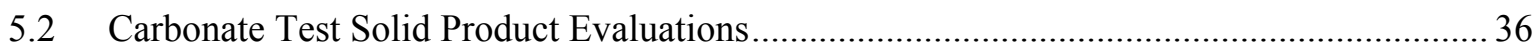

5.2.1 Solid Product Distribution and Mass Balance Closure.............................................. 37

5.2.2 Bed Building and Product Elutriation..................................................................... 38

5.2.3 Solid Product Characterization and Particle Size ....................................................... 39

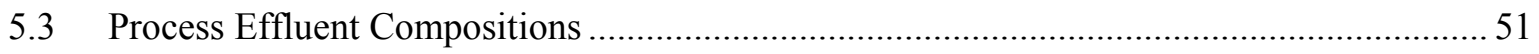

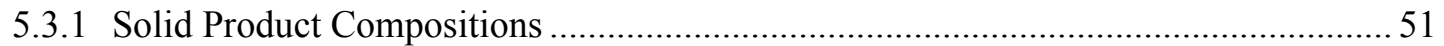

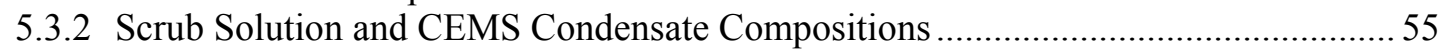

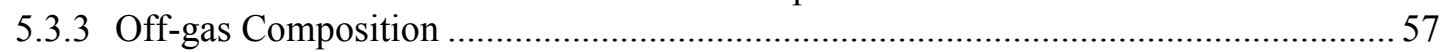

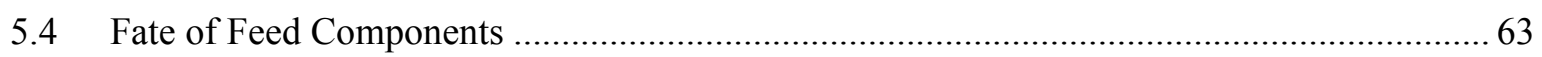

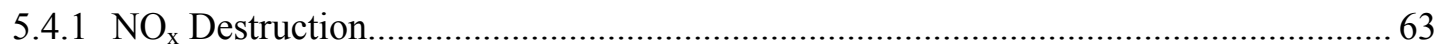

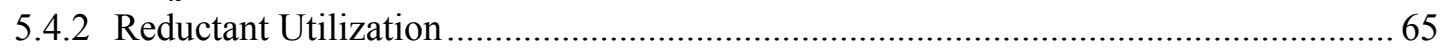

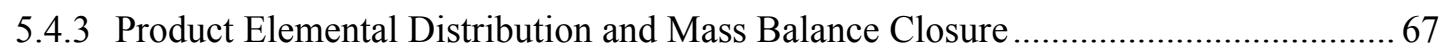

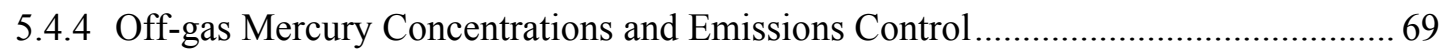

6. MINERALIZED TEST SERIES ……………………………………………………….... 71

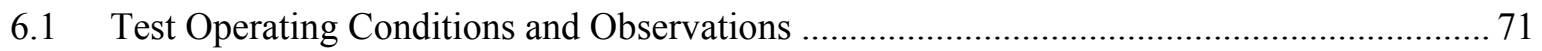

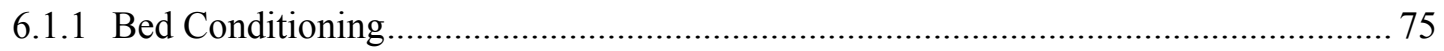

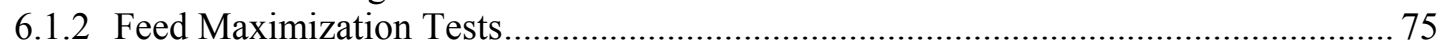

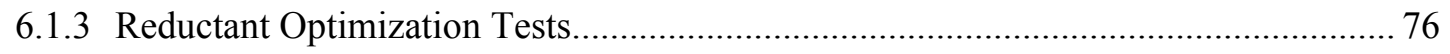

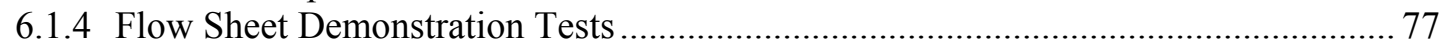

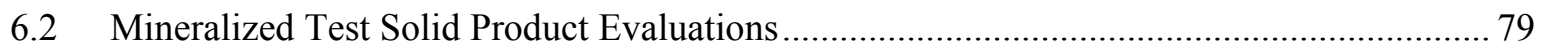

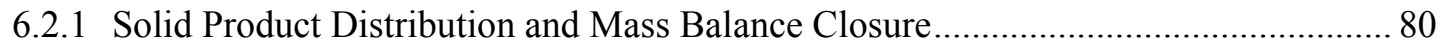

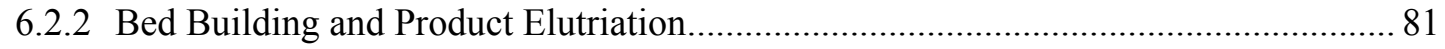

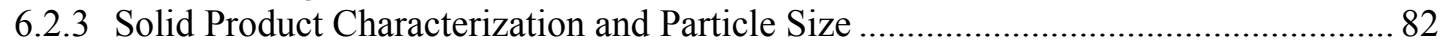

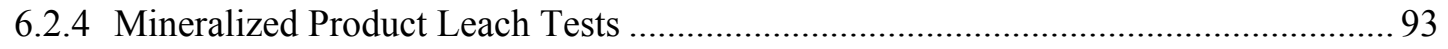

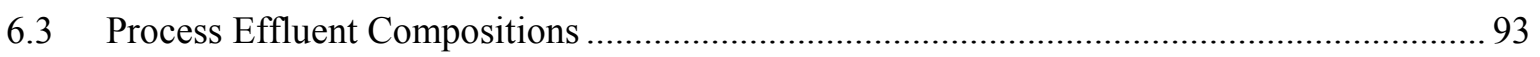

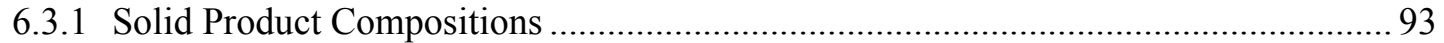

6.3.2 Scrub Solution and CEMS Condensate Compositions ............................................... 98

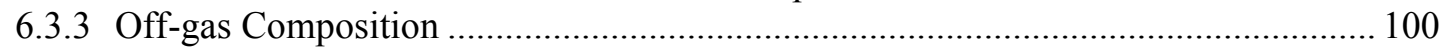

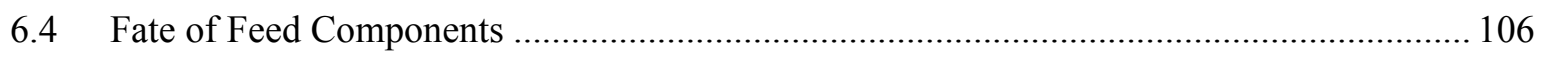

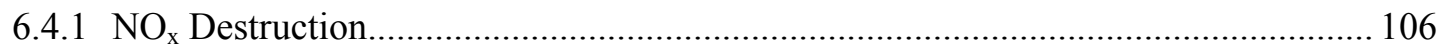

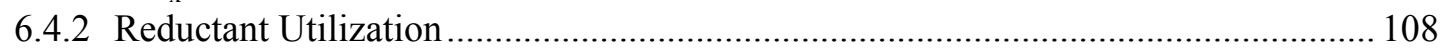


6.4.3 Product Elemental Distribution and Mass Balance Closure

7. SUMMARY AND CONCLUSIONS

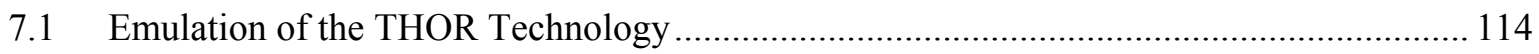

7.2 Phase 2 Test Accomplishments, Conclusions, and Recommendations............................. 115

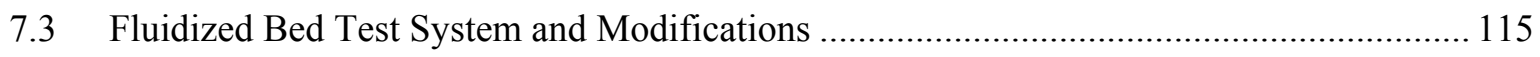

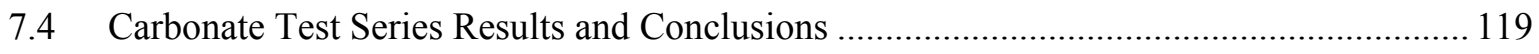

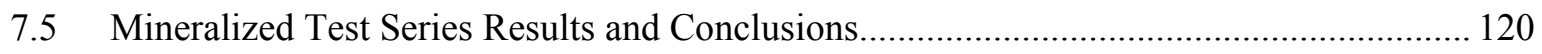

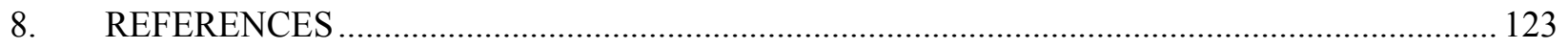

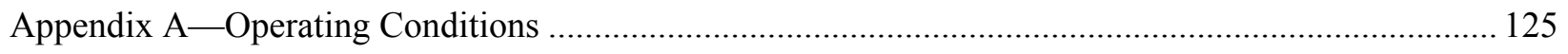

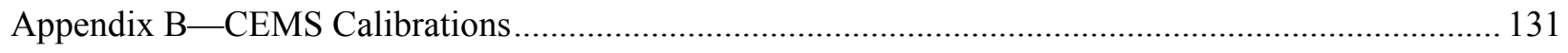

Appendix C - Quality Assurance/Quality Control Activities and Results .......................................... 139

\section{FIGURES}

2-1. Fluidized bed test system at the SAIC STAR Center. ......................................................... 4

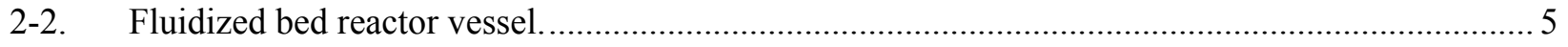

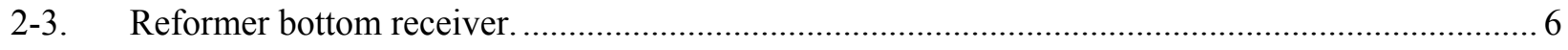

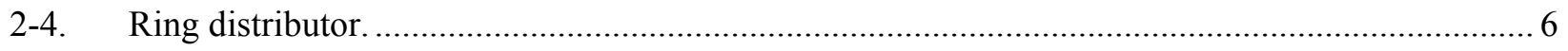

3-1. CEMS 1 for steam reformer off-gas measurements at the filter outlet sample location, upstream of the thermal oxidizer.

3-2. PSA analytical Hg CEMS with dual sampling and conditioning systems................................ 18

3-3. CEMS 2 for steam reformer off-gas measurements downstream of the carbon bed. ................... 20

5.1-1. Feed simulant and fluidizing steam flow rates for the THOR carbonate test series..................... 30

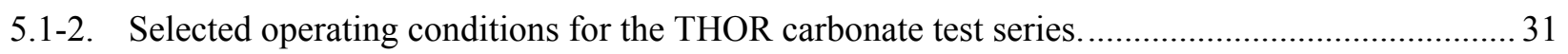

5.2-1. Continuously measured in situ bed depth and mass for the THOR carbonate test series. .............. 39

5.2-2. SEMs of bed product at various cumulative feed amounts..................................................... 40

5.2-3. Mass and harmonic mean bed product particle diameter versus cumulative SBW fed................ 41 
5.2-4. Mass fraction in various size ranges versus continuous operating time (COT) in hours.

5.2-5. Optical microscope photograph of bed product particles from THOR carbonate flowsheet......... 43

5.2-6. SEMs of THOR carbonate bed product, sample 109 (Test Condition 3.1). ............................. 44

5.2-7. SEMs of THOR carbonate flowsheet cyclone product, sample 101 (Test Condition 2.13b)........ 46

5.2-8. SEMs of THOR carbonate flowsheet filter catch, sample 118 (Test Condition 3.4)................... 47

5.2-9. Differential particle size distribution for the recycled cyclone catch material from the THOR carbonate test series.

5.2-10. Differential particle size distribution for filter catch material from the THOR carbonate test series.

5.3-1. Wet basis concentrations of $\mathrm{CH}_{4}, \mathrm{NO}, \mathrm{CO}_{2}, \mathrm{H}_{2} \mathrm{O}, \mathrm{O}_{2}, \mathrm{CO}, \mathrm{THC}$, and $\mathrm{H}_{2}$ in the off-gas upstream of the oxidizer for the THOR carbonate test series.

5.4-1. $\mathrm{NO}_{\mathrm{x}}$ destruction for the THOR carbonate test series.

6.1-2. Selected key operating conditions for the THOR mineralized test series. .74

6.2-1. Continuously measured in situ bed depth and mass for the THOR mineral test series. 81

6.2-1. SEMs of mineralized bed product at various cumulative feed amounts.

6.2-2. Mass and harmonic mean bed product particle diameter versus cumulative SBW fed. 84

6.2-3. Mass fraction in various size ranges versus COT. 84

6.2-4. Optical microscope photographs of bed product particles from THOR mineralized flowsheet. 85

6.2-5. SEMs of THOR mineralized bed product, sample 234 (Test Condition 5.3)............................. 86

6.2-6. SEMs of THOR mineralized flowsheet cyclone catch, sample 165 (Test Condition 4.5)............ 88

6.2-7. SEMs of THOR mineralized flowsheet filter catch, sample 164 (Test Condition 4.5)................ 89

6.2-8. Cyclone catch differential PSD for the THOR mineralized test series..................................... 90

6.2-9. Filter catch differential PSD (obtained manually) for the THOR mineral test series.................. 91

6.4-1. $\mathrm{NO}_{\mathrm{x}}$ destruction for the THOR mineral test series........................................................... 108 


\section{TABLES}

2-4. Summary of waste reforming physical and chemical reactions............................................. 10

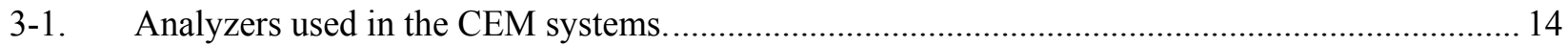

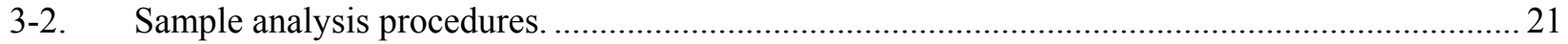

4-1. Simulant compositions for the THOR carbonate product tests................................................ 24

4-2. Simulant compositions for the THOR mineralized product tests. .......................................... 25

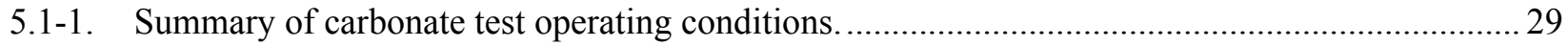

5.1-2. Properties of activated carbons used as steam reforming reductants........................................ 32

5.2-1. Solid product distribution and mass balance closure for the THOR carbonate test series............. 37

5.2-2. Bed product bulk and particle densities for THOR carbonate flowsheet.................................... 45

5.2-3. Cyclone recycle rates for THOR carbonate flowsheet............................................................ 49

5.3-1. Calculated solid product distribution and composition based on chemical equilibrium

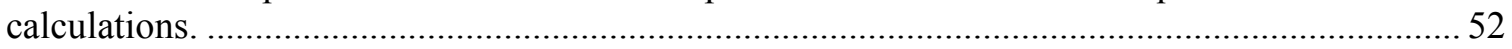

5.3-2. Elemental composition of the bed product for the THOR carbonate test series......................... 53

5.3-2a. Product solubilities for the THOR carbonate test series. ......................................................... 53

5.3-3. Elemental composition of the cyclone and filter catch samples for the THOR carbonate test

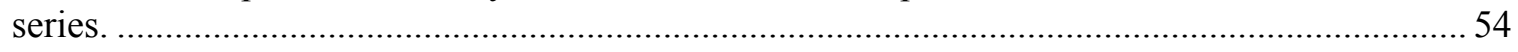

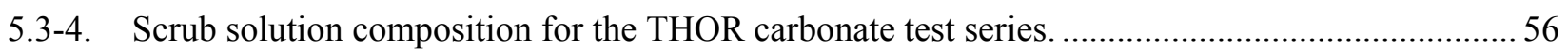

5.3-5. Off-gas Composition (wet basis) at the outlet of the heated filter for the THOR carbonate test

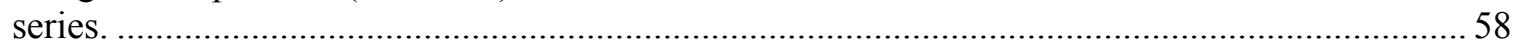

5.3-6. Off-gas Composition (wet basis) downstream of the oxidizer and scrubber for the

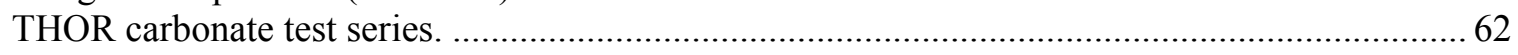

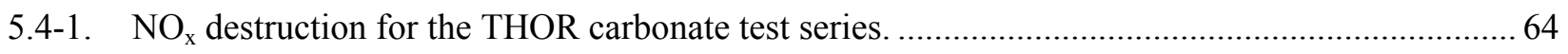

5.4-2. Carbon distribution for the THOR carbonate test series (at CEM 1) ......................................... 66

5.4-3. Elemental distributions and mass balance closure for SBW simulant feed components............... 68

5.4-4. Hg speciation, concentrations, mass balance closure, and carbon bed sorption efficiency

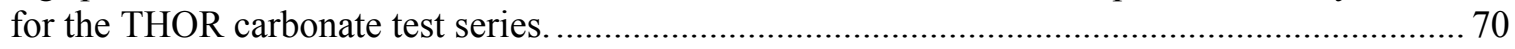

6.1-1. Summary of mineralizing operating conditions for the THOR mineralized test series............... 72

6.2-1. Solid product distribution and mass balance closure for the THOR mineral test series.............. 80 
6.2-2. Bed product bulk and particle densities for THOR mineralized test series.

6.2-3. Filter catch bulk and particle densities for THOR mineral test series. ..................................... 91

6.2-4. Cyclone recycle rates for THOR mineralized flowsheet. ....................................................... 92

6.2-5. Results from TCLP testing of mineralized test bed, cyclone and filter products......................... 94

6.3-1. Calculated solid product distribution and composition based on chemical equilibrium calculations.

6.3-2. Elemental composition of the bed product for the THOR mineral test series.

6.3-3. Elemental composition of the cyclone and filter catch samples for the THOR mineral test series.

6.3-3a. Product solubilities for the THOR mineralized test series..................................................... 97

6.3-4. Scrub solution and CEMS condensate composition for the THOR mineral test series.

6.3-5. Off-gas Composition (wet basis) at the outlet of the heated filter for the THOR mineral test series.

6.3-6. Off-gas composition (wet basis) downstream of the oxidizer and scrubber for the THOR mineral test series.

6.4-1. $\mathrm{NO}_{\mathrm{x}}$ destruction for the THOR mineral test series

6.4-2. Carbon mass distribution and balance for the THOR mineralized test series.

6.4-3. Elemental distributions and mass balance closure for the THOR mineral test series.

6.4-4. Hg speciation, concentrations, mass balance closure, and carbon bed sorption efficiency for the THOR mineral test series.

7-1. Phase 2 test objectives and accomplishments. 


\section{ACRONYMS}

ALD Analytical Laboratory Department

ASTM American Society of Testing and Materials

CAI California Analytical Instruments

CAI California Analytical Instruments

CEMS continuous emissions monitoring system

$\mathrm{CF} \quad$ cumulative feed

CFR Code of Federal Regulations

COD chemical oxygen demand

COT cumulative operating time

CST continuous sampling train

CVAA cold vapor atomic absorption

DOE Department of Energy

DOT Department of Transportation

DUV dispersive ultraviolet

EPA Environmental Protection Agency

FID flame ionization detector

GAC granular activated carbon

GFC gas filter correction

GUI graphical user interface

HMI human-machine interface

HMPD harmonic mean particle diameter

HWC Hazardous Waste Combustor

IC ion chromatography

ICP-AES inductively coupled plasma atomic emission spectroscopy

INEEL Idaho National Engineering and Environmental Laboratory

INTEC Idaho Nuclear Technology and Engineering Center

IRC INEEL Research Center

LRB laboratory record book

MACT maximum achievable control technology

MMPD mass mean particle diameter

NAR nozzle atomizing ratio

NDIR nondispersive infrared

OD outside diameter 


$\begin{array}{ll}\text { PCT } & \text { product consistency test } \\ \text { PLC } & \text { process logic controller } \\ \text { PM } & \text { particulate matter } \\ \text { PSD } & \text { particle size distribution } \\ \text { QA/QC } & \text { quality assurance/quality control } \\ \text { RCRA } & \text { Resource Conservation and Recovery Act } \\ \text { RFA/COC } & \text { request for analysis/chain of custody } \\ \text { RPD } & \text { relative percent difference } \\ \text { SAIC } & \text { Science Applications International Corporation } \\ \text { SBW } & \text { sodium-bearing waste } \\ \text { SEM } & \text { scanning electron micrograph or microscope } \\ \text { STAR } & \text { Science and Technology Applications Research } \\ \text { TCLP } & \text { Toxicity Characteristic Leaching Procedure } \\ \text { TECO } & \text { Thermo Environmental Company } \\ \text { THC } & \text { total hydrocarbon } \\ \text { THOR } & \text { thermal organic reduction } \\ \text { TRA } & \text { Test Reactor Area } \\ \text { TTT } & \text { THOR Treatment Technologies } \\ \text { UDS } & \text { undissolved solids } \\ \text { WIPP } & \text { Waste Isolation Pilot Plant } \\ \text { WIR } & \text { waste incidental to reprocessing }\end{array}$




\section{Phase 2 THOR Steam Reforming Tests for Sodium- Bearing Waste Treatment}

\section{INTRODUCTION}

The Idaho Nuclear Technology and Engineering Center (INTEC) was home to nuclear fuel reprocessing activities for decades until recovery of unspent uranium was halted in the 1990s. As a result of the reprocessing activities, INTEC has accumulated about one million gallons of acidic, radioactive, sodium-bearing waste (SBW). To date, the raffinates from reprocessing activities and much of the SBW have been calcined into solid granular form for storage pending final treatment. Further treatment of the SBW inventory is on hold pending a review and determination of the most appropriate treatment method. Steam reforming is a candidate technology being investigated for treatment of the SBW into a road ready waste form that can be shipped to the Waste Isolation Pilot Plant (WIPP) in New Mexico for interment.

A steam reforming technology, patented by Studsvik, Incorporated and licensed to THOR Treatment Technologies (TTT), was demonstrated on a WM-180 SBW simulant in Phase 1 tests performed in January of 2003 using a Department of Energy (DOE) owned fluidized bed test system located at the Science Applications International Corporation (SAIC) Science and Technology Applications Research (STAR) Center located in Idaho Falls, Idaho (Marshall 2003a). This demonstration showed that SBW could be successfully converted into an alkali carbonate granule form without serious agglomeration, but the emphasis was on process viability and reliability rather than on production and optimization.

\subsection{Purpose and Scope}

Phase 2 tests were performed in November 2003 to evaluate the THOR process under a wider range of conditions. The process feed rate, stoichiometry, and chemistry were varied to identify and demonstrate how the process might be optimized to improve operation and product characteristics. Separate tests were performed to produce a sodium carbonate product similar to that of the January 2003 tests and also a mineralized sodium aluminosilicate product designed to be more leach-resistant than the carbonate product. The tests also demonstrated the performance of a prototype off-gas system designed to comply with the Hazardous Waste Combustor (HWC) Maximum Achievable Control Technology (MACT) standards. The prototype off-gas system was based on a system design developed by the INEEL. This off-gas system does not accurately emulate the off-gas system that TTT has proposed for a full-scale test facility.

The Phase 2 tests were performed using the fluidized bed test system at the SAIC STAR Center. The fluidized bed test system is a DOE-owned prototype system designed for testing various fluidized bed steam reforming technologies and process conditions. The tests were performed using a nonradioactive simulant of SBW from Tank WM-180. The tests were conducted during two weeks. In the first week, the process chemistry was designed to convert the SBW simulant to a sodium carbonate product while controlling $\mathrm{NO}_{\mathrm{x}}$, total hydrocarbons, $\mathrm{Hg}$, and other off-gas constituents to meet $\mathrm{HWC}$ MACT standards. In the second week, the feed chemistry and operation were modified to produce a mineralized sodium aluminosilicate product. Process and off-gas monitoring and sample collection and analysis were used to monitor and control the process operation, determine the fate of feed constituents, product characteristics, and the composition of the off-gas. 


\subsection{Test Objectives}

The tests were configured to provide data to satisfy the following objectives, prioritized in order of their importance:

- $\quad$ Determine suitable fluidized-bed operating parameters for treating the simulated WM-180 SBW supernate and suspended solids, which will

- $\quad$ Reduce carryover of unreacted carbon in the product to $\leq 10 \mathrm{wt} \%$

- $\quad$ Achieve $90 \%$ destruction of $\mathrm{NO}_{\mathrm{x}}$ off-gas emissions relative to nitrates in the feed

- $\quad$ Maintain a stable bed with minimal addition of bed seed particles

- $\quad$ Reduce or eliminate solid catalyst addition

- $\quad$ Demonstrate a mineralizing flow sheet

- $\quad$ Sustain the SBW processing rate similar to or greater than previous tests ( $\geq 4 \mathrm{~L} / \mathrm{hr}$ )

- Demonstrate compliance of the maximum achievable control technology (MACT) for the Hazardous Waste Combustor (HWC):

- Determine the efficiency of the thermal oxidizer and characterize the outlet gas composition

- $\quad$ Determine the control efficiencies for $\mathrm{Hg}$ and $\mathrm{Cl}$ in the scrubber and carbon bed

- $\quad$ Determine the capacity of the granular activated carbon for $\mathrm{Hg}$ and leachability of $\mathrm{Hg}$ sorbed on the granular activated carbon

- Determine the fate of feed constituents and additives, including the halides, volatile heavy metals, cesium, etc.

- Characterize solid product composition, quantity, and handling properties of all products and the leach resistance of the mineralized product.

- $\quad$ Demonstrate in-line mixing of the SBW and liquid reductant. 


\section{FLUIDIZED BED TEST SYSTEM DESCRIPTION}

A simplified process flow and instrumentation diagram of the fluidized bed test system at the SAIC STAR Center is shown in Figure 2-1. The primary components of the test system include the reformer vessel, the product collection systems, the feed systems, the off-gas control system, and the process logic controller (PLC) system. The test system covers a footprint of about $40 \times 40$ feet. All wetted components are constructed from corrosion resistant materials. Equipment and piping are fabricated from 300 -series stainless steel except for the reformer vessel, which is fabricated from Inconel $800 \mathrm{H}$. The system can be manually controlled or automatically controlled using a PLC system with multiple humanmachine interface stations.

\subsection{Test System Equipment Description}

The reformer vessel is the primary component of the test system. The other components (the product collection systems, the feed systems, the off-gas control system, and the PLC system are ancillary components necessary for operation.

\subsubsection{Reformer Vessel}

The fluidized-bed steam reformer vessel (shown in Figure 2-2) was made of Inconel $800 \mathrm{H}$ pipe to tolerate operating conditions, including temperatures that could reach $800^{\circ} \mathrm{C}$, oxidizing or reducing conditions, and the presence of corrosive or hazardous materials. The main features of the fluidized bed vessel were the fluidized-bed section, the freeboard (particle disengaging) section, and the gas distributor through which the fluidizing gas enters the vessel.

The fluidized-bed section was 6 inches in diameter and 30 inches tall with 6-inch 150\# flanges on either end. Numerous ports in the bed section provided the versatility and instrumentation required to conduct research and development activities. The ports were arranged in three vertical columns, 120 degrees apart, to accommodate external radiant heaters and to prevent direct impingement of any feed material on another port.

Four of the ports were constructed of 1.5 -inch, schedule 40 pipe that enter the bed section at 60-degree angles (relative to horizontal) and were located at 4, 13, and 22 inches above the bottom of the bed section. These ports were angled to reduce the accumulation of stagnant bed and to facilitate clearing. Solid additives have traditionally been introduced through these ports via pneumatic and auger conveyances. Two 2 -inch schedule 40 ports were located at 4 and 13 inches above the bottom of the bed section. These ports were horizontal and intended for introduction of liquids and/or gases. The atomizing feed nozzle was installed in the lower of these two ports. Additional ports were provided for thermocouple penetrations at 6-inch intervals over the length of the bed section and a pressure port located 12 inches above the lower flange of the bed section. The pressure port was used to monitor the differential pressure across a portion of the fluid bed as a measure of the average fluidized-bed density.

The bed section was bolted below a freeboard section that was 12 inches in diameter and 5 feet tall. The two sections were coupled with a concentric $12 \times 6$-inch reducer welded to the freeboard. The bed and freeboard sections were externally heated with radiant heaters designed to fit the contours of the vessel and fit in the vertical areas between the penetrations. 


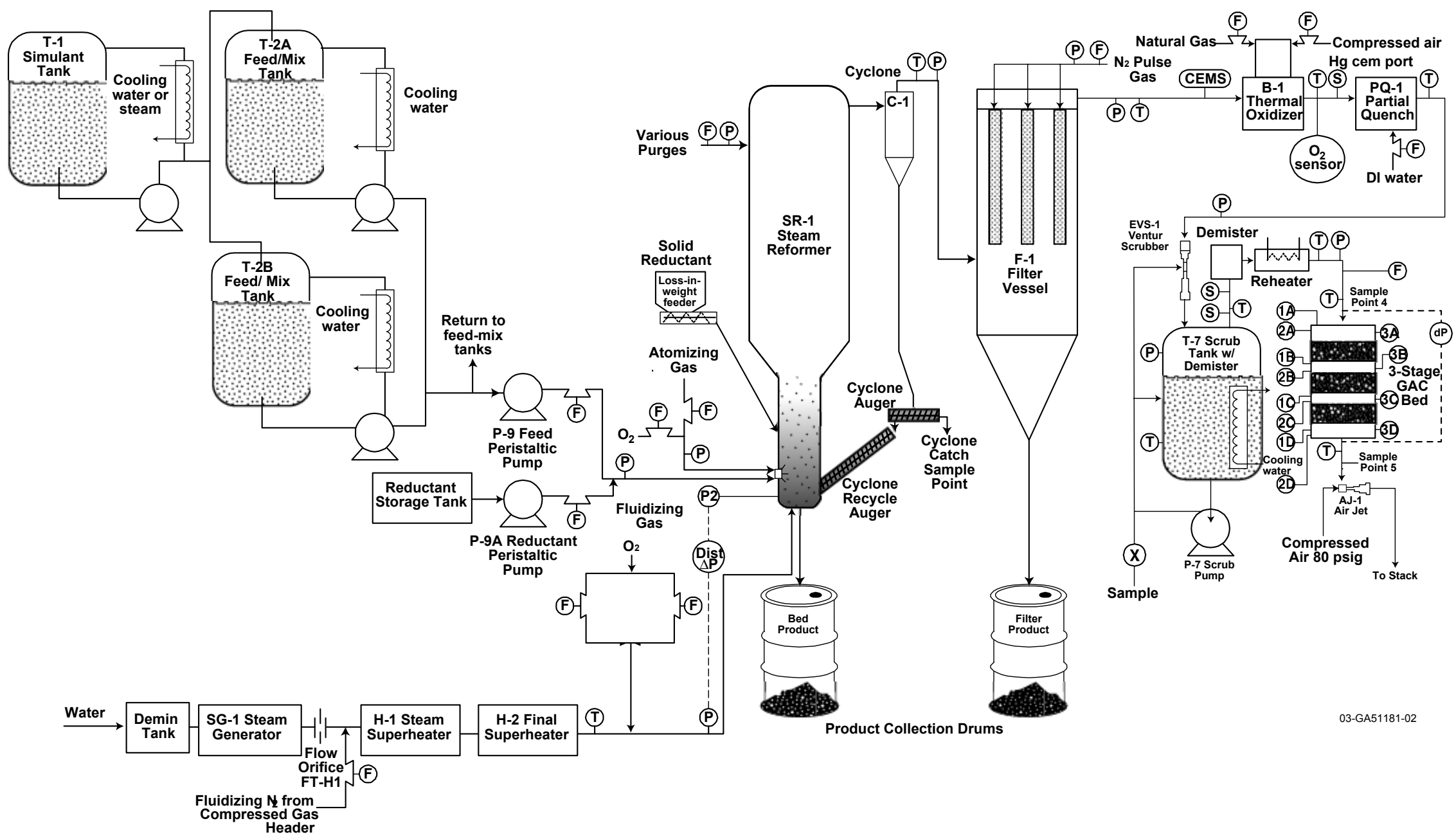

Figure 2-1. Fluidized bed test system at the SAIC STAR Center. 

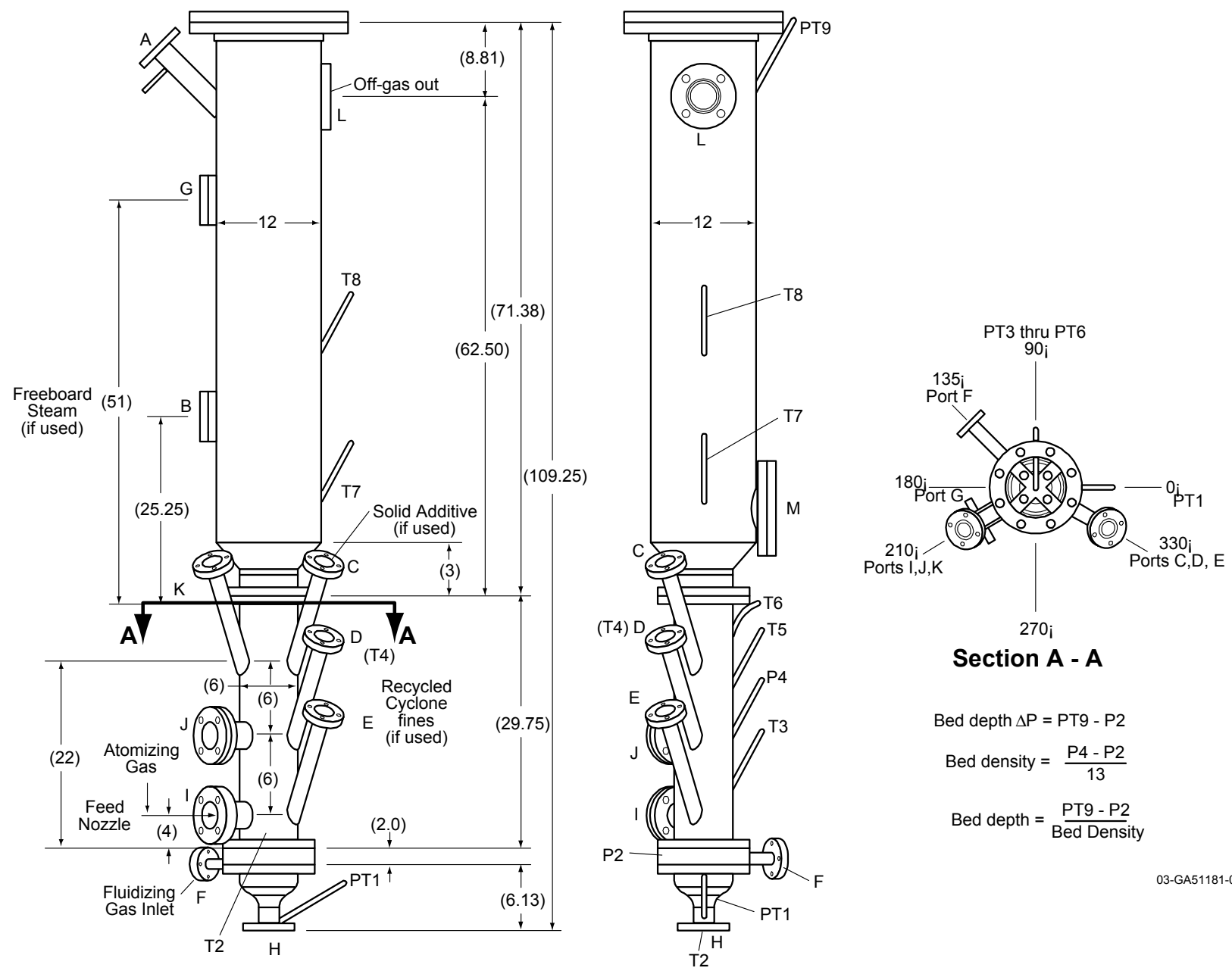

Figure 2-2. Fluidized bed reactor vessel.

The reformer bottom receiver (Figure 2-3) was a 6-inch, 150\# blind flange that had been drilled and milled to provide an eccentric 1.9-inch-diameter bottom drain (OD of a nominal 1.5-inch pipe), a sample riser (3/4-inch tubing extending 2 inches above the distributor), a thermocouple port, and an auxiliary port with a 0.25 -inch opening. The auxiliary port can be fitted with a rudimentary feed nozzle composed of concentric 1/4- and 1/8-inch tubing, with liquids fed through the smaller tube and the atomizing gas through the annulus between the tubes.

The distributors used during conduct of the test were of two designs. One was a 4-inch-diameter sparge ring made of half-inch, 300-series stainless steel tubing mounted in a 316 stainless steel, 6-inch, 150\# flange (Figure 2-4). Several orifices were drilled into the ring to distribute the fluidizing gas. Half of the orifices oriented radially inward at a downward angle of 45 degrees off-vertical, while the other half were oriented radially outward at a downward angle of 30 degrees off-vertical. The ring fully encompassed all of the penetrations/ports from the receiver. The other distributor was also mounted in a 6-inch, 150\# flange, but has aspects considered by TTT to be proprietary and is not discussed in this document. The distributor flanges were each provided with a pressure port through the side of the flange for measuring distributor, total bed, and bed density differential pressures and absolute reactor pressure. 


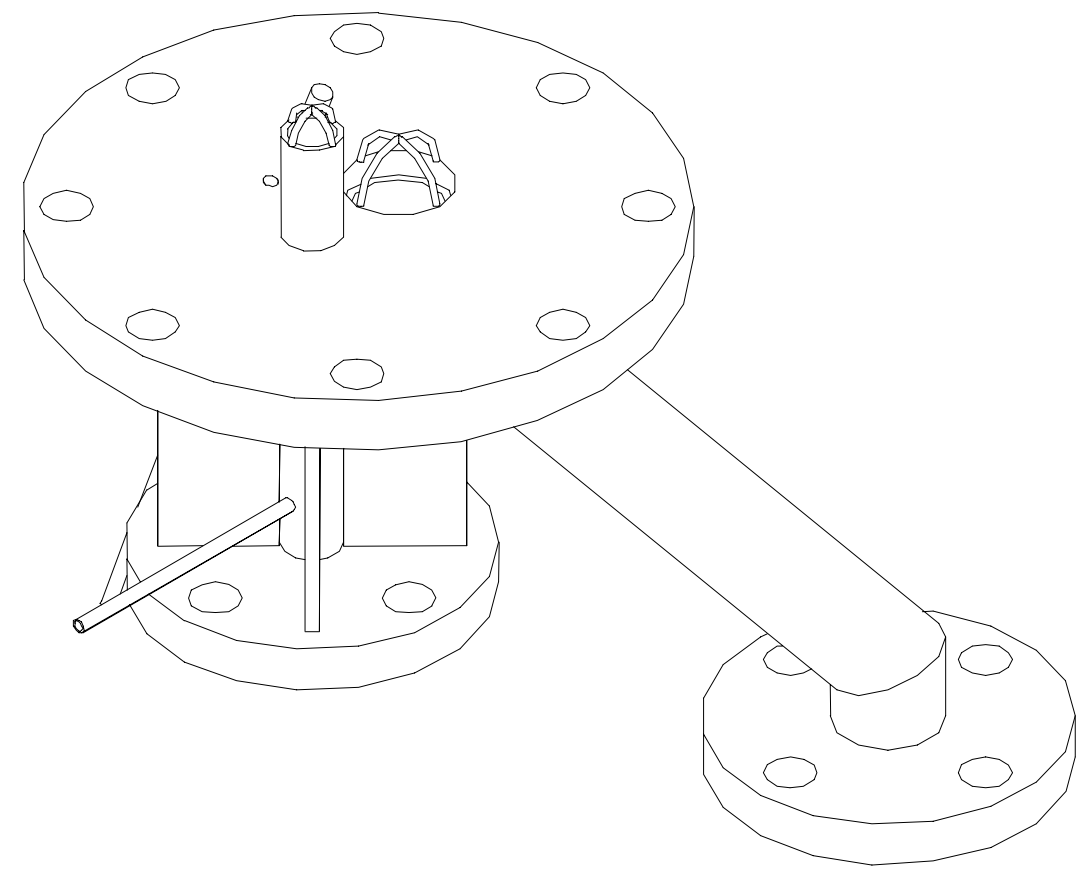

Figure 2-3. Reformer bottom receiver.

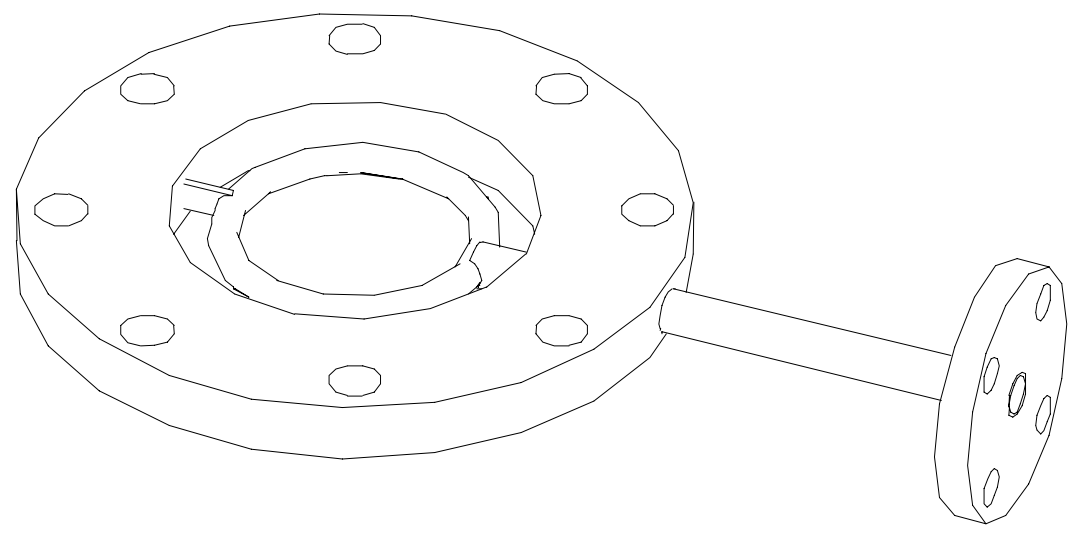

Figure 2-4. Ring distributor.

\subsubsection{Fines Collection}

Product fines and process gases exited the freeboard section and passed through a 5-inch-diameter cyclone separator to remove most of the particles in excess of $15 \mu \mathrm{m}$. The off-gas was subsequently filtered in a vessel with seven 2.5-inch-diameter, 24-inch-long, sintered-metal filters with a nominal pore size of $2 \mu \mathrm{m}$.

The cyclone catch was continuously recycled to the reformer through a series of two augers. The first auger could be operated in either forward or reverse rotation. With the forward rotation, the cyclone catch was fed into a second auger that pushed the product through port E (Figure 2-2) into the bottom of the bed. When the auger was reversed, the cyclone catch was collected in a sample container located 
below two valves, which provide pressure isolation and minimize air in-leakage. With the exception of the product collected during sampling events, all of the cyclone catch was recycled to the reformer.

The filter catch collected continuously in a product drum located below the filter vessel. Samples were collected with a split tube (i.e., spoon) that was rotated to face upward for collecting the filter cake as it fell from the filter candles. This sampling technique provided a reasonably clean catch of the product being collected on the filters at any given time.

\subsubsection{Liquid Feed Systems}

Feed systems included the simulant hold/makeup tank, two day-tanks, and solid additive feed systems. The simulant tank was designed to hold 800 liters of solution, and the day tanks were designed for 200 liters to accommodate feed rates up to 8 liters/hour. All three tanks were equipped with variable speed agitators and a recirculation/transfer pump to ensure that the solutions were fully mixed and that undissolved solids remained suspended and uniformly blended.

In the demonstration conducted in January 2003, sugar was dissolved in the SBW simulant and pumped to the process via a peristaltic pump that pulled a slipstream from the recirculation line. The feed system was retrofitted with a separate peristaltic pump and coriolis mass flow meter for sugar syrup addition so that the SBW and reductant blend ratios could be easily varied and to mimic what is envisioned for a full-scale treatment system. The two feed streams were combined just before being atomized in the feed nozzle.

The testing was completed using a Spraying Systems Co. extended nozzle body with a 60100 liquid nozzle and a 120 air cap. The liquid orifice was 0.060 inches in diameter and the air cap provided a 0.010 -inch-wide annulus around the orifice through which the atomizing gas (nitrogen) was passed. The extended nozzle body was incorporated into a customized water jacket to prevent the nozzle from overheating in the reformer.

\subsubsection{Solid Feed Systems}

Solid activated carbons were metered into the process by a vibratory feeder at the recommendation of TTT, rather than by an auger-feed Acrison weight loss feeder. We believed that the auger-feed system used in January 2003 test attrited the carbon particles, causing them to be too small to be retained in the fluidized bed. Unlike the weight-loss feeder, however, the vibratory feeder had to be manually controlled and adjusted because it lacked feedback on how fast the carbon was depleting in the hopper. Operators made periodic mass discharge rate checks and kept a record of the masses of carbons added to or removed from the feeder. The vibratory feeder discharged to a funnel that ducted the carbon into a pipe bounded on the inlet and outlet by two ball valves that operated sequentially to form a lock hopper. A nitrogen gas purge on the pipe kept atmospheric air excluded from the process and provided some motive force to inject the light-weight carbon into the bed.

The vibratory feeder had a hopper that fed into a bowl with a helical flight that wound its way up the sidewall of the bowl. The vibratory motion caused the carbon particles to migrate up and along the flight to the discharge chute above the funnel on the lock hopper. The feed rate was adjusted by controlling the depth of the carbon in the hopper/bowl and by adjusting the vibrational frequency. The hopper had a separate vibrator to cause the carbon to subside into the bowl. The feed rate tended to vary with time, because the mass of carbon in the bowl and hopper affected the amplitude of the vibrations and the required lift. 
The bed media was added directly to the bed via two valves that formed a lock hopper and had sufficient density that it subsided into the fluidized bed without further assistance. Iron oxide and iron powders were added to the process via the carbon funnel.

\subsubsection{Off-Gas Treatment}

Filtered gases were passed into a natural gas-fired thermal oxidizer, operated at $1000^{\circ} \mathrm{C}$, where they were combined with air to oxidize the hydrogen, carbon monoxide, methane, and other hydrocarbons resulting from the decomposition and reformation of the syrup and activated carbon. The oxidized gases were quenched with a water spray and scrubbed with a venturi scrubber. The quench exit temperature and the scrub solution temperatures were controlled to maintain scrub solution levels in the scrubber relatively constant. During portions of the test, ancillary water cooling systems were not functioning properly, which resulted in the scrub temperature being too high to control scrub level as desired. The quench discharge temperature was adjusted to help compensate, but for portions of the tests, the scrub level decreased over time and periodic adjustments with water had to be made.

The scrubbed off-gases were subsequently passed through a divided column of granular, sulfurimpregnated, activated carbon to capture the mercury emissions and prove that technology for mercury capture and removal.

Off-gas treatment equipment downstream of the off-gas filter (i.e., thermal oxidizer, quench, scrubber, and activated carbon column) were added for data generation purposes. They were not required to be in place for emission control.

\subsubsection{Process Data Acquisition and Control Systems}

The test system is equipped with an automated process logic controller (PLC) system. The PLC uses Rockwell hardware and software to monitor and control operation of the process from two or more human-machine interface (HMI) personal computer workstations, located in the vicinity of the process equipment. Additional workstations are available, one for use at the CEMS panels, and one for monitoring only (no control allowed) located in an office area for non-operating personnel. The process control functions include automated control of valve and pump sequences for the feed system, automated control of all total gas flow rates, selectable input temperature control for the fluidized bed vessel, vacuum control of the system based on the pressure in the reformer, and limited control of the CEMS. The graphical user interface (GUI) for the system shows the status of the components, provides a control interface for the operator, and displays readings from all the instrumentation in numeric and trend form.

The data acquisition system utilizes Rockwell software integrated with the PLC and a Sequel database for electronically archiving data as it is monitored. Each record in the database includes the tag name for the data-point, the description, the value, the units, and a time-stamp. Analog values from the system are archived once per second, and discrete values are archived on change of state. The process monitoring workstation in the office area is equipped with a Web interface to the database for access to the archived data during the tests. The Web interface provides data access from the database and averages at user-defined intervals in Microsoft Excel spreadsheets.

\subsection{Theory and Experimental Approach}

\subsubsection{Basic Steam Reforming}

Carbonaceous materials such as biomass, plastics, petroleum fractions, etc., react with steam at high temperatures, decomposing the materials into hydrogen, carbon monoxide, carbon dioxide, and chemical radicals that can recombine to form a host of hydrocarbons (e.g., methane, aromatic compounds, 
etc.). Steam reforming is a leading candidate for producing hydrogen for fueling stations from agricultural residues and post-consumer products.

The ability to produce carbon dioxide, hydrogen, methane, and reactive radicals is an asset when considering treatment of alkali nitrate waste solutions. The high temperatures, steam, and reactive gases facilitate the denitration of alkali nitrates and the reduction of $\mathrm{NO}_{\mathrm{x}}$ to nitrogen and carbon oxides. In the absence of mineralizing compounds, a dry alkali carbonate product is formed, which can be containerized for immediate disposal or further conditioning as necessary.

The extent of $\mathrm{NO}_{\mathrm{x}}$ reduction mostly depends on the concentrations of hydrogen and methane (and their associated radicals) that are produced in the steam reformer and the presence of metal compounds that catalyze the formation of hydrogen and methane or the reaction between them and $\mathrm{NO}_{\mathrm{x}}$ species. Known catalytically active metals employed in steam reforming processes are nickel, copper, and zinc (Magrini-Bair 2002, Ogden). Other important metals are magnesium, which stabilizes the nickel metal, and potassium, which is often used to inhibit coking of the catalyst. The methanation reaction reacts carbon monoxide and hydrogen to produce methane in the presence of a Group VIII catalyst, such as iron and nickel. All of these metals are present in the SBW and promote the formation of hydrogen by the water gas and water-gas shift reactions and the production of methane via methanation.

A summary of potential reaction mechanisms is given in Table 2-4.

\subsubsection{THOR Steam Reforming Technology}

The THOR steam reforming technology, offered by TTT, for the treatment of SBW involves the use of a dense inert starting bed, such as alumina, that will become coated with product. The intent is to accumulate a layer of product on the starting bed and to attrit or spall off enough product pieces to create seed particles for more product growth and a sustainable mean particle size. Alumina was selected as the starting bed media because it is attrition resistant and relatively inert to the product. To encourage the product to attrit, the nozzle atomizing ratio (NAR) and fluidizing velocities were kept as high as practical to increase particle momentum within the bed to induce attrition through energetic inter-particle collisions.

The THOR process uses a steam-oxygen blend as the fluidizing gas and nitrogen for the atomizing gas. The steam reforms carbonaceous materials to form carbon monoxide and hydrogen in the water gas reaction [Equation (2-1)]; the oxygen reacts with carbon and water gas to generate carbon oxides, water vapor, and heat; and the nitrogen is mostly inert in the process. Some of the carbon eventually reacts with the alkali and other metals in the SBW to form carbonate salts, thus averting bed agglomeration by suppressing alkali hydroxide formation in the product.

$$
\mathrm{H}_{2} \mathrm{O}(\mathrm{g})+\mathrm{C}(\mathrm{s}) \rightarrow \mathrm{H}_{2}(\mathrm{~g})+\mathrm{CO} \quad \text { water-gas reaction }
$$

Typically, carbon monoxide and water react, in the water-gas shift reaction, to form hydrogen and carbon dioxide. This reaction [Equation (2-2)] promotes hydrogen production at the cost of carbon monoxide. Carbon monoxide, however, can also react with available hydrogen to form methane through a methanation reaction shown in Equation (2-3). A high partial pressure of carbon dioxide may suppress the water-gas shift reaction and encourage methanation by keeping the carbon monoxide partial pressure somewhat higher. Carbon monoxide is the limiting reactant in either equation, so any process that increases the partial pressure of carbon monoxide will encourage the formation of methane.

$$
\begin{array}{ll}
\mathrm{CO}+\mathrm{H} 2 \mathrm{O} \leftrightarrow \mathrm{CO} 2+\mathrm{H} 2 & \text { water-gas shift reaction } \\
\mathrm{CO}+3 \mathrm{H}_{2} \leftrightarrow \mathrm{CH}_{4}+\mathrm{H}_{2} \mathrm{O} & \text { methanation reaction }
\end{array}
$$


Table 2-4. Summary of waste reforming physical and chemical reactions.

\begin{tabular}{|c|c|c|}
\hline Process Step & General Reaction Examples & Comments \\
\hline $\begin{array}{l}\text { Solution evaporation/particles } \\
\text { drying }\end{array}$ & $\begin{array}{l}\text { Waste sol'n (liquid) } \rightarrow \\
\qquad \mathrm{H}_{2} \mathrm{O} \text { (gas) }+\mathrm{NaNO}_{3}, \mathrm{Al}_{\left(\mathrm{NO}_{3}\right)_{3}, \text { etc. }}\end{array}$ & $\begin{array}{l}\text { Commences in liquid droplet, continues in particle film, except at high } \\
\text { temperatures/high heating rates when evaporation occurs above the } \\
\text { solid-gas boundary layer. Rapid evaporation of spray droplets results } \\
\text { in sub-micron-size particles. }\end{array}$ \\
\hline $\begin{array}{l}\text { Solid salt thermal dissociation/ } \\
\text { decomposition }\end{array}$ & $\begin{array}{l}2 \mathrm{Al}_{(}\left(\mathrm{NO}_{3}\right)_{3}(\mathrm{~s}) \rightarrow \mathrm{Al}_{2} \mathrm{O}_{3}(\mathrm{~s})+6 \mathrm{NO}_{2}(\mathrm{~g})+1 \frac{1}{2} \mathrm{O}_{2}(\mathrm{~g}) \\
2 \mathrm{NaNO}_{3}(\mathrm{~s}) \rightarrow \mathrm{Na}_{2} \mathrm{O}(\mathrm{s})+2 \mathrm{NO}_{2}(\mathrm{~g})+1 / 2 \mathrm{O}_{2}(\mathrm{~g}) \\
\mathrm{Na}_{2} \mathrm{CO}_{3}(\mathrm{~s}) \leftrightarrow \mathrm{Na}_{2} \mathrm{O}(\mathrm{s})+\mathrm{CO}_{2}(\mathrm{~g}) \\
\mathrm{Na}_{2} \mathrm{CO}_{3}(\mathrm{~s})+\mathrm{H}_{2} \mathrm{O}(\mathrm{g}) \leftrightarrow 2 \mathrm{NaOH}(\mathrm{l})+\mathrm{CO}_{2}(\mathrm{~g})\end{array}$ & $\begin{array}{l}\text { Transition metal nitrates typically rapidly dissociate below } 400^{\circ} \mathrm{C} \text {. } \\
\text { Alkali metal nitrates typically denitrate slowly and can persist to } \\
\text { temperatures up to } 600^{\circ} \mathrm{C} \text {. Molten alkali hydroxides can lead to } \\
\text { dissolution of other salts and bed agglomeration, which is not desirable } \\
\text { in a fluidized bed. }\end{array}$ \\
\hline $\begin{array}{l}\text { Organic compound } \\
\text { depolymerization// } \\
\text { devolatilization// } \\
\text { char formation }\end{array}$ & $\begin{array}{l}\mathrm{C}_{\mathrm{m}} \mathrm{H}_{\mathrm{n}}(\mathrm{s}) \rightarrow \text { char }(\mathrm{s})+\text { tars/oils, } \mathrm{C}_{\mathrm{x}} \mathrm{H}_{\mathrm{y}}(\mathrm{g}) \\
\mathrm{C}_{1} \mathrm{H}_{\mathrm{m}} \mathrm{O}_{\mathrm{n}} \rightarrow \text { char }(\mathrm{s})+\text { tars } / \text { oils, } \mathrm{C}_{\mathrm{x}} \mathrm{H}_{\mathrm{y}}(\mathrm{g})+\mathrm{H}_{2}, \mathrm{OH}, \mathrm{H}_{2} \mathrm{O}(\mathrm{g}) \\
\mathrm{C}_{12} \mathrm{H}_{22} \mathrm{O}_{11}(\mathrm{~s}) \rightarrow 12 \mathrm{C}(\mathrm{s})+11 \mathrm{H}_{2} \mathrm{O}(\mathrm{g})\end{array}$ & $\begin{array}{l}\text { Organic evolution rates and speciation depends on hydrocarbon } \\
\text { functional groups, particle heating rates, reactor temperature, and } \\
\text { particle residence time. Light gases and tars evolve competitively. }\end{array}$ \\
\hline $\begin{array}{l}\text { Solid state organic } \\
\text { redox reactions }\end{array}$ & $\begin{array}{l}2 \mathrm{NaNO}_{3}(\mathrm{~s})+\mathrm{C}(\mathrm{s}) \text { or carbon source }(\mathrm{s}) \\
\rightarrow \mathrm{Na}_{2} \mathrm{CO}_{3}(\mathrm{~s})+\mathrm{N}_{2}(\mathrm{~g}) \\
\text { @ solid waste-char or carbon particle boundary [or] } \\
\text { @ solid waste-organic compound/char in dehydrated droplets or } \\
\text { solid layer on an existing particle. }\end{array}$ & $\begin{array}{l}\text { Nitrate-organic reduction occurs spontaneously at } 250- \\
350^{\circ} \mathrm{C} \text { and the reaction zone rapidly propagates through the remaining } \\
\text { unreacted solid reactant mixture. }\end{array}$ \\
\hline Solid state inorganic reactions & $\begin{array}{l}2 \mathrm{NaNO}_{3}(\mathrm{~s})+\mathrm{Al}_{2} \mathrm{O}_{3}(\mathrm{~s}) \rightarrow 2 \mathrm{NaAlO}_{2}(\mathrm{~s})+2 \mathrm{NO}_{2}(\mathrm{~g})+1 \frac{1}{2} \mathrm{O}_{2}(\mathrm{~g}) \\
\mathrm{Na}_{2} \mathrm{O}(\mathrm{s})+\mathrm{Al}_{2} \mathrm{O}_{3}(\mathrm{~s}) \rightarrow 2 \mathrm{NaAlO}_{2}(\mathrm{~s}) \\
\mathrm{Na}_{2} \mathrm{O}(\mathrm{s})+\mathrm{SiO}_{2}(\mathrm{~s}) \rightarrow \mathrm{Na}_{2} \mathrm{SiO}_{3}(\mathrm{l}) \\
\mathrm{Na}_{2} \mathrm{O}(\mathrm{s})+\mathrm{Al}_{2} \mathrm{Si}_{2} \mathrm{O}_{7} \cdot 2 \mathrm{H}_{2} \mathrm{O}(\mathrm{s}) \rightarrow 2 \mathrm{NaAlSiO}_{4}(\mathrm{~s})+2 \mathrm{H}_{2} \mathrm{O}(\mathrm{g})\end{array}$ & $\begin{array}{l}\text { Silica is present as a contaminant in the makeup water and in the } \\
\text { simulated heel solids. Aluminum nitrate is present in the } \\
\mathrm{SBW} \text { and decomposes to } \mathrm{Al}_{2} \mathrm{O}_{3} \text {. Alkali silicates may be molten at } \\
\text { process temperatures. Kaolin can be added to the simulant to form } \\
\text { alkali aluminosilicates and discourage bed agglomeration. }\end{array}$ \\
\hline $\begin{array}{l}\text { Heterogeneous carbon } \\
\text { gasification reactions }\end{array}$ & $\begin{array}{l}\text { 1. } \mathrm{H}_{2} \mathrm{O}(\mathrm{g})+\mathrm{C}(\mathrm{s}) \rightarrow \mathrm{CO}(\mathrm{g})+\mathrm{H}_{2}(\mathrm{~g}) \\
\text { 2. } \mathrm{CO}_{2}(\mathrm{~g})+\mathrm{C}(\mathrm{s}) \rightarrow 2 \mathrm{CO}(\mathrm{g}) \\
\text { 3. } \mathrm{O}_{2}(\mathrm{~g})+2 \mathrm{C}(\mathrm{s}) \rightarrow 2 \mathrm{CO}(\mathrm{g}) \\
\text { 4. } \mathrm{NO}_{2}(\mathrm{~g})+\mathrm{C}(\mathrm{s}) \rightarrow \mathrm{CO}(\mathrm{g})+\mathrm{NO}(\mathrm{g})\end{array}$ & $\begin{array}{l}\text { Gasification to CO is typically endothermic. } \\
\text { Equation } 3 \text { is negligible under fuel-rich, steam reforming conditions } \\
\text { unless oxygen is intentionally introduced. } \\
\text { Equation } 4 \text { is slower than Equations } 1 \text { and } 2 \text { and may not be significant. } \\
\text { Oxides and carbonates in the solids can catalyze char reactions. }\end{array}$ \\
\hline $\begin{array}{l}\text { Heterogeneous inorganic } \\
\text { reactions }\end{array}$ & $\begin{array}{l}\mathrm{Na}_{2} \mathrm{O}(\mathrm{s})+\mathrm{NO}_{2}(\mathrm{~g})+\mathrm{NO}(\mathrm{g}) \leftrightarrow 2 \mathrm{NaNO}_{3}(\mathrm{~s}) \\
\mathrm{Na}_{2} \mathrm{O}(\mathrm{s})+\mathrm{CO}_{2}(\mathrm{~g}) \rightarrow \mathrm{Na}_{2} \mathrm{CO}_{3}(\mathrm{~s}) \\
\left.\mathrm{Na}_{2} \mathrm{O}(\mathrm{s})+\mathrm{H}_{2} \mathrm{O}(\mathrm{g}) \rightarrow 2 \mathrm{NaOH} \mathrm{l}\right) \\
\mathrm{Na}_{2} \mathrm{O}(\mathrm{s})+2 \mathrm{HCl}(\mathrm{g}) \rightarrow 2 \mathrm{NaCl}(\mathrm{s})+\mathrm{H}_{2} \mathrm{O}(\mathrm{g}) \\
\mathrm{CaO}(\mathrm{s})+2 \mathrm{HCl}(\mathrm{g}) \rightarrow \mathrm{CaCl}_{2}(\mathrm{~s})+\mathrm{H}_{2} \mathrm{O}(\mathrm{g}) \\
2 \mathrm{NaOH}(\mathrm{l})+\mathrm{Al}_{2} \mathrm{O}_{3}(\mathrm{~s}) \rightarrow 2 \mathrm{NaAlO}_{2}(\mathrm{~s})+\mathrm{H}_{2} \mathrm{O}(\mathrm{g}) \\
2 \mathrm{NaOH}(\mathrm{l})+\mathrm{SiO}_{2}(\mathrm{~s}) \rightarrow \mathrm{Na}_{2} \mathrm{SiO}_{3}(\mathrm{l})+\mathrm{H}_{2} \mathrm{O}(\mathrm{g}) \\
2 \mathrm{NaOH}(\mathrm{l})+\mathrm{Al}_{2} \mathrm{Si}_{2} \mathrm{O}_{7} \cdot 2 \mathrm{H}_{2} \mathrm{O}(\mathrm{s}) \rightarrow 2 \mathrm{NaAlSiO}_{4}(\mathrm{~s})+3 \mathrm{H}_{2} \mathrm{O}(\mathrm{g})\end{array}$ & $\begin{array}{l}\text { Product nitration, carbonate formation, and hydration are all possible. } \\
\text { Nitration occurs at } \mathrm{T}<400^{\circ} \mathrm{C} \text {. Carbonate formation occurs at } \mathrm{T}<800^{\circ} \mathrm{C} \text {. } \\
\text { Hydration produces a molten phase of alkali metals capable of } \\
\text { dissolving other product solids and causing agglomerations. Formation } \\
\text { of alkali silicates is undesirable due to molten phases that can cause } \\
\text { agglomeration. Kaolin can be added to form alkali aluminosilicates, } \\
\text { which are insoluble and do not melt at process temperatures. }\end{array}$ \\
\hline
\end{tabular}


Table 2-4. Summary of waste reforming physical and chemical reactions (continued).

\begin{tabular}{|c|c|c|}
\hline Process Step & General Reaction Examples & Comments \\
\hline $\begin{array}{l}\text { Gaseous hydrocarbon } \\
\text { chemistry }\end{array}$ & $\begin{array}{l}\text { 1. } \mathrm{CO}+\mathrm{H}_{2} \mathrm{O} \leftrightarrow \mathrm{CO}_{2}+\mathrm{H}_{2} \\
\text { 2. } \mathrm{CO}+3 \mathrm{H}_{2} \leftrightarrow \mathrm{CH}_{4}+\mathrm{H}_{2} \mathrm{O} \\
\text { 3. } \mathrm{H}_{2} \mathrm{O} \leftrightarrow \mathrm{H} \cdot+\mathrm{OH} \cdot \\
\text { 4. } \mathrm{CO}+\mathrm{OH} \cdot \rightarrow \mathrm{CO}_{2}+\mathrm{H} \cdot \\
\text { 5. } \mathrm{H}_{2} \leftrightarrow 2 \mathrm{H} \cdot \\
\text { 6. } \mathrm{H} \cdot+\mathrm{H}_{2} \mathrm{O} \leftrightarrow \mathrm{H}_{2}+\mathrm{OH} \cdot \\
\text { 7. } \mathrm{CO}_{2} \leftrightarrow \mathrm{CO}+1 / 2 \mathrm{O}_{2} \\
\text { 8. } \mathrm{CH}_{3} \cdot+\mathrm{H} \cdot \leftrightarrow \mathrm{CH}_{4} \\
\text { 9. } 2 \mathrm{CH}_{3} \cdot+\mathrm{H} 2 \rightarrow 2 \mathrm{CH}_{4} \\
\end{array}$ & $\begin{array}{l}\text { 1. Water-gas shift reaction, significant at } \mathrm{T}>600-625^{\circ} \mathrm{C} \text {. } \\
\text { 2. Methanation is generally low. } \\
\text { Hydrogen and carbon give rise to highly reactive hydrogen, hydroxide, } \\
\text { peroxide, and oxygen radicals through the fuel-rich zone. Such } \\
\text { reactions promote ring opening, chain breaking, hydrogen } \\
\text { extraction } / \text { substitution reaction, etc. These reactions are very fast for } \\
\mathrm{T}>600-650^{\circ} \mathrm{C} \text { and lead to chain propagation. Below } 600^{\circ} \mathrm{C} \text {, many } \\
\text { radicals terminate and continued reaction is driven by } \mathrm{OH} \text { radical (e.g., } \\
\text { Reaction 4). }\end{array}$ \\
\hline $\begin{array}{l}\text { Gaseous nitrogen } \\
\text { chemistry }\end{array}$ & $\begin{array}{l}\mathrm{CH}_{4}+4 \mathrm{NO}_{2} \rightarrow 4 \mathrm{NO}+\mathrm{CO}_{2}+2 \mathrm{H}_{2} \mathrm{O} \\
\mathrm{CH}_{3} \cdot+\mathrm{NO} \rightarrow \mathrm{HCN}+\mathrm{H} 2 \mathrm{O} \\
\mathrm{CH}_{3} \cdot+\mathrm{NO}_{2} \rightarrow \mathrm{CH}_{3} \mathrm{O} \cdot \mathrm{NO} \\
\mathrm{CH}_{2} \cdot+\mathrm{NO} \rightarrow \mathrm{HCN}+\mathrm{OH} \cdot \\
\mathrm{CH} \cdot+\mathrm{NO} \rightarrow \mathrm{HCN}+\mathrm{O} \cdot \\
\mathrm{HCN}+\mathrm{OH} \cdot \rightarrow \mathrm{HNCO}+\mathrm{H} \cdot \\
\mathrm{HCNO}+\mathrm{H} \cdot \rightarrow \ldots \mathrm{NHi}(\mathrm{i}=1,2,3) \\
\mathrm{NH} 2+\mathrm{NO} \rightarrow \mathrm{N}_{2}+\mathrm{H}_{2} \mathrm{O} \\
2 \mathrm{CO}+2 \mathrm{NO} \rightarrow \mathrm{N}_{2}+2 \mathrm{CO}_{2} \\
\mathrm{NO}+\mathrm{H}_{2} \rightarrow \mathrm{NH} \cdot+\mathrm{OH} \cdot \\
\mathrm{NHi}=0,1,2+\mathrm{H} \cdot \rightarrow \mathrm{NHj}=1,2,3 \\
\end{array}$ & $\begin{array}{l}\text { Nitrogen oxides are reduced to cyanides, ammonia, and nitrogen in the } \\
\text { reducing atmosphere. Upward of } 100 \text { significant elementary-step } \\
\text { reactions may be important. } \\
\text { The reactions between the methyl radical and } \mathrm{NO}_{\mathrm{x}} \text { species are thought } \\
\text { to be important mechanisms for } \mathrm{NO}_{\mathrm{x}} \text { destruction under these reforming } \\
\text { conditions, especially for } \mathrm{NO}_{2} \text {, based on prior tests conducted by the } \\
\text { INEEL. }\end{array}$ \\
\hline $\begin{array}{l}\text { Overall Sugar-NO3 } \\
\text { and C-NO3 Redox } \\
\text { Reactions }\end{array}$ & $\begin{array}{l}\mathrm{C}_{12} \mathrm{H}_{22} \mathrm{O}_{11}+9.6 \mathrm{NaNO}_{3} \rightarrow 4.8 \mathrm{Na}_{2} \mathrm{CO}_{3}+4.8 \mathrm{~N}_{2}+7.2 \mathrm{CO}_{2}+11 \mathrm{H}_{2} \mathrm{O} \\
\mathrm{C}_{12} \mathrm{H}_{22} \mathrm{O}_{11}+9.6 \mathrm{NaNO}_{3}+4.8 \mathrm{Al}_{2} \mathrm{O}_{3} \cdot 2 \mathrm{SiO}_{2} \cdot 2 \mathrm{H}_{2} \mathrm{O} \rightarrow 9.6 \mathrm{NaAlSiO}_{4}+4.8 \mathrm{~N}_{2}+ \\
12 \mathrm{CO}_{2}+20.6 \mathrm{H}_{2} \mathrm{O} \\
5 \mathrm{C}+4 \mathrm{NaNO}_{3} \rightarrow 2 \mathrm{Na}_{2} \mathrm{CO}_{3}+2 \mathrm{~N}_{2}+3 \mathrm{CO}_{2} \\
5 \mathrm{C}+4 \mathrm{NaNO}_{3}+2 \mathrm{Al}_{2} \mathrm{Si}_{2} \mathrm{O}_{7} \cdot 2 \mathrm{H}_{2} \mathrm{O} \rightarrow 4 \mathrm{NaAlSiO}_{4}+2 \mathrm{~N}_{2}+5 \mathrm{CO}_{2}+4 \mathrm{H} 2_{\mathrm{O}}\end{array}$ & $\begin{array}{l}\text { All pathways utilize the reductant to react only with the } \mathrm{NO}_{3} \text {, } \\
\text { producing } \mathrm{N}_{2} \text { and no } \mathrm{CO}, \mathrm{H}_{2} \text {, or } \mathrm{C} \text { char. Any balanced reaction } \\
\text { equations showing } \mathrm{H}_{2}, \mathrm{CO} \text {, or } \mathrm{C} \text { production are less efficient or } \\
\text { summed with water-gas reactions. All of these reaction equations have } \\
\text { a C:NO} \mathrm{NO}_{3} \text { mole ratio of } 1.25 \text { to } 1 \text {. }\end{array}$ \\
\hline
\end{tabular}


Methane and other hydrocarbons are also formed as products of decomposition and pyrolysis of organic materials that contain hydrogen, such as sugar.

Carbonaceous reductants fed to the reformer provide chemically reducing conditions in the reformer via the kinds of reactions described above. The higher the reducing conditions of the reformer, the more effectively nitrates in the feed are chemically reduced to $\mathrm{N}_{2}$. TTT uses the level of $\mathrm{H}_{2}$ as an indicator of the reducing conditions in the reactor. To promote highly reducing conditions and the destruction of nitrates and $\mathrm{NO}_{\mathrm{x}}$, TTT adds has used both activated carbon (added as a solid to the fluidized bed), and sugar (dissolved directly into the waste stream or added as a syrup).

The most stoichiometrically efficient reactions between sugar (and carbon) and SBW do not produce any residual reduced species such as $\mathrm{CO}, \mathrm{H}_{2}, \mathrm{CH}_{4}$, or solid carbon char. For example, the stoichiometric reaction of sodium nitrate with sugar is given in Equations (2-4) and (2-5), for the carbonate and mineralizing flow sheets respectively. Each of these equations have a $\mathrm{C}: \mathrm{NO}_{3}$ mole ratio of 1.25:1. Similar equations in Table 2-4 show that the most efficient reaction of carbon with sodium nitrate also has a $\mathrm{C}: \mathrm{NO}_{3}$ mole ratio of 1.25:1.

$$
\begin{aligned}
& \mathrm{C}_{12} \mathrm{H}_{22} \mathrm{O}_{11}+9.6 \mathrm{NaNO}_{3} \rightarrow 4.8 \mathrm{Na}_{2} \mathrm{CO}_{3}+4.8 \mathrm{~N}_{2}+7.2 \mathrm{CO}_{2}+11 \mathrm{H}_{2} \mathrm{O} \\
& \mathrm{C}_{12} \mathrm{H}_{22} \mathrm{O}_{11}+9.6 \mathrm{NaNO}_{3}+4.8 \mathrm{Al}_{2} \mathrm{O}_{3} \cdot 2 \mathrm{SiO}_{2} \cdot 2 \mathrm{H}_{2} \mathrm{O} \rightarrow 9.6 \mathrm{NaAlSiO}_{4}+4.8 \mathrm{~N}_{2}+12 \mathrm{CO}_{2}+20.6 \mathrm{H}_{2} \mathrm{O}
\end{aligned}
$$

These $100 \%$ stoichiometric equations do not produce any excess $\mathrm{CO}, \mathrm{C}_{\mathrm{n}} \mathrm{H}_{\mathrm{m}}$, and $\mathrm{H}_{2}$. Reductant (sugar or carbon) added in excess reductant sugar and activated carbon fed to the reactor produce the excess $\mathrm{CO}, \mathrm{C}_{\mathrm{n}} \mathrm{H}_{\mathrm{m}}$, and $\mathrm{H}_{2}$ reformed by the steam or pyrolyzed by the temperature to form other compounds, including those previously mentioned.

\subsubsection{Steam Reforming Product}

Using the THOR process, the liquid SBW nitrate waste can be converted into a dry alkali carbonate salt that is readily soluble, or into an insoluble, mineralized product. Having a highly soluble carbonate product makes recovery of a failed fluidized bed and remote decontamination more feasible and should be no more problematic than dissolving out calcine produced in the New Waste Calciner Facility. The carbonate product, however, is more prone to agglomeration because alkali hydroxides and eutectic salt mixtures can form. Under the assumption that the SBW will be reclassified as waste-incidental-toreprocessing (WIR), the solubility of the carbonate product will not be detrimental for interment of the treated waste at the WIPP, unless the waste acceptance criteria are modified to require immobilization of RCRA hazardous constituents. The carbonate product could be fed to a glass melter, if necessary, but $\mathrm{CO}_{2}$ evolution from the carbonate product would add to the offgas flowrate and could contribute to foaming in the melter.

A carbonate product is produced when sufficient reductant is used to react with nitrates in the feed to reduce the nitrates to $\mathrm{N}_{2}$. If a mineralized product is desired, mineralizing additives must be used in addition to reducing additives. TTT recommended adding fine silica powder and ground kaolin clay to provide sufficient $\mathrm{Al}$ and $\mathrm{Si}$ in the right forms to combine with alkali elements (primarily $\mathrm{Na}$ and $\mathrm{K}$ ) in the feed to produce nepheline and other aluminosilicate mineral phases in the reformer. Toxic metals and radionuclides are immobilized in the matrix, either by forming an incorporated mineral phase or by microencapsulation. The silica was intended to augment the aluminum that was already present in the SBW simulant so that, with the added kaolin, all of the alkali metals could be converted into aluminosilicates. 


\section{MEASUREMENTS, SAMPLE COLLECTION, AND SAMPLE ANALYSIS}

Diagnostic activities performed during steam reformer tests included (a) continuous process measurements including key process flow rates, temperatures, and pressures, (b) continuous off-gas composition measurements, and (c) sample collection for laboratory analysis. These diagnostic activities provided data for controlling the process operation and for determining the fate of feed constituents, product characteristics, and the off-gas composition.

\subsection{Process Measurements}

Process monitoring, process control, and data collection were performed primarily by the Process Logic Controller (PLC). The PLC continuously and automatically monitored and controlled key system components and electronically logged key data. Process data that was not electronically logged by this system was recorded manually on operator data sheets. Control of process parameters that were not automatically controlled was also done according to operator discretion, the test plan, and steam reformer system operating instructions (SAIC 2003).

\subsection{Continuous Off-gas Composition Monitoring}

Continuous monitoring provided off-gas composition measurements for process control, air emissions measurements, and determination of the fate of feed constituents that are converted to gaseous compounds. Measurements were made at the outlet of the heated filter (inlet to the thermal oxidizer) and at operator-selected locations at the inlet of the carbon bed, or after each stage of the carbon bed. Four separate continuous emissions monitoring systems (CEMSs) were used. Analyzers used in each CEMS are summarized in Table 3-1.

CEMS 1 measures the steam reformer off-gas composition at the outlet of the heated filter, upstream of the thermal oxidizer, before the off-gas is oxidized. The CEMS 1 measurements are necessary for characterizing and controlling the steam reformer process.

Two Hg CEMSs were used to continuously monitor $\mathrm{Hg}$ concentrations upstream and downstream of the wet scrubber and the carbon bed.

CEMS 2 measures the off-gas composition downstream of the thermal oxidizer and wet scrubber. Like the second Hg CEMS, CEMS 2 sampling is selectable between inlet, intermediate stages, or outlet of the carbon bed. 
Table 3-1. Analyzers used in the CEM systems.

\begin{tabular}{|c|c|c|c|c|c|c|c|c|}
\hline \multirow[b]{2}{*}{ Gas species } & \multirow[b]{2}{*}{ Instrument } & \multirow{2}{*}{$\begin{array}{l}\text { Detection } \\
\text { principle }\end{array}$} & \multirow[b]{2}{*}{ Instrument range } & \multicolumn{4}{|c|}{ Acceptance limits, \% FS } & \multirow{2}{*}{$\begin{array}{l}\text { Reference } \\
\text { method }\end{array}$} \\
\hline & & & & Calibration & Drift & Linearity & Bias & \\
\hline \multirow[t]{2}{*}{$\mathrm{O}_{2}$} & Servomex 1440 (CEMS 1) & Paramagnetism & \multirow[t]{2}{*}{0 to $25 \%$} & \multirow[t]{4}{*}{2} & \multirow[t]{4}{*}{3} & \multirow[t]{4}{*}{4} & \multirow[t]{4}{*}{5} & \multirow{4}{*}{$\begin{array}{l}40 \text { CFR } 60 \\
\text { App. A } \\
\text { Method } 3 A\end{array}$} \\
\hline & $\begin{array}{l}\text { Ametek WDG-IV in situ } \\
\mathrm{ZrO}_{2} \text { probe (CEMS 2) }\end{array}$ & Electrochemical & & & & & & \\
\hline \multirow[t]{2}{*}{$\mathrm{CO}_{2}$} & Nova 4230 RM (CEMS 1) & \multirow[t]{2}{*}{$\begin{array}{l}\text { Nondispersive } \\
\text { infrared (NDIR) }\end{array}$} & $\begin{array}{l}0 \text { to } 40 \% \\
0 \text { to } 100 \%\end{array}$ & & & & & \\
\hline & CAI ZRH (CEMS 2) & & $0-100 \%$ & & & & & \\
\hline $\mathrm{H}_{2}$ & Nova 4230 RM (CEMS 1) & $\begin{array}{l}\text { Thermal } \\
\text { conductivity }\end{array}$ & 0 to $5 \%$ & --- & --- & --- & --- & --- \\
\hline \multirow[t]{2}{*}{$\mathrm{CO}$} & CAI 200 (CEMS 1) & \multirow[t]{3}{*}{ NDIR } & $\begin{array}{l}0 \text { to } 1 \% \\
0 \text { to } 2 \%\end{array}$ & \multirow[t]{2}{*}{5} & \multirow[t]{2}{*}{10} & \multirow[t]{2}{*}{2} & \multirow[t]{2}{*}{---} & \multirow{2}{*}{$\begin{array}{l}40 \text { CFR } 60 \\
\text { App. A } \\
\text { Method } 10\end{array}$} \\
\hline & CAI ZRH (CEMS 2) & & $\begin{array}{l}0-500 \mathrm{ppm} \\
0-2,500 \mathrm{ppm}\end{array}$ & & & & & \\
\hline $\mathrm{CH}_{4}$ & CAI 200 (CEMS 1) & & $\begin{array}{l}0 \text { to } 0.5 \% \\
0 \text { to } 1 \% \\
\end{array}$ & --- & --- & --- & --- & --- \\
\hline \multirow[t]{3}{*}{$\mathrm{NO}, \mathrm{NO}_{\mathrm{x}}$} & Ametek M922 (CEMS 1) & $\begin{array}{l}\text { Dispersive } \\
\text { ultraviolet } \\
\text { (DUV) }\end{array}$ & $\begin{array}{l}0-5,000 \mathrm{ppm} \mathrm{NO} \\
0-25,000 \mathrm{ppm} \mathrm{NO}_{2} \\
0-13,500 \mathrm{ppm} \mathrm{SO}_{2}\end{array}$ & \multirow[t]{3}{*}{2} & \multirow[t]{3}{*}{3} & \multirow[t]{3}{*}{4} & \multirow[t]{3}{*}{5} & \multirow[t]{3}{*}{$\begin{array}{l}40 \text { CFR } 60 \\
\text { App. A } \\
\text { Method 7E }\end{array}$} \\
\hline & CAI 600 CLD (CEMS 1) & \multirow{2}{*}{$\begin{array}{l}\text { Chemilumines- } \\
\text { cence }\end{array}$} & 0 to $5,000 \mathrm{ppm}$ & & & & & \\
\hline & $\begin{array}{l}\text { Thermo Environmental } \\
\text { Company (TECO) 42C } \\
\text { High Range (CEMS 2) }\end{array}$ & & $0-4,000 \mathrm{ppm}$ & & & & & \\
\hline THC & $\begin{array}{l}\text { CAI } 300 \text { HFID (CEMS } 1 \\
\text { and 2) }\end{array}$ & $\begin{array}{l}\text { Flame ionization } \\
\text { detection (FID) }\end{array}$ & $0-3 \% \mathrm{C}$ & 5 & 3 & --- & --- & $\begin{array}{l}40 \text { CFR } 60 \\
\text { App. A } \\
\text { Method } \\
25 \mathrm{~A}\end{array}$ \\
\hline $\mathrm{HCl}$ & TECO 15C (CEMS 2) & $\begin{array}{l}\text { NDIR with gas } \\
\text { filter correlation } \\
\text { (GFC) }\end{array}$ & $\begin{array}{l}0-5 \mathrm{ppm} \text { to } \\
0-5,000 \mathrm{ppm}\end{array}$ & --- & --- & --- & --- & --- \\
\hline $\begin{array}{l}\text { Total and } \\
\text { elemental } \\
\mathrm{Hg}\end{array}$ & $\begin{array}{l}\text { PSA Analytical Sir Galahad } \\
\text { (CEMS } 3 \text { and } 4 \text { ) }\end{array}$ & $\begin{array}{l}\text { Atomic } \\
\text { fluorescence }\end{array}$ & $0-3,000 \mathrm{ug} / \mathrm{m}^{3}$ & --- & --- & --- & --- & --- \\
\hline
\end{tabular}

\subsubsection{CEMS 1}

The off-gas composition at different locations in the off-gas system can vary significantly, so the configurations of CEMSs 1 and 2 vary somewhat. The CEMS 1 for the filter outlet (thermal oxidizer inlet) measurements is shown in Figure 3-1. A heated sample probe is used to continuously extract a portion of the off-gas from the off-gas pipe. A heated filter at the back end of the heated probe removes particulate matter from the sample gas. The sample gas flows under negative pressure from the probe through a heated stainless steel sample line to the chiller system. Stainless steel is used for this sample line instead of more commonly used Teflon to better ensure retention of any $\mathrm{H}_{2}$ in the sample gas. 


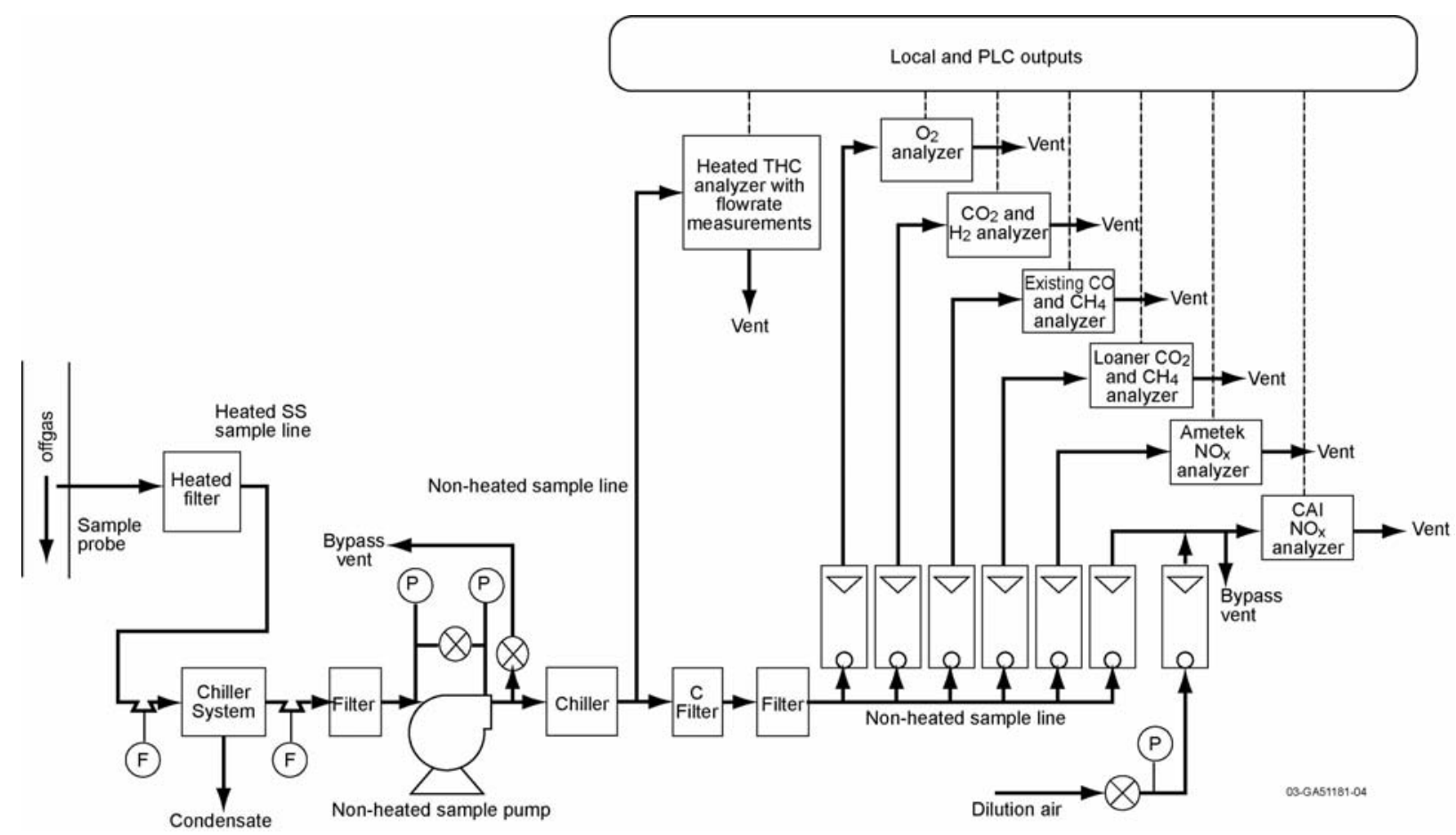

Figure 3-1. CEMS 1 for steam reformer off-gas measurements at the filter outlet sample location, upstream of the thermal oxidizer.

The wet sample gas flow rate is measured upstream of the chiller using a Micromotion coriolis meter. This meter measures the mass flow rate independently of gas composition or density. The gas flow rate is measured here and also downstream of the chiller, after moisture is removed, to determine the moisture content of the sample gas.

The chiller system cools the sample gas and removes moisture. In this design, some of the watersoluble gases such as $\mathrm{NO}_{2}$ and $\mathrm{HCl}$, and some higher molecular weight or water-soluble hydrocarbons, if present, could be captured with the water condensate. If so, those amounts of condensed or scrubbed gases would not be detected by the analyzers. More complex ways to better retain these gases in the sample gas are available but have not been implemented in this test system due to their cost and complexity.

Two actions minimize and quantify lost soluble/condensable gas species. First, the chiller system is designed according to guidance in EPA 2002 to minimize acid gas scrubbing. Second, condensate samples are collected for analysis as a quality assurance check to determine amounts, if any, of condensed or scrubbed species. Results of these analyses from prior tests have shown negligible $\mathrm{NO}_{\mathrm{x}}$ scrubbing (Marshall 2003a, Marshall 2003c, Soelberg 2003a). The sample gas is analyzed on a dry basis, because the chiller removes moisture from the sample gas.

All components downstream of the sample gas chiller system are unheated, because most of the condensable moisture is removed in the chiller. The sample pump induces the negative pressure needed to draw the sample gas from the off-gas pipe into the CEMS. A small backup chiller and a backup filter located immediately downstream of the sample pump provide added protection for the flow meters and analyzers from condensate or particulate matter damage or fouling. 
The components of the sample pump, and all other components of the CEMS that contact the sample gas, are constructed of stainless steel, Teflon, glass, or other materials designed to avoid reaction with the sample gas.

After the first testing week, fouling of some of the rotameters and analyzers from condensable organic matter was observed. Several rotameters, some tubing, and some analyzers were cleaned or replaced before testing week two. An activated carbon filter was added to the CEMS between the backup chiller and backup filter to better scrub the condensable organic material. This carbon filter prevented further fouling from condensable organic material, improving CEM 1 performance during testing week two. The carbon filter was also observed to sorb $\mathrm{NO}_{\mathrm{x}}$ for the first few hours after test startup. Shortduration tests with and without the carbon filter showed that after the first few testing hours, the carbon filter reached saturation for $\mathrm{NO}_{\mathrm{x}}$ and did not affect $\mathrm{NO}_{\mathrm{x}}$ readings.

The chilled and conditioned off-gas was split and delivered through valved rotameters to the various analyzers. The sample gas for the total hydrocarbon (THC) analyzer was taken upstream of the carbon filter, which would otherwise have sorbed hydrocarbons intended for analysis in the THC meter.

The THC analysis is made by flame ionization detection of $\mathrm{C}$ ions that are produced when hydrocarbon compounds are ionized at high temperatures in a hydrogen-air flame.

The two $\mathrm{NO}_{\mathrm{x}}$ analyzers used in CEMS 1 during this test are based on different measurement techniques. The dispersive ultraviolet (DUV) Ametek analyzer detects $\mathrm{NO}$ and $\mathrm{NO}_{2}$ simultaneously. This analyzer can also detect $\mathrm{SO}_{2}$ by DUV. This analyzer replaced the Ecophysics chemiluminescent $\mathrm{NO}_{\mathrm{x}}$ analyzer used in prior tests because (a) the chemiluminescent analyzer used at this sample location was subject to interferences and required air dilution of the sample gas to mitigate some of this interference, and (b) the chemiluminescent analyzer was relocated to sample the fully oxidized off-gas downstream of the thermal oxidizer, where interferences to the chemiluminescent analysis are mitigated.

While the DUV analyzer was expected to be relatively impervious to interferences, considerable interferences on this analyzer were observed during the test weeks. Ametek theorizes that the interferences are due to levels of hydrocarbons that are higher in the steam reformer off-gas than are found in most other off-gases. The interferences caused the zero to drift over time, and also caused a bias on the measured $\mathrm{NO}$ values. The interferences were significant enough on the $\mathrm{SO}_{2}$ and the $\mathrm{NO}_{2}$ readings that these readings from this analyzer were not valid during the two-week test. The NO readings were corrected for the zero drift and the measurement bias. The corrected NO readings are useable estimates of the NO levels in the off-gas.

After test week 1, a second $\mathrm{NO}_{\mathrm{x}}$ analyzer was added to CEMS 1 to provide better $\mathrm{NO}_{\mathrm{x}}$ readings. This analyzer was a California Analytical Instruments (CAI) chemiluminescent analyzer. This analyzer uses a low-temperature vitreous carbon converter that converts $\mathrm{NO}_{2}$ to $\mathrm{NO}$, so the $\mathrm{NO}_{2}$ can be detected along with the $\mathrm{NO}$ when the analyzer is in the $\mathrm{NO}_{\mathrm{x}}$ detection mode. This converter is more impervious to interferences observed on the more traditional higher temperature stainless steel $\mathrm{NO}_{\mathrm{x}}$ converters more commonly used in chemiluminescent $\mathrm{NO}_{\mathrm{x}}$ analyzers (Marshall 2003a and 2003c). The sample gas for this analyzer was diluted with air to mitigate $\mathrm{NO}_{\mathrm{x}}$ converter and $\mathrm{NO}_{\mathrm{x}}$ detection interferences that were observed in the January 2003 THOR steam reformer technology tests. After dilution correction (and $\mathrm{NO}_{\mathrm{x}}$ saturation of the CEMS 1 carbon filter), the $\mathrm{NO}_{\mathrm{x}}$ measurements from this analyzer were valid. 


\subsubsection{Partial Quench Outlet and Carbon Bed Inlet Hg CEM}

Continuous mercury measurements were made at the thermal oxidizer outlet (inlet to the partial quench) and at the inlet of the carbon bed using a PSA Analytical Sir Galahad continuous mercury analyzer system shown in Figure 3-2. This single analyzer is equipped with 2 separate sampling and conditioning systems, one each dedicated to the two separate sampling locations. Using 2 separate sampling and conditioning systems minimizes potential interferences from sampling artifacts at one location on the measurements for the other location.

Hg Continuous Sampling Train (CST) 3 was used to extract and condition relatively high-Hg offgas from sample locations downstream of the thermal oxidizer (upstream of the partial quench and wet scrubber), and downstream of the reheater (upstream of the carbon bed). Hg CST 4 was used to extract and condition relatively low-Hg off-gas from any of the two selectable locations in between each of the three stages of carbon in the carbon bed or at the carbon bed outlet. The diluted, conditioned off-gas from CST 3 and 4 are delivered to the single Hg CEM. The Hg CEM sequentially measures elemental and total $\mathrm{Hg}$ for each of the two CSTs. The cycle time for the Hg CEM to make all four measurements required 20-30 minutes, depending on the sampling time for each of the four input sample gas streams.

The high-Hg off-gas was diluted in CST-3 by up to 120:1 to lower the expected Hg levels to ranges within the instrument full-scale range of $0-3,000 \mathrm{ug} / \mathrm{dscm}$. The lower-Hg off-gas downstream of the carbon bed was diluted by up to $80: 1$.

For each sampling and conditioning system, the sample gas was extracted from the sample location through a heated probe, and filtered using a heated filter. This filter was designed for occasional pulsing to remove any particulate matter, blowing it back into the off-gas system.

A heated head sample pump was used to provide positive pressure to the critical flow venturi to ensure that the flow of sample gas through the venturi is choked flow. Choked flow, necessary for proper operation of the critical flow venturi, occurs when the static pressure upstream of the venturi is at least twice the static pressure downstream of the venturi. The venturi upstream pressure, and the flow rate of dilution gas (compressed air or nitrogen) to the diluter jet pump, establish the dilution factor. The upstream pressure is controlled using a control valve on the sample pump bypass. The flow rate of sample gas through the filter and sample pump is controlled using a bypass valve and rotameter to ensure that, even when the sample gas is diluted, sufficient sample gas flows through the sampling system to minimize $\mathrm{Hg}$ measurement bias due to low sample flow rate.

The diluted sample gas flows through either of two selectable pathways that enable the separate measurement of either total $\mathrm{Hg}$ or only elemental $\mathrm{Hg}$. In the total $\mathrm{Hg}$ measurement mode, the sample gas flows through an impinger system containing stannous chloride solution, which converts any oxidized $\mathrm{Hg}$ (principally $\mathrm{HgCl}_{2}$ ) to $\mathrm{Hg}^{0}$. The sample then flows through a Peltier cooler to the $\mathrm{Hg}$ analyzer, where total $\mathrm{Hg}$ is measured. In the elemental $\mathrm{Hg}$ measurement mode, the sample gas flows through an impinger system containing $\mathrm{KCl}$ solution, which scrubs any oxidized $\mathrm{Hg}$ species out of the sample gas but allows elemental $\mathrm{Hg}$ to pass through. The sample gas flows from this impinger system through a separate Peltier cooler to the $\mathrm{Hg}$ analyzer, where only elemental $\mathrm{Hg}$ is measured. 


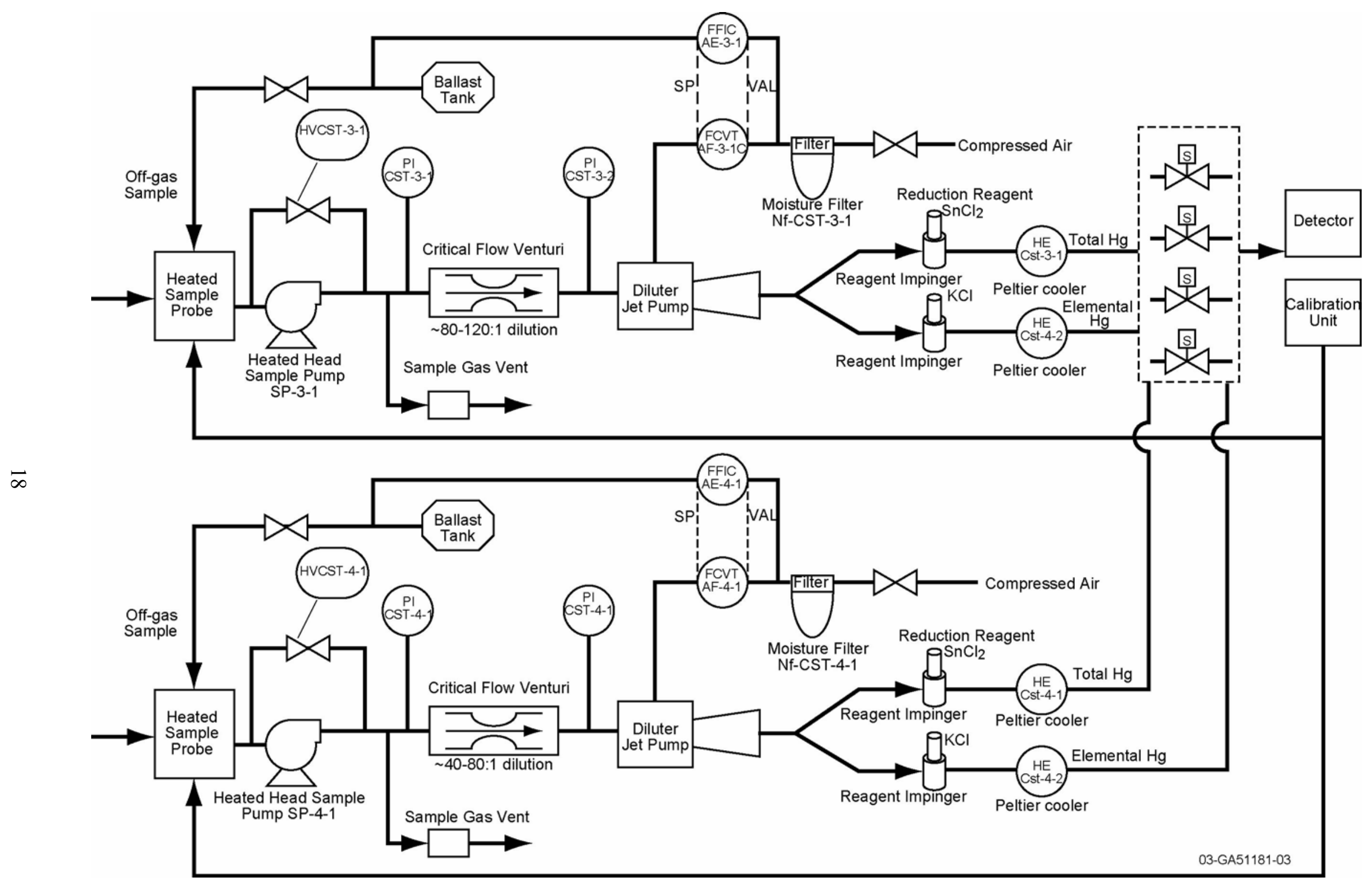

Figure 3-2. PSA analytical Hg CEMS with dual sampling and conditioning systems. 


\subsubsection{CEMS 2}

CEMS 2 was used to monitor the fully oxidized off-gas downstream of the thermal oxidizer. The thermal oxidizer outlet $\mathrm{O}_{2}$ measurement was fixed at that location, but the sample probe for the other CEMS 2 analyzers was switchable between the inlet of the carbon bed, the outlet of the carbon bed, or any intermediate carbon bed stage.

The CEMS 2 is shown in Figure 3-3. While some of the analyzers for CEMS 2 were different from CEMS 1, the sampling and conditioning system was identical to that of CEMS 1, except that (a) coriolis meters were not used to measure the CEMS 2 off-gas moisture content, and (b) no carbon filter was required or used in CEMS 2.

Since off-gas measured by CEMS 2 was similar to typical combustion off-gas, the analyzers were typical of those that work well on combustion off-gases with minimal interferences. Analyzers used in CEMS 2 are listed in Table 3-1.

\subsection{Process Sample Collection and Analysis}

Process samples were collected and analyzed to characterize feed and product streams, perform key mass balances, and determine the fate of feed constituents in the steam reforming process. Over 300 samples were collected during the THOR tests. Process streams that were sampled include the feed simulant, carbon additives, bed, cyclone, and filter solids, the scrub solution, off-gas, and CEMS condensates. Depending on sample matrix and analysis objectives, the samples were analyzed for a wide variety of analyses. Hundreds of analyses were performed to identify and quantify dozens of analytes and characteristics of the samples.

Sample analysis procedures are summarized in Table 3-2. Depending on the analysis complexity, analysis procedures, and turnaround time goals, some analyses were performed onsite at the SAIC STAR Center, the INEEL Research Center (IRC), the INEEL Analytical Laboratory Department (ALD), the laboratory at the INEEL Test Reactor Area (TRA), and Lionville Laboratory, a subcontractor laboratory. Some analyses that were relatively simple and used simple or mobile equipment were performed at the STAR Center in order to speed turnaround time. Speedy results of some analyses such as particle size, nitrate content, carbonate content, and carbon content were used to facilitate the parametric tests and to diagnose the health of the reformer system. Performing these analyses onsite at the STAR Center enable turnaround times of a few hours or less for some analyses. More complex analyses or those that required larger or more expensive equipment than can be readily transported to the STAR Center were performed in laboratories at the INEEL.

Many of the analyses at the STAR Center and other laboratories were simplified or optimized from more complex or traditional analytical procedures. 


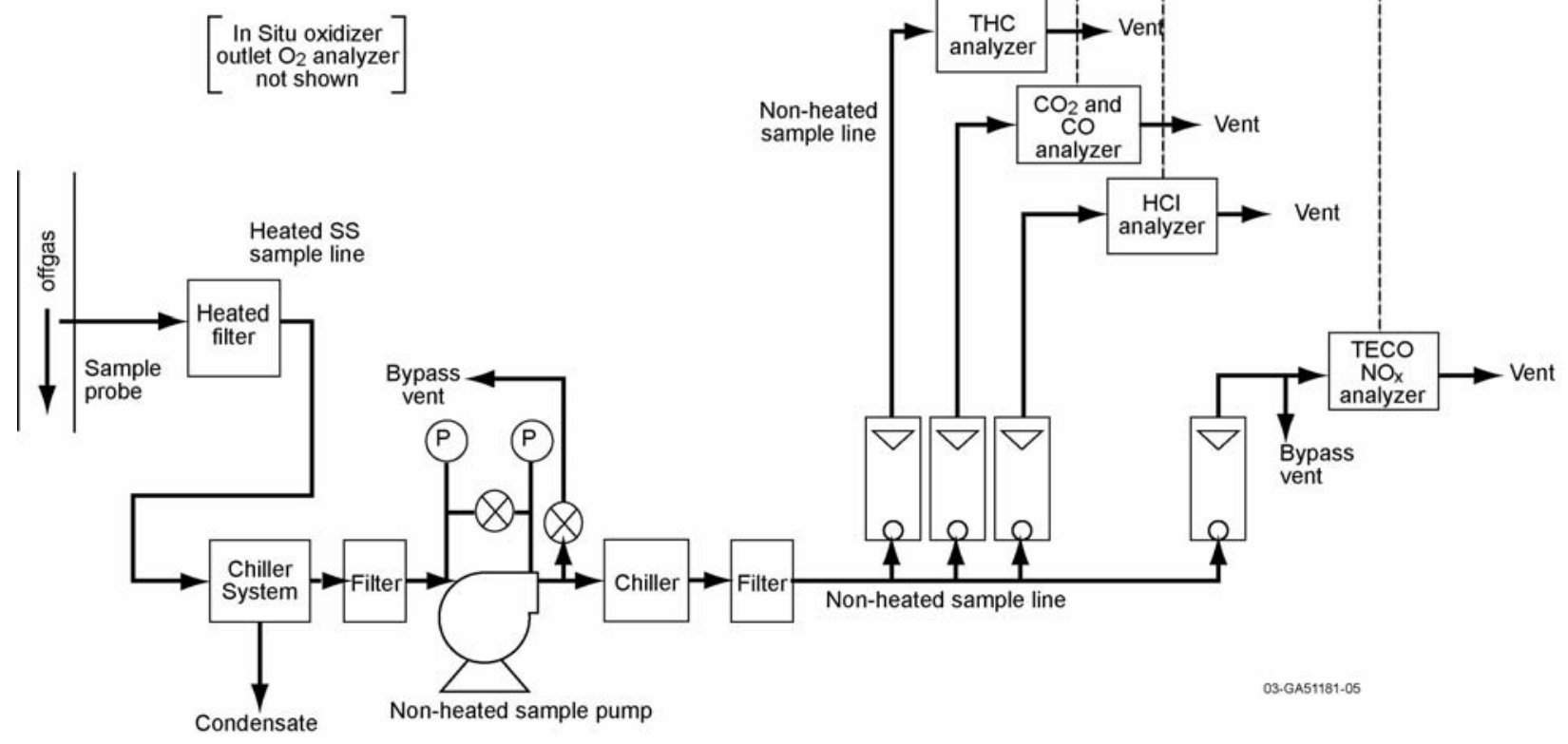

Figure 3-3. CEMS 2 for steam reformer off-gas measurements downstream of the carbon bed. 
Table 3-2. Sample analysis procedures.

\begin{tabular}{|c|c|c|c|c|c|}
\hline Analytes & Method (reference) & Analysis technique & $\begin{array}{l}\text { Detection } \\
\text { limits }\end{array}$ & Performed at: & Method summary, comments \\
\hline Total mass & $\begin{array}{l}\text { Good laboratory } \\
\text { practice }\end{array}$ & Calibrated laboratory balance & $\begin{array}{l}\text { Depends } \\
\text { on range }\end{array}$ & $\begin{array}{l}\text { All laboratories } \\
\text { used in the test } \\
\text { program }\end{array}$ & $\begin{array}{l}\text { Using an appropriately ranged, calibrated balance, determine the net weight of } \\
\text { sample by subtracting the container tare weight from the total weight of the } \\
\text { sample and the container. }\end{array}$ \\
\hline Nitrate & \multicolumn{2}{|c|}{ Onsite at the STAR Center: Sulphonated phenol colorimetry } & $\sim 0.1 \mathrm{wt} \%$ & $\begin{array}{l}\text { STAR Center, } \\
\text { TRA }\end{array}$ & $\begin{array}{l}\text { Treat solid product or dried water leachate with sulphonated phenol/ } \mathrm{H}_{2} \mathrm{SO}_{4}-\text { add } \\
\text { excess base and measure absorbance @ } 400 \mathrm{~nm}\end{array}$ \\
\hline Carbonate & \multicolumn{2}{|c|}{$\begin{array}{l}\text { Volumetric determination of } \mathrm{CO}_{2} \text { evolved from solid-phase } \\
\mathrm{CO}_{3}\end{array}$} & $\sim 0.5 \mathrm{wt} \%$ & $\begin{array}{l}\text { STAR Center, } \\
\text { TRA }\end{array}$ & $\begin{array}{l}\text { React sample with hot } \mathrm{H}_{2} \mathrm{SO}_{4} \text { in a syringe, normalize its pressure, and measure the } \\
\text { volume of } \mathrm{CO}_{2} \text { released }\end{array}$ \\
\hline Bulk density & \multicolumn{2}{|c|}{ Gravimetric and volumetric analysis } & $\sim 0.1 \mathrm{~g} / \mathrm{mL}$ & $\begin{array}{l}\text { STAR Center, } \\
\text { TRA, IRC }\end{array}$ & $\begin{array}{l}\text { Fill a tared graduate cylinder, tap for } \sim 30 \text { seconds to settle, measure the mass and } \\
\text { volume }\end{array}$ \\
\hline $\begin{array}{l}\text { Particle ("true") } \\
\text { density }\end{array}$ & \multicolumn{2}{|c|}{ Gravimetric and volumetric analysis } & --- & $\begin{array}{l}\text { STAR Center, } \\
\text { TRA }\end{array}$ & $\begin{array}{l}\text { Determine bulk density, then fill in interstitial space with hexane or other liquid } \\
\text { that does not dissolve solid particles, reweigh to determine the void volume, } \\
\text { subtract the void volume from the bulk volume, and determine void-free density. }\end{array}$ \\
\hline $\begin{array}{l}\text { Total Organic } \\
\text { Carbon (TOC, } \\
\text { Loss on Ignition) }\end{array}$ & & Gravimetry & $0.1 \mathrm{wt} \%$ & TRA & $\begin{array}{l}\text { Dry solid sample in convection oven at } 105^{\circ} \mathrm{C} \text {. Heat a known mass of the dried } \\
\text { solid in a ceramic crucible at } 500^{\circ} \mathrm{C} \text { for } 10 \text { minutes to burn off carbon. Cool \& } \\
\text { reweigh. Does not discriminate between carbonate and organic carbon. }\end{array}$ \\
\hline TOC & $\begin{array}{l}\text { Chemical oxygen } \\
\text { demand (COD) } \\
\text { determination }\end{array}$ & Colorimetry & $0.01 \mathrm{wt} \%$ & $\begin{array}{l}\text { STAR Center \& } \\
\text { TRA }\end{array}$ & $\begin{array}{l}\text { React sample with chromate in hot concentrated sulfuric acid. Determine } \\
\text { chromate consumption colorimetrically and calculate TOC content. Applicable to } \\
\text { low-level TOC solid and liquid samples. }\end{array}$ \\
\hline $\begin{array}{l}\text { Total inorganic } \\
\text { carbon (TIC) and } \\
\text { TOC for liquid } \\
\text { samples }\end{array}$ & \multicolumn{2}{|c|}{$\begin{array}{l}\text { Persulfate-Ultraviolet Oxidation/Combustion-Infrared method } \\
5310 \mathrm{~B} / \mathrm{C} \text { (PUO-IM) }\end{array}$} & $\sim 0.1 \mathrm{wt} \%$ & IRC & Gasifies organic and inorganic carbon from liquid samples. \\
\hline Elemental & $\begin{array}{l}\text { SW-846 } 6000 \text { or } 7000 \\
\text { series or equivalent }\end{array}$ & $\begin{array}{l}\text { Inductively-coupled plasma atomic } \\
\text { emission spectroscopy (ICP-AES) } \\
\text { for most metals; ICP-mass } \\
\text { spectroscopy (ICP-MS) for Cs and } \\
\text { Re; cold vapor atomic absorption } \\
\text { (CVAA) spectroscopy for } \mathrm{Hg}\end{array}$ & $1 \mathrm{mg} / \mathrm{L}$ & $\begin{array}{l}\text { IRC, ALD, and } \\
\text { Lionville (ICP- } \\
\text { AES; TRA (ICP- } \\
\text { MS); ALD } \\
\text { (CVAA) }\end{array}$ & $\begin{array}{l}\text { Completely digest per EPA } 3050 \text { or equivalent for all elements. If } \mathrm{HF} \text { is needed } \\
\text { for complete dissolution, then perform a second lithium borate fusion and } \\
\text { digestion in } \mathrm{HNO}_{3} \text { for } \mathrm{Si} \text { analysis. ICP analysis of digested solution (CVAA } \\
\text { analysis for } \mathrm{Hg} \text { ). If no solids are present in liquid samples, digestion will not be } \\
\text { done. Analyses performed at Lionville Laboratory did not include any HF } \\
\text { digestions. }\end{array}$ \\
\hline $\begin{array}{l}\text { Anions (not } \\
\text { including } \mathrm{CO}_{3} \text { ) }\end{array}$ & $\begin{array}{l}\text { SW-846 } 9056 \text { or } \\
\text { equivalent }\end{array}$ & Ion chromatography (IC) & $1 \mathrm{mg} / \mathrm{L}$ & IRC, Lionville & $\begin{array}{l}\text { Water digestion (of solids) followed by analysis per 9056. If no solids are present } \\
\text { in liquid samples, digestion was not done. }\end{array}$ \\
\hline Moisture & $\begin{array}{l}\text { ASTM D } 3273 \text { or } \\
\text { equivalent (b) }\end{array}$ & Gravimetry & $1 \mathrm{mg}$ & $\begin{array}{l}\text { STAR Center, } \\
\text { TRA, Lionville }\end{array}$ & $\begin{array}{l}\text { Weigh sample, dry in oven at a temperature between } 104-110^{\circ} \mathrm{C} \text {, reweigh to } \\
\text { constant weight, calculate } \% \text { moisture. }\end{array}$ \\
\hline $\mathrm{Hg}$ & $\begin{array}{l}\text { SW846 } 7470 \text { or } \\
\text { equivalent }\end{array}$ & CVAA & $1 \mathrm{mg} / \mathrm{kg}$ & ALD & $\begin{array}{l}\text { Digest sample per SW- } 8463050 \text { and analyze by CVAA; re-digest solid residues } \\
\text { to determine completeness of the first digestion }\end{array}$ \\
\hline $\begin{array}{l}\text { Anions } \mathrm{Cl}, \mathrm{F}, \mathrm{I} \\
\text { nitrate }\end{array}$ & SW-846 & IC & $1 \mathrm{mg} / \mathrm{L}$ & IRC, Lionville & Water dissolution followed by analysis per 9056 \\
\hline $\mathrm{S}$ & SW-846 6000 & IC & & ALD & $\begin{array}{l}\text { Total digestion (of non-carbon solids) per EPA } 3050 \text { followed by analysis per } \\
9056 .\end{array}$ \\
\hline
\end{tabular}


Table 3-2. Sample analysis procedures (continued).

\begin{tabular}{|c|c|c|c|c|c|}
\hline Analytes & Method (reference) & Analysis technique & $\begin{array}{l}\text { Detection } \\
\text { limits }\end{array}$ & Performed at: & Method summary, comments \\
\hline TCLP & $\begin{array}{l}\text { Toxicity Characteristic } \\
\text { Leaching Procedure } \\
\text { (TCLP) EPA } 1311\end{array}$ & $\begin{array}{l}\text { Leach the solid sample and analyze } \\
\text { solution using ICP-AES and } \\
\text { CVAA }\end{array}$ & $1 \mathrm{mg} / \mathrm{L}$ & ALD & $\begin{array}{l}\text { Leach the solid, determine and analyze per } 6010 \mathrm{~B} \text { or } 6020 \text { (ICP-AES) (and per } \\
7470 \text { for } \mathrm{Hg} \text { ). A post-leach, post-filter digestion was not done. }\end{array}$ \\
\hline Volatile Matter & $\begin{array}{l}\text { ASTM D } 3175 \text { or } \\
\text { equivalent (b) }\end{array}$ & Gravimetric & & & $\begin{array}{l}\text { Volatilize VOCs at a controlled temperature and time; determine weight loss, } \\
\text { differentiating between weight loss from VOCs and weight loss from other } \\
\text { volatile constituents such as water and carbonate. }\end{array}$ \\
\hline $\begin{array}{l}\text { Optical } \\
\text { microscopy }\end{array}$ & \multicolumn{2}{|c|}{$\begin{array}{l}\text { Use optical microscope to observe particle properties. Use } \\
\text { camera to document particle properties. }\end{array}$} & $\begin{array}{l}\sim 10-100 \\
\text { um }\end{array}$ & IRC & $\begin{array}{l}\text { Document visible particle properties - shape, appearance, etc. Count numbers of } \\
\text { particles within selected size ranges in the field of view or in grids in the field of } \\
\text { view }\end{array}$ \\
\hline Water solubility & $\begin{array}{l}\text { Good laboratory } \\
\text { practice }\end{array}$ & Commercial conductivity meter & $\sim 0.1 \mathrm{wt} \%$ & $\begin{array}{l}\text { STAR Center, } \\
\text { TRA }\end{array}$ & $\begin{array}{l}\text { Add measured amounts of solid to a known volume of boiling, stirred water until } \\
\text { the water clouds with undissolved matter. Measure electrical conductivity of the } \\
\text { water and compare to conductivity curves. }\end{array}$ \\
\hline $\begin{array}{l}\text { Submicron particle } \\
\text { morphology }\end{array}$ & \multicolumn{2}{|c|}{ Scanning electron microscope (SEM) } & --- & $\begin{array}{l}\text { Mount on stages, } \\
\text { sputter with } \\
\text { conducting } \\
\text { carbon or gold } \\
\end{array}$ & $\begin{array}{l}\text { Determine and document submicron particle structures, including surface deposits } \\
\text { or layers, and individual submicron particles }\end{array}$ \\
\hline \multirow[t]{3}{*}{ Particle size } & $\begin{array}{l}\text { ASTM D 293, adapted } \\
\text { to granule particle size } \\
\text { detrmination }\end{array}$ & Sieve trays & $<1 \mathrm{um}$ & & $\begin{array}{l}\text { Mechanically separate particles of different sizes on calibrated sieve trays; } \\
\text { determine the net weight of each size cut by subtracting the sieve tare weight } \\
\text { from the total weight of the sample and the sieve. }\end{array}$ \\
\hline & --- & Coulter counter & $<1 \mathrm{um}$ & & \\
\hline & --- & Particle counting & $\sim 0.1 \mathrm{um}$ & & $\begin{array}{l}\text { Use particle counting/sizing software or visual observation to count and estimate } \\
\text { sizes of particles in micrographs. }\end{array}$ \\
\hline $\mathrm{HCN}$ & EPA SW 846 & Colorimetry & $\begin{array}{l}0.05 \mathrm{ppm} \\
\text { in liquid, } \\
\text { solids } \\
\text { variable }\end{array}$ & $\begin{array}{l}\text { STAR Center, } \\
\text { TRA }\end{array}$ & $\begin{array}{l}\text { Solids: Distill from hot phosphoric acid into dilute } \mathrm{NaOH} \text { absorption solution, } \\
\text { then apply barbituric acid/pyridine spectrophotometric method } \\
\text { Liquid: Direct barbituric acid/pyridine method }\end{array}$ \\
\hline $\mathrm{NH}_{3}$ & Nesslerization & Colorimetry & $\begin{array}{l}<100 \\
\text { ppmv } \\
\mathrm{NH}_{3} \text { in } \\
\text { sample } \\
\text { gas }\end{array}$ & $\begin{array}{l}\text { Gaseous/liquid } \\
\text { samples at STAR } \\
\text { center - solids } \\
\text { (after distillation) } \\
\text { at TRA }\end{array}$ & $\begin{array}{l}\text { Gas: Collect a gas sample into a syringe containing } \sim 2 \mathrm{cc} 0.05 \mathrm{M} \mathrm{H}_{2} \mathrm{SO}_{4} \text { to ensure } \\
\text { dissolution of } \mathrm{NH}_{3} \text {, rinse with water into cuvette, add Nessler's reagent, and } \\
\text { measure } \mathrm{NH}_{4}^{+} \text {colorimetrically } \\
\text { Solids - distill from sample slurried with conc. } \mathrm{NaOH} \text { into dilute } \mathrm{H}_{2} \mathrm{SO}_{4} \text { and then } \\
\text { Nesslerize that liquid }\end{array}$ \\
\hline $\mathrm{pH}$ & \multicolumn{2}{|l|}{ Commercial $\mathrm{pH}$ probe } & & --- & \\
\hline PCT & $\begin{array}{l}\text { INEEL method: } \\
\text { ACMM-7997 }\end{array}$ & $\begin{array}{l}\text { One week leach of sub } 100 \text { mesh } \\
\text { sample particles with } 10 \mathrm{x} \text { as much } \\
\text { water at } 90^{\circ} \mathrm{C}\end{array}$ & & IRC & $\begin{array}{l}\text { Differs from the regular version (SATM C-1285-02) in that there is no minimum } \\
\text { particle size, and the sample particles are not pre-rinsed before being leached. } \\
\text { Separating the fines prevents accurate measurement of samples with significant } \\
\text { fines, and pre-rinsing can partially dissolve samples that are partially water- } \\
\text { soluble. }\end{array}$ \\
\hline
\end{tabular}




\section{SBW SIMULANT COMPOSITIONS}

Non-radioactive simulants designed to simulate the SBW in Tank WM180 was prepared by SAIC to produce the composition shown in Tables 4-1 and 4-2. The actual compositions determined by laboratory analysis of feed samples are also shown. Mass balance calculations were made using the compositions calculated from the feed recipes, rather than using the laboratory analyses. Most of the time, the calculated compositions from the feed recipes would be more accurate than the laboratory analyses, as long as there were no mistakes in the feed preparation, and as long as the reagents used in the recipes were relatively pure.

The laboratory analyses are compared to the compositions based on the feed compositions to identify if there are any significant anomalies due to preparation errors or reagent impurities that would affect mass balance closure calculations.

Simulant without heel solids was prepared just a few days before the THOR carbonate tests. Most of the carbonate testing was conducted using simulant without heel solids. Near the end of the carbonate tests, testing was also done while a WM-180 simulant that contained a limited amount of simulated heel solids was fed. This was to demonstrate that the steam reformer process could process a liquid feed that contained simulated heel solids.

The simulated heel solids were prepared by SAIC using the metathesis recipe, shown in Table 4-3, for WM-186 tank heel solids. The simulant that contained the heel solids was prepared about 3 weeks before the THOR carbonate test series. The metathesized solids are expected to be similar in chemical composition, on the atomic level, to the solids in tank WM-180. It is recognized, however, that the chemical form of the solids is determined by the kinetics of precipitation. The solids are amorphous and very finely divided. Given decades of time, the solids may mutate into more thermodynamically stable compounds and crystalline forms, as have the actual waste solids in the waste tanks.

WM-180 is expected to contain about 0.23 grams of undissolved solids (UDS) per liter of solution (Barnes 2001). This is among the lowest concentrations of UDS among the SBW tanks. The tank with the highest estimated UDS content is WM-186, which contains about 5.05 grams UDS per liter of solution.

The heel solids metathesis recipe was expected to form sufficient precipitate to enable adding 5 grams of UDS for each liter of supernate simulant. Difficulties occurred during preparation that resulted in the addition of only $1.34 \mathrm{~kg}$ of solids added to 800 liters of simulant. The UDS concentration based on the added solids was $1.68 \mathrm{gm} / \mathrm{L}$, less than the estimated value in Tank WM186, but more than in Tank WM-180. The solids preparation did not go as planned because the solids slurry could not be filtered and did not centrifuge well. The solid residue following centrifugation was dried without further washing. Some material precipitated from the centrifuged solution, suggesting that some aluminum nitrate was not precipitated with the silicates. Regardless of these preparation difficulties, the dried solids were added to the simulant and were considered a suitable representation of the UDS in the SBW. The simulant containing heel solids was filtered through a 300-micron sock filter and allowed to settle so that coarse solids, which could plug the feed nozzle, were no longer available. 
Table 4-1. Simulant compositions for the THOR carbonate product tests.

\begin{tabular}{|c|c|c|c|c|c|c|c|c|c|}
\hline \multicolumn{2}{|l|}{\begin{tabular}{|l} 
Test number \\
\end{tabular}} & \multicolumn{4}{|c|}{0.5 to $2.13 \mathrm{~b}, 3.2$} & \multicolumn{4}{|c|}{3.3 to 5.4} \\
\hline \multicolumn{2}{|l|}{ Simulant } & \multicolumn{4}{|c|}{ New SBW w/o heel solids } & \multicolumn{4}{|c|}{ New SBW with residual heel solids $(\mathrm{a}, \mathrm{b})$} \\
\hline \multirow[b]{3}{*}{ Component } & \multirow{3}{*}{$\begin{array}{l}\text { Mole } \\
\text { weight }\end{array}$} & \multicolumn{8}{|c|}{ Composition } \\
\hline & & \multicolumn{2}{|c|}{$\begin{array}{l}\text { Calculated from } \\
\text { simulant } \\
\text { supernate recipe }\end{array}$} & \multirow{2}{*}{$\begin{array}{c}\begin{array}{c}\text { Measured } \\
\text { (Sample 2) }\end{array} \\
\mathrm{gm} / \mathrm{L}\end{array}$} & \multirow{2}{*}{$\begin{array}{l}\mathrm{RPD}, \% \\
\text { (c) }\end{array}$} & \multicolumn{2}{|c|}{$\begin{array}{l}\text { Calculated from } \\
\text { simulant and heel } \\
\text { solids recipe }\end{array}$} & \multirow{2}{*}{$\begin{array}{c}\begin{array}{c}\text { Measured } \\
\text { (Sample 116) }\end{array} \\
\mathrm{gm} / \mathrm{L}\end{array}$} & \multirow{2}{*}{$\begin{array}{l}\mathrm{RPD}, \% \\
\text { (c) }\end{array}$} \\
\hline & & $M$ & $\mathrm{gm} / \mathrm{L}$ & & & $M$ & $\mathrm{gm} / \mathrm{L}$ & & \\
\hline Acid & 1.0 & 1.12 & 1.1 & NM & --- & 1.1 & 1.1 & NM & --- \\
\hline Aluminum & 27.0 & 0.66 & 18 & 17 & $5 \%$ & 0.66 & 18 & 17 & $6 \%$ \\
\hline Boron & 10.8 & 0.012 & 0.13 & 0.098 & $30 \%$ & 0.012 & 0.13 & 0.095 & $33 \%$ \\
\hline Calcium & 40.1 & 0.047 & 1.9 & 1.8 & $5 \%$ & 0.048 & 1.9 & 1.7 & $9 \%$ \\
\hline Cesium & 132.9 & 0.0032 & 0.43 & 0.25 & $55 \%$ & 0.0032 & 0.43 & 0.24 & $55 \%$ \\
\hline Chromium & 52.0 & 0.0033 & 0.17 & 0.16 & $8 \%$ & 0.0033 & 0.17 & 0.14 & $23 \%$ \\
\hline Copper & 63.5 & 0.0007 & 0.044 & 0.029 & $41 \%$ & 0.0007 & 0.044 & 0.044 & $0 \%$ \\
\hline Iron & 55.9 & 0.022 & 1.2 & 1.2 & $5 \%$ & 0.022 & 1.2 & 0.81 & $41 \%$ \\
\hline Lead & 207.2 & 0.0013 & 0.27 & 0.24 & $13 \%$ & 0.0013 & 0.27 & 0.24 & $11 \%$ \\
\hline Magnesium & 24.3 & 0.012 & 0.29 & 0.33 & $11 \%$ & 0.012 & 0.30 & 0.35 & $15 \%$ \\
\hline Manganese & 54.9 & 0.014 & 0.77 & 0.75 & $3 \%$ & 0.014 & 0.78 & 0.77 & $1 \%$ \\
\hline Mercury & 200.6 & 0.0014 & 0.27 & 0.27 & $1 \%$ & 0.0013 & 0.27 & 0.27 & $0 \%$ \\
\hline Nickel & 58.7 & 0.0015 & 0.086 & 0.080 & $8 \%$ & 0.0015 & 0.086 & 0.078 & $9 \%$ \\
\hline Potassium & 39.1 & 0.20 & 7.7 & 7.9 & $3 \%$ & 0.19 & 7.6 & 7.3 & $4 \%$ \\
\hline Rhenium & 186.2 & 0.0011 & 0.20 & 0.20 & $2 \%$ & 0.0011 & 0.20 & 0.20 & $2 \%$ \\
\hline Silicon & 28.1 & --- & --- & 0.012 & --- & 0.0053 & 0.15 & 0.016 & $162 \%$ \\
\hline Sodium & 23.0 & 2.1 & 47 & 50 & $5 \%$ & 2.1 & 47 & 57 & $18 \%$ \\
\hline Tin & 118.7 & --- & --- & 0.000 & --- & 0.000 & 0.052 & 0.007 & $153 \%$ \\
\hline Zinc & 65.4 & 0.0011 & 0.069 & 0.073 & $7 \%$ & 0.001 & 0.068 & 0.075 & $10 \%$ \\
\hline Zirconium & 91.2 & --- & --- & 0.000 & --- & 0.000 & 0.034 & 0.000 & $199 \%$ \\
\hline Chloride & 35.5 & 0.030 & 1.1 & 1.2 & $15 \%$ & 0.031 & 1.1 & 1.3 & $14 \%$ \\
\hline Fluoride (d) & 19.0 & 0.024 & 0.45 & 0.48 & $6 \%$ & 0.047 & 0.45 & 0.54 & $17 \%$ \\
\hline Nitrate & 62.0 & 5.3 & 330 & 307 & $7 \%$ & 5.3 & 330 & 278 & $17 \%$ \\
\hline Phosphate & 95.0 & 0.029 & 2.7 & --- & --- & 0.031 & 2.9 & --- & --- \\
\hline Sulfate & 96.1 & 0.070 & 6.7 & 7.9 & $17 \%$ & 0.070 & 6.7 & 7.4 & $10 \%$ \\
\hline \multicolumn{10}{|l|}{ Total } \\
\hline TDS+UDS & --- & 9.638 & 421 & & & 9.7 & 421 & & \\
\hline Water & 18.0 & --- & 838 & & & --- & 844 & & \\
\hline Heel solids & --- & --- & --- & & & --- & 2 & & \\
\hline Density (d) & --- & --- & 1,259 & 1,270 & 0.8 & --- & 1,267 & 1,240 & 2.2 \\
\hline \multicolumn{2}{|c|}{$\begin{array}{l}\text { Carbon needed to } \\
\text { convert } \mathrm{NO}_{3} \text { to } \mathrm{N}_{2}(\mathrm{e})\end{array}$} & 8.0 & 96 & & & 8.0 & 96 & & \\
\hline
\end{tabular}

a. Simulant was prepared by adding simulated heel solids for some prior tests. Instead of the planned UDS level of $5 \mathrm{gm} / \mathrm{L}$, the actual starting UDS concentration was $1.68 \mathrm{mg} / \mathrm{L}$. The elemental concentration shown above is based on the initial planned UDS level of $5 \mathrm{mg} / \mathrm{L}$.

b. When the fluidized bed feed system fouled and plugged due to the presence of the heel solids, some of the solids were filtered out of the remaining simulant using a filtering recycle loop for the simulant tank. Simulant with a portion of the initial amount of heel solids was fed during some of the carbonate test series.

c. The RPD indicates differences due to sample analysis results and recipe calculations, and also differences due to the presence of residual heel solids.

d. Target $\mathrm{F}$ concentration is half the intended value -- test log indicates $50 \%$ error in simulant makeup.

$\mathrm{NM}=$ "not measured".

e. The stoichiometric $\mathrm{NO}_{3}-\mathrm{C}$ reaction is $3 \mathrm{C}+2 \mathrm{NO}_{3}=3 \mathrm{CO}_{2}+\mathrm{N}_{2}$. 
Table 4-2. Simulant compositions for the THOR mineralized product tests.

\begin{tabular}{|c|c|c|c|c|c|c|c|c|c|c|c|c|c|c|c|c|c|c|c|}
\hline \multicolumn{2}{|l|}{ Test number } & \multicolumn{2}{|c|}{$\begin{array}{l}\text { No tests performed } \\
\text { using supernate alone }\end{array}$} & \multicolumn{4}{|c|}{4.1 to $5.2,5.2 \mathrm{~b}$, and $5.2 \mathrm{c}$} & \multicolumn{4}{|c|}{$5.2 \mathrm{a}$} & \multicolumn{4}{|c|}{$5.2 \mathrm{~d}$ to 5.3} & \multicolumn{4}{|c|}{5.4 to 5.6} \\
\hline Simulant & & Supern & e (a) & \multicolumn{4}{|c|}{ Supernate $\mathrm{w} /$ Clay \& Si } & \multicolumn{4}{|c|}{ w/ Clay, $\mathrm{Si}, \& \mathrm{Fe}$} & \multicolumn{4}{|c|}{ w/ Xtra Clay \& Si } & \multicolumn{4}{|c|}{$100 \%$ Clay } \\
\hline \multirow[b]{3}{*}{ Component } & \multirow{3}{*}{$\begin{array}{l}\text { Mole } \\
\text { weight }\end{array}$} & \multicolumn{18}{|c|}{ Composition } \\
\hline & & \multicolumn{2}{|c|}{$\begin{array}{l}\text { Calculated from } \\
\text { simulant supernate } \\
\text { recipe }\end{array}$} & \multicolumn{2}{|c|}{$\begin{array}{c}\text { Calculated from } \\
\text { recipe and added } \\
\text { kaolin and silica }\end{array}$} & \multirow{2}{*}{$\begin{array}{c}\begin{array}{c}\text { Measured } \\
\text { (Sample } \\
177)\end{array} \\
\mathrm{gm} / \mathrm{L}\end{array}$} & \multirow{2}{*}{$\begin{array}{l}\text { RPD, } \\
\% \text { (b) }\end{array}$} & \multicolumn{2}{|c|}{\begin{tabular}{|c|} 
Calculated from recipe \\
and added kaolin, \\
silica, and Fe
\end{tabular}} & \multirow{2}{*}{$\begin{array}{c}\text { Measured } \\
\text { (Sample } \\
178) \\
\mathrm{gm} / \mathrm{L}\end{array}$} & \multirow{2}{*}{$\begin{array}{c}\text { RPD, } \\
\%\end{array}$} & \multicolumn{2}{|c|}{$\begin{array}{l}\text { Calculated from } \\
\text { recipe and added } \\
\text { kaolin and silica }\end{array}$} & \multirow[t]{2}{*}{$\begin{array}{c}\begin{array}{c}\text { Measured } \\
\text { (Sample } \\
197)\end{array} \\
\mathrm{gm} / \mathrm{L}\end{array}$} & \multirow{2}{*}{$\begin{array}{c}\text { RPD, } \\
\%\end{array}$} & $\begin{array}{r}\text { Calcula } \\
\text { recipe ar } \\
\mathrm{kac}\end{array}$ & $\begin{array}{l}\text { from } \\
\text { added } \\
n\end{array}$ & $\begin{array}{c}\text { Measured } \\
\text { (Sample } \\
246)\end{array}$ & RPD, \\
\hline & & $M$ & $\mathrm{gm} / \mathrm{L}$ & $M$ & $\mathrm{gm} / \mathrm{L}$ & & & $M$ & $\mathrm{gm} / \mathrm{L}$ & & & $M$ & $\mathrm{gm} / \mathrm{L}$ & & & $M$ & $\mathrm{gm} / \mathrm{L}$ & $\mathrm{gm} / \mathrm{L}$ & $\%$ \\
\hline Acid & 1.01 & 1.1 & 1.1 & 1.0 & 1.02 & NM & --- & 1.0 & 1.0 & NM & & 0.98 & 0.99 & NM & & 1.0 & 1.0 & NM & \\
\hline Aluminum & 26.98 & 0.66 & 18 & 2.2 & 60 & 23 & $89 \%$ & 2.2 & 60 & 23 & $90 \%$ & 2.6 & 70 & 21 & $107 \%$ & 2.7 & 72 & 23 & $104 \%$ \\
\hline Boron & 10.81 & 0.012 & 0.13 & 0.011 & 0.12 & 0.083 & $36 \%$ & 0.011 & 0.12 & 0.087 & $32 \%$ & 0.011 & 0.12 & 0.090 & $26 \%$ & 0.011 & 0.12 & 0.066 & $59 \%$ \\
\hline Calcium & 40.1 & 0.0472 & 1.9 & 0.043 & 1.7 & 1.9 & $9 \%$ & 0.043 & 1.7 & 1.9 & $9 \%$ & 0.041 & 1.7 & 2.0 & $17 \%$ & 0.043 & 1.7 & 1.9 & $8 \%$ \\
\hline Cesium & 132.9 & 0.0032 & 0.43 & 0.0029 & 0.39 & 0.22 & $55 \%$ & 0.0029 & 0.39 & 0.21 & $60 \%$ & 0.0028 & 0.38 & 0.22 & $52 \%$ & 0.0029 & 0.39 & 0.21 & $62 \%$ \\
\hline Chromium & 52.0 & 0.0033 & 0.17 & 0.0030 & 0.16 & 0.15 & $6 \%$ & 0.0030 & 0.16 & 0.15 & $8 \%$ & 0.0029 & 0.15 & 0.15 & $0 \%$ & 0.0030 & 0.16 & 0.14 & $10 \%$ \\
\hline Copper & 63.5 & 0.00070 & 0.044 & 0.00063 & 0.040 & 0.041 & $3 \%$ & 0.00063 & 0.040 & 0.040 & $1 \%$ & 0.00061 & 0.039 & 0.042 & $8 \%$ & 0.00063 & 0.040 & 0.038 & $5 \%$ \\
\hline Iron & 55.9 & 0.022 & 1.2 & 0.020 & 1 & 1.3 & $17 \%$ & 0.070 & 3.9 & 4.3 & $9 \%$ & 0.019 & 1.1 & 1.3 & $22 \%$ & 0.020 & 1.1 & 1.3 & $19 \%$ \\
\hline Lead & 207.2 & 0.0013 & 0.27 & 0.0012 & 0.25 & 0.21 & $16 \%$ & 0.0012 & 0.25 & 0.20 & $20 \%$ & 0.0012 & 0.24 & 0.22 & $7 \%$ & 0.0012 & 0.25 & 0.20 & $19 \%$ \\
\hline Magnesium & 24.3 & 0.012 & 0.29 & 0.011 & 0.26 & 0.35 & $29 \%$ & 0.011 & 0.26 & 0.35 & $27 \%$ & 0.011 & 0.26 & 0.37 & $36 \%$ & 0.011 & 0.26 & 0.35 & $28 \%$ \\
\hline Manganese & 54.9 & 0 & 0 & 13 & 0 & 0.68 & $2 \%$ & 13 & 0.70 & 0.66 & $6 \%$ & 0.012 & 0.68 & 0.71 & $5 \%$ & 0.013 & 0.70 & 0.67 & $5 \%$ \\
\hline Mercury & 200.6 & 0.0014 & 0.27 & 0.0012 & 0. & --- & --- & 0.0012 & 0.24 & --- & --- & 0.0012 & 0.24 & 0.23 & $5 \%$ & 0.0012 & 0.24 & 0.21 & $16 \%$ \\
\hline Nickel & 58.7 & 0.0015 & 0.086 & 0.0013 & 0.078 & 0.072 & $8 \%$ & 0.0013 & 0.078 & 0.062 & $23 \%$ & 0.0013 & 0.076 & 0.075 & $1 \%$ & 0.0013 & 0.078 & 0.069 & $12 \%$ \\
\hline Potassium & 39.1 & 0.20 & 7.7 & 0.18 & 6.9 & 7.1 & $3 \%$ & 0.18 & 6.9 & 7.0 & $1 \%$ & 0.17 & 6.7 & 7.5 & $11 \%$ & 0.18 & 6.9 & 7.0 & $1 \%$ \\
\hline Rhenium & 186.2 & 0.0011 & 0.20 & 0.0010 & 0.18 & 0.18 & $1 \%$ & 0.0010 & 0.18 & 0.17 & $4 \%$ & 0.00094 & 0.18 & 0.18 & $4 \%$ & 0.0010 & 0.18 & 0.17 & $6 \%$ \\
\hline Silicon & 28.1 & --- & --- & 2.2 & 63 & --- & --- & 2.2 & 63 & --- & --- & 2.6 & 73 & --- & --- & 2.1 & 58 & --- & --- \\
\hline Sodium & 23.0 & 2 & 47 & 1.9 & 43 & 46 & $7 \%$ & 1.9 & 43 & 43 & $1 \%$ & 1.8 & 42 & 43 & $3 \%$ & 1.9 & 43 & 40 & $7 \%$ \\
\hline Zinc & 65.4 & 0.0011 & 0.069 & 0.00095 & 0.062 & 0.069 & $11 \%$ & 0.00095 & 0.062 & 0.063 & $1 \%$ & 0.00092 & 0.060 & 0.076 & $23 \%$ & 0.00095 & 0.062 & 0.065 & $5 \%$ \\
\hline Chlori & 35.5 & & 1. & & & 1. & $51 \%$ & & 0. & & $39 \%$ & 0.0 & 0.93 & 1 & $42 \%$ & 0.0 & 0.96 & 1.5 & $44 \%$ \\
\hline Fluoride (d) & 19.0 & 0 & 0.45 & 21 & 0.41 & 0.28 & $37 \%$ & 0.021 & 0.4 & 0.29 & $32 \%$ & 0.021 & 0.39 & 0.26 & $42 \%$ & 0.021 & 0.41 & 0.24 & $50 \%$ \\
\hline Nitrate & 62.0 & 5.3 & 330 & 4.8 & 297 & 288 & $3 \%$ & 4.8 & 297 & 282 & $5 \%$ & 4.7 & 290 & 289 & $0 \%$ & 4.8 & 297 & 260 & $14 \%$ \\
\hline Phosphate & 95.0 & & 2.7 & & 2.5 & --- & --- & 0.026 & 2.5 & --- & --- & 0.025 & 2.4 & --- & --- & 0.026 & 2.5 & --- & --- \\
\hline Sulfate & 96.1 & 0.070 & 6.7 & 0.063 & 6.0 & 10.9 & $58 \%$ & 0.063 & 6.0 & 15.5 & $88 \%$ & 0.061 & 5.9 & 11 & $62 \%$ & 0.063 & 6.0 & 10 & $50 \%$ \\
\hline Water & 18.0 & & 838 & & 788 & & & & 788 & & & & 777 & & & & 796 & & \\
\hline Kaolin & 258.2 & & & & 235 & & & & 235 & & & & 295 & & & & 295 & & \\
\hline Silica & & & & & 40 & & & & 40 & & & & 40 & & & & 0 & & \\
\hline Ferric Nitrate & 404.0 & & & & & & & & 20 & & & & & & & & & & \\
\hline Density (c) & & & 1,259 & --- & 1,390 & 1,370 & 1.4 & --- & 1,431 & 1,370 & 4.4 & --. & 1,410 & 1,400 & 0.7 & --- & 1,400 & 1,380 & 1.4 \\
\hline
\end{tabular}

a. The supernate simulant was prepared a few days prior to the start of the THOR tests. Heel solids were not included in the recipe. During test operation, the appropriate amounts of silica, kaolin, and ferric nitrate were added to specific feed tanks according to the test design.

b. $\mathrm{RPD}=2 \mathrm{x}$ abs(measurement 2 - measurement 1)/(measurement $2+$ measurement 1$)$. The RPD indicates differences due to sample analysis results and recipe calculations.

c. The calculated densities are from Table 6.1-1. The measured density values are from the coriolis flow meter. The coriolis density for test $5.2 \mathrm{a}$ was estimated based on the test 5.2 density. Bubbles in the flowmeter during test 5.2a prevented a valid density measurement during that test.

d. Target $\mathrm{F}$ concentration is half the intended value -- test log indicates $50 \%$ error in simulant makeup.

Kaolin $=\mathrm{Al} 2 \mathrm{Si} 2 \mathrm{O} 5(\mathrm{OH}) 4=\mathrm{Al} 2 \mathrm{O} 32 \mathrm{SiO} 22 \mathrm{H} 2 \mathrm{O} .14 \%$ of the mass of kaolin in the simulant is water of hydration, which has been added to the water in the simulant.

Ferric nitrate $=\mathrm{Fe}(\mathrm{NO} 3) 3(9 \mathrm{H} 2 \mathrm{O})$. The amounts of water of hydration and nitrate in the ferric nitrate is small compared to those amounts already in the simulant, so these amounts have not been added to the total water and nitrate in the simulant.

$\mathrm{NM}=$ "not measured". 
Table 4-3. Heel solids (WM-186) metathesis simulant.

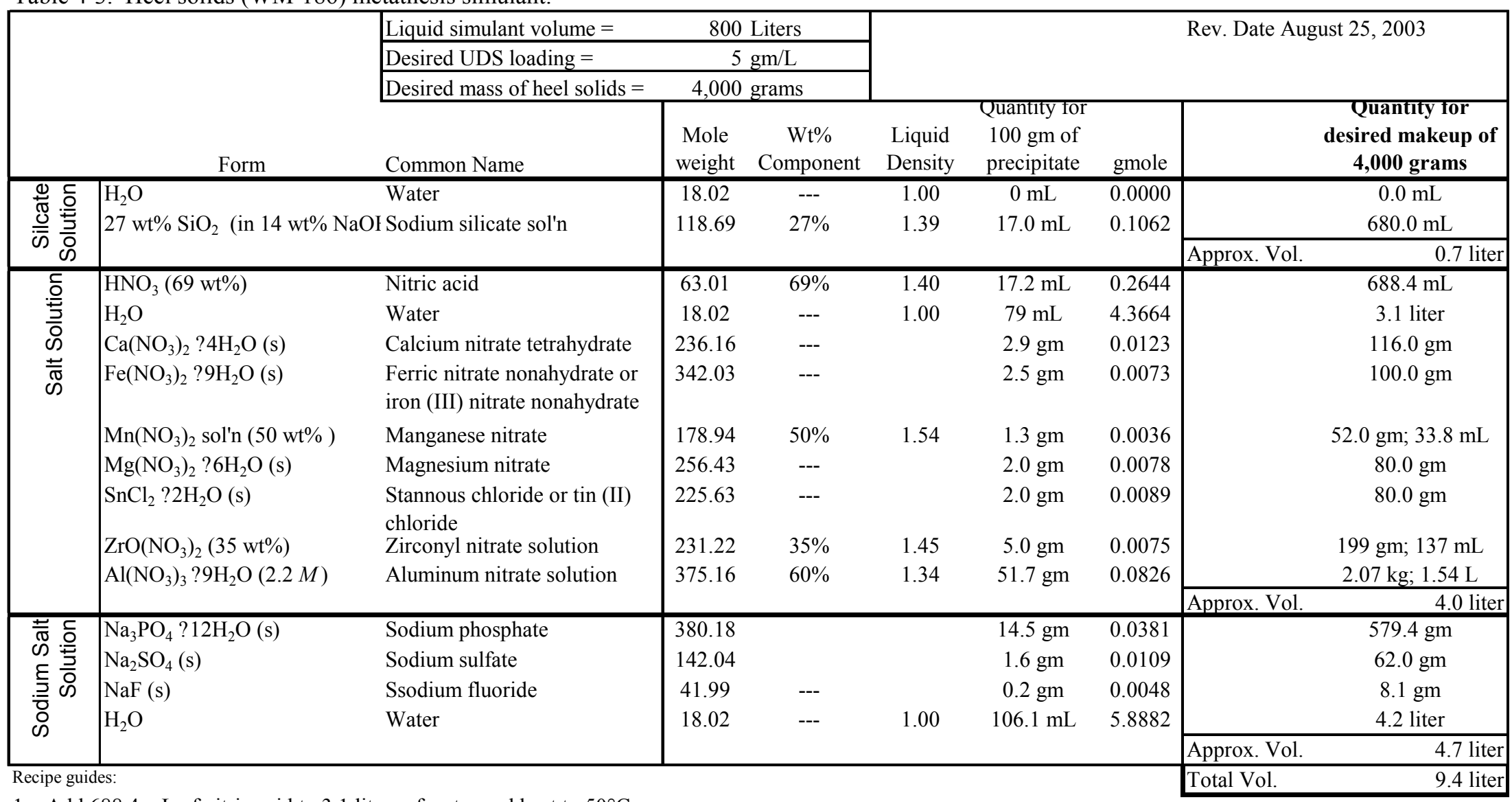

1. Add $688.4 \mathrm{~mL}$ of nitric acid to 3.1 liters of water and heat to $50^{\circ} \mathrm{C}$.

2. Dissolve non-sodium salts in the warm nitric acid solution.

3. Add the zirconyl nitrate and aluminum nitrate solutions to the salt solution.

4. Dissolve the sodium salts in 4.2 liters of water and set the sodium salt solution aside.

5. Dilute the sodium silicate solution with $0.0 \mathrm{~mL}$ of water (as necessary).

6. Stir the salt solution vigorously while simultaneously dribbling in the silicate and sodium salt solutions.

7. Let the slurry stand overnight.

8. Filter and wash the precipitate. (This instruction was not performed because the filtration was so slow.) NOTE: NOx will evolve when some salts are dissolved in the dilute nitric acid. Use a fume hood to mitigate fumes. 
The actual amount of UDS in the simulant was further reduced when, during tests before the THOR test series, the simulant with added UDS was filtered using a recycle loop. A slipstream of simulant was pumped from the T-1 Simulant Tank, through a sock filter, and back to the Simulant Tank. This filtration was done to reduce the amount of UDS in the simulant, as the UDS was causing plugging problems in the fluidized bed feed system. Before the THOR test series, the feed system was modified to streamline the piping and remove the points where UDS plugging was occurring. The feed system problems are an artifact of the small scale of the feed system. A full-scale feed system designed for feeding a UDS-laden liquid would not experience the plugging problems that occurred before the THOR tests.

The slip-stream simulant filtration activity did not remove all of the UDS, because only a slipstream was filtered. The mass of filtered solids was $0.26 \mathrm{gm}$, about $19 \%$ of the intended amount of 1.34 $\mathrm{kg}$ of solids initially added. The residual UDS concentration was about $1.35 \mathrm{gm} / \mathrm{L}$ of simulant. Table 4-1 compares the average blended UDS laden composition with the UDS composition calculated by assuming that the full amount of UDS was still in the simulant. 


\section{CARBONATE TEST SERIES}

Two test series were conducted during November 2003. During the first weeklong test series, the steam reforming chemistry and operating conditions were designed to produce a solid product consisting mainly of sodium and potassium carbonate. The second weeklong test week was designed with steam reforming chemistry and operating conditions to produce a sodium-potassium aluminosilicate product. During the first few days of each test week, different test conditions were parametrically evaluated in order to identify optimum conditions to select for demonstration testing that was performed during the final days of each test week. Even though the test program was designed to maintain relatively constant operating conditions during the demonstration test portion of each test week, a few parametric changes that were not made during the parametric evaluations were made during the demonstration tests.

The results of the carbonate test series are discussed here in Section 5. The mineralized test results are discussed in Section 6, Mineralized Test Series.

\subsection{Test Operating Conditions and Observations}

The reformer system startup included several steps performed over several hours. First, preheated air or $\mathrm{N}_{2}$ flows were initiated to begin preheating the fluidized bed test system. After reaching a minimum temperature, starting bed media were charged to the fluidized bed. The presence of the bed facilitates heat transfer and helps prevent wall heater over-temperature conditions as the system heat-up continues to reach the target bed temperature. The thermal oxidizer was also started according to the North American burner control system, and allowed to preheat for several hours.

When the fluidized bed and oxidizer temperatures reach the target temperatures, the fluidizing gas was switched to superheated steam. After temperature stabilization, the test operations began as water and reductant feeds were started.

The parametric tests included several different test series summarized in Table 5.1-1. Pretests prior to Test Series 1 were intended to provide time for comparative evaluations of the different reductants, and to provide operating time for process stabilization and initial bed building before the start of subsequent test series. Test Series 1 was intended to determine the maximum and optimum SBW feed rates for the process. Test Series 2 was intended to vary and optimize the reductant stoichiometry.

During the first test condition in Test Series 3, no SBW was fed, and the NAR was increased to (a) attrit the bed particles that had been growing, and (b) provide sample time to determine interferences on the steam reformer outlet NO measurement when there was no source of NO in the off-gas. After several hours of bed attrition time, Test Series 3 also included a restart of the SBW feed at a somewhat lower feed rate in order to better control bed particle size growth.

At the end of Test Series 3 and during Test Series 5, the Type-1b carbon was replaced with the Type- 2 carbon. These tests provided performance data for the Type- 2 carbon compared to the Type- $1 \mathrm{~b}$ carbon.

Operating conditions during the parametric and demonstration tests are summarized in Figures 5.1-1 and 5.1-2. 
Table 5.1-1. Summary of carbonate test operating conditions.

\begin{tabular}{|c|c|c|c|c|c|c|c|c|c|c|c|c|c|c|c|c|c|c|}
\hline \multirow[b]{3}{*}{ Test } & \multirow[b]{3}{*}{ Start time } & \multirow[b]{3}{*}{$\begin{array}{c}\text { Duration } \\
\mathrm{hr}\end{array}$} & \multirow[b]{3}{*}{ NAR $s L / L$} & \multirow[b]{3}{*}{ Feed type } & \multicolumn{8}{|c|}{ Reactant feed rates } & \multicolumn{6}{|c|}{ Reductant stoichiometric ratios } \\
\hline & & & & & \multicolumn{2}{|c|}{ SBW } & \multicolumn{3}{|c|}{ Syrup } & \multicolumn{2}{|c|}{ Act. Carbon } & \multirow{2}{*}{$\begin{array}{c}\mathrm{O}_{2} \\
\mathrm{~kg} / \mathrm{hr}\end{array}$} & \multicolumn{3}{|c|}{$\mathrm{C}: \mathrm{NO}_{3}$} & \multicolumn{3}{|c|}{$\mathrm{C}:\left(\mathrm{NO}_{3}+\mathrm{O}_{2}\right)$} \\
\hline & & & & & $\mathrm{kg} / \mathrm{hr}$ & $\mathrm{L} / \mathrm{hr}$ & $\begin{array}{l}\text { Mass } \\
\text { Ratio }\end{array}$ & $\mathrm{kg} / \mathrm{hr}$ & $\begin{array}{c}\text { Sugar } \\
\text { equiv. } \\
\mathrm{kg} / \mathrm{hr}\end{array}$ & Type & $\mathrm{kg} / \mathrm{hr}$ & & Syrup & $\begin{array}{c}\text { Act. } \\
\text { carbon }\end{array}$ & $\begin{array}{c}\text { Total } \\
\text { carbon }\end{array}$ & Syrup & $\begin{array}{c}\text { Act. } \\
\text { carbon }\end{array}$ & Total C \\
\hline 0.5 & 11/11/2003 07:49 & $6: 54$ & \multirow{12}{*}{500} & & 5.3 & 4.2 & \multirow{6}{*}{0.66} & 3.5 & 1.9 & & $\sim \sim 1.0$ & \multirow{11}{*}{1.51} & \multirow{6}{*}{2.4} & 2.6 & 5.0 & 1.0 & 1.1 & 2.1 \\
\hline 1.1 & $11 / 11 / 200314: 43$ & $2: 24$ & & & \multirow{6}{*}{6.0} & \multirow{6}{*}{4.8} & & \multirow{5}{*}{4.0} & \multirow{5}{*}{2.2} & & $\sim 1.3$ & & & 3.0 & 5.4 & \multirow{5}{*}{1.1} & 1.4 & 2.5 \\
\hline 2.1 & $11 / 11 / 200317: 08$ & $2: 03$ & & & & & & & & & 0.00 & & & 0.0 & 2.4 & & 0.0 & 1.1 \\
\hline 2.2 & 11/11/2003 19:11 & $0: 41$ & & & & & & & & & $\sim 0.5$ & & & 1.1 & 3.6 & & 0.5 & 1.7 \\
\hline 2.3 & $11 / 11 / 200319: 52$ & $1: 38$ & & & & & & & & & 1.35 & & & 3.1 & 5.5 & & 1.5 & 2.6 \\
\hline 2.4 & 11/11/2003 21:30 & $1: 39$ & & & & & & & & & 0.34 & & & 0.8 & 3.2 & & \multirow{3}{*}{0.4} & 1.5 \\
\hline 2.5 & 11/11/2003 23:09 & $1: 53$ & & & & & 0.82 & 4.9 & 2.7 & & 0.34 & & 3.0 & 0.8 & 3.8 & 1.4 & & 1.8 \\
\hline 2.6 & 11/12/2003 01:03 & $0: 41$ & & & 5.3 & 4.2 & 1.10 & 5.8 & 3.2 & & 0.32 & & 4.0 & 0.8 & 4.8 & 1.7 & & 2.1 \\
\hline 2.7 & $11 / 12 / 200301: 45$ & $2: 50$ & & & \multirow{4}{*}{6.0} & \multirow{4}{*}{4.8} & & & & & 1.18 & & & 2.7 & 5.1 & & 1.3 & 2.4 \\
\hline 2.8 & $11 / 12 / 200304: 35$ & $3: 56$ & & & & & 0.66 & 4.0 & 2.2 & Type-1b & 0.52 & & 2.4 & 1.2 & 3.6 & 1.1 & & 1.7 \\
\hline 2.9 & $11 / 12 / 200308: 31$ & $1: 34$ & & & & & & 45 & 25 & & 0.56 & & & 1.3 & 4.0 & 1.3 & 0.6 & 1.8 \\
\hline 2.10 & 11/12/2003 10:06 & $4: 52$ & & & & & & 4.5 & 2.3 & & 0.47 & & & 1.1 & 3.8 & 1.5 & & 2.1 \\
\hline 2.11 & $11 / 12 / 2003 \quad 14: 58$ & $9: 37$ & 750 & & 5.0 & 4.0 & 0.75 & 3.8 & 2.1 & & 0.65 & 1.20 & 2.7 & 1.8 & 4.5 & & 0.9 & 2.2 \\
\hline 2.12 & $11 / 13 / 200300: 35$ & $9: 14$ & 860 & & 4.9 & 3.9 & & 3.7 & 2.0 & & 0.59 & 1.22 & & 1.6 & 4.4 & 1.3 & 0.8 & 2.1 \\
\hline $2.13 \mathrm{a}$ & $11 / 13 / 200309: 49$ & $2: 10$ & 940 & & & & 0.90 & 4.1 & 2.2 & & 0.50 & 1.30 & 3.3 & 1.5 & 4.8 & 1.4 & 0.6 & 2.0 \\
\hline $2.13 \mathrm{~b}$ & $11 / 13 / 2003$ 12:00 & $7: 32$ & 960 & & 4.5 & 3.6 & 0.76 & 3.4 & 1.9 & & 0.70 & 1.13 & 2.8 & 2.1 & 4.9 & 1.3 & 1.0 & 2.3 \\
\hline 3.1 & 11/13/2003 19:32 & $4: 47$ & 2620 & $\begin{array}{c}\text { water@1 } \\
\mathrm{kg} / \mathrm{hr}\end{array}$ & --- & --- & 1.60 & 1.6 & 0.9 & & 0.69 & 1.12 & --- & --- & --- & 0.8 & & 2.1 \\
\hline 3.2 & 11/14/2003 00:19 & $2: 20$ & & SBW & & & & & & & 0.91 & & & 2.5 & 5.2 & & 1.3 & \\
\hline 3.3 & $11 / 14 / 200302: 40$ & $1: 00$ & & & & & 0.74 & 3.0 & 1.6 & & 0.95 & & 2.7 & 2.6 & 5.3 & 1.1 & & 2.4 \\
\hline 3.4 & $11 / 14 / 2003 \quad 03: 40$ & $4: 25$ & 1150 & & 40 & 32 & & & & & 0.95 & 122 & & 2.6 & 5.3 & & & \\
\hline S.1 & $11 / 14 / 200308: 05$ & $1: 54$ & 1150 & $\begin{array}{c}\text { SBW + } \\
\text { heel slds }\end{array}$ & 4.0 & 3.2 & 0.41 & 1.6 & 0.9 & Tyne-2 & 1.16 & 1.22 & 1.5 & 3.2 & 4.7 & 0.6 & 1.6 & 2.2 \\
\hline S.2 & 11/14/2003 09:59 & $2: 05$ & & & & & & & & Type-2 & 1.40 & & & 3.8 & 3.8 & & 2.0 & 2.0 \\
\hline S.3 & $11 / 14 / 2003 \quad 12: 05$ & $1: 55$ & & & & & 0.00 & 0.0 & 0.0 & & 1.65 & & 0.0 & 4.5 & 4.5 & 0.0 & 2.3 & 2.3 \\
\hline Totals & & $78: 10$ & & & $366 \mathrm{~kg}$ & $288 \mathrm{~L}$ & & $289 \mathrm{~kg}$ & $159 \mathrm{~kg}$ & & $69 \mathrm{~kg}$ & & & & & & & \\
\hline
\end{tabular}

Assumes $13 \mathrm{wt} \%$ non-carbon constituents in the Type- $1 \mathrm{~b}$ and $6 \mathrm{wt} \%$ in the Type 2 activated carbons. 


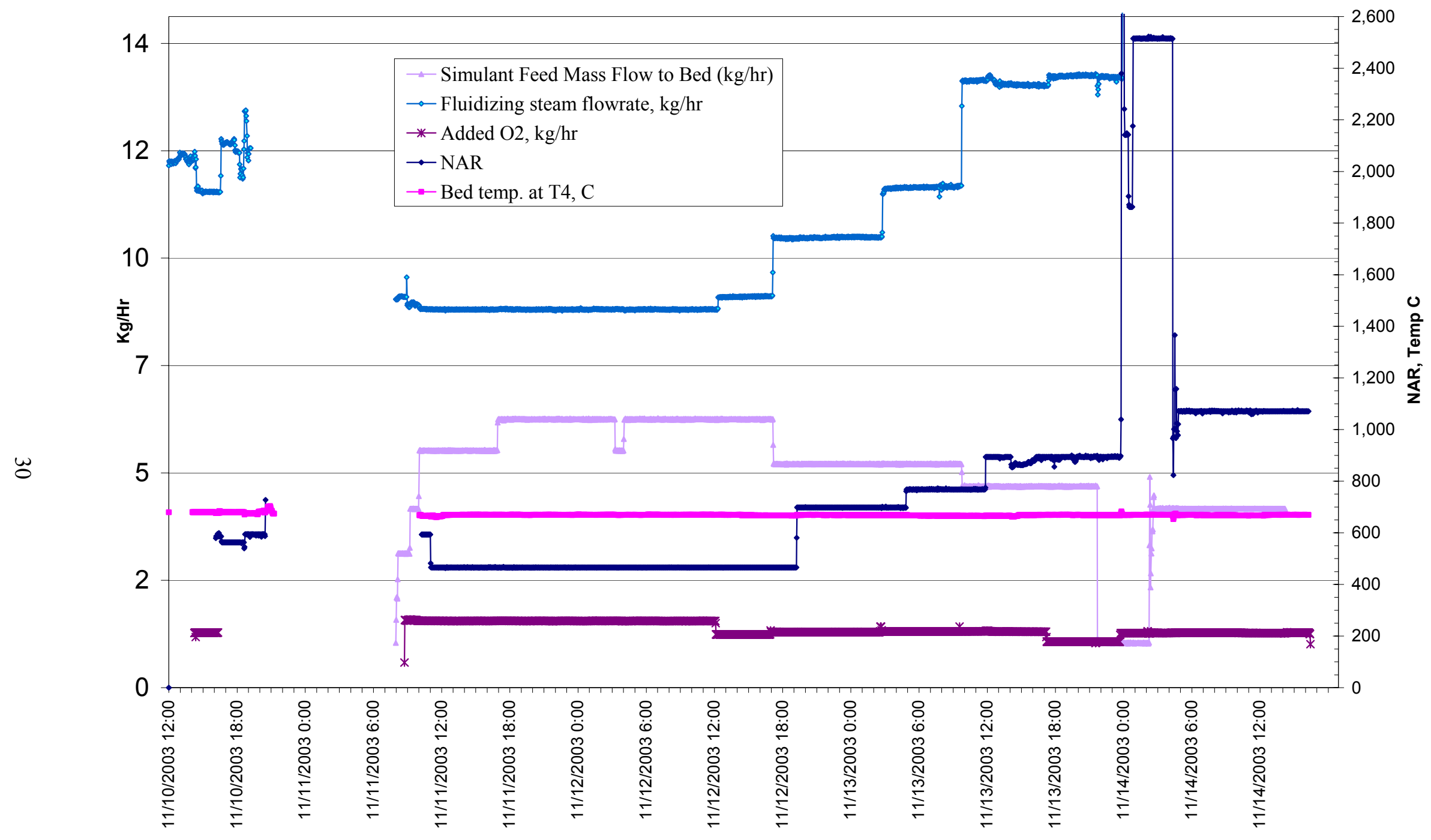

Figure 5.1-1. Feed simulant and fluidizing steam flow rates for the THOR carbonate test series. 


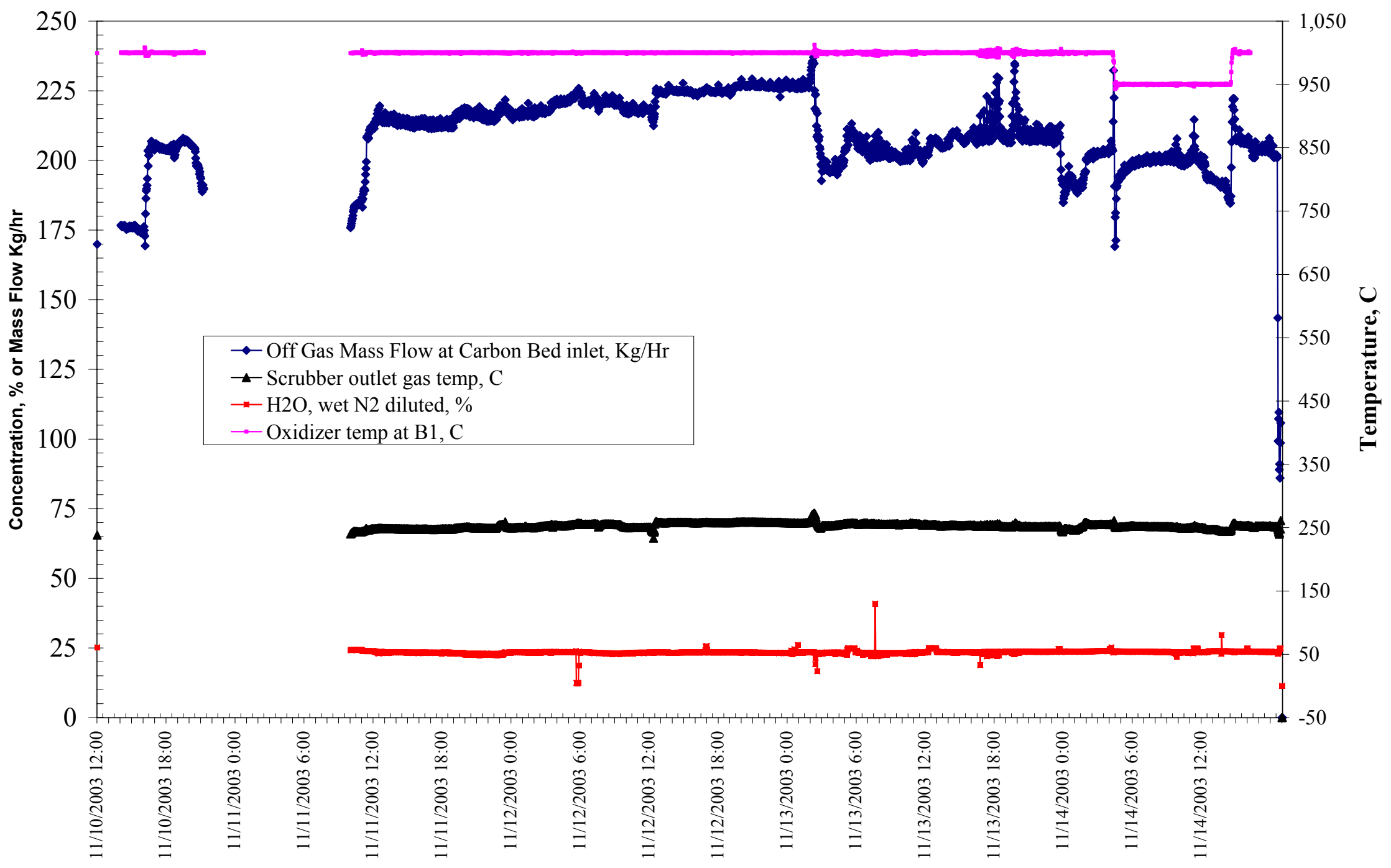

Figure 5.1-2. Selected operating conditions for the THOR carbonate test series. 


\subsubsection{Solid Carbon Equivalency Tests}

Granular activated carbon is used in the THOR process as a nitrate reductant and source of solid carbon for other in-bed heterogeneous reactions. During the steam reforming tests of January 2003, the activated carbon was Type-1a. This carbon was not available from the vendor in sufficient quantity for the entire test duration, so two other carbons were used for all but a few hours of operation (at the end of the mineralized test series), during which the Type-1a carbon was used in order to provide comparative operating data. The other two carbons were Type- $1 \mathrm{~b}$ carbon and Type- 2 carbon. The Type- $1 \mathrm{~b}$ carbon was supplied by TTT as an alternate to the Type- 1 a carbon. The Type- 2 carbon was procured by BBWI through SAIC. A summary of carbon properties from vendor data is given in Table 5.1-2.

Table 5.1-2. Properties of activated carbons used as steam reforming reductants.

\begin{tabular}{|l|c|c|c|c|c|c|c|}
\hline $\begin{array}{l}\text { Activated } \\
\text { Carbon }\end{array}$ & $\begin{array}{c}\text { Bulk Density } \\
\text { ASTM D-2854 }\end{array}$ & Size & Shape & $\begin{array}{c}\text { Ball-Pen } \\
\text { Hardness } \\
\text { ASTM D-3467 }\end{array}$ & $\begin{array}{c}\text { Ash } \\
\text { Content } \\
\text { ASTM D-2866 }\end{array}$ & $\begin{array}{c}\text { Moisture } \\
\text { Content } \\
\text { ASTM D-2867 }\end{array}$ & $\begin{array}{c}\text { Gas } \\
\text { Adsorption } \\
\text { Capacity } \\
\text { ASTM D-3467 }\end{array}$ \\
\hline Type-1a & $.22-.30 \mathrm{~g} / \mathrm{cc}$ & $4 \times 12$ & irregular & 80 & $\leq 7 \mathrm{wt} \%$ & $\leq 10 \mathrm{wt} \%$ & $\leq 30 \mathrm{wt} \%$ \\
\hline Type-1b & $.22-.29 \mathrm{~g} / \mathrm{cc}$ & $6 \times 18$ & granular & $40-60$ & -- & $\leq 10 \mathrm{wt} \%$ & -- \\
\hline Type-2 & $.48 \mathrm{~g} / \mathrm{cc}$ & $4 \times 8$ & planar & 98 & $\leq 3 \mathrm{wt} \%$ & $\leq 5 \mathrm{wt} \%$ & $\leq 60 \mathrm{wt} \%$ \\
\hline
\end{tabular}

Carbon selection was based on perceived reactivity in the fluidized bed, and attrition-resistance, indicated by the hardness. Attrition-resistance may reduce the amount of carbon carried over into the filter catch. A sufficient quantity of Type-1a carbon could not be procured from the supplier in time for the test series, so the Type- $1 \mathrm{~b}$ carbon selected by TTT for the January 2003 tests was used as an alternative carbon. Since the Type- $1 b$ is not as hard (and potentially less attrition-resistant) as the Type1a carbon, The harder Type- 2 carbon was also used.

Each of the three carbons was bench-tested in the vibratory feeder to develop a calibration curve of mass feed rate versus vibratory setting. Feeder calibrations for the Type-1b carbon, especially at the target carbon feed rates, were best, because the Type- $1 \mathrm{~b}$ carbon particles were more uniformly shaped granules. The Type- 2 and NB carbon feed rates were least controllable.

Tests were devised in which the reactivity of sugar syrup and the three carbons would be tested in the reformer by feeding each at a known rate into the reformer without any SBW feed. The intent was to monitor and compare hydrogen, $\mathrm{CO}, \mathrm{CO}_{2}$, and methane production for each reductant. Starting with a virgin alumina bed, $55 \mathrm{wt} \%$ sugar syrup was fed to the reactor at $4 \mathrm{~kg} / \mathrm{hr}$, with $10 \mathrm{wt} \%$ oxygen in the fluidizing steam for about an hour. After ascertaining that the off-gas conditions appeared stable, the syrup feed was terminated, water feed was started at $3 \mathrm{~kg} / \mathrm{hr}$ and Type- $1 \mathrm{~b}$ carbon was fed to the reformer at a nominal rate of $1 \mathrm{~kg} / \mathrm{hr}$. After 45 minutes, the carbon addition rate was increased to a nominal 3 $\mathrm{kg} / \mathrm{hr}$ to build the carbon inventory in the reformer. After 40 minutes at the increased carbon addition rate, the rate was decreased to $1 \mathrm{~kg} / \mathrm{hr}$, and oxygen was started at $5 \mathrm{wt} \%$ in the steam.

In less than 20 minutes, the bed temperature thermocouple readings started diverging, indicating poorer in-bed heat transfer, which is a typical sign of bed agglomeration. Actions were taken to recover from the temperature divergence. A bed sample showed a significant quantity of carbon particles in the bed. The conditions worsened, and the reformer was shut down. It was determined that the rate of carbon addition was higher than predicted by the calibrations, because the vibratory feeder was inadvertently not isolated from the fluidized bed structure. 
When removed from the bed vessel, the bed media was loosely agglomerated. Many of the dark alumina particles were shiny. Examination of the bed media under an optical microscope showed that the used bed media had a glazed surface. Subsequent analysis of the Type-1b carbon ash determined that it was high in silicon and phosphorus, and that the liberated ash had probably formed a low-temperature glass that coated the bed particles and caused the agglomeration. The Type- $1 \mathrm{~b}$ is activated using a phosphoric acid process. The phosphorus lowers the softening point of glasses. It is believed that when oxygen was introduced to the reformer, the hot carbon particles began to oxidize (as intended). The heat liberated by the oxidation would have elevated the carbon particle temperature well above the average temperature of the bed. The ash would have formed a molten phase that would stick to bed particles on contact with the carbon until a sufficiently deep layer of sticky glass formed on the bed particles to cause them to adhere to each other. Further testing of the carbons without SBW feed was suspended because of the time required to recover from the bed agglomeration. Note that activated carbons with a high ash content may be more likely to cause bed agglomeration in the absence of a diluent such as the waste product.

\subsubsection{Bed Conditioning}

Past experience was reconfirmed during the initial period of feeding simulated SBW to the steam reformer in that $\mathrm{NO}_{\mathrm{x}}$ destruction improved as the bed became conditioned. Catalytically active metals in the SBW facilitate the destruction of $\mathrm{NO}_{\mathrm{x}}$ after a product layer has accumulated on the alumina bed media. The conditioning period was designated as Test 0.5 and lasted for a period of nearly 7 hours. During this period, the process and feed conditions were deliberately established to resemble the final conditions during the January 2003 test, except for the elimination of iron oxide catalyst and the substitution of a sugar syrup and in-line mixing instead of dissolving sugar into the SBW simulant. The bed temperature (nominally $670^{\circ} \mathrm{C}$ ) and the effective feed rates of SBW simulant and sugar matched the previous test. Sugar addition provided $240 \%$ of the stoichiometric quantity needed to theoretically reduce the nitrates to nitrogen (based on a stoichiometric $\mathrm{C}: \mathrm{NO}_{3}$ mole ratio of 1.25).

Activated carbon addition was lower than in January because cyclone-catch recycle was expected to improve carbon utilization. It was observed that activated carbon addition rate about half of the rate in January was sufficient. The system performed well with a combined SBW+Syrup feed rate of $7 \mathrm{~L} / \mathrm{hr}$ $(8.8 \mathrm{~kg} / \mathrm{hr})$. The measured $\mathrm{NO}_{\mathrm{x}}$ destruction rose from about $93 \%$ to about $99 \%$ during this time.

\subsubsection{Feed Maximization Test}

After the bed was conditioned, the feed rate of the SBW simulant and syrup was increased to $6 \mathrm{~kg} / \mathrm{hr} \mathrm{SBW}$ and $4 \mathrm{~kg} / \mathrm{hr}$ syrup (10 kg/hr combined), thus initiating Test 1.1, which lasted for about 2.5 hours. Sugar stoichiometry was maintained at $240 \%$. Activated carbon was increased, but the oxygen introduction in the steam was held constant. Methane, THC, and hydrogen off-gas concentrations increased and NO decreased during this time period.

The bed thermocouple at the distributor began reading higher than the other thermocouples, and filter candle blow-back frequency had increased to an interval of about once every three minutes. This was interpreted as an indication that we had an excess of activated carbon in the bed, which accounted for a compression of the oxidation zone near the distributor and excessive carbon fines generation.

The bed heater output was nearly maximized, so the effective maximum feed rate had been reached for the $240 \%$ sugar stoichiometry without increasing oxygen to the fluidizing gas. Increasing the oxygen in the presence of excess carbon was not deemed prudent. The high temperatures in the vicinity of the carbon pieces could cause bed particle surfaces to melt and thereby promote bed agglomeration. Since the syrup and the SBW simulant have similar densities and similar water contributions (after sugar decomposition), the maximum feed rate is about $10 \mathrm{~kg} / \mathrm{hr}$ for the test system and is limited by the rate of 
heat transfer into and generation in the fluidized bed. Some increase in feed rate was possible (noted below) before the heaters are maximized.

At the higher feedrate of Test 1.1, the $\mathrm{NO}_{\mathrm{x}}$ destruction stayed high at about $98 \%$.

\subsubsection{Reductant Optimization Test Series}

Test 2.1 was initiated when activated carbon addition was terminated, concluding Test 1.1, but syrup, SBW simulant, and oxygen addition rates were held constant. Over the subsequent 2 hours, methane, THC, and hydrogen increased slightly, and $\mathrm{NO}_{\mathrm{x}}$ destruction stayed high while the inventory of carbon persisted in the bed. After 2 hours, the NO emissions began to rise rapidly, and hydrogen generation began to fall, indicating that activated carbon had been depleted in the bed. Filter blow-back frequency was reduced to once in 10 to 15 minutes.

Test 2.2 started when activated carbon addition was reinitiated at a reduced rate. The intent was to add carbon at $0.5 \mathrm{~kg} / \mathrm{hr}$, based on a bench calibration of the vibratory feeder. It was later determined that the actual addition rate was different for the feeder in the installed location. Methane, hydrogen, and THC declined, and NO continued to rise, even though syrup addition remained unchanged, indicating continued depletion of the activated carbon in the bed.

Activated carbon addition rate was increased again, after 40 minutes of operation, to about $1.3-1.4 \mathrm{~kg} / \mathrm{hr}$ in an attempt to replenish the carbon inventory in the bed. SBW, syrup, and oxygen additions remained unchanged. This carbon addition rate was maintained until the bottom bed thermocouple once-again began to read higher than the others, indicating that the carbon inventory was replenished. During this test (Test 2.3), which lasted for 1 hour 38 minutes, the hydrogen, methane, THC, and carbon dioxide concentrations in the off-gas continued to decline, and the NO concentration continued to rise, in spite of increasing the activated carbon feed rate.

Test 2.4 began with decreasing the activated carbon addition rate to about $0.35 \mathrm{~kg} / \mathrm{hr}$ while holding all other feed rates constant. During the ensuing 1 hour 39 minutes, the off-gas hydrogen concentration fell off sharply, carbon dioxide and THC rose slightly, while carbon monoxide and methane remained nearly constant. The $\mathrm{NO}$ concentration rose sharply as well, indicating that $\mathrm{NO}_{\mathrm{x}}$ destruction is related to $\mathrm{H}_{2}$ levels.

Test 2.5 lasted for about 2 hours, with a significant increase in the sugar syrup addition. SBW simulant was held at $6 \mathrm{~kg} / \mathrm{hr}$, but the syrup was increased to $4.9 \mathrm{~kg} / \mathrm{hr}(300 \%$ stoichiometry). Activated carbon and oxygen addition rates were held constant. Hydrogen generation increased slightly, as did the THC. Carbon monoxide and methane production remained relatively constant, but NO increased slightly. The increase of total liquid mass feed from 10 to $10.9 \mathrm{~kg} / \mathrm{hr}$ kept the electrical heaters at nearly full power.

In Test 2.6, the SBW feed was decreased to $5.3 \mathrm{~kg} / \mathrm{hr}$, and the syrup was increased to $5.8 \mathrm{~kg} / \mathrm{hr}$ ( $400 \%$ stoichiometry) to determine the effect of increased dissolved carbon on the process. Activated carbon and oxygen were held at their previous addition rates. The THC concentration jumped in response to the increase in excess syrup. Carbon dioxide increased sharply, and carbon monoxide and methane showed modest increases in concentration. The hydrogen concentration increased by over a third to about $9 \% . \mathrm{NO}_{\mathrm{x}}$ destruction increased perceptibly from about $90 \%$ to about $94 \%$.

Having evaluated the effect of high sugar on $\mathrm{NO}_{\mathrm{x}}$ destruction, Test 2.7 was designed to evaluate the effect of high activated carbon on $\mathrm{NO}_{\mathrm{x}}$ destruction. The sugar stoichiometry was reduced back to $240 \%$, increase the SBW feed rate again to $6 \mathrm{~kg} / \mathrm{hr}$, and the activated carbon rate was increased to about 1.2 $\mathrm{kg} / \mathrm{hr}$. This condition was held for about 3 hours to allow the carbon inventory in the bed to stabilize. 
$\mathrm{NO}_{\mathrm{x}}$ destruction initially decreased, due to the elimination of some of the sugar reductant, before the increase in the carbon feed rate could increase the reducing potential in the bed. Later in this test condition, as the carbon inventory in the bed increased, both the $\mathrm{H}_{2}$ level and $\mathrm{NO}_{\mathrm{x}}$ destruction increased.

Test 2.8 started when the activated carbon addition rate was decreased to about $0.5 \mathrm{~kg} / \mathrm{hr}$ because the temperature at the bottom of the bed was elevated, indicating a high inventory of carbon. SBW, syrup, and oxygen addition rates were held at the same values from the previous test. These conditions were held for nearly 4 hours, during which time the $\mathrm{CO}_{2}$, and $\mathrm{H}_{2}$ levels, and $\mathrm{NO}_{\mathrm{x}}$ destruction, fell sharply.

When the NO emissions started to rise, the syrup addition rate was increased to $275 \%$ stoichiometry $(4.5 \mathrm{~kg} / \mathrm{hr})$ in hope of increasing hydrogen production and stemming NO emissions. Other addition rates were held constant. Test 2.9 conditions were held for about 1.5 hours. The system took about 90 minutes to stabilize after the change in sugar stoichiometry. Carbon dioxide, carbon monoxide, methane, and THC concentrations remained constant. Hydrogen rose slightly, but the NO concentration began to increase.

Test 2.10 was a 5 -hour test, where the oxygen addition rate was decreased by $20 \%$ to increase the overall reducing condition in the bed, and the effective activated carbon rate was reduced by $16 \%$. All other addition rates were held constant except for the fluidizing steam, which increased automatically when the oxygen addition was decreased. Methane and hydrogen concentrations in the off-gas rose, carbon dioxide fell, and the other constituents remained nearly unchanged. $\mathrm{NO}_{\mathrm{x}}$ destruction stabilized at about $91 \%$.

\subsubsection{Demonstration Test Series}

Up to the end of Test 2.10, the emphasis was on optimizing the syrup and activated carbon addition rates and maintaining the feed rates high. The bed particle size had grown steadily since feed was initiated, in spite of keeping the nozzle atomizing ratio (NAR) at 500, which had been adequate to control product growth for softer products, such as SBW calcines. From this point forward, the emphasis shifted from short-term reductant tests to longer duration demonstrations and attempts to control bed particle growth and seed particle generation. Tests 2.11 and 2.12 had reduced aqueous feed rates, with constant sugar stoichiometry, and slightly increased activated carbon addition. The total carbon from the sugar syrup and the activated carbon was held constant. The NAR was increased to encourage jet grinding of the bed and generation of seed particles. $\mathrm{CO}, \mathrm{CO}_{2}, \mathrm{H}_{2}$, and $\mathrm{NO}$ remained relatively constant throughout the changes. Starting with Test $2.12, \mathrm{NO}_{\mathrm{x}}$ levels rose from below $90 \%$ to above $95 \%$.

With the decrease in SBW and syrup feed rates in the previous test, we determined that the total excess carbon from the combination of sugar and activated carbon was about $0.16 \mathrm{~kg} / \mathrm{hr}$ less than it had been before. The oxygen addition increased when revised bed particle size and density data were entered into the computer. The syrup feed rate was increased from 3.4 to $4.0 \mathrm{~kg} / \mathrm{hr}$ to compensate for the loss of carbon in Test 2.13a. The increase, however, had only a slight positive effect on hydrogen production after 2 hours at the increased setting and no benefit for NO destruction. For Test $2.13 \mathrm{~b}$, the syrup addition was reduced back to $3.4 \mathrm{~kg} / \mathrm{hr}$, and the activated carbon was increased from 0.5 to $0.7 \mathrm{~kg} / \mathrm{hr}$. Oxygen was also reduced to $1 \mathrm{~kg} / \mathrm{hr}$ part way through the test. The net result of the changes was that the total hydrocarbon concentration responded inversely to the oxygen addition rate. Other off-gas constituents, and $\mathrm{NO}_{\mathrm{x}}$ destruction, remained largely unchanged.

Test 3.1 was designed with two objectives. The SBW feed was turned off and replaced with a water feed rate of $1 \mathrm{~kg} / \mathrm{hr}$, and the atomizing gas NAR was increased significantly to determine if operating for a period of time with a high NAR would tend to attrit the bed, which had continued to grow

as SBW feed was continued. This test condition also provided a time period for evaluating the magnitude of interference on the Ametek $\mathrm{NO}_{\mathrm{x}}$ analyzer, while there was no source of $\mathrm{NO}_{\mathrm{x}}$. Oxygen and activated 
carbon additions remained unchanged from the previous tests. A significant NO concentration was measured even without a nitrate source. This NO response, recorded at several syrup feed rates, was used to determine the interference correction for the NO data. Bed particle size measurements after almost 5 hours of operation showed negligible bed attrition. Other means are necessary to accomplish bed particle size control than attrition by the atomizing gas in the existing configuration in the test system.

Tests 3.2 and 3.3 were at essentially the same conditions (SBW at $4 \mathrm{~kg} / \mathrm{hr}, 275 \%$ sugar stoichiometry, $1.22 \mathrm{~kg} / \mathrm{hr}$ oxygen addition rate, and activated carbon addition rates of $1 \mathrm{~kg} / \mathrm{hr}$ ). The only difference was the conversion from SBW supernate feed to SBW with simulated heel solids. $\mathrm{NO}_{\mathrm{x}}$ destruction started low at about $87 \%$ but rapidly rose to about $95 \%$ during this test condition.

Test 3.4 was the same as Test 3.3, except that the activated carbon was switched from Type-1b to the Type- 2 carbon. Most of the off-gas species remained unchanged except for NO and carbon dioxide, which both decreased. This test was conducted for nearly 4.5 hours to allow the Type- $1 \mathrm{~b}$ carbon to be fully displaced by the Type- 2 . Near the end of this test condition, as the Type- 2 carbon replaced the Type- 1 b carbon, the $\mathrm{NO}_{x}$ destruction rose from about $94 \%$ to $99 \%$. Although indications in the field, during the test, and reduced data indicate that the Type- 2 carbon performed better, the test duration was too short to be completely conclusive.

Three short-duration $(\sim 2 \mathrm{hr})$ adhoc tests were conducted at the end of the testing period. These were designated as syrup reduction tests $(\mathrm{S} .1-\mathrm{S} .3)$ where the activated carbon addition rate was increased to compensate for reduced syrup addition. The SBW and oxygen addition rates were held constant, while the syrup was reduced to $150 \%$ stoichiometry (S.1) and 100\% stoichiometry (S.2 and S.3). As the syrup was reduced and the carbon increased, the THC, CO, and NO concentrations dropped, hydrogen increased, and the other constituents remained nearly constant. $\mathrm{NO}_{\mathrm{x}}$ destruction dropped from about $99 \%$ for Test 3.4 to a range between $93-97 \%$. These results suggest that both carbon and sugar together are more effective for $\mathrm{NO}_{\mathrm{x}}$ reduction than carbon alone, although carbon alone may still be adequate if the $\mathrm{NO}_{\mathrm{x}}$ reduction goal is $90 \%$.

None of the efforts to reduce the bed particle size and to generate seed particles succeeded. Increasing the NAR and decreasing the SBW feed rate slowed the particle growth, but the particle size distribution remained narrow, with little indication of seed particle formation. Using the nozzle atomizing gas to jet grind the bed media was not effective during the carbonate test series, using the existing nozzle and fluidized bed design.

\subsection{Carbonate Test Solid Product Evaluations}

The feed solution, when sprayed into the bed, dries and undergoes evaporation, thermal decomposition, and other reactions that denitrate the feed constituents. The solid residual products of the steam reforming process either stay in the bed or elutriate from the bed with the off-gas, depending on operating conditions and properties of the bed media and solid products. If the solid products form relatively durable coatings on existing bed particles, then the products tend to stay in the bed. During continued operation, the bed mass would grow and would need to be removed. Most of the steamreformed product would be in the form of bed media drained from the bed.

If the solid products tend to form new, small particles, or fragile coatings on bed particles that readily break off of the products, they would be easily entrained in the fluidizing gas and would tend to elutriate from the bed. This mode of operation would tend to leave the bed particles intact and result in a primary elutriated product captured in the cyclone and filter. 
In practice, operating variations could include purposefully operating the fluidized bed to attrit bed particles for particle size control or to elutriate product. Alternatively, other operating modes could include recycling some elutriated fines back to the fluidized bed to further treat elutriated fines or minimize the net amount of elutriated fines.

The product distribution can often be tailored by system design and operation to produce a bed product, elutriated product, or combination of the two. During the THOR Phase 2 tests, $100 \%$ of elutriated fines that were captured in the cyclone were recycled back to the fluidized bed. Some of the elutriated fines passed through the cyclone and were captured on the sintered metal filters but not recycled back to the fluidized bed.

\subsubsection{Solid Product Distribution and Mass Balance Closure}

The solid product distribution and mass balance closure are shown in Table 5.2-1. The total input masses were the starting bed media, solid material from the reformed SBW feed, and the carbon additive. Total output masses were the bed product, the mass of the cyclone recycle material that was sampled, and the filter catch. The output bed product was the sum of the mass of bed removed at the end of the test, the mass of bed material in bed samples, and the mass of bed material removed (called excess bed) during the test series to maintain the design bed level as bed particles grew in size and became less dense.

The total bed product of $52.8 \mathrm{~kg}$, compared to the starting bed mass of $26 \mathrm{~kg}$, shows a bed turnover of the total mass of 1.0 times. This calculation is based on assuming that none of the starting bed media elutriates past the cyclone recycle. On average, $50 \%$ of the bed product was new solids from the simulant feed. Excess bed product and bed samples were semicontinously removed during operation, so the ending bed would have a concentration of new solids higher than $50 \%$, due to the depletion of starting bed media.

Table 5.2-1. Solid product distribution and mass balance closure for the THOR carbonate test series.

\begin{tabular}{|c|c|c|c|c|c|c|c|c|c|c|}
\hline \multirow[b]{3}{*}{ Date, time } & \multirow[b]{3}{*}{ Test condition } & \multicolumn{3}{|c|}{ Mass inputs, $\mathrm{kg}$} & \multicolumn{6}{|c|}{ Mass outputs, $\mathrm{kg}$} \\
\hline & & \multirow[b]{2}{*}{$\begin{array}{l}\text { Starting bed } \\
\text { Bed material } \\
\text { added, kg (a) }\end{array}$} & \multirow[b]{2}{*}{$\begin{array}{l}\text { Total solids } \\
\text { from SBW } \\
\text { feed, } \mathrm{kg}(\mathrm{b})\end{array}$} & \multirow{2}{*}{$\begin{array}{l}\text { Estimated solid } \\
\text { residual from } \\
\text { solid carbon, kg } \\
\text { (c) }\end{array}$} & \multicolumn{3}{|c|}{ Bed } & \multirow{2}{*}{$\begin{array}{c}\text { Cyclone } \\
\text { solids } \\
\text { sample } \\
\text { mass }\end{array}$} & \multicolumn{2}{|c|}{ Filter } \\
\hline & & & & & $\begin{array}{c}\text { Bed } \\
\text { removed at } \\
\text { test end }\end{array}$ & $\begin{array}{c}\text { Bed sample } \\
\text { mass }\end{array}$ & $\begin{array}{l}\text { Cumulative } \\
\text { excess bed }\end{array}$ & & $\begin{array}{l}\text { Filter solids } \\
\text { sample mass }\end{array}$ & $\begin{array}{c}\text { Filter solids } \\
\text { increment mass }\end{array}$ \\
\hline $11 / 11 / 032: 52$ & Pretest & \multirow[t]{6}{*}{26.0} & \multirow{6}{*}{$\begin{array}{c}36.0 \\
0.0 \\
5.2\end{array}$} & \multirow{6}{*}{$\begin{array}{l}5.9 \\
0.5\end{array}$} & \multirow{6}{*}{\multicolumn{2}{|c|}{12.1}} & \multirow{6}{*}{26.9} & \multirow{6}{*}{1.70} & \multirow{6}{*}{0.132} & \multirow{6}{*}{24.7} \\
\hline $11 / 11 / 037: 45$ & 0.5 & & & & & & & & & \\
\hline $11 / 13 / 0319: 29$ & 3.1 & & & & & & & & & \\
\hline $11 / 14 / 032: 40$ & 3.3 & & & & & & & & & \\
\hline--- & All & & & & & & & & & \\
\hline $11 / 14 / 0316: 38$ & Shutdown & & & & & & & & & \\
\hline \multicolumn{2}{|c|}{ Totals of individual streams } & 26.0 & 41.3 & 8.0 & 13.8 & 12.1 & 26.9 & 1.7 & 0.1 & 24.7 \\
\hline \multirow{2}{*}{\multicolumn{2}{|c|}{$\begin{array}{l}\text { Total bed or filter product } \\
\text { Total input or output }\end{array}$}} & \multirow{2}{*}{\multicolumn{3}{|c|}{75.2}} & \multicolumn{3}{|c|}{52.8} & \multirow[b]{2}{*}{79.3} & \multirow{2}{*}{\multicolumn{2}{|c|}{24.8}} \\
\hline & & & & & & & & & & \\
\hline \multirow{2}{*}{\multicolumn{5}{|c|}{$\begin{array}{l}\text { Distribution of solids to bed product, wt } \%(\mathrm{~d}) \\
\text { Mass balance closure = (output mass)/(input mass) }\end{array}$}} & & 50.3 & & 3.2 & \multicolumn{2}{|c|}{46.5} \\
\hline & & & & & & & & 1.05 & & \\
\hline
\end{tabular}

a. The initial start on November 10 is not included here because the bed agglomerated and was replaced before any significant SBW was fed.

b. Total SBW solids was estimated from the calculated amount of solid product per liter of feed $(0.15 \mathrm{~kg} / \mathrm{L})$ and the total SBW feed volume for the test.

c. The residual solid carbon was estimated using a weighted average of $2.2 \%$ inorganic in the carbons used, and assuming about $90 \mathrm{wt} \%$ of the elemental solid carbon was gasified or converted to $\mathrm{CO} 3$ in the product.

d. Percentage of the total product mass in each of the three solid product streams. In this calculation the mass of the bed product stream was reduced by the mass of the virgin bed material that was fed to the reformer. 


\subsubsection{Bed Building and Product Elutriation}

One of the objectives of this testing was to obtain a stable bed in the steam reforming reactor. In stable operation, the bed mass, density, height, particle size, and product distribution would be controlled within acceptance limits. The product may be primarily elutriated from the bed, leaving the starting bed essentially intact, or the product may distribute partially or primarily to the bed product, eventually replacing the starting bed media. Under the first scenario, the starting bed provides the fluidized bed environment, acting as a catalyst or heat/mass transfer medium to facilitate the conversion of feed materials to products with little or no change to the starting bed. The entering feed forms new particles that elutriate from the bed or temporarily coat the bed particles with a layer that eventually spalls off and is elutriated. This process is dynamic in that the starting bed is continually gaining and losing mass as the feed materials enter, react, spall, and then elutriate.

The solid product mass distribution between the bed product and filter fines indicates that the feed solids predominantly partitioned to the bed product. As the simulant feed was fed to the reformer, the feed solids tended to coat the bed particles rather than forming separate small particles that would be elutriated from the bed. The sizes of the bed particles continued to grow. Bed media was periodically drained from the bed to maintain a target bed depth (indicated by continuous measurements fluidized bed density and bed height) of about 30-35 inches. As the bed particles grew in size, the bulk and particle densities decreased because of the larger particle sizes and the lower particle density of the carbonate product compared to the heavier starting alumina bed media. Figure 5.2-1 shows that as the bed height was maintained near the top of target range, the fluidized bed specific gravity decreased from about 1.7 to about 0.9 . These measurements were made using pressure taps located in the bed to measure the total fluidized bed pressure drop, and the fluidized bed pressure drop for a given 13-inch bed depth.

Late in the test series, water was fed to the reformer, while the NAR was increased (for a few hours) to attrit the bed particles for particle size control. A small amount of attrition was achieved, slightly reducing the bed and reducing the effect of bed particle size growth on the fluidized bed bulk density. After the SBW feed was restarted, a higher NAR was used. Even with the higher NAR, the particle size growth was not controlled, although the fluidized bed density was better controlled, since most of the mass of the bed media was carbonate product this late in the test.

Longer duration testing may provide more data about the desired fluidized bed particle size and mechanisms to better control bed particle size growth solid product distribution. At a relatively steadystate condition, the bed particle size, bed density, and the product distribution between bed product and elutriated mass would be relatively constant. If bed particle size cannot be controlled by fluidized bed operating conditions, then particle size could still be controlled by periodic additions of starting bed media or recycled crushed or water-washed bed product. Water-washing bed product that is recycled to the reformer would dissolve the primarily water-soluble carbonate product material off of the insoluble alumina bed particles, allowing the alumina particles to be re-used without significantly diluting the bed product. These optimizations of feed product distributions between the bed, cyclone, and filter products could be evaluated in subsequent design and optimization studies. 


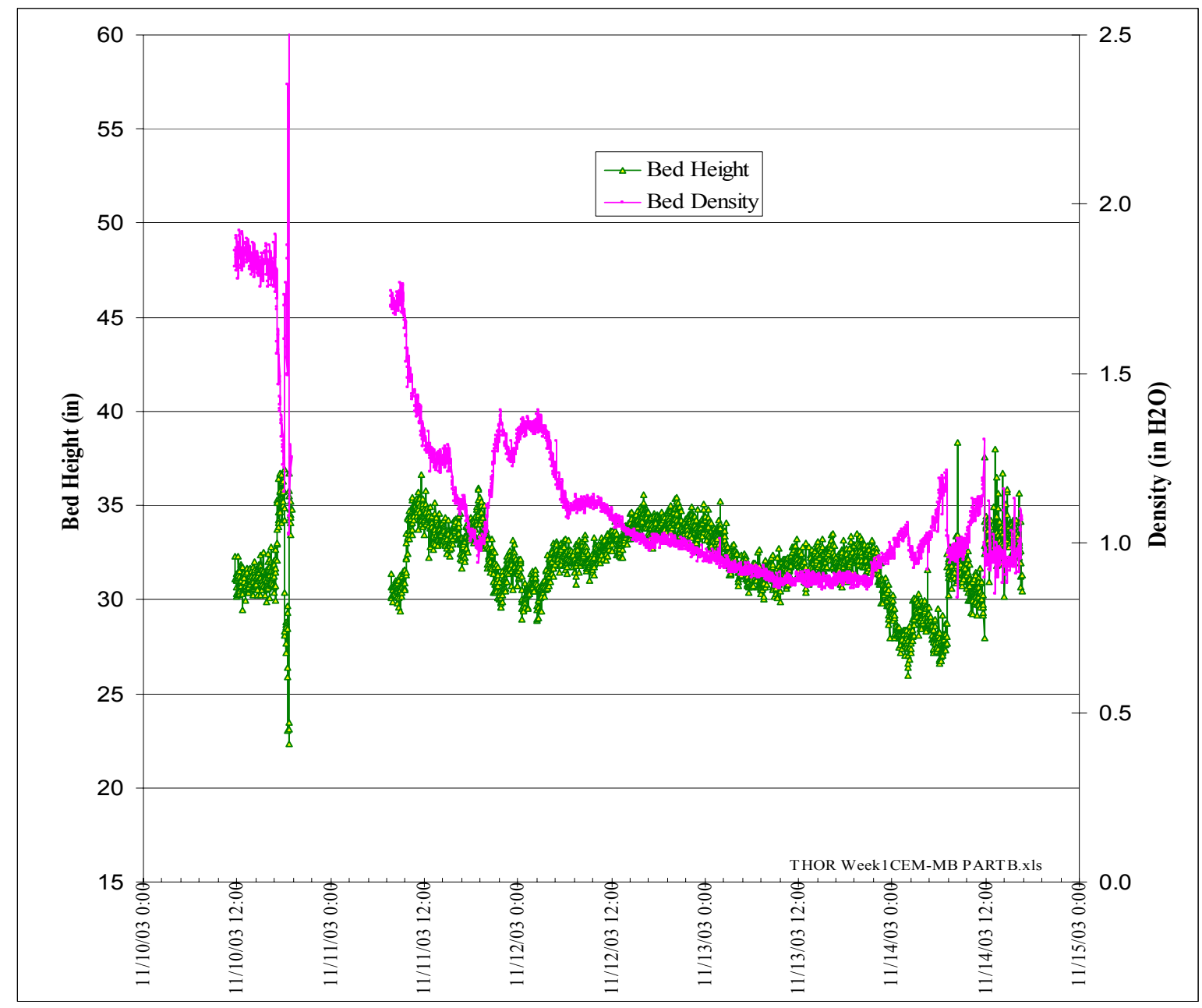

Figure 5.2-1. Continuously measured in situ bed depth and mass for the THOR carbonate test series.

\subsubsection{Solid Product Characterization and Particle Size}

Solid products were bed product and filter fines. Solid material that was elutriated from the fluidized bed, and captured and recycled by the cyclone, was also sampled and characterized.

5.2.3.1 Bed Product. As noted in prior testing (Marshall 2003a), two distinct product phases formed on the bed particles, one composed of spheroids, the other a white mass that coated the particle in the interstices between these spheroids. Scanning electron micrographs (SEMs) of the solid bed product particles are shown in Figure 5.2-2. The figure shows samples from different times throughout the test (indicated by the cumulative feed $[\mathrm{CF}]$ parameter) and the test condition at the time each sample was taken. Changes in the morphology of the particles as the run progressed can be seen, notably the sizes of both the aggregate bed particles and their spheroidal inclusions. From the scale shown in the SEMs, the bed product particles increase in size from about $500 \mu \mathrm{m}$ (for starting virgin bed) to about 1,000 $\mu \mathrm{m}$.

Examination of SEM micrographs (particularly for samples 88, 109, and 137) reveals how the spheroidal growths on the particles eroded during a period of high NAR and no SBW simulant feed (\#109) and re-growth of the knobs when SBW simulant feed was resumed. 


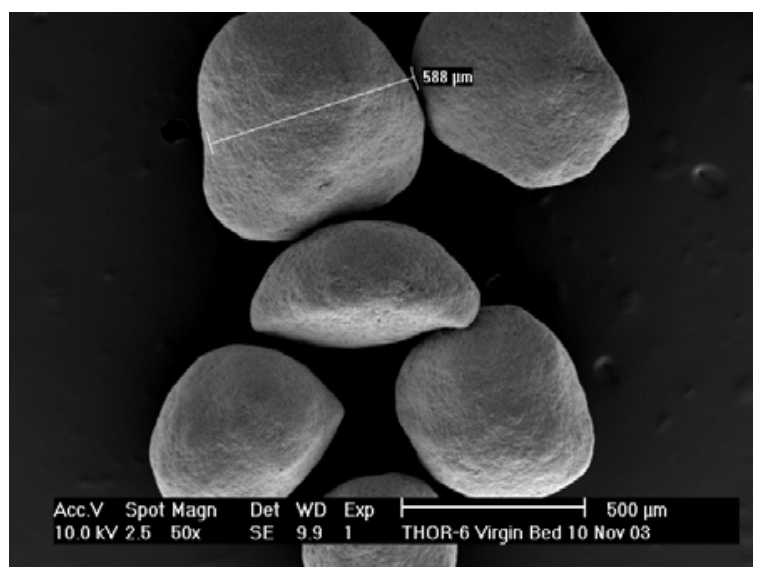

Sample 6 (0 kg CF—virgin bed)

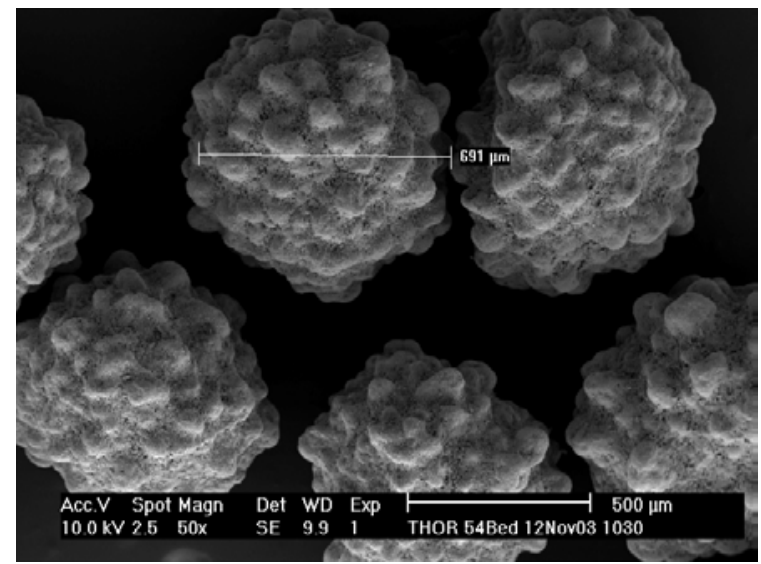

Sample 54 (145 kg CF, Test Condition 2.10)

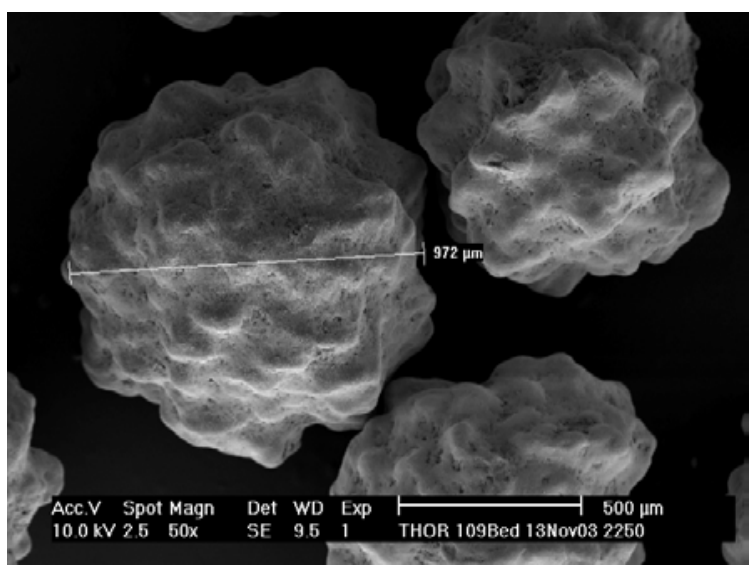

Sample 109(323 kg CF, Test Condition 3.1)

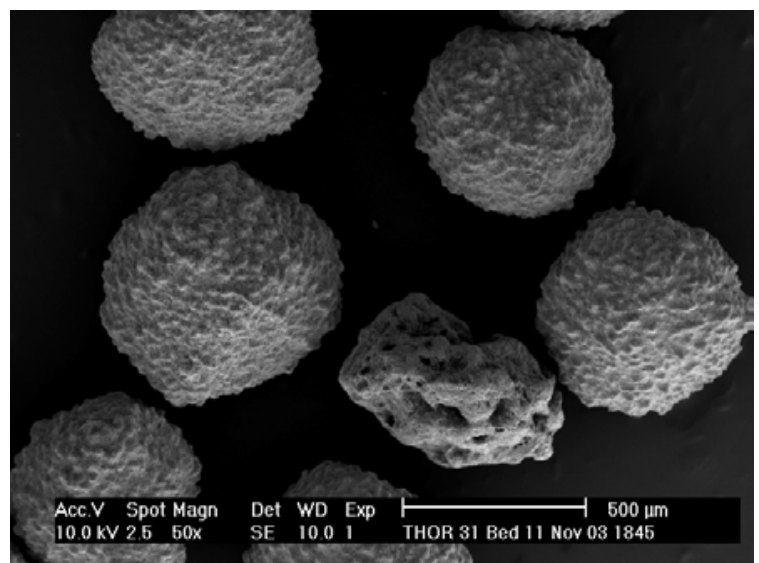

Sample 31 (51.4 kg CF, Test Condition 2.1)

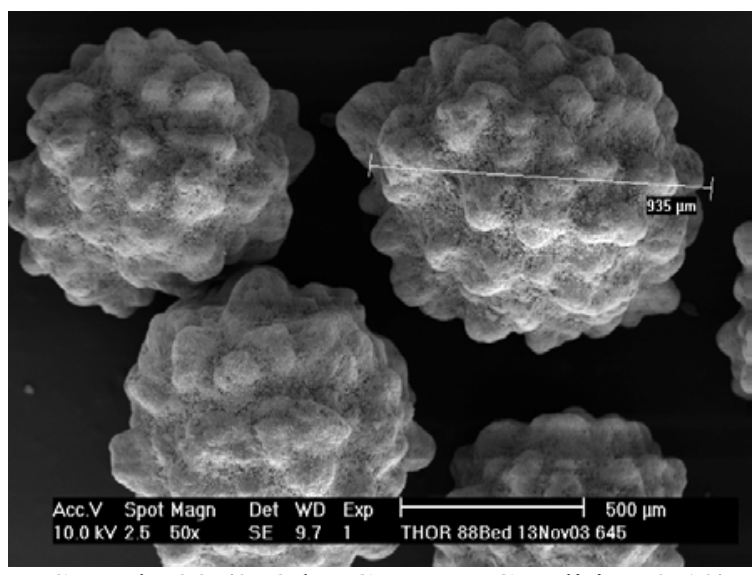

Sample 88 (253 kg CF, Test Condition 2.12)

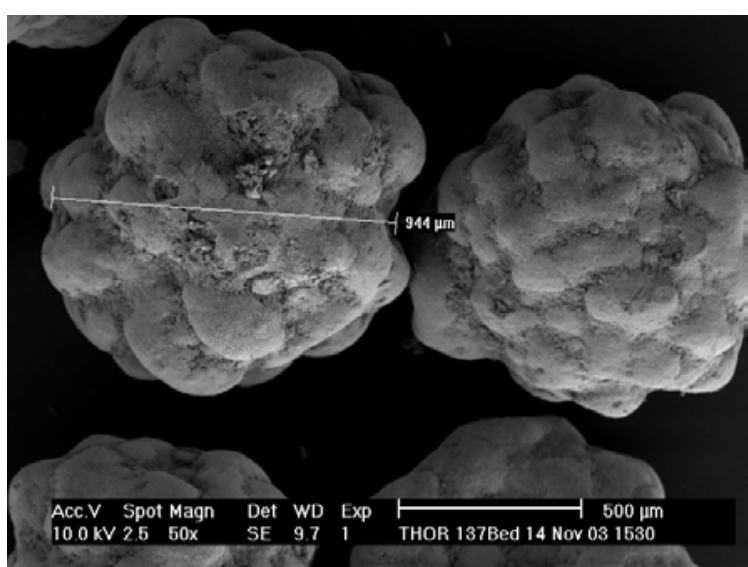

Sample 137 (379 kg CF, Test Condition 5.4)

Figure 5.2-2. SEMs of bed product at various cumulative feed amounts. 
The degree to which the objective of a stable bed was achieved in the current tests may be seen by examining bed product characteristics and parameters, principally the particle size distribution and mean size. These characteristics were determined by sieve analysis using standard screen sizes. The resulting mass and harmonic mean particle diameters (MMPD and HMPD) are shown as functions of the cumulative SBW simulant fed in Figure 5.2-3. Consistent with the SEM photos, these data indicate that the mean particle size increased during the test from about $500 \mu \mathrm{m}$ to $1,100 \mu \mathrm{m}$. That data further indicate that a stable bed was not achieved during the course of the testing, as the mean particle diameter shows a monotonic increase, again consistent with the previous observation from the SEMs.

The dynamics of bed growth are further illustrated in the 3-D histogram shown in Figure 5.2-4. In this figure, the $\mathrm{z}$-axis (into the page) indicates the chronological order in which the bed samples were taken throughout the run, the x-axis (across) indicates the mid-ranges of the particle size classes (in $\mathrm{mm}$ ), and the y-axis (vertical) gives the percentage of the total sample mass that was found in the respective size classes. The PSDs of samples collected early in the run are those closest to the reader and those collected late are farthest. In this representation, one can again clearly see the migration of the bed mass into larger and larger particles. For example, early in the run, there was no mass in the size classes above $0.922 \mathrm{~mm}$. As the run progressed, however, the mass in the $0.922 \mathrm{~mm}$ size class steadily increased, consistent with the above observations from the SEMs and the MMPD values.

Additional qualitative information about the nature of the bed product formed is provided by the optical microscope photograph shown in Figure 5.2-5. The figure shows several of the intact bed product particles and one particle that was crushed, exposing a structure consisting of an inner core and an outer shell. The photo suggests that the smaller spheroidal clusters constituting the outer shell of the particles may have been formed by some chemical or physical process other than agglomeration of the discrete spheroids in the bed. The porous appearance of the solid material in the outer layer also appears to support this speculation.

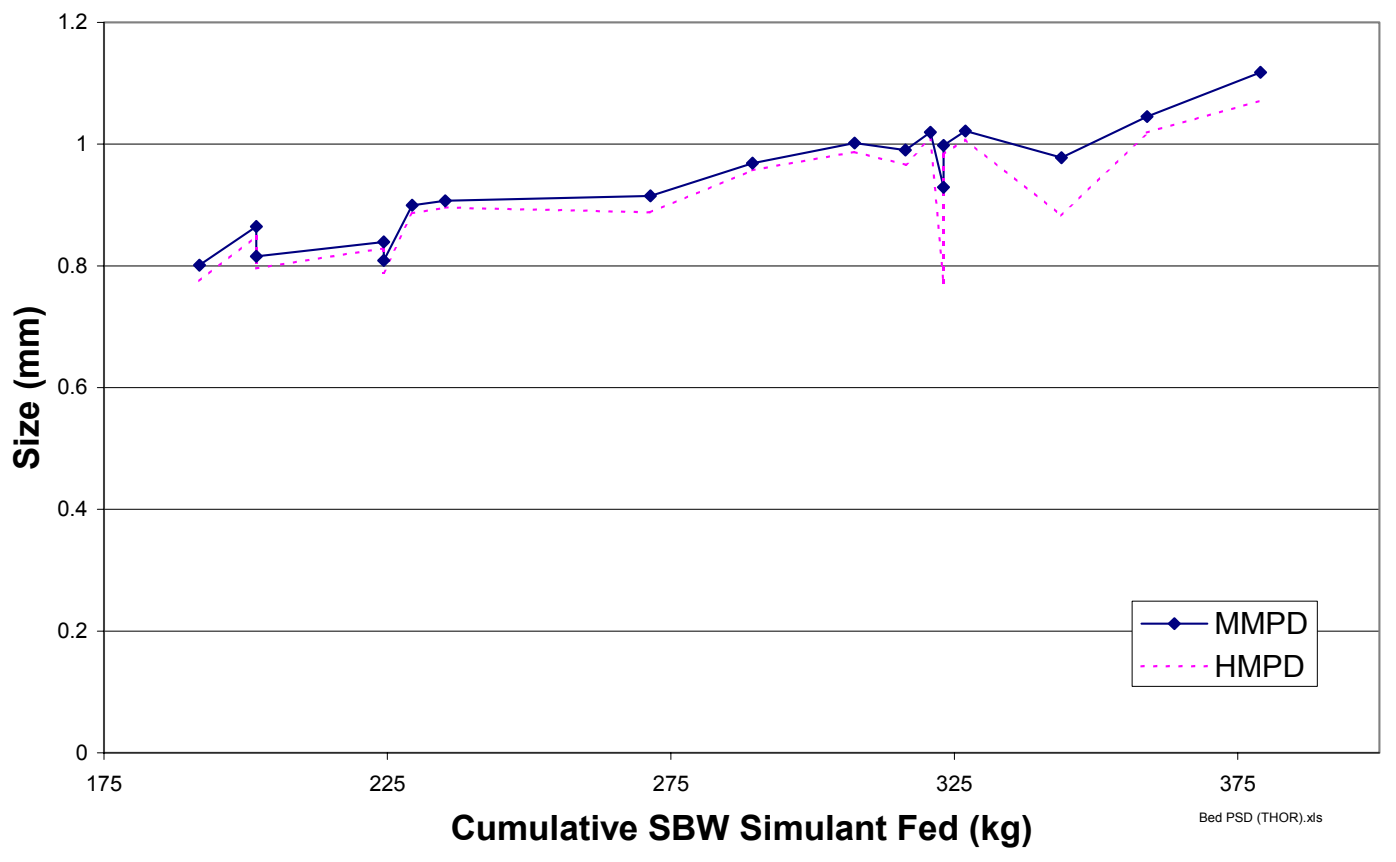

Figure 5.2-3. Mass and harmonic mean bed product particle diameter versus cumulative SBW fed. 


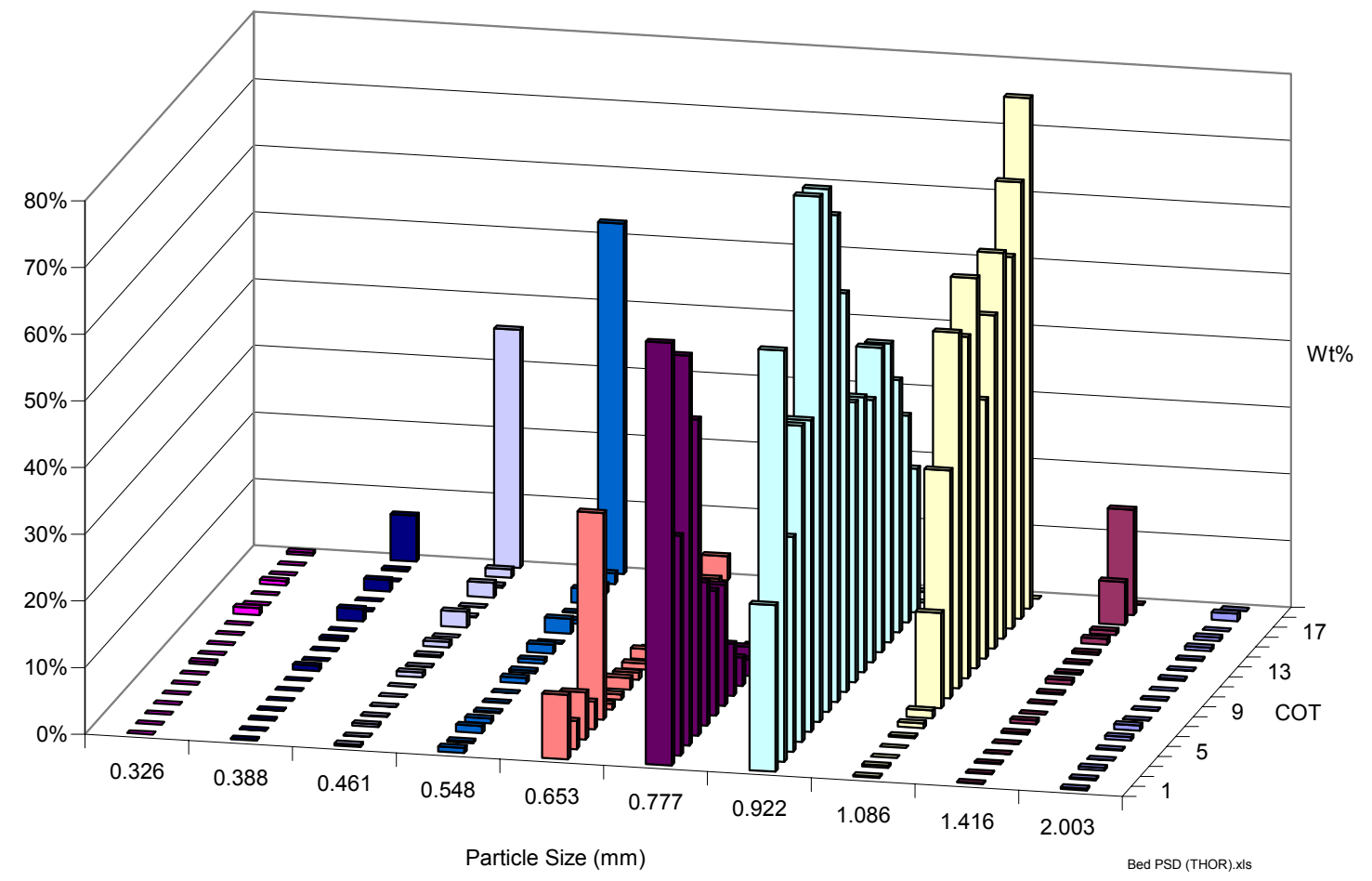

Figure 5.2-4. Mass fraction in various size ranges versus continuous operating time (COT) in hours. (NOTE: The COT axis is not linear. The COT value indicates only chronological order in which samples were drawn through the run.)

In Figure 5.2-5, SEMs of the bed product are presented at 50x to 20,000x magnification, with insets in each view showing the portion presented in the next higher magnification. Scale bars are also shown in all the figures. Proceeding from upper left across the page and then down, the different scales at which the particle formation processes proceed are shown. The spheroidal masses shown at the largest scale (50x magnification) may represent either the scale of gaseous expansion within a bed particle or the scale of particles that agglomerate while the bed particles possess a viscous outer covering. At the other scale extreme (20,000x magnification), it is evident that distinct physical processes were occurring at scales as small as $0.1-0.2 \mu \mathrm{m}$, as evidenced by the smallest distinct particles. Looking at the next larger scale (2,000x magnification), the fissures and caverns evident suggest that the surface was not formed by bombardment of smaller particles but rather by some other process. This conclusion is based on the premise that a uniform accretion from bombardment would not produce the type of fissures and caverns apparent in the intermediate scale SEMs (350x and 2,000x magnifications), and which were plainly evident in other SEMs examined but not shown here. 


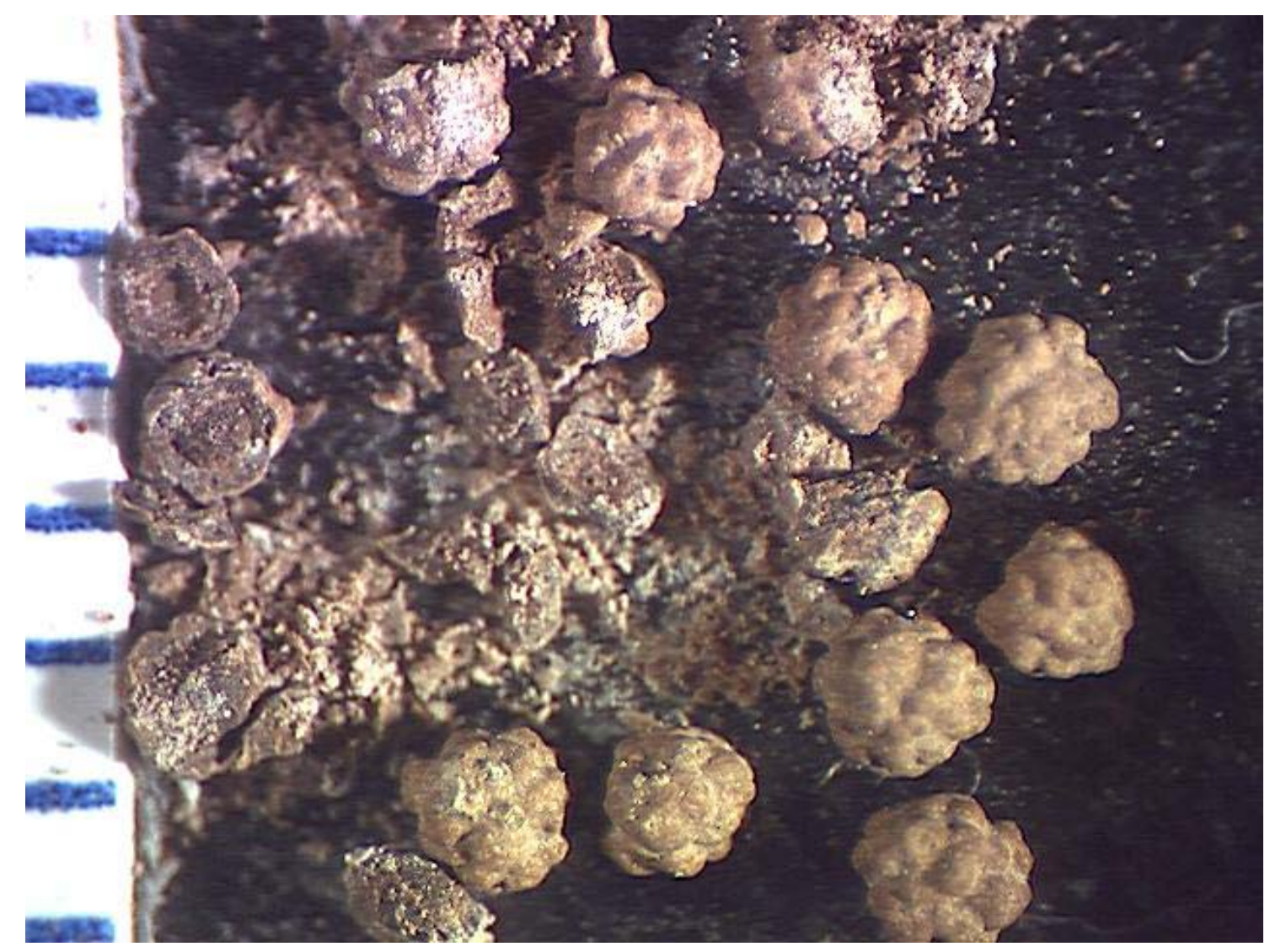

Figure 5.2-5. Optical microscope photograph of bed product particles from THOR carbonate flowsheet. Blue marks at the left indicate scale ( $1 \mathrm{~mm}$ between marks). Note the split particle upper left, showing the outer layer and inner core of the particle.

Additional useful information about the nature of the bed particles was obtained by periodic determination of individual particle densities and of overall (bulk) densities of the aggregated product. These parameters were measured by weighing a bed sample, measuring its volume in a graduated cylinder, and then determining the mass of liquid hexane required to barely fill the void spaces between particles in the graduated cylinder. The individual particle densities were then calculated by subtracting the volume of hexane from the bulk volume of the particles. In these determinations it was presumed that the bed material would be totally insoluble in the hexane and non-absorbent. The data in Table 5.2-2 show both the bed product particle density and bulk densities decreasing throughout the test, again indicating that a static bed condition was not achieved. The disparity between the bulk and particle densities suggests that the product is compactable to reduce final volume. 

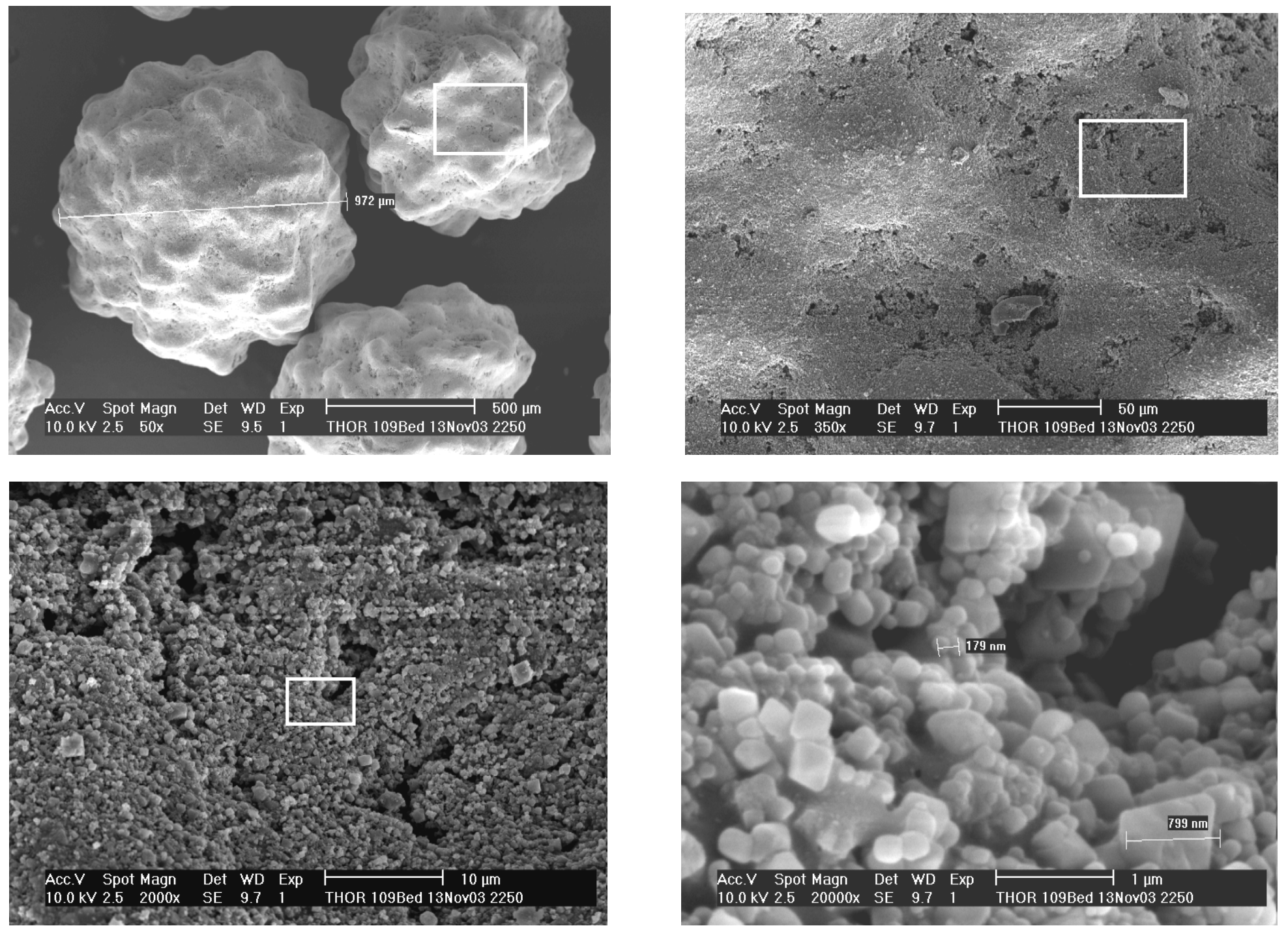

Figure 5.2-6. SEMs of THOR carbonate bed product, sample 109 (Test Condition 3.1). Scale decreases from left to right and top to bottom. Insets show field illustrated at next lower scale to right or below. 
Table 5.2-2. Bed product bulk and particle densities for THOR carbonate flowsheet.

\begin{tabular}{|cccccc|}
\hline Sample & Date & Test Cond & $\begin{array}{c}\text { Cumulative SBW Fed } \\
(\mathrm{kg})\end{array}$ & $\begin{array}{c}\text { Particle Density } \\
(\mathrm{g} / \mathrm{cc})\end{array}$ & $\begin{array}{c}\text { Bulk Density } \\
(\mathrm{g} / \mathrm{cc})\end{array}$ \\
\hline 6 & $11 / 10 / 037: 30$ & pretest & 0 & 3.58 & 2.17 \\
18 & $11 / 11 / 039: 35$ & 0.5 & 2 & 3.46 & 2.02 \\
20 & $11 / 11 / 0310: 45$ & 0.5 & 8 & 3.44 & 1.93 \\
35 & $11 / 11 / 0322: 30$ & 2.4 & 74 & 3.3 & 1.66 \\
38 & $11 / 12 / 030: 20$ & 2.5 & 85 & 3.22 & 1.62 \\
45 & $11 / 12 / 033: 00$ & 2.7 & 101 & 3.09 & 1.53 \\
46 & $11 / 12 / 034: 00$ & 2.7 & 106 & 3.09 & 1.52 \\
51 & $11 / 12 / 037: 10$ & 2.8 & 125 & 3.1 & 1.41 \\
64 & $11 / 12 / 0314: 30$ & 2.10 & 169 & 2.92 & 1.25 \\
88 & $11 / 13 / 036: 45$ & 2.12 & 253 & 2.69 & 1.15 \\
\hline
\end{tabular}

5.2.3.2 Cyclone and Filter Products. Figures 5.2-7 and 5.2-8 show SEMs of the solid cyclone and filter products. The 50x view in Figure 5.2-7 shows that a very broad spectrum of particle shapes and sizes was collected by the cyclone in contrast with those indicated in the bed product and filter catch. Some of the particles are fines and agglomerated fines from the simulant feed, and some are unreacted carbon particles (when carbon was in the bed). The agglomerations are probably artifacts of the deposition process in the cyclone or on the filter, or agglomerations that occurred after collection.

Submicron particles are evident in the bed product and in the cyclone and filter catches, as shown by the views at 20,000x magnification. Similarities in the morphology and sizes of these submicron particles may indicate that all are formed by the same process. If so, they may represent fragments of bed particles broken off by erosion (attrition) and fracturing within the bed. The 20,000x view (lower right) in Figure 5.2-7 seems consistent with the earlier speculation - that the submicron particles may be crystals formed from the feed liquids deposited on the surfaces of the largest bed particles, after evaporation of water and calcination of the solids. The SEMs imply further that these submicron particles may either adhere to bed particle surfaces as the feed coating on the particles dry (as indicated at the 20,000x scale in Figure 5.2-7), or be released into the bulk gas phase as the feed liquid on the bed particle surfaces dry (as indicated at the same scale in Figure 5.2-8). 

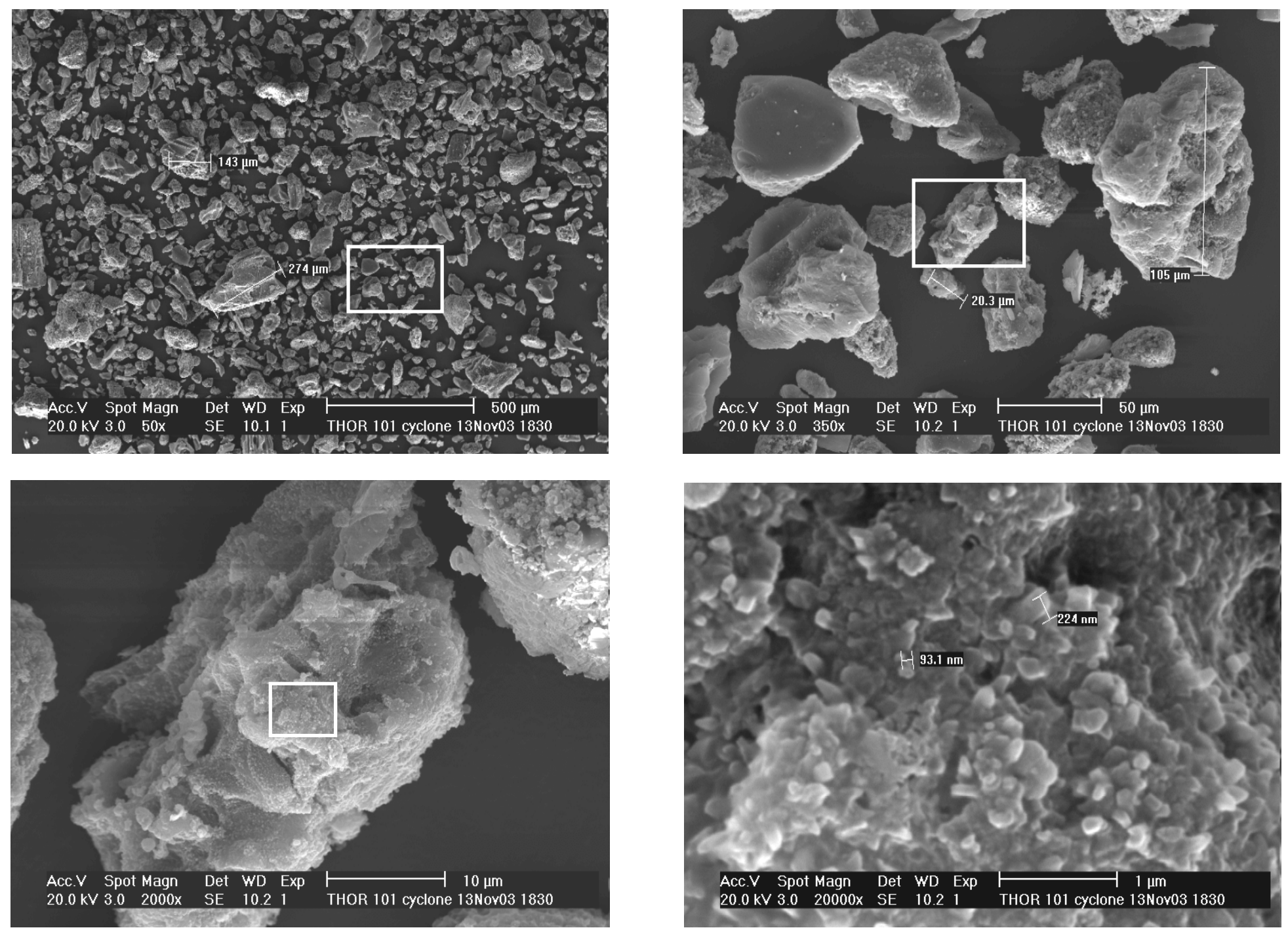

Figure 5.2-7. SEMs of THOR carbonate flowsheet cyclone product, sample 101 (Test Condition 2.13b). Scale decreases from left to right and top to bottom. Insets show field illustrated at next lower scale to right or below (Note that most of the lower left figure is off the SEM in the upper right). 

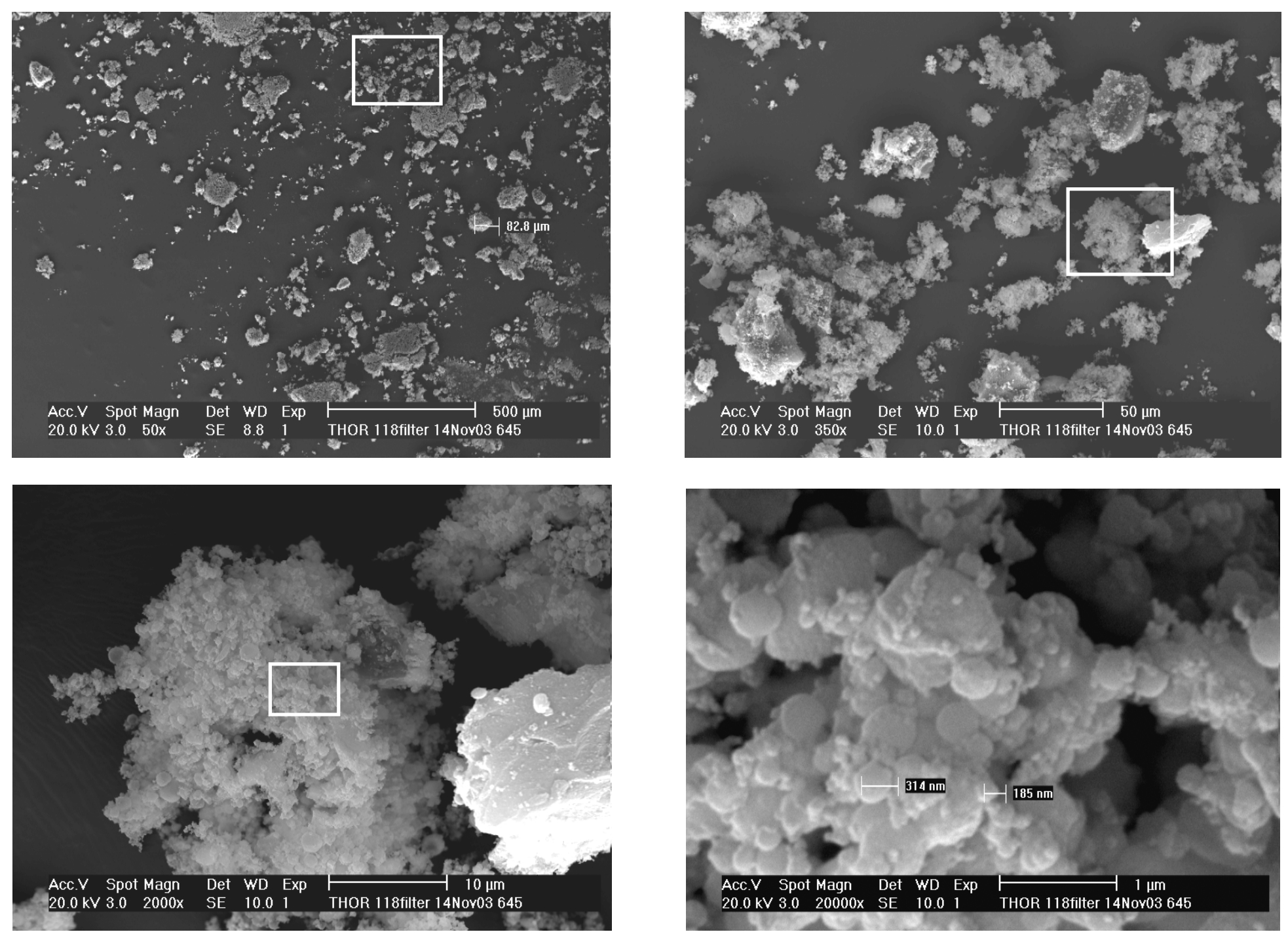

Figure 5.2-8. SEMs of THOR carbonate flowsheet filter catch, sample 118 (Test Condition 3.4). Scale decreases from left to right and top to bottom. Insets show field illustrated at next lower scale to right or below. 
Particle size distributions for the cyclone and filter catches were obtained using different techniques. For the cyclone catch the sample was prepared by placing about 50-100 $\mathrm{mg}$ of material in a vial with $\sim 10 \mathrm{ml}$ of hexane. This suspension was dispersed using an immersed sonication probe for 2 minutes and was then added to a Coulter Counter particle size analysis sample cell where it was further diluted with hexane until a target loading was achieved. The particles in the suspension were then counted using low-angle forward particle scattering to detect and size particles in the $0.1-700-\mu \mathrm{m}$ size range. The particle size distribution in a sample suspension is calculated using angular particle-scattering data collected with a He-Ne laser and a linear-detector array.

The results of these measurements are shown for four cyclone catch samples in Figure 5.2-9. The size data show that Samples 23 and 101 both display multi-modal size distributions with volume (or mass) mean size below $100 \mathrm{um}$. These observations appear consistent with the cyclone catch SEMs. The data for Samples 122 and 136, however, indicate PSDs with very different characteristics — one being nearly monomodal with a mean particle size about $200-300 \mu \mathrm{m}$, the other being distinctly bimodal with modes between 10-20 $\mu \mathrm{m}$ and above $600 \mu \mathrm{m}$. The analyst determined that the suspensions of Samples 122 and 136 agglomerated and coalesced probably as a result of static attraction, resulting in skewed distributions. On this basis, one might conjecture that the other two samples may also be nonrepresentative. However, the qualitative consistency of the particle size distribution for Samples 23 and 101 with the SEMs lends them credibility as reasonable estimates for the cyclone catch PSDs.

Particles in the filter catch were counted and sized using optical imaging software. This software scans the digitized optical microscope photographs and identifies particle profiles from variations in color, contrast, intensity, etc. These determinations are generally imprecise, except when all particles counted are physically separate in the optical image. Though this was not uniformly true, some portions of the optical microscope images approximated this criterion, providing approximate counts of particles in the size range $0.2-6.0 \mu \mathrm{m}$ for one of the filter catch samples (Sample 24). The results are shown in Figure 5.2-10 and indicate a bi-modal distribution with a small peak about $1.0 \mu \mathrm{m}$, and a second, large peak above $6.0 \mu \mathrm{m}$. As a check on the accuracy of the software-generated PSD, a SEM for filter Sample 118 was examined and particles were manually counted and classified into 20 uniformly spaced size classes from 0 to $2.0 \mu \mathrm{m}$. The results from this manual count, also shown in Figure 5.2-10, agree qualitatively with the software-generated PSD, showing a bi-modal distribution of particle volume (mass). The smaller peak from the manual count, however, is about $0.5 \mu \mathrm{m}$ rather than $1.0 \mu \mathrm{m}$. Also, the second peak is just below $2.0 \mu \mathrm{m}$, rather than above $6.0 \mu \mathrm{m}$. The second peak above $2.0 \mu \mathrm{m}$ is likely an artifact caused by particle agglomeration after the mass was collected. Assuming this to be the case, the PSD for the filter catch is mainly in the $0.1-1.0 \mu \mathrm{m}$ size range.

The filter catch particle and bulk densities, determined from a single sample, are:

Filter catch particle density $=2.05 \mathrm{gm} / \mathrm{cm}^{3}$

Filter catch bulk density $\quad=\quad 0.34 \mathrm{gm} / \mathrm{cm}^{3}$.

The low bulk density indicates the light, fluffy nature of the filter catch. This material could potentially be recycled to the reformer and so would not necessarily be a separate product stream.

Cyclone catch was recycled to the reformer to attempt to improve carbon utilization and reduce the carbon content of the final reformer products. The mass rate of recycle of this material varied considerably throughout the test. The rate was measured and is tabulated in Table 5.2-3. 
Table 5.2-3. Cyclone recycle rates for THOR carbonate flowsheet.

\begin{tabular}{|ccc|}
\hline Date & Test Cond & $\begin{array}{c}\text { Cyclone Product } \\
\text { Recycle Rate } \\
(\mathrm{g} / \mathrm{hr})\end{array}$ \\
\hline $11 / 11 / 0311: 14$ & 0.5 & 842 \\
$11 / 11 / 0314: 12$ & 0.5 & 536 \\
$11 / 12 / 0311: 10$ & 2.10 & 233 \\
$11 / 12 / 0315: 12$ & 2.11 & 238 \\
$11 / 12 / 0319: 16$ & 2.11 & 294 \\
$11 / 13 / 036: 46$ & 2.12 & 318 \\
$11 / 13 / 0310: 56$ & $2.13 \mathrm{a}$ & 281 \\
$11 / 13 / 0314: 52$ & $2.13 \mathrm{~b}$ & 313 \\
$11 / 13 / 0318: 42$ & $2.13 \mathrm{~b}$ & 268 \\
$11 / 14 / 037: 20$ & 3.4 & 238 \\
$11 / 14 / 037: 46$ & 3.4 & 254 \\
$11 / 14 / 03$ 9:46 & $\mathrm{S} .1$ & 191 \\
$11 / 14 / 0314: 10$ & $\mathrm{~S} .3$ & 160 \\
\hline
\end{tabular}

[Auxilliary THOR data.xls]THOR cylone recycles 


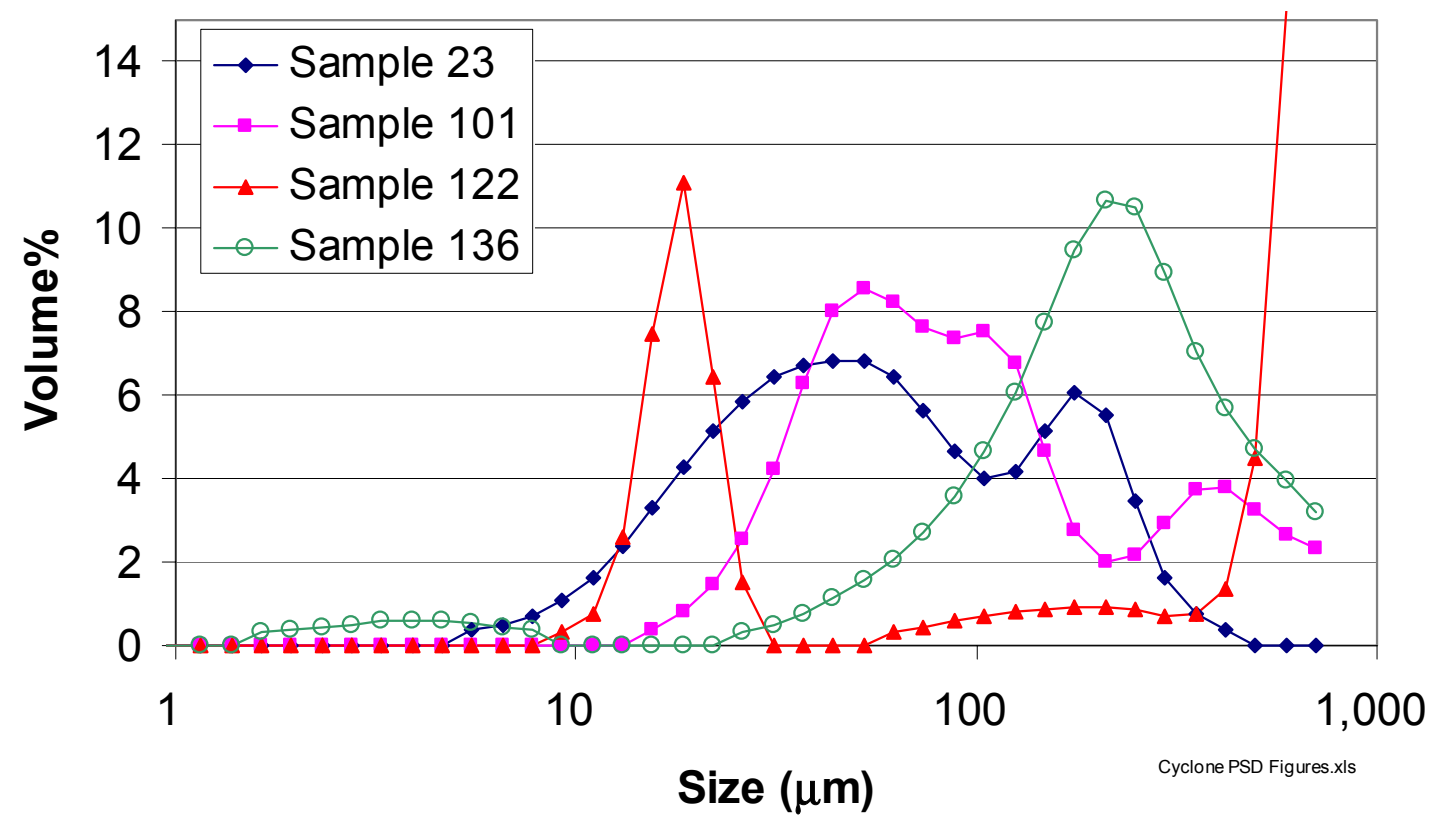

Figure 5.2-9. Differential particle size distribution for the recycled cyclone catch material from the THOR carbonate test series.

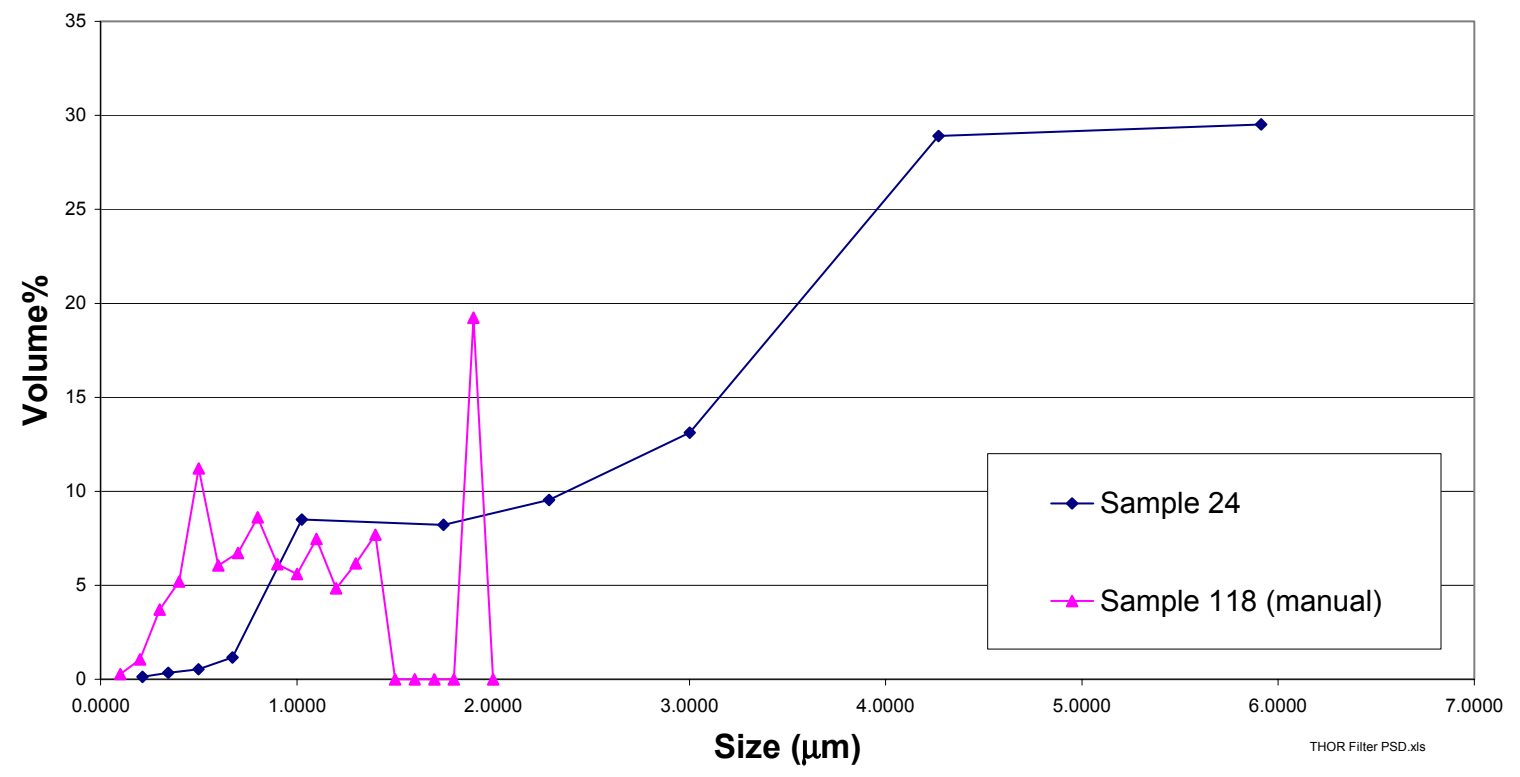

Figure 5.2-10. Differential particle size distribution for filter catch material from the THOR carbonate test series. 


\subsection{Process Effluent Compositions}

The solid and gaseous effluent compositions were determined at each effluent location. Samples of bed product, cyclone recycle, and filter catch collected both during test operations and at the end of the test series were analyzed for the main constituents of the feed streams. The off-gas was characterized at two locations - at the outlet of the heated filter (upstream of the thermal oxidizer) and downstream of the oxidizer, wet scrubber, and reheater.

\subsubsection{Solid Product Compositions}

The composition of the solid products was estimated based on the SBW simulant feed rate and composition, and also measured using sample collection and analysis.

The average product composition calculated from the SBW simulant composition is estimated in Table 5.3-1. This average composition excludes any residual alumina bed media or solid carbon. The table also shows the solid product rate and the rate of carbon used (regardless of whether the carbon comes from added sugar or added solid carbon) to form the carbonate product from the input feed solids. The product composition was estimated using simplifying assumptions based in part on chemical equilibrium composition calculations under representative steam reformer conditions using a commercial chemical equilibrium model (HSC Chemistry). The calculations included the major chemical species in the feed and expected to be potentially possible in the products (Taylor 2004). The equilibrium modeling did not account for some of the minor constituents, including $\mathrm{Cu}, \mathrm{Fe}, \mathrm{Ni}$, and $\mathrm{Pb}$, and some of the potential chloride, fluoride, phosphate, and sulfate species. Simplifying assumptions include:

- All of the nitrate is converted to gaseous $\mathrm{N}_{2}$, leaving no $\mathrm{N}$ in the solid product, according to the equilibrium calculations.

- $\quad$ All water and $\mathrm{Hg}$ volatilizes to the gas phase

- $\quad$ Aluminum in the feed reacts with an equimolar amount of $\mathrm{Na}$, forming sodium aluminate $\left(\mathrm{NaAlO}_{2}\right)$

- $\quad$ Essentially all of the anions are retained in the solid product (although the equilibrium modeling suggests some appreciable partitioning to the gas phase)

- $\quad$ Reaction of the anions with $\mathrm{Na}$ to from $\mathrm{NaCl}, \mathrm{NaF}, \mathrm{Na}_{2} \mathrm{SO}_{4}$, and $\mathrm{Na}_{3} \mathrm{PO}_{4}$ (even though equilibrium modeling shows anion reactions with $\mathrm{Na}, \mathrm{Ca}, \mathrm{K}$, etc., to form various other species)

- $\quad$ The remaining available $\mathrm{Na}$ after reactions with $\mathrm{Al}$ and the anions forms $\mathrm{Na}_{2} \mathrm{CO}_{3}$.

The bed product, cyclone recycle, and filter catch sample analyses are shown in Tables 5.3-2 and 5.3-3. The concentrations of primary simulant feed products $\left(\mathrm{CO}_{3}, \mathrm{~K}\right.$, and $\left.\mathrm{Na}\right)$ in the bed samples show a continuous trend of increasing amounts of simulant feed products. The amounts of these species in the bed product would continue to asymptotically approach the theoretically calculated concentrations for these species (up to $29 \mathrm{wt} \% \mathrm{CO}_{3}, 5.2 \mathrm{wt} \% \mathrm{~K}$, and $30 \mathrm{wt} \% \mathrm{Na}$ ). The amounts of these species measured in the bed product indicate that between $39-76 \%$ of the bed material was solids from the simulant feed rather than starting bed alumina. The measured concentration of $\mathrm{Na}$ in the bed product seems to understate the estimated amount of feed product in the bed, because the total mass of bed product (2.0 times that of the starting bed) indicates that the concentration of feed product in the bed would be at least $50 \%$.

As indicated in Table 5.3-1, soluble carbonates constitute a significant portion of the expected product mix from the process. Product water solubilities for the bed, cyclone, and filter product catches were measured. The measured solubilities are tabulated below in Table 5.3-2a. 
Table 5.3-1. Calculated solid product distribution and composition based on chemical equilibrium calculations.

\begin{tabular}{|c|c|c|c|c|c|c|c|c|c|}
\hline \multirow{2}{*}{\multicolumn{2}{|c|}{ Test number }} & \multicolumn{2}{|c|}{$\begin{array}{l}\text { Elemental composition of solid } \\
\text { product (a) }\end{array}$} & \multicolumn{6}{|c|}{ Mass of solid product per liter of SBW simulant (a) } \\
\hline & & 0.5 to $2.13 \mathrm{~b}, 3.2$ & 3.3 to 5.4 & 0.5 to $2.13 \mathrm{~b}, 3.2$ & 3.3 to 5.4 & \multirow{3}{*}{$\begin{array}{l}\text { Product } \\
\text { species }\end{array}$} & \multirow{3}{*}{$\begin{array}{c}\text { Mole } \\
\text { weight } \\
\end{array}$} & 0.5 to $2.13 \mathrm{~b}, 3.2$ & 3.3 to 5.4 \\
\hline \multirow{2}{*}{$\begin{array}{c}\text { Feed } \\
\text { component }\end{array}$} & \multirow{2}{*}{$\begin{array}{c}\text { Mole } \\
\text { weight }\end{array}$} & $\begin{array}{c}\text { New SBW w/o } \\
\text { heel solids }\end{array}$ & $\begin{array}{c}\text { New SBW with } \\
\text { residual heel } \\
\text { solids } \\
\end{array}$ & $\begin{array}{c}\text { New SBW w/o } \\
\text { heel solids }\end{array}$ & $\begin{array}{c}\text { New SBW } \\
\text { with residual } \\
\text { heel solids } \\
\end{array}$ & & & \multicolumn{2}{|l|}{$\begin{array}{c}\text { New SBW w/o } \\
\text { heel solids }\end{array}$} \\
\hline & & Weight \% & Weight \% & $\mathrm{gm} / \mathrm{L}$ & $\mathrm{gm} / \mathrm{L}$ & & & $\mathrm{gm} / \mathrm{L}$ & $\mathrm{gm} / \mathrm{L}$ \\
\hline Acid & 1.0 & --- & --- & --- & --- & --- & --- & --- & --- \\
\hline Aluminum & 27.0 & 12 & 12 & 18 & 18 & $\mathrm{NaAlO} 2$ & 82.0 & 54 & 54 \\
\hline Boron & 10.8 & 0.090 & 0.090 & 0.13 & 0.13 & B2O3 & 69.6 & 0.43 & 0.43 \\
\hline Calcium & 40.1 & 1.3 & 1.3 & 1.9 & 1.9 & $\mathrm{CaCO} 3$ & 100.1 & 4.7 & 4.8 \\
\hline Cesium & 132.9 & 0.29 & 0.29 & 0.43 & 0.43 & $\mathrm{Cs} 2 \mathrm{CO} 3$ & 325.8 & 0.53 & 0.52 \\
\hline Chromium & 52.0 & 0.12 & 0.12 & 0.17 & 0.17 & $\mathrm{Cr} 2 \mathrm{O} 3$ & 152.0 & 0.25 & 0.25 \\
\hline Copper & 63.5 & 0.030 & 0.030 & 0.044 & 0.044 & $\mathrm{CuO}$ & 79.5 & 0.06 & 0.06 \\
\hline Iron & 55.9 & 0.82 & 0.83 & 1.2 & 1.2 & $\mathrm{FeO}$ & 71.9 & 1.6 & 1.6 \\
\hline Lead & 207.2 & 0.19 & 0.18 & 0.27 & 0.27 & $\mathrm{PbO}$ & 223.2 & 0.29 & 0.29 \\
\hline Magnesium & 24.3 & 0.20 & 0.20 & 0.29 & 0.30 & $\mathrm{MgCO} 3$ & 84.3 & 1.0 & 1.0 \\
\hline Manganese & 54.9 & 0.53 & 0.53 & 0.77 & 0.78 & $\mathrm{MnCO} 3$ & 114.9 & 1.6 & 1.6 \\
\hline Mercury & 200.6 & --- & --- & -- & --- & -- & --- & --- & -- \\
\hline Nickel & 58.7 & 0.059 & 0.058 & 0.09 & 0.09 & $\mathrm{NiO}$ & 74.7 & 0.11 & 0.11 \\
\hline Potassium & 39.1 & 5.2 & 5.2 & 7.7 & 7.6 & $\mathrm{~K} 2 \mathrm{CO} 3$ & 138.2 & 14 & 13 \\
\hline Rhenium & 186.2 & 0.14 & 0.13 & 0.20 & 0.20 & $\mathrm{Re} 2 \mathrm{O} 3$ & 420.4 & 0.23 & 0.22 \\
\hline Silicon & 28.1 & --- & 0.10 & --- & 0.15 & $\mathrm{SiO} 2$ & 60.1 & --- & 0.32 \\
\hline Sodium & 23.0 & 30 & 30 & 47 & 47 & $\mathrm{Na} 2 \mathrm{CO} 3$ & 106.0 & 59 & 59 \\
\hline Tin & 118.7 & -- & 0.035 & -- & 0.052 & $\mathrm{SnO} 2$ & 150.7 & -- & 0.07 \\
\hline Zinc & 65.4 & 0.047 & 0.046 & 0.069 & 0.068 & $\mathrm{ZnCO} 3$ & 125.4 & 0.13 & 0.13 \\
\hline Zirconium & 91.2 & --- & 0.023 & --- & 0.034 & $\mathrm{ZrO} 2$ & 123.2 & --- & 0.05 \\
\hline Chloride & 35.5 & 0.72 & 0.74 & 1.1 & 1.1 & $\mathrm{NaCl}$ & 58.4 & 1.8 & 1.8 \\
\hline Fluoride & 19.0 & 0.31 & 0.30 & 0.45 & 0.45 & $\mathrm{NaF}$ & 42.0 & 1.0 & 1.0 \\
\hline Nitrate & 62.0 & --- & --- & --- & --- & --- & --- & --- & --- \\
\hline Phosphate & 95.0 & 0.61 & 0.65 & 2.7 & 2.9 & Na3PO4 & 163.9 & 1.6 & 1.7 \\
\hline Sulfate & 96.1 & 2.3 & 2.3 & 6.7 & 6.7 & $\mathrm{Na} 2 \mathrm{SO} 4$ & 142.0 & 5.0 & 5.0 \\
\hline Carbonate & 60.0 & 30 & 30 & --- & --- & -- & --- & --- & -- \\
\hline Oxide & 16.0 & 15 & 15 & --- & --- & --- & --- & --- & --- \\
\hline Total & --- & 100 & 100 & 89 & 90 & Total & --- & 147 & 147 \\
\hline $\begin{array}{l}\mathrm{C} \text { used to } \\
\text { form } \mathrm{CO} 3\end{array}$ & 12.0 & --- & --- & 8.8 & 8.7 & & & & \\
\hline
\end{tabular}

a. Not including any starting bed material or organic carbon, and assuming no volatilization except for water, acid, and nitrate. 
Table 5.3-2. Elemental composition of the bed product for the THOR carbonate test series.

\begin{tabular}{|c|c|c|c|c|c|c|c|c|c|c|c|c|c|c|c|c|c|c|c|c|c|c|c|c|c|c|c|}
\hline \multirow[b]{2}{*}{ Sample } & \multirow[b]{2}{*}{ Sample date } & \multirow{2}{*}{$\begin{array}{l}\text { Test } \\
\text { Cond } \\
\end{array}$} & \multicolumn{25}{|c|}{ Measured concentrations, $\mathrm{wt} \%$} \\
\hline & & & TOC & $\mathrm{CO}_{3}$ & $\mathrm{NO}_{3}$ & $\mathrm{PO}_{4}$ & $\mathrm{SO}_{4}$ & $\mathrm{Cl}$ & $\mathrm{F}$ & Al & $\mathrm{Ca}$ & $\mathrm{Cr}$ & Cs & $\mathrm{Cu}$ & $\mathrm{Fe}$ & $\mathrm{Hg}$ & $\mathrm{K}$ & $\mathrm{Mg}$ & $\mathrm{Mn}$ & $\mathrm{Na}$ & $\mathrm{Ni}$ & $\mathrm{Pb}$ & $\operatorname{Re}$ & $\mathrm{Si}$ & $\mathrm{Sn}$ & $\mathrm{Zn}$ & $\mathrm{Zr}$ \\
\hline 6 & $11 / 10 / 20037: 30$ & pretest & & --- & 0.006 & 0.006 & 0.021 & 0.006 & 0.01 & $\overline{---}$ & 0.03 & 0.002 & 0.001 & 0.001 & 0.09 & $\overline{---}$ & 0.038 & 0.00 & 0.042 & 0.2 & 0.004 & \begin{tabular}{|l|}
0.018 \\
\end{tabular} & 0.00 & 0.021 & 0.000 & 0.001 & 0.006 \\
\hline 26 & $11 / 11 / 200314: 30$ & 0.5 & 3.2 & 0.386 & 0.024 & 0.969 & 0.115 & 0.024 & 0.02 & 1.54 & 0.115 & 0.006 & 0.004 & 0.002 & 0.84 & --- & 0.164 & 0.023 & 0.123 & 2.25 & 0.005 & 0.007 & 0.01 & -- & --- & 0.003 & --- \\
\hline 31 & $11 / 11 / 200318: 45$ & 2.1 & 5 & 1.542 & 0.025 & 1.21 & 0.182 & 0.025 & 0.03 & 2.14 & 0.169 & 0.009 & 0.003 & 0.003 & 1.02 & -- & 0.277 & 0.032 & 0.147 & 3.27 & 0.008 & 0.008 & 0.016 & -- & -- & 0.005 & --- \\
\hline 54 & $11 / 12 / 200310: 30$ & 2.10 & 0.85 & 9.32 & 0.025 & 2.71 & 1.11 & 0.164 & 0.03 & 5.85 & 0.623 & 0.038 & \begin{tabular}{|l|}
0.015 \\
\end{tabular} & 0.011 & 1.04 & -- & 1.54 & 0.123 & 0.247 & 13 & 0.027 & 0.014 & 0.063 & --- & --- & 0.016 & -- \\
\hline 72 & $11 / 12 / 200322: 30$ & 2.11 & 0.4 & 12.62 & 0.025 & 3.44 & 1.64 & 0.252 & 0.03 & 7.45 & 0.772 & \begin{tabular}{|l|}
0.051 \\
\end{tabular} & 0.014 & 0.014 & 1.00 & -- & 2.18 & 0.123 & 0.30 & 17.5 & 0.035 & 0.010 & 0.073 & -- & --- & 0.021 & -- \\
\hline 103 & $11 / 13 / 200318: 30$ & $2.13 b$ & 0.4 & 16.09 & 0.025 & 4.4 & 2.02 & 0.3 & 0.02 & 9.13 & 0.944 & 0.047 & 0.014 & 0.021 & 0.959 & -- & 2.64 & 0.132 & 0.333 & 21.8 & 0.039 & 0.003 & \begin{tabular}{|l|}
0.088 \\
\end{tabular} & -- & -- & 0.022 & -- \\
\hline 128 & $11 / 14 / 200310: 30$ & S.2 & 8.2 & \begin{tabular}{|l|}
21.96 \\
\end{tabular} & 0.024 & 4.12 & 1.86 & 0.19 & 0.02 & 9.80 & 1.02 & 0.046 & 0.005 & 0.020 & 0.84 & $9 \mathrm{E}-06$ & 2.65 & 0.154 & \begin{tabular}{|l|}
0.358 \\
\end{tabular} & 24.2 & 0.043 & 0.002 & 0.051 & 0.111 & \begin{tabular}{|l|}
0.002 \\
\end{tabular} & 0.021 & 0.001 \\
\hline 137 & $11 / 14 / 200315: 30$ & S.3 & 0.9 & \begin{tabular}{|l|}
19.22 \\
\end{tabular} & 0.024 & 4.43 & 2.22 & 0.195 & 0.02 & 8.57 & 0.901 & 0.042 & 0.033 & 0.016 & 0.709 & --- & 2.89 & 0.134 & 0.33 & 21.7 & 0.038 & 0.003 & 0.031 & \begin{tabular}{|l|l}
0.106 \\
\end{tabular} & \begin{tabular}{|l|l|}
0.001 \\
\end{tabular} & 0.020 & 0.001 \\
\hline \multicolumn{4}{|c|}{ Calculated product composition, wt $\%$} & 29.66 & --- & 0.646 & 2.28 & 0.737 & 0.30 & 12.13 & 1.291 & 0.12 & 0.29 & 0.030 & 0.83 & --- & 5.166 & 0.20 & 0.529 & 30.05 & 0.058 & 0.184 & 0.135 & 0.095 & 0.03 & 0.046 & 0.022 \\
\hline \multicolumn{4}{|c|}{$\begin{array}{l}\text { Highest measured concentration as a percent of the } \\
\text { calculated product composition }\end{array}$} & 74.02 & --- & --- & 97.37 & 40.71 & 9.508 & 80.79 & 79.02 & 43.77 & 11.27 & 70.67 & 125.3 & -- & 55.94 & 76 & 67.73 & 80.52 & 73.6 & 9.817 & 65.03 & 117.2 & 4.489 & 47.1 & 29.49 \\
\hline
\end{tabular}

[Master Analytical Data (ddt).xls]Master RFA (2)

Table 5.3-2a. Product solubilities for the THOR carbonate test series. Bed Product

\begin{tabular}{|cccc|}
\hline Sample & Date & Test Cond & $\begin{array}{c}\text { Solubility } \\
(\mathrm{wt} \%)\end{array}$ \\
\hline 18 & $11 / 11 / 03$ 9:35 & 0.5 & 1.3 \\
20 & $11 / 11 / 0310: 45$ & 0.5 & 2.1 \\
26 & $11 / 11 / 0314: 30$ & 0.5 & 4.9 \\
31 & $11 / 11 / 0318: 45$ & 2.1 & 8.4 \\
35 & $11 / 11 / 0322: 30$ & 2.4 & 13.6 \\
38 & $11 / 12 / 030: 20$ & 2.5 & 18.8 \\
45 & $11 / 12 / 033: 00$ & 2.7 & 23.7 \\
46 & $11 / 12 / 034: 00$ & 2.7 & 24.8 \\
51 & $11 / 12 / 037: 10$ & 2.8 & 30.4 \\
54 & $11 / 12 / 0310: 30$ & 2.10 & 36.6 \\
64 & $11 / 12 / 0314: 30$ & 2.10 & 42.4 \\
88 & $11 / 13 / 036: 45$ & 2.12 & 55.3 \\
\hline Average & & & 21.9 \\
\hline
\end{tabular}

Cyclone Catch

Filter Catch

\begin{tabular}{|cccc|}
\hline Sample & Date & Test Cond & $\begin{array}{c}\text { Solubility } \\
(\text { wt } \%)\end{array}$ \\
\hline 11 & $11 / 10 / 0318: 00$ & pretest & 5.3 \\
22 & $11 / 11 / 0313: 45$ & 0.5 & 29.5 \\
34 & $11 / 11 / 0319: 50$ & 2.2 & 44.0 \\
43 & $11 / 12 / 032: 30$ & 2.7 & 42.1 \\
43 & $11 / 12 / 032: 30$ & 2.7 & 40.5 \\
56 & $11 / 12 / 0310: 30$ & 2.10 & 56.6 \\
62 & $11 / 12 / 0314: 30$ & 2.10 & 59.3 \\
\hline Average & & & 39.6 \\
\hline
\end{tabular}

\begin{tabular}{|c|c|c|c|}
\hline Sample & Date & Test Cond & $\begin{array}{c}\text { Solubility } \\
\text { (wt } \%)\end{array}$ \\
\hline 50 & $11 / 12 / 037: 10$ & 2.8 & 54.6 \\
\hline 57 & $11 / 12 / 0310: 30$ & 2.10 & 72.6 \\
\hline Average & & & 63.6 \\
\hline
\end{tabular}


Table 5.3-3. Elemental composition of the cyclone and filter catch samples for the THOR carbonate test series.

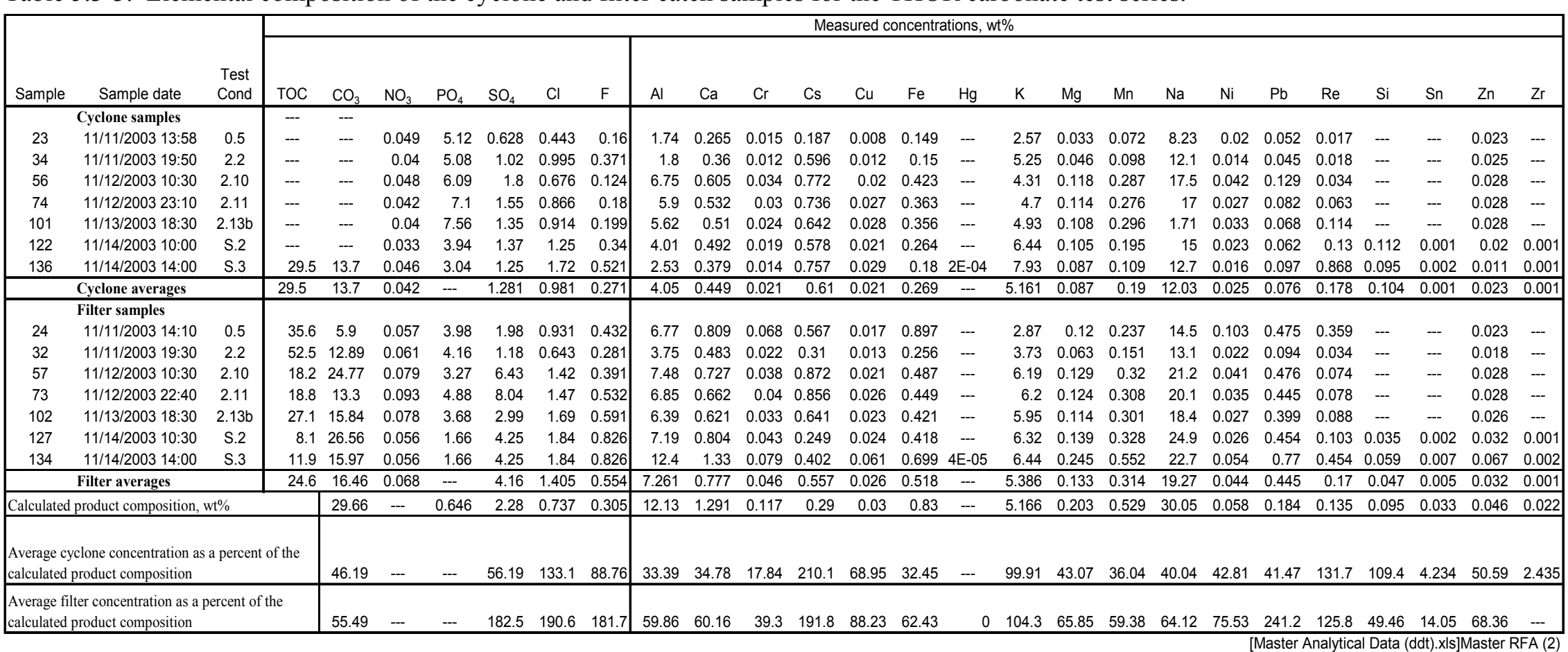


Concentrations of a few species ( $\mathrm{F}, \mathrm{Cs}, \mathrm{Pb}, \mathrm{Sn}$, and $\mathrm{Zr})$ in the bed samples appear to be lower than expected, assuming that about $50 \%$ or more of the bed product near the end of the test series is feed product. $\mathrm{F}, \mathrm{Cs}$, and $\mathrm{Pb}$ are among those species considered more volatile. Concentrations of some other species $\left(\mathrm{PO}_{4}, \mathrm{Fe}\right.$, and $\left.\mathrm{Si}\right)$ are higher than would be indicated from the calculated feed product compositions. The calculated feed product compositions do not account for $\mathrm{PO}_{4}, \mathrm{Fe}$, or $\mathrm{Si}$ from the solid carbon.

The cyclone and filter fines are produced from material that elutriates from the bed. Elutriated material can include combinations of unreacted carbon and smaller particles of new feed product. The compositions of the cyclone and filter samples vary somewhat but, after the initial startup time, do not show the same strong trend of decreasing starting bed and increasing feed product, because the starting bed media are attrition resistant. The total organic carbon content of the filter fines decreased from above $50 \mathrm{wt} \%$ near the start of the test series to $8 \mathrm{wt} \%$ near the end of the test series.

Based on the concentrations of $\mathrm{CO}_{3}$ and $\mathrm{Na}$, the material captured in the cyclone and returned to the fluidized bed averaged about $40-47 \%$ new feed product. The filter samples averaged about $57-64 \%$ feed product. Several of the more volatile feed constituents $\left(\mathrm{PO}_{4}, \mathrm{SO}_{4}, \mathrm{Cl}, \mathrm{Cs}, \mathrm{Cu}, \mathrm{K}\right.$, and $\left.\mathrm{Re}\right)$ were enriched in the cyclone and filter samples compared to expected concentrations in the average feed product. As was found in the bed product, the $\mathrm{PO}_{4}$ and $\mathrm{Si}$ levels in the fines may be higher in part because these species, components of the carbon additives, may not have been fully accounted for in the product composition calculations.

\subsubsection{Scrub Solution and CEMS Condensate Compositions}

Samples of the scrub solution were collected and analyzed to indicate amounts of various species that were volatilized or elutriated out of the fluidized bed and also pass through the cyclone and heated filter to be captured in the wet scrubber. The scrub solution and CEMS condensate sample analyses are shown in Table 5.3-4.

The scrubber was designed with heat exchanger cooling to remove latent heat from the off-gas as the scrubber cools the hot off-gas to its dew point and performs acid gas and particulate matter scrubbing. By removing latent heat from the off-gas using the heat exchanger, the scrubber can be operated so that essentially no scrub water is evaporated and no moisture in the off-gas is condensed. The heat removal from the scrub solution is automatically controlled to maintain a relatively constant scrub water level in the scrub tank.

As the scrub solution volume remains constant at about 45 gallons, species scrubbed out of the offgas become enriched in the scrub solution. The scrub solution was not changed during the test series, so the ending composition of the scrub solution provides the total amounts of species scrubbed during the test series. The concentrations of key species, including $\mathrm{NO}_{3}, \mathrm{SO}_{4}, \mathrm{Cl}, \mathrm{F}$, and $\mathrm{Hg}$, all increased to a maximum at the end of the test series. In order to avoid complications that would be caused by added $\mathrm{NaOH}$ or other $\mathrm{pH}$-neutralizing caustic, none was added. The scrub solution became somewhat, but not extremely, acidic during the test series. The $\mathrm{pH}$ ranged as low as 2-3. 
Table 5.3-4. Scrub solution composition for the THOR carbonate test series.

\begin{tabular}{|c|c|c|c|c|c|c|c|c|c|c|c|c|c|c|c|c|c|c|c|c|c|c|c|c|c|c|c|c|}
\hline \multicolumn{3}{|c|}{ Scrub solution } & \multicolumn{26}{|c|}{ Measured concentrations } \\
\hline Sample & Sample date & $\begin{array}{l}\text { Test } \\
\text { Cond }\end{array}$ & TOC & $\begin{array}{l}\text { Total } \\
\text { Carbon }\end{array}$ & $\mathrm{CO}_{3}$ & $\mathrm{NO}_{3}$ & $\mathrm{PO}_{4}$ & $\mathrm{SO}_{4}$ & $\mathrm{Cl}$ & $\mathrm{F}$ & Al & $\mathrm{Ca}$ & $\mathrm{Cr}$ & Cs & $\mathrm{Cu}$ & $\mathrm{Fe}$ & $\mathrm{Hg}$ & $\mathrm{K}$ & $\mathrm{Mg}$ & $\mathrm{Mn}$ & $\mathrm{Na}$ & $\mathrm{Ni}$ & $\mathrm{Pb}$ & $\operatorname{Re}$ & $\mathrm{Si}$ & $\mathrm{Sn}$ & $\mathrm{Zn}$ & $\mathrm{Zr}$ \\
\hline & & & ug/ml & $\mathrm{ug} / \mathrm{ml}$ & & $\mathrm{ug} / \mathrm{ml}$ & --- & $\mathrm{ug} / \mathrm{ml}$ & $\mathrm{ug} / \mathrm{ml}$ & $\mathrm{ug} / \mathrm{ml}$ & $u g / m l$ & $\mathrm{ug} / \mathrm{ml}$ & $\mathrm{ug} / \mathrm{ml}$ & $u g / m l$ & $\mathrm{ug} / \mathrm{ml}$ & $\mathrm{ug} / \mathrm{ml}$ & $u g / m l$ & $u g / \mathrm{ml}$ & $u g / m l$ & $u g / \mathrm{ml}$ & $\mathrm{ug} / \mathrm{ml}$ & $u g / \mathrm{ml}$ & $u g / m l$ & $\mathrm{ug} / \mathrm{ml}$ & $\mathrm{ug} / \mathrm{ml}$ & $\mathrm{ug} / \mathrm{ml}$ & $\mathrm{ug} / \mathrm{ml}$ & $\mathrm{ug} / \mathrm{ml}$ \\
\hline 3 & 11/10/2003 7:30 & pretest & 2.7218 & 2.721809 & -- & 7.682 & -- & 5.704 & 1.034 & 1.84 & -- & -- & -- & -- & --- & -- & 0.029 & -- & -- & -- & --- & -- & -- & -- & -- & -- & -- & -- \\
\hline 40 & 11/12/2003 0:00 & 2.7 & 3.7127 & 3.712676 & -- & & --- & & & & --- & -- & --- & -- & --- & --- & --- & -- & -- & --- & -- & --- & -- & --- & --- & --- & -- & --- \\
\hline 52 & $11 / 12 / 200310: 30$ & 2.10 & 2.5359 & 2.535851 & -- & 23.36 & --- & 142.3 & 5.524 & 17.88 & --- & --- & --- & -- & --- & -- & 0.293 & -- & --- & --. & -.- & -- & --- & --- & --- & --- & --. & --. \\
\hline 98 & 11/13/2003 14:30 & $2.13 b$ & 2.7215 & 2.721539 & -- & 30.76 & --- & 184.2 & 9.421 & 34.27 & -.- & --- & --- & --- & --- & --- & 0.441 & --- & -.- & --- & --. & --- & --- & --- & --- & --- & --- & --- \\
\hline 131 & & S.3 & 2.5978 & 2.597814 & -- & 41.74 & --- & 317.2 & 12.43 & 43.94 & 8.84 & 9.41 & 0.29 & 0.637 & 0.275 & 5.45 & 0.845 & 3.435 & 0.645 & 0.28 & 1.59 & 1.33 & 0.16 & 0.828 & 12.41 & 0.111 & 0.465 & 0.047 \\
\hline \multicolumn{3}{|c|}{ CEMS 1 condensate } & $\mathrm{w} t \%$ & -- & $\mathrm{M}$ & $\mathrm{ug} / \mathrm{ml}$ & -- & $\mathrm{ug} / \mathrm{ml}$ & $\mathrm{ug} / \mathrm{ml}$ & $\mathrm{ug} / \mathrm{ml}$ & -- & -- & -- & -- & -- & -- & -- & -- & -- & -- & -- & -- & -- & -- & -- & -- & -- & -- \\
\hline 29 & 11/11/2003 18:30 & 2.1 & 0.0126 & -- & 0.906 & 0.283 & -- & 4.499 & 0.082 & 31.52 & --- & -- & -- & -- & -- & -- & -- & -- & -- & -- & -- & -- & -- & -- & -- & -- & -- & -- \\
\hline 99 & $11 / 13 / 200318: 30$ & $2.13 b$ & 0.0094 & -- & 0.183 & 2.829 & --- & 2.926 & 1.308 & 28.14 & --- & -- & --- & -- & -- & -- & -- & -- & -- & -- & -- & -- & -- & -- & -- & -- & -- & -- \\
\hline 132 & $11 / 14 / 200314: 00$ & S.3 & 0.0022 & -- & 0.262 & 2.829 & --- & 2.926 & 0.815 & 23.1 & -- & -- & -- & -- & -- & -- & -- & -- & -- & -- & -- & -- & -- & -- & -- & -- & -- & -- \\
\hline \multicolumn{3}{|c|}{ CEMS 2 condensate } & -- & -- & -- & $\mathrm{ug} / \mathrm{ml}$ & -- & $\mathrm{ug} / \mathrm{ml}$ & $\mathrm{ug} / \mathrm{ml}$ & $\mathrm{ug} / \mathrm{ml}$ & -- & --- & --- & -- & -- & -- & -- & -- & -- & --- & -- & -- & -- & --- & -- & --- & -- & --- \\
\hline 33 & 11/11/2003 19:30 & 2.2 & -- & --- & --- & 10.52 & --- & 37.25 & 0.082 & 0.501 & -- & --- & --- & --- & -- & --- & -- & -- & --- & --- & --- & --- & -- & --- & -- & -- & --- & --- \\
\hline 42 & $11 / 12 / 20032: 30$ & 2.7 & --- & -- & -- & 9.843 & -- & 39.11 & 0.082 & 0.092 & -- & -- & -- & -- & -- & -- & -- & -- & -- & -- & -- & -- & -- & -- & -- & -- & -- & -- \\
\hline 126 & $11 / 14 / 200310: 30$ & S.2 & --- & -- & -- & 0.283 & -- & 2.592 & 0.082 & 22.13 & -- & -- & -- & -- & -- & -- & -- & -- & -- & -- & -- & -- & -- & --- & --- & -- & -.- & -- \\
\hline 133 & 11/14/2003 14:00 & S.3 & --- & -- & --- & 6.749 & --- & 11.92 & 0.222 & 2.856 & --- & --- & --- & --. & --- & --- & -.- & --- & --- & --- & -.- & -- & --- & -- & --- & -- & -- & --- \\
\hline
\end{tabular}

[Master Analytical Data (ddt).ks]]Master RFA (2) 
CEMS 1 measures the off-gas composition at the outlet of the heated filter and upstream of the thermal oxidizer. The off-gas at this location contains various incompletely oxidized gas species, including $\mathrm{CO}, \mathrm{CH}_{4}$, and other hydrocarbons that were not speciated during this test but were measured as total hydrocarbons (THC). Investigatory grab sample tests also showed the presence of $\mathrm{NH}_{3}$ and $\mathrm{HCN}$ in the off-gas at this location. The water condensate collected in the CEMS 1 condenser contains levels of water-soluble or condensable hydrocarbons, as well as other water-soluble or condensable species. The CEM 1 condensate analysis indicates the presence of species in the off-gas that were not directly measured by CEMS $1 . \mathrm{CO}_{3}, \mathrm{NO}_{3}, \mathrm{PO}_{4}, \mathrm{SO}_{4}, \mathrm{Cl}$, and $\mathrm{F}$ were detected in the CEMS 1 condensate.

The CEMS 1 condensate analysis also indicates the amount of $\mathrm{NO}_{2}$ scrubbed in the condenser and thereby not detected by the CEM $1 \mathrm{NO}_{\mathrm{x}}$ analyzer. The nitrate in the condensate represents less than 2 ppm of the $\mathrm{NO}$ detected by the $\mathrm{NO}_{\mathrm{x}}$ analyzer, indicating that although some $\mathrm{NO}_{\mathrm{x}}$ was scrubbed in the CEMS 1 condensate, that amount was negligible compared to the amount of NO detected in the off-gas.

The CEMS 2 condensate could contain species that remain in the off-gas downstream of the thermal oxidizer and the wet scrubber. Levels of $\mathrm{NO}_{3}, \mathrm{PO}_{4}, \mathrm{SO}_{4}, \mathrm{Cl}$, and $\mathrm{F}$ were the same magnitude or less than the levels of those species found in the CEMS 1 condensate.

\subsubsection{Off-gas Composition}

The CEMS 1 was used to measure the off-gas composition at the outlet of the heated filter (upstream of the thermal oxidizer) and downstream of the oxidizer. The CEMS 2 was used to measure the off-gas composition at operator-selectable locations at the inlet of the carbon bed or the outlet of any of the three stages of the carbon bed.

5.3.3.1 Off-gas Composition at the Steam Reformer Heated Filter Outlet. The average off-gas composition (wet basis) at the outlet of the heated filter is shown in Table 5.3-5 for each test condition. The wet basis composition was calculated from the dry, as-measured composition by (a) correcting for zero and span calibration error/drift, and (b) normalizing the dry composition to a wet basis using the off-gas moisture content. The moisture content at the filter outlet location was not directly measured but was calculated from the fluidize bed input flow rates of fluidizing steam, evaporated water from the SBW and syrup feeds, and water from oxidation of the sugar in the syrup feed. The moisture content calculations are shown in water mass balance calculations (Section 5.4.2).

The off-gas measurements were continuous, and recorded data-reduced in 2-minute averages. The two-minute trend data are shown in Figure 5.3-1. The trends over time indicate graphically how the gas composition varied during the test series.

The 2-minute averages were averaged for each test condition. The various test conditions were of varying length, so the average composition for the test series is an average of all valid 2-minute data, equivalent to a time-weighted average of the test condition averages. The CEMS data were corrected for zero calibration error, zero drift, span calibration error, span drift, and interferences if the errors, drifts, and interferences were outside of acceptance limits. The calibration data are summarized in Appendix B. 
Table 5.3-5. Off-gas Composition (wet basis) at the outlet of the heated filter for the THOR carbonate test series.

\begin{tabular}{|c|c|c|c|c|c|c|c|c|c|c|c|}
\hline \multirow[b]{2}{*}{ Test } & \multicolumn{10}{|c|}{ Average composition for each test condition on a wet basis } & \multirow[b]{2}{*}{$\begin{array}{c}\text { Off-gas } \\
\text { MW }\end{array}$} \\
\hline & $\begin{array}{c}\mathrm{O}_{2} \\
\%\end{array}$ & $\begin{array}{c}\mathrm{CO}_{2}, \\
\% \\
\end{array}$ & $\begin{array}{c}\mathrm{CO} \\
\% \\
\end{array}$ & $\begin{array}{c}\mathrm{NO}, \\
\operatorname{ppm}(\mathrm{b})\end{array}$ & $\begin{array}{c}\mathrm{H}_{2}, \\
\%\end{array}$ & $\begin{array}{l}\mathrm{CH}_{4}, \\
\mathrm{ppm}\end{array}$ & $\begin{array}{c}\text { THC, } \\
\text { ppm }\end{array}$ & $\begin{array}{c}\mathrm{H}_{2} \mathrm{O}, \\
\% \\
\end{array}$ & $\begin{array}{c}\mathrm{N}_{2}, \\
\%\end{array}$ & $\begin{array}{c}\text { Total, } \\
\%\end{array}$ & \\
\hline 0.5 & 0.85 & 6.91 & 1.17 & 500 & 4.4 & 1,372 & 1,937 & 60.5 & 25.7 & 100.0 & 21.9 \\
\hline 1.1 & 0.61 & 7.83 & 1.01 & 396 & 6.3 & 1,489 & 2,137 & 59.9 & 24.2 & 100.0 & 21.6 \\
\hline 2.1 & 0.51 & 6.80 & 0.91 & 239 & 5.8 & 1,471 & 1,987 & 65.8 & 19.8 & 100.0 & 21.0 \\
\hline 2.2 & 0.54 & 7.70 & 1.02 & 548 & 5.4 & 1,291 & 1,837 & 62.7 & 24.9 & 100.0 & 21.8 \\
\hline 2.3 & 0.55 & 7.93 & 1.08 & 1,032 & 4.7 & 1,056 & 1,776 & 58.4 & 28.2 & 100.0 & 22.3 \\
\hline 2.4 & 0.52 & 6.12 & 0.86 & 1,444 & 2.5 & 1,051 & 1,773 & 64.9 & 24.5 & 100.0 & 21.8 \\
\hline 2.5 & 0.55 & 6.22 & 0.85 & 1,512 & 2.3 & 940 & 1,955 & 65.0 & 26.0 & 100.0 & 22.0 \\
\hline 2.6 & 0.64 & 6.08 & 1.03 & 1,160 & 3.1 & 1,144 & 2,853 & 64.8 & 24.0 & 100.0 & 21.7 \\
\hline 2.7 & 0.67 & 7.37 & 1.19 & 1,254 & 4.3 & 1,578 & 3,443 & 60.0 & 26.4 & 100.0 & 22.1 \\
\hline 2.8 & 0.61 & 6.87 & 0.95 & 1,195 & 3.7 & 1,491 & 2,033 & 62.7 & 24.9 & 100.0 & 21.9 \\
\hline 2.9 & 0.65 & 6.47 & 0.92 & 1,918 & 2.9 & 1,418 & 2,034 & 63.7 & 25.2 & 100.0 & 21.9 \\
\hline 2.10 . & 0.61 & 6.35 & 0.89 & 1,795 & 3.4 & 1,873 & 2,400 & 64.3 & 24.7 & 100.0 & 21.8 \\
\hline 2.11 & 0.65 & 5.97 & 0.78 & 1,607 & 3.4 & 2,208 & 1,970 & 62.6 & 26.4 & 100.0 & 21.8 \\
\hline 2.12 & 0.62 & 4.98 & 0.83 & 641 & 3.6 & 2,384 & 2,015 & 62.2 & 28.9 & 100.0 & 21.5 \\
\hline $2.13 \mathrm{a}$ & 0.57 & 4.31 & 0.57 & 419 & 2.9 & 1,453 & 1,439 & 66.0 & 25.5 & 100.0 & 21.3 \\
\hline $2.13 b$ & 0.55 & 5.29 & 0.67 & 568 & 3.9 & 1,512 & 1,635 & 62.8 & 29.2 & 100.0 & 21.8 \\
\hline 3.1 & 0.58 & --- & --- & --- & --- & --- & --- & 63.0 & 28.3 & 100.0 & 21.4 \\
\hline 3.2 & 0.58 & 4.18 & 0.63 & 460 & 1.5 & 1,312 & 1,556 & 64.5 & 25.9 & 100.0 & 21.1 \\
\hline 3.3 & 0.58 & 4.85 & 0.78 & 734 & 3.6 & 1,327 & 1,467 & 65.1 & 26.2 & 100.0 & 21.5 \\
\hline 3.4 & 0.54 & 4.50 & 0.77 & 456 & 2.7 & 1,215 & 1,402 & 65.4 & 24.5 & 100.0 & 21.3 \\
\hline S.1 & 0.45 & 5.36 & 0.65 & 230 & 3.3 & 1,138 & 1,431 & 63.8 & 26.7 & 100.0 & 21.6 \\
\hline S. 3 & 0.39 & 5.43 & 0.39 & 479 & 3.1 & 1,017 & 1,533 & 64.8 & 25.5 & 100.0 & 21.6 \\
\hline S. 3 & 0.43 & 6.63 & 0.52 & 513 & 2.3 & 953 & --- & 64.0 & 28.1 & 100.0 & 20.2 \\
\hline Overall Average & 0.60 & 5.90 & 0.83 & 916 & 3.6 & 1,576 & 1,928 & 63.0 & 26.1 & 100.0 & 21.6 \\
\hline STD DEV & 0.23 & 1.29 & 0.36 & 590 & 1.2 & 446 & 487 & 2.8 & 2.8 & 0.0 & 1.1 \\
\hline
\end{tabular}

Notes:

1. $\mathrm{CO}_{2}$ values are averages from both Nova analyzers. Data has been corrected for zero drift for each

2. Ametek NO data has been corrected for zero drift for each calibration period and has been corrected for THC interference.

3. The $\mathrm{N}_{2}$ was determined by difference. 

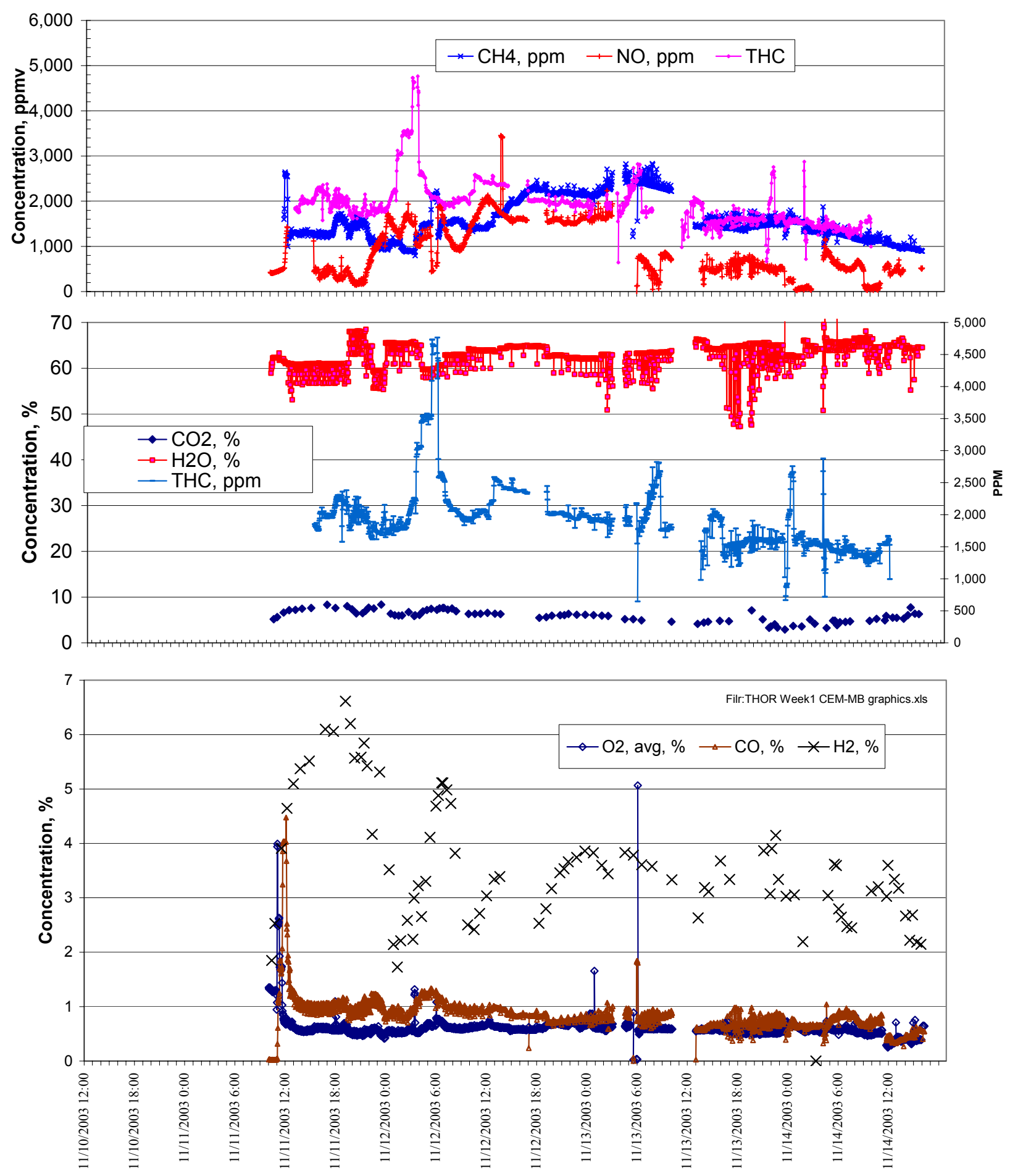

Figure 5.3-1. Wet basis concentrations of $\mathrm{CH}_{4}, \mathrm{NO}, \mathrm{CO}_{2}, \mathrm{H}_{2} \mathrm{O}, \mathrm{O}_{2}, \mathrm{CO}$, THC, and $\mathrm{H}_{2}$ in the off-gas upstream of the oxidizer for the THOR carbonate test series. 
Measuring the off-gas composition for this off-gas that contains not only moisture and acid gases but also incompletely reacted hydrocarbons and other reduced gas species is especially challenging for data quality. The wide range of hydrocarbons and other reduced gas species such as $\mathrm{HCN}$ and $\mathrm{NH}_{3}$ can interfere with measurement techniques, which are industry standards worldwide for combustion gases. Even after sample gas conditioning, residual amounts of condensable hydrocarbons gradually impaired readings as optical windows and sensors slowly became coated with condensed hydrocarbons.

The affects of these various interferences were mitigated by frequent (daily or more often) calibrations, during which calibration factors were recorded. When the calibration factors exceeded EPA acceptance criteria for air emission compliance monitoring, the data were adjusted during post-test data reduction.

All data were measured on a dry basis, after moisture in the off-gas was condensed. The dry-basis as-measured data (corrected for calibration error and interferences when applicable) were adjusted to a wet basis to provide results that represented the actual concentrations of the off-gas inside the system. The moisture content was determined by mass balance using the input steam reformer flow rates of gases, fluids including the SBW simulant and the syrup, and accounting for water from oxidizing the reductants.

The wet-basis $\mathrm{O}_{2}$ concentration was measured between $0.5-1 \mathrm{vol} \%$. The measured level of free $\mathrm{O}_{2}$ does not indicate that there was much $\mathrm{O}_{2}$ in the steam reformer off-gas-instead, it indicates that there was a small amount of air in-leakage into the off-gas system or CEMS downstream of the steam reformer, where the gas temperature was cool enough to limit reactions of the in-leaked $\mathrm{O}_{2}$ with incompletely oxidized gas species such as $\mathrm{H}_{2}$ or $\mathrm{CH}_{4}$ in the steam reformer off-gas. About this level of free $\mathrm{O}_{2}$ is typically detected in the test system at the outlet of the heated filter during system leak checks, when no source of $\mathrm{O}_{2}$ is fed to the system. A free $\mathrm{O}_{2}$ concentration of $0.5 \%$ represents an air leak of $2.5 \%$ of the initial steam reformer gas flow rate.

No zero, span, or interference corrections were necessary for the $\mathrm{O}_{2}$ measurements. In addition to the measured $\mathrm{O}_{2}$ levels that were due to small air in leakage, a small amount of measured $\mathrm{O}_{2}$, perhaps $0.1-0.2 \%$, was due to $\mathrm{NO}_{\mathrm{x}}$ interference on the paramagnetic $\mathrm{O}_{2}$ measurement. While this interference is common, it is rarely corrected and was not corrected in these tests, because the interference was very small.

The Ametek $\mathrm{NO}_{\mathrm{x}}$ analyzer was configured to independently detect both $\mathrm{NO}$ and $\mathrm{NO}_{2}$ using dispersive ultraviolet (DUV) detection. While this analyzer is used reliably worldwide for combustion off-gas measurements, and is impervious to the kinds of interferences experienced by chemiluminescent detection used to measure $\mathrm{NO}_{\mathrm{x}}$ concentrations in the prior steam reformer tests (Marshall 2000a and Marshall 2000c), it experienced other interferences during the steam reforming tests. The levels of incompletely oxidized gas species, which were higher in the steam reformer off-gas than in off-gas from typical industrial combustion processes, caused a positive bias on the $\mathrm{NO}$ and $\mathrm{NO}_{2}$ measurements.

The NO measurement was successfully corrected for this bias by subtracting a calibrated value of the interference from the as-measured $\mathrm{NO}$ values. The $\mathrm{NO}_{2}$ measurement was too strongly affected by the interference (compared to the expected $\mathrm{NO}_{2}$ values) and could not be corrected to provide useable results. Because of this interference, no useable $\mathrm{NO}_{2}$ measurements were obtained during the carbonate test series at the filter outlet location. The NO measurements are used in this test series to represent total $\mathrm{NO}_{\mathrm{x}}$ levels. Repeated steam reforming test results from the Phase 1 and Phase 2 tests have shown that, under the reducing conditions that exist in the steam reformer during carbonate tests, $\mathrm{NO}_{2}$ levels are a small fraction of the NO. During the Phase 1 THOR steam reforming test, the $\mathrm{NO}_{2}$ concentration averaged $8 \%$ of the NO concentration (Marshall 2003a). 
The NO measurement also experienced zero drift during the tests, which was corrected using calibration data. Because of the magnitude of the zero and interference corrections, the accuracy of the corrected NO data is about $\pm 25 \%$ of the measured values, depending on the test period and the magnitude of the measured values.

$\mathrm{CO}_{2}$ was measured using two analyzers, an existing NOVA $\mathrm{CO}_{2} / \mathrm{H}_{2}$ analyzer and also a NOVA $\mathrm{CO}_{2} / \mathrm{H}_{2}$ analyzer loaned by NOVA for the duration of the THOR tests. NOVA loaned the second analyzer because the existing analyzer failed to communicate with the PLC just before the THOR test series. The output of the existing analyzer was manually recorded; the output of the loaner analyzer was logged by the PLC and also manually recorded. The output of the loaner analyzer exceeded the output range, and so the only useable $\mathrm{CO}_{2}$ data from the loaner analyzer were the manually recorded data. The data used in this report are the average of the $\mathrm{CO}_{2}$ measurements from both analyzers.

$\mathrm{CO}_{2}$ measurements by the existing analyzer were corrected for a zero shift for which the analyzer could not be adjusted. No span or bias adjustments were made to the $\mathrm{CO}_{2}$ measurements from the existing analyzer. No adjustments were required for the loaner $\mathrm{CO}_{2}$ analyzer. The calibrations from both analyzers (after applicable adjustments) were within the EPA acceptance limits. The two analyzers typically agreed within $5 \%$ of the full-scale value of the analyzers. This resulted in a potential error of the measured values of about $\pm 20 \%$ of the reported values.

Like $\mathrm{CO}_{2}, \mathrm{H}_{2}$ was measured using the two NOVA $\mathrm{CO}_{2} / \mathrm{H}_{2}$ analyzers. The $\mathrm{H}_{2}$ data required no zero or span corrections, and the $\mathrm{CO}_{2}$ interference on the $\mathrm{H}_{2}$ reading was low enough that no correction was necessary. The $\mathrm{H}_{2}$ data from the two analyzers were averaged. Considering calibration errors of up to $10 \%$ of the full-scale values, the accuracy of the $\mathrm{H}_{2}$ readings was about $\pm 20 \%$ of the average reading.

The CO readings were accurate within EPA's acceptance criteria without any adjustments. The $\mathrm{CO}$ measurements were accurate to within about $\pm 10 \%$ of the measured readings.

The $\mathrm{CH}_{4}$ analyzer experienced zero calibration error because of interference from other incompletely reacted hydrocarbons. Condensable hydrocarbons tended to discolor the optical windows. After post-test cleaning, zero error was within calibratable ranges. The zero error was corrected mathematically for data collected during the test series. Some of the time, the $\mathrm{CH}_{4}$ output to the PLC was pegged at about $1.0 \% \mathrm{CH}_{4}$. Considering the occurrences of pegged data and the magnitude of the zero correction, the $\mathrm{CH}_{4}$ data are accurate to within about $\pm 20 \%$ of the measured values.

5.3.3.2 Off-gas Composition Downstream of the Thermal Oxidizer and Scrubber. The average off-gas composition (wet basis) downstream of the thermal oxidizer and scrubber is shown in Table 5.3-6 for each test condition. All of the CEMS 2 measurements were made on a dry basis, after condensing off-gas moisture from the off-gas, except for the $\mathrm{O}_{2}$ measurement. The $\mathrm{O}_{2}$ measurement was made using a heated extractive $\mathrm{ZrO}_{2}$ electrochemical sensor, on a wet basis, for thermal oxidizer process control. Except for the $\mathrm{O}_{2}$ measurement, the wet basis composition was calculated from the dry, asmeasured composition by (a) correcting for zero and span calibration error/drift and (b) normalizing the dry composition to a wet basis using the off-gas moisture content. The $\mathrm{O}_{2}$ measurement required no calibration corrections and was measured on a wet basis.

The moisture content downstream of the scrubber was not directly measured, but was calculated from a dew point calculation at the temperature and absolute pressure of the off-gas exiting the wet scrubber. The off-gas moisture content downstream of the scrubber is defined by the scrubber outlet gas dew point (except for any water aerosols that remain in the off-gas downstream of the mist eliminator, that could bias the moisture content upward slightly if they are evaporated in the reheater). The moisture content calculations are shown in water mass balance calculations (Section 5.4.2). 
Table 5.3-6. Off-gas Composition (wet basis) downstream of the oxidizer and scrubber for the THOR carbonate test series.

\begin{tabular}{|c|c|c|c|c|c|c|c|c|c|c|c|}
\hline \multirow[b]{2}{*}{ Test condition } & \multicolumn{10}{|c|}{ Compositon, wet basis } & \multirow[b]{2}{*}{$\begin{array}{c}\text { Off-gas } \\
\text { MW }\end{array}$} \\
\hline & $\mathrm{O}_{2}, \%$ & $\begin{array}{c}\mathrm{CO}_{2}, \\
\% \\
\end{array}$ & $\begin{array}{l}\mathrm{CO}, \\
\mathrm{ppm}\end{array}$ & $\begin{array}{l}\text { NO, } \\
\text { ppm }\end{array}$ & $\begin{array}{l}\mathrm{NO}_{2}, \\
\text { ppm }\end{array}$ & $\begin{array}{l}\mathrm{NO}_{\mathrm{x}}, \\
\mathrm{ppm}\end{array}$ & $\begin{array}{c}\mathrm{H} 2 \mathrm{O}, \\
\% \\
\end{array}$ & $\begin{array}{l}\mathrm{HCl}, \\
\mathrm{ppm}\end{array}$ & $\begin{array}{c}\mathrm{N}_{2} \\
\% \\
\end{array}$ & Total, $\%$ & \\
\hline 0.5 & 3.00 & 4.53 & 7 & --- & -- & --- & 39.9 & 0.4 & 52.6 & 100.0 & 24.9 \\
\hline 1.1 & 3.00 & 4.55 & 8 & --- & --- & --- & 40.0 & 0.3 & 52.5 & 100.0 & 24.9 \\
\hline 2.1 & 3.00 & 4.64 & 8 & --- & --- & --- & 39.6 & 0.5 & 52.8 & 100.0 & 24.9 \\
\hline 2.2 & 3.00 & 4.63 & 7 & --- & --- & --- & 39.7 & 0.7 & 52.7 & 100.0 & 24.9 \\
\hline 2.3 & 3.00 & 4.68 & 7 & --- & --- & --- & 39.6 & 0.7 & 52.7 & 100.0 & 24.9 \\
\hline 2.4 & 3.00 & 4.52 & 7 & --- & --- & --- & 39.5 & 1.2 & 52.9 & 100.0 & 24.9 \\
\hline 2.5 & 3.00 & 4.56 & 8 & --- & --- & --- & 39.4 & 1.5 & 53.0 & 100.0 & 24.9 \\
\hline 2.6 & 3.00 & 3.60 & 7 & --- & --- & --- & 39.0 & 1.4 & 54.4 & 100.0 & 24.8 \\
\hline 2.7 & 3.00 & 4.54 & 8 & --- & --- & --- & 39.6 & 1.3 & 52.8 & 100.0 & 24.9 \\
\hline 2.8 & 3.00 & 4.62 & 8 & --- & --- & --- & 39.3 & 1.3 & 53.0 & 100.0 & 24.9 \\
\hline 2.9 & 3.00 & 4.53 & 9 & --- & --- & --- & 39.1 & 1.2 & 53.4 & 100.0 & 24.9 \\
\hline 2.10 . & 3.00 & 3.84 & 5 & --- & --- & --- & 43.0 & 0.5 & 50.1 & 100.0 & 24.4 \\
\hline 2.11 & 2.95 & 4.21 & 2 & --- & --- & --- & 43.4 & -0.2 & 49.5 & 100.0 & 24.5 \\
\hline 2.12 & 2.00 & 4.51 & 3 & --- & --- & --- & 41.0 & -0.2 & 52.5 & 100.0 & 24.7 \\
\hline $2.13 a$ & 2.00 & 4.55 & 8 & --- & --- & --- & 39.6 & -0.3 & 53.8 & 100.0 & 24.8 \\
\hline $2.13 b$ & 2.00 & 4.46 & 10 & --- & --- & --- & 40.2 & 0.0 & 53.3 & 100.0 & 24.8 \\
\hline 3.1 & 2.00 & 4.24 & 19 & --- & --- & --- & 40.8 & 0.2 & 52.9 & 100.0 & 24.7 \\
\hline 3.2 & 2.00 & 3.64 & 31 & --- & --- & --- & 40.5 & 0.5 & 53.8 & 100.0 & 24.6 \\
\hline 3.3 & 2.00 & 2.23 & 19 & 116 & 13 & 129 & 41.0 & 0.3 & 54.8 & 100.0 & 24.3 \\
\hline 3.4 & 2.00 & 2.76 & 15 & 104 & 10 & 114 & 41.3 & 0.2 & 53.9 & 100.0 & 24.4 \\
\hline S. 1 & 2.00 & 4.27 & 6 & 71 & 1 & 71 & 41.5 & 0.4 & 52.2 & 100.0 & 24.6 \\
\hline S. 3 & 2.00 & 4.17 & 7 & 71 & -9 & 62 & 42.2 & 0.3 & 51.6 & 100.0 & 24.5 \\
\hline S. 3 & 2.00 & 4.53 & 7 & 72 & -2 & 70 & 41.0 & 0.4 & 52.4 & 100.0 & 24.7 \\
\hline Weighted average & 2.51 & 4.25 & 8 & 88 & 4 & 92 & 40.8 & 0.3 & 52.5 & 100.0 & 24.7 \\
\hline Std dev & 0.50 & 0.85 & 13 & 21 & 7 & 28 & 1.8 & 0.6 & 1.9 & 0.0 & 0.2 \\
\hline
\end{tabular}

\begin{tabular}{|lrrrrrr|}
\hline Dry, 7\% $\mathrm{O}_{2}$ basis & 12 & --- & --- & --- & --- & 0.5 \\
HWC MACT limit $\left(\right.$ dry, $\left.7 \% \mathrm{O}_{2}\right)$ & 100 & --- & --- & --- & --- & 21 \\
\hline$\%$ of the HWC MACT limit & 12 & --- & --- & --- & --- & 2 \\
\hline
\end{tabular}

Notes: $\quad 1$. The $\mathrm{CO}_{2}$ values are the averages from both Nova analyzers.

2. The $\mathrm{N}_{2}$ values were determined by difference. 
The off-gas measurements were continuous, and recorded in the data reduction database in 2minute averages. The 2-minute averages were averaged for each test condition. The various test conditions were of varying length, so the average composition for the test series is an average of all valid 2-minute data, equivalent to a time-weighted average of the test condition averages.

The average CEM 2 measurements for $\mathrm{CO}$ and $\mathrm{HCl}$ were converted to a dry, $7 \% \mathrm{O}_{2}$ basis for comparison to the HWC MACT standards. The $\mathrm{CO}$ and $\mathrm{HCl}$ levels averaged about $1 / 10^{\text {th }}$ or less of the MACT limits.

\subsection{Fate of Feed Components}

Input and output mass balances were performed to determine the fate of feed components. Key calculations include (a) determination of nitrate and $\mathrm{NO}_{\mathrm{x}}$ destruction, (b) utilization of the organic reductants used to reduce $\mathrm{NO}_{\mathrm{x}}$, and (c) the fate of and mass balance closure for the main SBW simulant components ( $\mathrm{Na}, \mathrm{Al}$, and $\mathrm{K})$, hazardous metals and radionuclide surrogates $(\mathrm{Cr}, \mathrm{Hg}, \mathrm{Pb}, \mathrm{Cs}$, and $\mathrm{Re})$, and anions in the SBW simulant.

\subsubsection{NO $\mathrm{NO}_{\mathrm{x}}$ Destruction}

As the SBW simulant and reductants are fed to the steam reformer, the nitrates react with the reductants under steam reformer conditions, converting the $\mathrm{N}$ in the nitrates to predominantly $\mathrm{N}_{2}$. Table 5.4-1 shows $\mathrm{NO}_{\mathrm{x}}$ destruction based on the amount of $\mathrm{NO}$ and $\mathrm{NO}_{2}$ in the off-gas compared to the amount of nitrate in the feed. $\mathrm{NO}_{\mathrm{x}}$ destruction trends during the test series are shown in Figure 5.4-1. The calculated steam reformer $\mathrm{NO}_{\mathrm{x}}$ destruction averaged about $93 \%$ (based on $\mathrm{NO}$ ) for the test series. This average $\mathrm{NO}_{\mathrm{x}}$ destruction is lower than observed during the Phase 1 tests (which averaged $>98 \%$ ), perhaps because of the uncertainty in the NO measurements at the CEMS 1 sample location, or because of other operational differences such as less reducing potential, no iron catalyst, or different carbons.

$\mathrm{NO}_{\mathrm{x}}$ destruction was calculated several ways. $\mathrm{NO}$ was measured at the steam reformer filter outlet, but the $\mathrm{NO}_{2}$ and total $\mathrm{NO}_{\mathrm{x}}$ measurements at that sample location were not valid. $\mathrm{NO}_{\mathrm{x}}$ destruction at the outlet of the steam reformer filter was determined based on $\mathrm{NO}$ alone. $\mathrm{NO}_{\mathrm{x}}$ destruction theory and empirical data both indicate that, under the steam reformer conditions during the THOR carbonate test, any residual $\mathrm{NO}_{2}$ is generally small compared to residual NO. During the Phase 1 test, the measured $\mathrm{NO}_{2}$ levels averaged $8 \%$ of the measured $\mathrm{NO}$ levels. The steam reformer $\mathrm{NO}_{\mathrm{x}}$ destruction efficiency based on $\mathrm{NO}$ alone is considered a valid indicator of the total $\mathrm{NO}_{\mathrm{x}}$ destruction. The $\mathrm{NO}_{\mathrm{x}}$ destruction calculations do not account for any $\mathrm{HCN}, \mathrm{N}_{2} \mathrm{O}, \mathrm{NH}_{3}$, or other reduced forms of nitrogen-bearing gas species.

$\mathrm{NO}_{\mathrm{x}}$ destruction was also determined for the entire steam reforming test system, using the NO and $\mathrm{NO}_{\mathrm{x}}$ measurements downstream of the thermal oxidizer and wet scrubber. These $\mathrm{NO}_{\mathrm{x}}$ destruction values show how a representative complete, integrated system performs to destroy nitrates in the feed and $\mathrm{NO}_{\mathrm{x}}$ in the off-gas. When CEMS $2 \mathrm{NO}_{\mathrm{x}}$ data were available during the last day of the test series, the overall system $\mathrm{NO}_{\mathrm{x}}$ destruction ranged between $93-97 \%$, compared to a range of $92-97 \%$ for the steam reformer $\mathrm{NO}_{\mathrm{x}}$ destruction (based on $\mathrm{NO}$ ). The thermal oxidizer seems to destroy $\mathrm{NO}_{\mathrm{x}}$ in the input gas when the input $\mathrm{NO}_{\mathrm{x}}$ levels are higher than about 200-500 ppm (wet basis). This is because reactions in the thermal oxidizer tend to approach chemical and kinetic equilibrium for $\mathrm{NO}_{\mathrm{x}}$ in the outlet gas, regardless of the input $\mathrm{NO}_{\mathrm{x}}$ levels. 
Table 5.4-1. $\mathrm{NO}_{\mathrm{x}}$ destruction for the THOR carbonate test series.

\begin{tabular}{|c|c|c|c|c|c|c|c|c|c|c|c|c|c|c|}
\hline \multirow[b]{2}{*}{ Test condition } & \multirow[b]{2}{*}{$\begin{array}{c}\text { Simulant } \\
\text { feedrate, } \\
1 / \mathrm{hr}\end{array}$} & \multirow[b]{2}{*}{$\begin{array}{l}\mathrm{NO}_{\mathrm{x}} \\
\text { feedrate, } \\
\text { scfm }\end{array}$} & \multicolumn{4}{|c|}{ NO destruction at the filter outlet on a wet basis } & \multicolumn{8}{|c|}{$\mathrm{NO}_{\mathrm{x}}$ destruction after the thermal oxidizer } \\
\hline & & & $\begin{array}{c}\text { Off-gas flowrate at } \\
\text { the filter outlet, } \\
\text { wet scfm }\end{array}$ & $\begin{array}{c}\mathrm{NO}_{\mathrm{x}} \\
\text { MTEC, wet } \\
\text { ppm }\end{array}$ & $\begin{array}{l}\mathrm{NO}, \\
\mathrm{ppm}\end{array}$ & $\begin{array}{c}\text { Steam reformer } \\
\text { NO destruction, } \\
\%\end{array}$ & \begin{tabular}{|c|} 
Off-gas \\
flowrate at the \\
carbon bed, wet \\
scfm \\
\end{tabular} & $\begin{array}{l}\mathrm{NO}_{\mathrm{x}} \\
\text { MTEC, wet } \\
\text { ppm }\end{array}$ & $\begin{array}{l}\mathrm{NO}, \\
\text { wet } \\
\mathrm{ppm}\end{array}$ & $\begin{array}{c}\mathrm{NO}_{2}, \\
\text { wet } \\
\mathrm{ppm}\end{array}$ & $\begin{array}{c}\mathrm{NO}_{\mathrm{x}}, \\
\text { wet ppm }\end{array}$ & $\begin{array}{c}\text { Total system } \\
\text { NO destruction, } \\
\% \\
\end{array}$ & $\begin{array}{c}\text { Total system } \\
\text { NO }_{\mathbf{x}} \\
\text { destruction, \% }\end{array}$ & $\begin{array}{c}\mathrm{NO}_{\mathrm{x}} \text { destruction } \\
\text { by thermal } \\
\text { oxidizer, } \%\end{array}$ \\
\hline 0.5 & 4.70 & 0.266 & 18 & 14,241 & 444 & 96.6 & 117 & 7,012 & --- & --- & --- & --- & --- & --- \\
\hline 1.1 & 5.41 & 0.306 & 19 & 15,560 & 397 & 97.5 & 121 & 2,521 & --- & --- & --- & --- & -- & --- \\
\hline 2.1 & 6.00 & 0.339 & 18 & 18,058 & 244 & 98.7 & 123 & 2,751 & --- & --- & --- & -- & -- & --- \\
\hline 2.2 & 6.00 & 0.339 & 19.4 & 17,217 & 520 & 97.0 & 122 & 2,764 & -- & --- & --- & -- & -- & -- \\
\hline 2.3 & 6.00 & 0.339 & 20.8 & 16,064 & 1,023 & 93.6 & 123 & 2,750 & --- & --- & --- & -- & -- & --- \\
\hline 2.4 & 6.00 & 0.339 & 18.7 & 17,828 & 1,444 & 91.9 & 123 & 2,754 & --- & --- & --- & -- & -- & --- \\
\hline 2.5 & 6.00 & 0.339 & 18.7 & 17,846 & 1,507 & 91.6 & 123 & 2,745 & --- & --- & --- & -- & --- & --- \\
\hline 2.6 & 6.00 & 0.339 & 19.5 & 17,099 & 1,185 & 93.1 & 126 & 2,695 & --- & --- & --- & --- & --- & --- \\
\hline 2.7 & 5.81 & 0.328 & 21.1 & 15,384 & 1,246 & 92.1 & 126 & 2,602 & --- & --- & --- & -- & -- & --- \\
\hline 2.8 & 6.00 & 0.339 & 19.4 & 17,227 & 1,194 & 93.1 & 125 & 2,713 & --- & --- & --- & -- & -- & --- \\
\hline 2.9 & 6.00 & 0.339 & 19.0 & 17,511 & 1,912 & 89.1 & 123 & 2,743 & --- & --- & --- & --- & --- & --- \\
\hline 2.10 & 6.00 & 0.339 & 19.5 & 17,103 & 1,796 & 90.0 & 130 & 2,610 & --- & --- & --- & --- & -- & --- \\
\hline 2.11 & 5.21 & 0.295 & 20.4 & 14,296 & 1,607 & 88.2 & 131 & 2,255 & --- & --- & --- & -- & -- & --- \\
\hline 2.12 & 4.99 & 0.282 & 21.7 & 12,874 & 679 & 94.7 & 116 & 2,434 & --- & --- & --- & -- & --- & --- \\
\hline $2.13 a$ & 4.50 & 0.255 & 22.8 & 11,017 & 412 & 96.2 & 117 & 2,169 & --- & --- & --- & -- & -- & --- \\
\hline $2.13 b$ & 4.50 & 0.255 & 24.2 & 10,483 & 568 & 94.5 & 120 & 2,116 & --- & --- & --- & -- & -- & --- \\
\hline 3.1 & --- & --- & 21.7 & -- & --- & -- & --- & --- & -- & --- & --- & -- & - & --- \\
\hline 3.2 & 1.62 & 0.092 & 23.0 & 3,815 & 885 & 89.0 & 115 & 806 & --- & --- & --- & -- & -- & --- \\
\hline 3.3 & 4.00 & 0.226 & 25.6 & 8,776 & 743 & 91.5 & 114 & 1,979 & 116 & 13 & 129 & 94.0 & 93.3 & 21.3 \\
\hline 3.4 & 4.00 & 0.226 & 25.6 & 8,782 & 446 & 94.9 & 116 & 1,947 & 104 & 10 & 114 & 94.6 & 94.1 & -15.5 \\
\hline S1 & 4.00 & 0.226 & 26.4 & 8,509 & 220 & 97.4 & 115 & 1,959 & 71 & 1 & 71 & 96.3 & 96.4 & -41.2 \\
\hline S2 & 4.00 & 0.226 & 24.6 & 9,127 & 480 & 94.7 & 111 & 2,033 & 71 & -9 & 62 & 96.5 & 97.0 & 43.4 \\
\hline S3 & 4.00 & 0.226 & 24.3 & 9,249 & 512 & 94.5 & 118 & 1,920 & 72 & -2 & 70 & 96.3 & 96.3 & 33.6 \\
\hline Overall Average & 4.82 & 0.273 & 21.4 & 12,872 & 968 & 93.2 & 121 & 2,752 & 88 & 4 & 92 & 95.5 & 95.3 & 8.3 \\
\hline STD DEV & 1.22 & 0.069 & 2.6 & 3,981 & 580 & 3.4 & 7 & 21,353 & 21.1 & 7.2 & 27.5 & 1.1 & 1.4 & 35.5 \\
\hline
\end{tabular}

1. The $\mathrm{NO}_{3}$ concentration in the simulant is $5.33 \mathrm{M}$.

2. The CEMS $2 \mathrm{NO}_{\mathrm{x}}$ analyzer was not operational until the last day of the test series.

3. $\mathrm{MTEC}=$ Maximum theoretical emission concentration, calculated from the input NOx feedrate and the off-gas flowrate. 


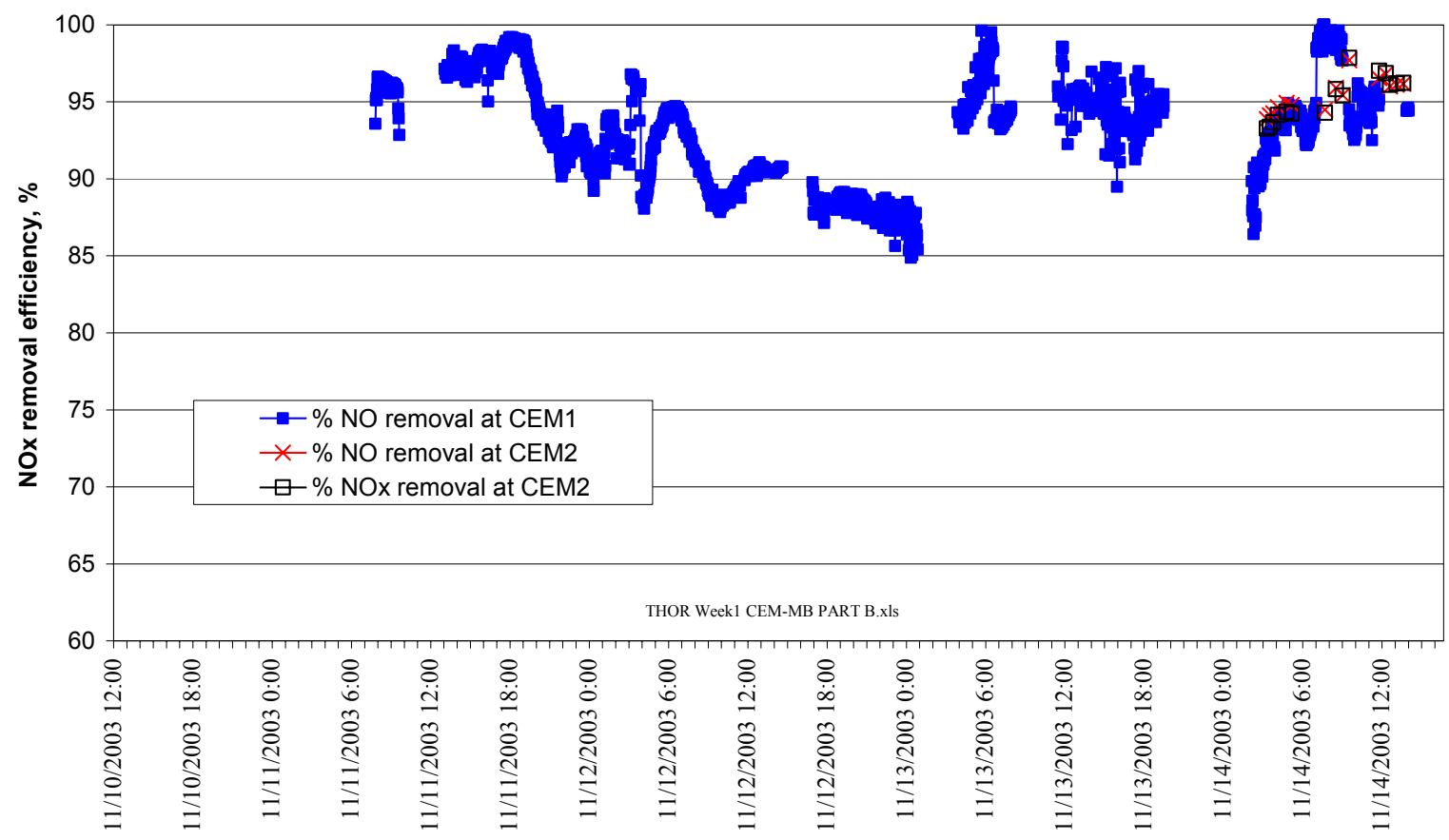

Figure 5.4-1. $\mathrm{NO}_{\mathrm{x}}$ destruction for the THOR carbonate test series.

\subsubsection{Reductant Utilization}

Organic reductants used during this test series were sugar and solid carbon. During different test conditions, they were fed to the reformer in different proportions and with varying stoichiometric ratios with respect to nitrates in the SBW simulant and added $\mathrm{O}_{2}$. Carbon mass balance closure and distribution to the output streams are shown in Table 5.4-2.

Sources of carbon in the system were the sugar and the solid carbon additive. These reductants were heated (and thermally decomposed in the case of sugar) and reacted with sources of oxygen (nitrates, steam, and oxygen) in the steam reformer. While the stoichiometry was varied for different test conditions, the overall stoichiometry was always reductant-rich to encourage $\mathrm{NO}_{\mathrm{x}}$ destruction.

The overall carbon mass balance closure (total output carbon divided by total input carbon) was 0.89 , indicating that less carbon was measured in the output streams than in the input streams. The largest output carbon stream was the off-gas $\mathrm{CO}_{2}$. Potential error in the measurement of the off-gas $\mathrm{CO}_{2}$ was the greatest source of error in the overall carbon balance. 
Table 5.4-2. Carbon distribution for the THOR carbonate test series (at CEM 1).

\begin{tabular}{|c|c|c|c|c|c|c|c|c|c|c|c|}
\hline & \multicolumn{3}{|c|}{ Carbon mass inputs, $\mathrm{kg}$} & \multicolumn{7}{|c|}{ Carbon mass outputs, $\mathrm{kg}$} \\
\hline & & \multirow[b]{2}{*}{$\begin{array}{l}\text { From } \\
\text { syrup }\end{array}$} & \multirow[b]{2}{*}{$\begin{array}{l}\text { Total solid } \\
\text { carbon } \\
\text { additive }\end{array}$} & \multirow{2}{*}{$\begin{array}{c}\text { Estimated } \\
\text { carbon from } \\
\text { solid carbon } \\
\text { additive }\end{array}$} & \multicolumn{3}{|c|}{ Solid outputs } & \multirow[b]{2}{*}{$\begin{array}{l}\text { Scrub } \\
\text { water }\end{array}$} & \multicolumn{3}{|c|}{ Off-gas at the filter outlet } \\
\hline & & & & & $\begin{array}{c}\text { Bed } \\
\text { product }\end{array}$ & $\begin{array}{l}\text { Cyclone } \\
\text { samples }\end{array}$ & $\begin{array}{l}\text { Filter } \\
\text { catch }\end{array}$ & & $\mathrm{CO}_{2}$ & $\mathrm{CO}$ & THC \\
\hline \multirow[b]{2}{*}{$\begin{array}{l}\text { Totals of } \\
\text { individual } \\
\text { streams }\end{array}$} & $\begin{array}{l}\text { Total organic } \\
\text { (reduced) carbon } \\
\text { (TOC) }\end{array}$ & 61 & 59.4 & 57.6 & 0.91 & 0.50 & 9.1 & 0.0 & 0.00 & 10.5 & 2.0 \\
\hline & $\begin{array}{l}\text { Total inorganic } \\
\text { (fully oxidized) } \\
\text { carbon (TIC) }\end{array}$ & 0 & 0 & 0 & 1.3 & 0.05 & 0.7 & 0.0 & 81 & 0.0 & 0.0 \\
\hline \multirow[b]{2}{*}{ Input/output } & TOC & \multicolumn{3}{|c|}{119} & \multicolumn{3}{|c|}{10.6} & 0.0004 & \multicolumn{3}{|c|}{12.6} \\
\hline & TIC & \multicolumn{3}{|c|}{---} & \multicolumn{3}{|c|}{2.1} & & \multicolumn{3}{|c|}{81} \\
\hline \multicolumn{2}{|c|}{ Total input/output } & \multicolumn{3}{|c|}{119} & \multicolumn{7}{|c|}{106} \\
\hline \multicolumn{5}{|c|}{$\begin{array}{l}\text { Total carbon mass balance closure, } \\
\% \text { (c) }\end{array}$} & \multicolumn{3}{|c|}{89.2} & & & & \\
\hline
\end{tabular}

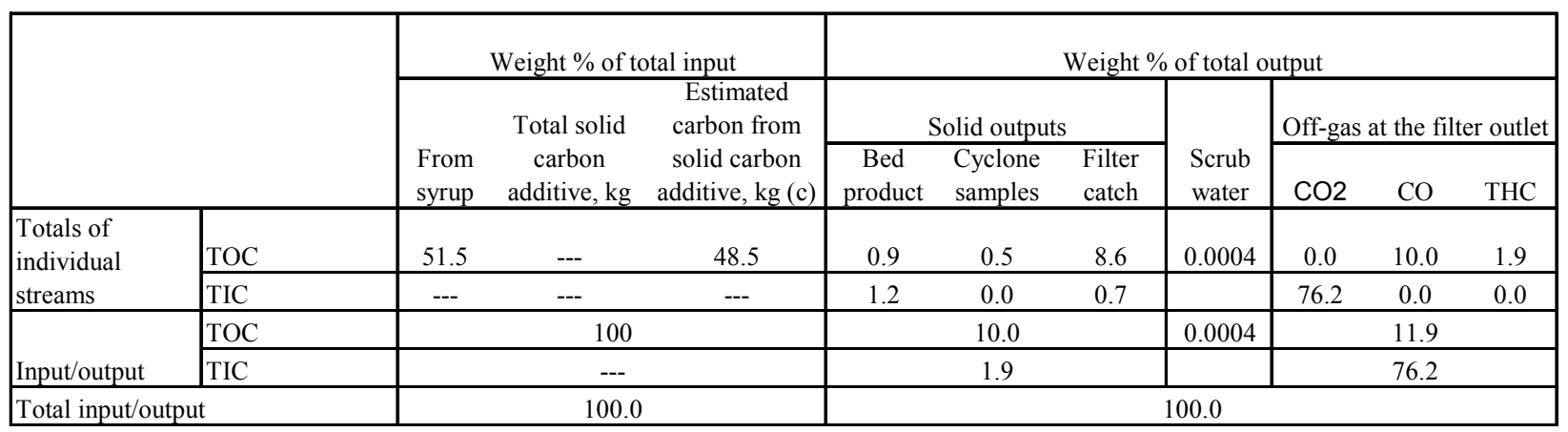

a. The initial start on November 10 is not included here because the bed agglomerated and was cleaned out and replaced before any significant SBW was fed.

b. The carbon in the solid carbon additive was estimated assuming that about $3 \%$ of the carbon additive was inorganic.

c. Calculated based on the mass of the output stream divided by the total mass of all output streams 
Most of the effluent carbon (about 88\%) was in the off-gas $\mathrm{CO}_{2}, \mathrm{CO}$, or THC. Only $12 \%$ of the carbon was found in the solid products, and a negligible amount was found in the wet scrubber. The total carbon in the solid products includes both organic carbon from unreacted reductants, and also inorganic carbon in the form of $\mathrm{CO}_{3}$. Of the carbon found in the solid output streams, most was in the form of organic carbon in the filter fines. Smaller amounts were found as organic carbon in the bed, cyclone, and scrubber water outputs, and about $2 \%$ of the output carbon was attributed to inorganic carbonate in the solid products.

\subsubsection{Product Elemental Distribution and Mass Balance Closure}

The SBW simulant components, hazardous metals, radionuclide surrogates, and anions distribute to the various solid and gaseous effluents from the steam reformer. Condensable and water-soluble gas species and fine particulate matter (PM) that pass through the heated filter can be scrubbed into the wet scrub solution.

Input and output measurements and calculations were made to determine the distribution of the feed constituents to the reformer products. The product distributions are shown in Table 5.4-3. On average, about $70 \%$ of the input mass distributed to the combined bed product and cyclone recycle material, and about $30 \%$ distributed to the filter fines. Only $0.1 \%$ of the input mass was collected in the scrub water.

Several species disproportionately partitioned more to the filter fines, compared to the total solids product distribution. These species were enriched in the filter fines. Such species include $\mathrm{PO}_{4}, \mathrm{SO}_{4}, \mathrm{Cl}$, $\mathrm{F}, \mathrm{Cs}, \mathrm{Cu}, \mathrm{K}, \mathrm{Ni}, \mathrm{Pb}, \mathrm{Re}, \mathrm{Sn}$, and $\mathrm{Zn}$.

This table also shows the mass balance closure (mass out divided by mass in) as an indicator of either (a) the mass distribution data quality, or (b) the amount of the species that passes on through the cyclone, heated filter, and wet scrubber with the off-gas. Some species $\left(\mathrm{NO}_{3}\right.$ and $\left.\mathrm{Hg}\right)$ are expected to either be destroyed or volatilized from the thermal process and not be significantly captured in the wet scrubber. The mass balance closures for those species, expectedly, are low. Most of the other measured species $(\mathrm{Cl}, \mathrm{Ca}, \mathrm{Cs}, \mathrm{Cu}, \mathrm{K}, \mathrm{Mg}, \mathrm{Mn}, \mathrm{Na}, \mathrm{Ni}, \mathrm{Pb}, \mathrm{Re}$, and $\mathrm{Si}$ ) have mass balance closures of $1.0 \pm 0.2$.

Even though the product distributions for $\mathrm{NO}_{3}$ show a split between the bed and filter fines similar to that of the total mass, the $\mathrm{NO}_{3}$ mass balance closure of 0.0004 shows that the nitrate destruction efficiency is about $99.96 \%$. The small amount of residual $\mathrm{NO}_{3}$ in the solids partitions between the bed product and filter in the same proportions as the total solid mass.

A few species (F, Al, Cr, Sn, Zn, and Zr) have mass balance closures less than 0.8 , even though they are not known to volatilize and pass through both an efficient filter (about $99.7 \%$ efficient for total particulate matter) and a wet scrubber. Several potential causes exist for either low or high mass balance closures. Some of these species may not have been adequately detected in the product samples due to inadequate digestion procedures prior to analysis. This was especially true for traditionally hard-to-digest elements including $\mathrm{Al}$ and $\mathrm{Si}$. Anions were analyzed from water leachates of the solid product samples, because the use of nitric acid, $\mathrm{HCl}$, or $\mathrm{HF}$ would interfere with those analyses. If some of the anions were not soluble in water solution, that amount would not be detected. Also, most of the species which had either low or high mass balance closure were present at relatively low levels in the simulant. Low-level impurities in some of the feed reagents may have significantly added to the total amounts of some species. Low concentrations of some species were more subject to interferences near the low end of the analytical measurement range. Finally, the simulant feed, which initially included heel solids, was partially filtered. This may account for low recoveries of $\mathrm{Sn}, \mathrm{Zn}$, and/or $\mathrm{Zr}$ assuming these species were less soluble, resulting in a larger portion being removed by the partial filtration. 
Table 5.4-3. Elemental distributions and mass balance closure for SBW simulant feed components.

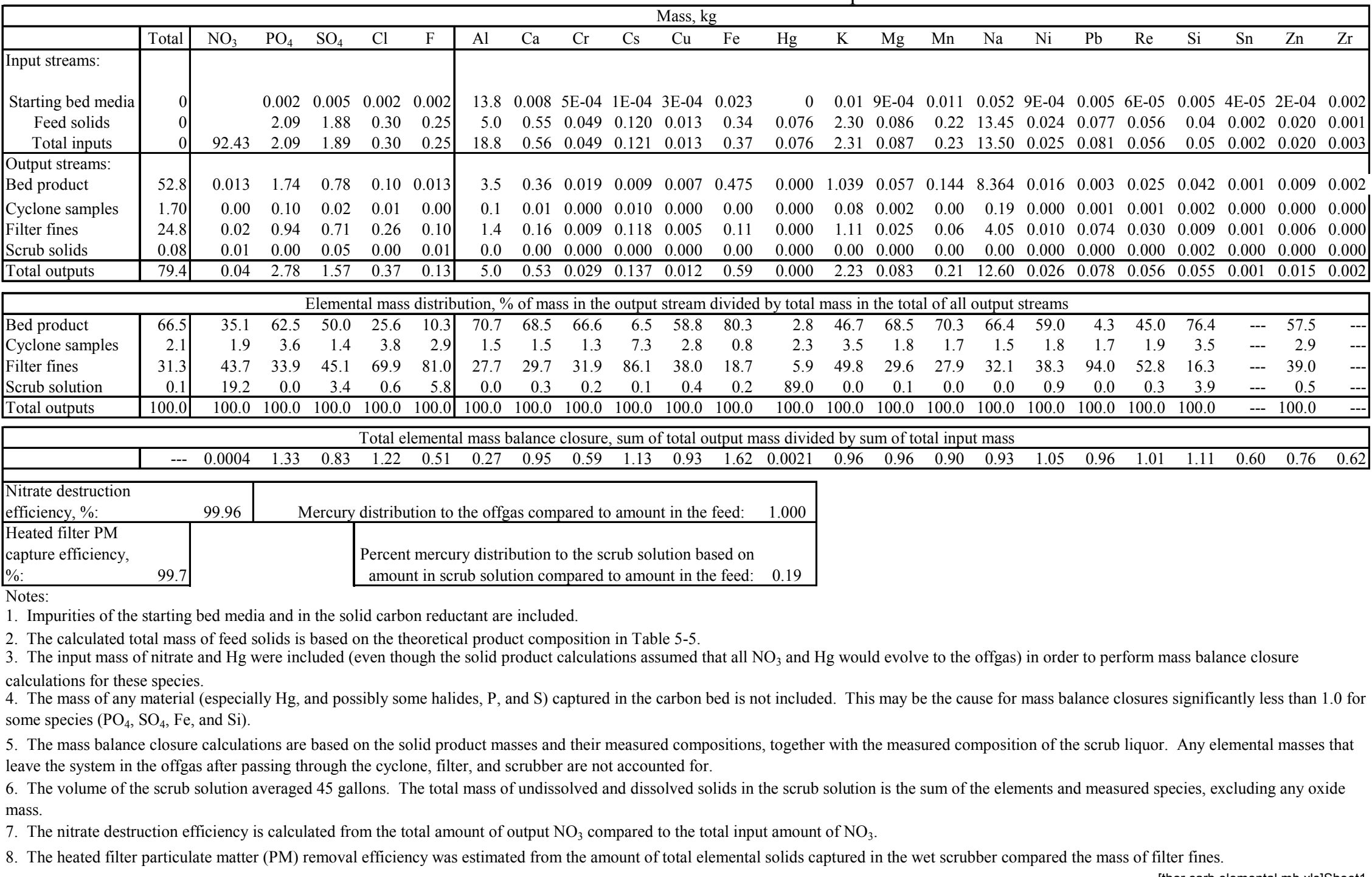


A few other species $\left(\mathrm{PO}_{4}, \mathrm{SO}_{4}, \mathrm{Fe}\right.$, and $\left.\mathrm{Si}\right)$ have mass balance closures above 1.2. In the case of $\mathrm{PO}_{4}$, analysis (onsite) was available for only one of the two carbons tested-for the other the $\mathrm{PO}_{4}$ concentration was assumed to be near-zero. This would account for the high mass balance closure for $\mathrm{PO}_{4}$. The product sample analyses for the other species may have been accurate, but the input levels may be higher than estimated based on the SBW simulant recipe. All of these species were present at relatively low levels in the simulant. Any unaccounted for impurities in the reagents used to make the simulant, the solid carbon reductant, or the starting bed media could bias the mass balance closure upward. In this case, the distributions to the output streams for these species, based on the output measurements, is still valid.

\subsubsection{Off-gas Mercury Concentrations and Emissions Control}

Mercury is a unique hazardous metal because of its toxicity and its volatility. Expectations that essentially no $\mathrm{Hg}$ is retained in the solid bed product and filter catch are confirmed by sample analyses that show very low Hg levels in those products. The Hg in the SBW simulant feed quantitatively evolved to the steam reformer off-gas. Table 5.4-4 shows the speciation and concentrations of $\mathrm{Hg}$ as the off-gas passed through the wet scrubber and 3-stage carbon bed. This table also shows the mass balance closure and carbon bed sorption efficiency.

Measured mercury levels upstream of the wet scrubber averaged almost $14,000 \mu \mathrm{g} / \mathrm{m}^{3}$. Very little of the total mercury was scrubbed in the wet scrubber, because the mercury was almost entirely element mercury which is not readily water-scrubbed. The total mercury removal efficiency of the carbon bed exceeded $99.9 \%$.

The carbon bed was designed with three stages in order to (a) show the potential loading capacity (mass of total $\mathrm{Hg}$ sorbed per mass of carbon sorbent) and (b) the potential total $\mathrm{Hg}$ removal efficiency from the steam reformer off-gas. These two objectives are mutually exclusive in discrete small-scale pilot tests. The theoretical sorption capacity for Nucon sulfur-impregnated carbon is up to $20 \mathrm{wt} \%$, so a carbon bed for discrete small-scale pilot tests would need to be too small to be appropriately designed according to vendor recommendations and design criteria for maximum superficial velocity, minimum residence time, and geometry (Soelberg 2003b).

The three-stage design enables both objectives to be accomplished. The first (3-inch deep) stage, while not designed with appropriate depth-to-diameter dimensions or residence time, has an appropriate superficial gas velocity and a small enough mass of carbon so that its capacity may be reached (defined by when breakthrough occurs) in a reasonable test duration. The Hg removal efficiency data confirm that the first stage is in fact not designed appropriately for high $\mathrm{Hg}$ removal efficiency. The first stage removed less than $85 \%$ of the total $\mathrm{Hg}$.

Breakthrough occurs when the outlet $\mathrm{Hg}$ levels start to increase from a relatively constant baseline level, asymptotically approaching the inlet level. By design, the first stage did not reach breakthrough during the THOR carbonate test series. The carbon capacity is at least the value shown for total $\mathrm{Hg}$ content at the time of the end of THOR mineral test series.

The combined first, second, and third stages have sufficient depth to meet vendor recommendations and design criteria. The Hg removal efficiency shown at the end of the second and third stages confirms that this bed design accomplishes very efficient $\mathrm{Hg}$ control. The $\mathrm{Hg}$ concentrations downstream of stage 3 , corrected to a dry, $7 \% \mathrm{O}_{2}$ basis, average about $1 / 10^{\text {th }}$ of the HWC MACT limit. 
Table 5.4-4. Hg speciation, concentrations, mass balance closure, and carbon bed sorption efficiency for the THOR carbonate test series.

\begin{tabular}{|c|c|c|c|c|c|c|c|c|c|c|c|c|c|c|c|c|c|c|c|c|c|c|c|}
\hline \multirow[b]{4}{*}{ Test } & \multirow[b]{4}{*}{$\begin{array}{c}\text { Simulant } \\
\text { feedrate, } \\
1 / \mathrm{hr}\end{array}$} & \multirow[b]{4}{*}{$\begin{array}{l}\mathrm{Hg} \\
\text { conc. } \\
\mathrm{g} / \mathrm{L}\end{array}$} & \multirow{4}{*}{$\begin{array}{c}\text { Off-gas } \\
\text { flow rate } \\
\text { at the } \\
\text { GAC } \\
\text { bed, } \\
\text { scfm }\end{array}$} & \multirow{3}{*}{\multicolumn{2}{|c|}{$\begin{array}{c}\text { Cooling water } \\
\text { mass flow to } \\
\text { PQ-1 partial } \\
\text { quench }\end{array}$}} & \multirow{4}{*}{$\begin{array}{l}\text { Off-gas } \\
\text { flow rate } \\
\text { at the } \\
\text { quench } \\
\text { inlet, } \\
\text { scfm }\end{array}$} & \multirow{4}{*}{$\begin{array}{l}\text { MTEC at } \\
\text { quench } \\
\text { inlet, ug/ } \\
\text { dscm wet }\end{array}$} & \multirow{4}{*}{$\begin{array}{c}\text { MTEC at } \\
\text { GAC } \\
\text { inlet, ug/ } \\
\text { dscm wet }\end{array}$} & \multicolumn{15}{|c|}{ Concentration, ug $/ \mathrm{m}^{3}$, wet basis } \\
\hline & & & & & & & & & \multirow{2}{*}{\multicolumn{3}{|c|}{ Quench inlet }} & \multirow{2}{*}{\multicolumn{3}{|c|}{ Scrubber outlet }} & \multicolumn{9}{|c|}{ Carbon bed } \\
\hline & & & & & & & & & & & & & & & \multicolumn{3}{|c|}{ Stage 1 outlet } & \multicolumn{3}{|c|}{ Stage 2 outlet } & \multicolumn{3}{|c|}{ Stage 3 outlet } \\
\hline & & & & $\mathrm{kg} / \mathrm{hr}$ & $\mathrm{scfm}$ & & & & Hg el corr & $\begin{array}{l}\text { Hg tot } \\
\text { corr }\end{array}$ & $\begin{array}{l}\mathrm{Hg} \text { ox } \\
\text { corr }\end{array}$ & $\begin{array}{l}\mathrm{Hg} \mathrm{el} \\
\text { corr }\end{array}$ & $\begin{array}{l}\text { Hg tot } \\
\text { corr }\end{array}$ & $\begin{array}{c}\mathrm{Hg} \text { ox } \\
\text { corr }\end{array}$ & $\begin{array}{l}\mathrm{Hg} \mathrm{el} \\
\text { corr }\end{array}$ & $\begin{array}{l}\text { Hg tot } \\
\text { corr }\end{array}$ & $\begin{array}{c}\mathrm{Hg} \text { ox } \\
\text { corr }\end{array}$ & $\begin{array}{c}\mathrm{Hg} \text { el } \\
\text { corr }\end{array}$ & $\begin{array}{l}\mathrm{Hg} \text { tot } \\
\text { corr }\end{array}$ & $\begin{array}{c}\mathrm{Hg} \text { ox } \\
\text { corr }\end{array}$ & $\begin{array}{l}\mathrm{Hg} \text { el } \\
\text { corr }\end{array}$ & $\begin{array}{c}\text { Hg tot } \\
\text { corr }\end{array}$ & $\begin{array}{c}\text { Hg ox } \\
\text { corr }\end{array}$ \\
\hline 0.5 & 4.70 & 0.27 & 118 & 41 & 32 & 86 & 8,704 & \begin{tabular}{l|}
6,328 \\
\end{tabular} & \begin{tabular}{|c|}
18,003 \\
\end{tabular} & 20,502 & 2,499 & --- & --- & --- & 1,272 & 1,188 & -84 & -+- & +-- & \begin{tabular}{l|l}
-- \\
--
\end{tabular} & +-- & --- & -- \\
\hline 1.1 & 5.41 & 0.27 & 121 & 41 & 32 & 89 & 9,681 & 7,131 & --- & --- & --- & --- & --- & --- & --- & --- & --- & --- & --- & --- & --- & --- & --- \\
\hline 2.1 & 6.00 & 0.27 & 123 & 42 & 33 & 90 & 10,589 & 7,785 & --- & --- & --- & --- & --- & --- & --- & --- & --- & --- & --- & --- & --- & --- & --- \\
\hline 2.2 & 6.00 & 0.27 & 122 & 41 & 32 & 90 & 10,612 & 7,820 & --- & --- & --- & --- & --- & --- & --- & --- & --- & --- & --- & --- & --- & --- & --- \\
\hline 2.3 & 6.00 & 0.27 & 123 & 41 & 32 & 91 & 10,505 & 7,780 & --- & --- & --- & --- & --- & --- & --- & --- & --- & --- & --- & --- & --- & --- & --- \\
\hline 2.4 & 6.00 & 0.27 & 123 & 41 & 32 & 90 & 10,589 & 7,793 & --- & --- & --- & --- & --- & --- & 769 & 1,136 & 368 & --- & --- & --- & 26 & 23 & -3 \\
\hline 2.5 & 6.00 & 0.27 & 123 & 41 & 32 & 91 & 10,535 & 7,767 & 18,353 & 19,379 & 1,026 & --- & --- & --- & 1,171 & 1,112 & -59 & --- & --- & --- & 10 & 14 & 4 \\
\hline 2.6 & 6.00 & 0.27 & 126 & 42 & 33 & 92 & 10,389 & 7,626 & 18,784 & 20,182 & 1,397 & --- & --- & --- & 1,220 & 1,139 & -82 & --- & --- & --- & 5 & 3 & -2 \\
\hline 2.7 & 5.81 & 0.27 & 126 & 42 & 33 & 93 & 10,003 & 7,361 & 18,058 & 19,767 & 1,709 & --- & --- & --- & 1,144 & 1,156 & 12 & --- & --- & --- & 0 & 1 & 0 \\
\hline 2.8 & 6.00 & 0.27 & 125 & 42 & 33 & 92 & 10,393 & 7,675 & --- & --- & --- & 7,205 & 7,568 & 364 & 880 & 910 & 30 & --- & --- & --- & -2 & -1 & 1 \\
\hline 2.9 & 6.00 & 0.27 & 123 & 42 & 33 & 91 & 10,573 & 7,762 & --- & --- & --- & 6,947 & 7,293 & 346 & 559 & 574 & 16 & --- & --- & --- & --- & --- & --- \\
\hline 2.10 . & 6.00 & 0.27 & 131 & 52 & 41 & 89 & 10,740 & 7,340 & --- & --- & --- & 7,407 & 7,692 & 285 & 504 & 526 & 22 & --- & --- & --- & --- & --- & --- \\
\hline 2.11 & 5.21 & 0.27 & 131 & 49 & 38 & 92 & 9,013 & 6,377 & --- & --- & --- & 6,271 & 6,515 & 244 & --- & --- & --- & -3 & -1 & 2 & --- & --- & --- \\
\hline 2.12 & 4.99 & 0.27 & 116 & 41 & 32 & 84 & 9,526 & 6,883 & --- & --- & --- & 6,382 & 6,792 & 410 & --- & --- & --- & -7 & 6 & 13 & --- & --- & --- \\
\hline $2.13 a$ & 4.50 & 0.27 & 117 & 3 & 30 & 8 & 8,249 & 6,134 & --- & --- & --- & 5,894 & 5,959 & 65 & --- & --- & --- & -2 & -3 & -1 & --- & --- & --- \\
\hline $2.13 b$ & 4.50 & 0.27 & 120 & 40 & 31 & 89 & 8,106 & 5,982 & 10,050 & 11,164 & 1,115 & 5,555 & 5,971 & 416 & --- & --- & --- & 2 & 1 & 0 & --- & --- & --- \\
\hline 3.1 & 0.00 & 0.00 & 114 & 37 & 29 & 86 & 0 & 0 & --- & --- & --- & --- & --- & --- & --- & --- & --- & --- & --- & --- & --- & --- & --- \\
\hline 3.2 & 1.62 & 0.27 & 115 & 36 & 28 & 87 & 2,956 & 2,277 & 14,420 & 13,549 & -871 & --- & --- & --- & --- & --- & --- & -2 & -6 & -4 & --- & --- & --- \\
\hline 3.3 & 4.00 & 0.27 & 114 & 34 & 27 & 87 & 7,318 & 5,596 & 14,397 & 13,526 & -871 & --- & --- & --- & --- & --- & --- & 1 & -7 & -8 & --- & --- & --- \\
\hline 3.4 & 4.00 & 0.27 & 116 & 34 & 27 & 89 & 7,157 & 5,504 & 14,404 & 13,484 & -920 & 4,008 & 3,993 & -16 & --- & --- & --- & 67 & 115 & 48 & --- & --- & --- \\
\hline S1 & 4.00 & 0.27 & 115 & 34 & 27 & 88 & 7,239 & 5,538 & --- & --- & --- & 3,863 & 4,018 & 154 & --- & --- & --- & -1 & -2 & -1 & --- & --- & --- \\
\hline S2 & 4.00 & 0.27 & 111 & 32 & 25 & 86 & 7,435 & 5,747 & --- & --- & --- & 4,053 & 3,984 & -69 & --- & --- & --- & -4 & -3 & 1 & --- & --- & --- \\
\hline S3 & 4.00 & 0.27 & 118 & 42 & 33 & 85 & 7,501 & 5,427 & --- & --- & --- & 3,794 & 3,790 & -4 & --- & --- & --- & -3 & -5 & -2 & --- & --- & --- \\
\hline $\begin{array}{l}\text { Weighted } \\
\text { average }\end{array}$ & 4.82 & 0.27 & 121 & 41 & 32 & 89 & 8,665 & 6,326 & 13,534 & 13,844 & 309 & 5,930 & 181 & 250 & 949 & 959 & 9 & 4 & 10 & 6 & 3 & 4 & 1 \\
\hline 0 & 1.22 & 0.00 & & & & & 2,108 & 1.484 & 3,0 & 3,417 & 1.790 & 1.272 & 1.432 & 644 & & 321 & 66 & 41 & 57 & 43 & & & \\
\hline
\end{tabular}

\begin{tabular}{|lc|}
\hline Mass balance closure, mass out/mass in & \\
\hline Wet scrubber removal efficiency, \% & 1.60 \\
Carbon bed stage 1 removal efficiency, \% & 2.3 \\
Carbon bed stage 2 removal efficiency, \% & 84.5 \\
Carbon bed stage 3 removal efficiency, \% & 98.9 \\
Carbon bed total removal efficiency, \% & 60.5 \\
\hline
\end{tabular}

Total $\mathrm{Hg}$ concentration, ug/dscm corrected to dry, $7 \% \mathrm{O}_{2}$ basis

HWC MACT limit for total $\mathrm{Hg}, \mathrm{ug} / \mathrm{dscm}\left(\mathrm{dry}, 7 \% \mathrm{O}_{2}\right)$

1. The Hg concentration in the simulant feed is $0.27 \mathrm{gm} / \mathrm{L}$.

2. The Hg mass balance closure exceeds $100 \%$. The scrub solution sample analyses show that very little $(0.18 \%)$ of the total mercury fed to the system was captured in the wet scrubber. Therefore, the quench inlet MTEC is used instead of the measured quench inlet values to calculate the scrubber efficiencies. The quench inlet MTEC concentrations have been normalized to the GAC inlet offgas flowrate in the scrubber efficiency calculation.

3. The correction factors to dry, $7 \% \mathrm{O}_{2}$ basis are the average CEMS $2 \mathrm{O}_{2}$ and $\mathrm{H}_{2} \mathrm{O}$ values. 


\section{MINERALIZED TEST SERIES}

Two test series were conducted during November 2003. During the first week-long test series, the steam reforming chemistry and operating conditions were designed to produce a solid product consisting mainly of sodium and potassium carbonate. The second week-long test week was designed with steam reforming chemistry and operating conditions to produce a sodium-potassium aluminosilicate product. During the first few days of each test week, different test conditions were parametrically evaluated in order to identify optimum conditions to select for demonstration testing that was performed during the final days of each test week. Even though the test program was designed to maintain relatively constant operating conditions during the demonstration test portion of each test week, a few parametric changes that were not made during the parametric evaluations were made during the demonstration tests.

The results of the carbonate test series are discussed in Section 5. The mineralized test results are discussed here in Section 6.

\subsection{Test Operating Conditions and Observations}

The tests included several different test series summarized in Table 6.1-1. For the first several tests, 235 grams of kaolin clay and 40 grams of Min-U-Sil 5 microfine crystalline silica were added as mineralizing agents for each liter of SBW simulant. The amount of added silica was stoichiometric with the amount of $\mathrm{Al}$ in the simulant, to utilize the $\mathrm{Al}$ already in the feed in the production of aluminosilicate. The rest of the $\mathrm{Al}$ and $\mathrm{Si}$ needed to react with $\mathrm{Na}$ and other metals in the feed were added in the form of kaolin clay. This quantity of additives (assuming the silica reacted with SBW alkali and aluminum) constituted about $110 \%$ of the stoichiometric quantity needed to form nepheline-like aluminosilicates. Various aluminosilicates may form, but nepheline was chosen as a basis for stoichiometry calculations and this discussion.

Results of initial test conditions indicated that the silica did not react with $\mathrm{Al}$ available in the simulant, leaving inadequate aluminosilicate stoichiometry to minieralize all of the metals in the simulant. Because of this insufficiency, the quantity of kaolin added was increased in subsequent tests (starting with Test 5.2d) to 295 grams for each liter of simulated SBW simulant, providing at least $101 \%$ aluminosilicate stoichiometry. While this seemed to be sufficient mineralizing stoichiometry, the excess silica was identified to be related to defluidizing bed agglomerations, which caused two process shutdowns. When the silica additive was eliminated in the final test series (Tests 5.4 through 5.6), no defluidizing bed agglomerations occurred.

Sugar syrup addition was accomplished through a separate feed stream that was blended in-line with the SBW-mineral slurry before feeding the slurry to the reaction vessel. Solid carbon reductant was added via a vibrator feeder. The syrup stoichiometry with $\mathrm{NO}_{3}$ ranged between 0 (when no syrup was added) and 3.03. The carbon additive stoichiometry with the $\mathrm{NO}_{3}$ ranged between 0 and 4.7. Even when the individual syrup or carbon additive stoichiometries with $\mathrm{NO}_{3}$ were less than unity, the stoichiometry of the combined reductants (syrup and carbon) always exceeded unity for stoichiometric reaction with both $\mathrm{NO}_{3}$ and total oxidants $\left(\mathrm{NO}_{3}\right.$ and $\left.\mathrm{O}_{2}\right)$. The total stoichiometry for total reductants and total oxidants ranged between 1.1 and 2.7 .

Operating conditions during the parametric and demonstration tests are summarized in Figures 6.1-1 and 6.1-2. All of the mineralization tests were conducted at a nominal bed temperature of $725^{\circ} \mathrm{C}$. Less fluidizing gas is required at this elevated temperature, leading to lower process gas dilution and increased off-gas concentrations. It was expected that the elevated temperatures would promote the water-gas shift reactions to produce reducing conditions (indicated by excess $\mathrm{H}_{2}$ ) to convert the feed nitrates to $\mathrm{N}_{2}$. 
Table 6.1-1. Summary of mineralizing operating conditions for the THOR mineralized test series.

\begin{tabular}{|c|c|c|c|c|c|c|c|c|c|c|c|c|c|c|c|c|c|c|c|c|}
\hline \multirow[b]{3}{*}{ Test } & \multirow[b]{3}{*}{ Start Time } & \multirow{3}{*}{$\begin{array}{c}\text { Duration } \\
\mathrm{hr}\end{array}$} & \multirow[b]{3}{*}{ NAR sL/L } & \multirow[b]{3}{*}{ Feed type } & \multicolumn{9}{|c|}{ Reactant feed rates } & \multicolumn{5}{|c|}{ Reductant stoichiometric ratios } & \multicolumn{2}{|c|}{ Mineralizers } \\
\hline & & & & & \multicolumn{3}{|c|}{ SBW slurry } & \multicolumn{3}{|c|}{ Syrup } & \multicolumn{2}{|c|}{ Act. Carbon } & $\overline{\mathrm{O}_{2}}$ & \multicolumn{2}{|c|}{$\mathrm{C}: \mathrm{NO}_{3}$} & \multicolumn{3}{|c|}{$\mathrm{C}:\left(\mathrm{NO}_{3}+\mathrm{O}_{2}\right)$} & \multirow{2}{*}{\begin{tabular}{|l|} 
Kaolin \\
$\mathrm{g} / \mathrm{L}$ SBW \\
\end{tabular}} & \multirow{2}{*}{\begin{tabular}{|l} 
Min-U-Sil \\
g/L SBW
\end{tabular}} \\
\hline & & & & & $\mathrm{kg} / \mathrm{hr}$ & $\mathrm{L} / \mathrm{hr}$ & $\begin{array}{l}\text { SBW } \\
\text { equiv. } \\
\mathrm{kg} / \mathrm{hr}\end{array}$ & $\begin{array}{l}\text { Mass } \\
\text { Ratio }\end{array}$ & $\mathrm{kg} / \mathrm{hr}$ & $\begin{array}{l}\text { Sugar } \\
\text { equiv. } \\
\mathrm{kg} / \mathrm{hr}\end{array}$ & Type & $\mathrm{kg} / \mathrm{hr}$ & $\mathrm{kg} / \mathrm{hr}$ & Syrup & $\begin{array}{c}\text { Act. } \\
\text { Carbon }\end{array}$ & Syrup & $\begin{array}{c}\text { Act. } \\
\text { Carbon }\end{array}$ & $\begin{array}{c}\text { Total } \\
\text { Carbon }\end{array}$ & & \\
\hline 4.1 & 11/17/2003 10:09 & $1: 12$ & \multirow{7}{*}{600} & \multirow{13}{*}{$\begin{array}{c}\text { Kaolin + } \\
\text { Min-U-Sil }\end{array}$} & \multirow{4}{*}{6.0} & \multirow{4}{*}{4.3} & \multirow{4}{*}{4.9} & \multirow{9}{*}{0.23} & \multirow{4}{*}{1.4} & \multirow{4}{*}{0.76} & \multirow{6}{*}{ Type-2 } & 1.0 & & & 2.47 & & 1.25 & 1.68 & & \\
\hline $4.1 \mathrm{a}$ & 11/17/2003 11:22 & $0: 49$ & & & & & & & & & & 1.2 & 1.35 & & 2.96 & 0.43 & 1.50 & 1.93 & & \\
\hline $4.1 \mathrm{~b}$ & 11/17/2003 12:11 & $0: 53$ & & & & & & & & & & 1.8 & & & 4.44 & & 2.26 & 2.68 & & \\
\hline $4.1 \mathrm{c}$ & 11/17/2003 13:04 & $3: 16$ & & & & & & & & & & 1.9 & & & 4.74 & 0.32 & & 2.14 & & \\
\hline 4.2 & $11 / 17 / 200316: 20$ & $0: 23$ & & & 7.0 & 5.0 & 5.7 & & 1.6 & 0.89 & & 2.0 & & 0.84 & 4.23 & 0.36 & 1.82 & 2.18 & & \\
\hline 4.3 & $11 / 17 / 2003 \quad 16: 44$ & $0: 50$ & & & 80 & 58 & 66 & & 18 & 101 & & 0.8 & & & 1.49 & 040 & 0.70 & 1.10 & & \\
\hline $4.3 \mathrm{a}$ & $11 / 17 / 2003 \quad 17: 35$ & $3: 16$ & & & 0.0 & 5.0 & 0.0 & & 1.0 & 1.01 & & 10 & 200 & & 1.63 & 0.40 & 0.77 & 117 & & \\
\hline 4.4 & $11 / 17 / 200320: 51$ & $0: 38$ & 525 & & 00 & 65 & 74 & & 1 & 14 & & & & & 1.45 & 042 & 0.74 & & & \\
\hline $4.4 \mathrm{a}$ & 11/17/2003 21:30 & $4: 47$ & $32 J$ & & 9.0 & 0.5 & 1.4 & & 2.1 & 1.14 & & 15 & & & 2.29 & 0.45 & 1.17 & 1.60 & $(81 \%$ & \\
\hline 4.5 & $11 / 18 / 20032: 17$ & $2: 55$ & 500 & & & & & 0.45 & 3.6 & 1.98 & & & & 1.64 & 2.57 & 0.78 & 1.21 & 1.99 & stoich.) & $40 \quad 30 \%$ \\
\hline 5.1 & $11 / 18 / 20035: 13$ & 2:04 & & & & & & 000 & 00 & 000 & & 2.3 & & 000 & 3.94 & 000 & 1.86 & 1.86 & & stoich.) \\
\hline $5.1 \mathrm{a}$ & $11 / 18 / 20037: 18$ & $2: 19$ & & & & & & & & & & 1.7 & 1.70 & & 2.87 & & 1.51 & 1.51 & & \\
\hline 5.2 & $11 / 18 / 20039: 37$ & $3: 32$ & & & & & & & & & & & & 2.04 & 1.19 & 1.17 & 0.68 & 1.85 & & \\
\hline $5.2 \mathrm{a}$ & 11/18/2003 13:10 & $3: 11$ & 450 & \begin{tabular}{|c} 
Kaolin + \\
Min-U-Sil + \\
$\mathrm{Fe}\left(\mathrm{NO}_{3}\right)_{3}$ \\
\end{tabular} & 8.0 & 5.8 & 6.6 & 0.56 & 4.5 & 2.46 & Type-1b & 0.7 & 1.50 & & 1.23 & 1.17 & 0.71 & 1.88 & & \\
\hline $5.2 b$ & $11 / 18 / 200316: 21$ & $0: 12$ & & Kaolin + & & & & & & & & & & 2.04 & & & & & & \\
\hline $5.2 \mathrm{c}$ & $11 / 18 / 200316: 33$ & $0: 15$ & 200 & Min-U-Sil & & & & & & & & & & & & & & & & \\
\hline $5.2 \mathrm{~d}$ & $11 / 18 / 2003 \quad 16: 49$ & $6: 02$ & 300 & & & 5.7 & 6.3 & & & & & 0.8 & & & 1.37 & & 0.78 & 1.95 & & \\
\hline $5.2 \mathrm{e}$ & $11 / 18 / 200322: 51$ & $0: 56$ & 350 & Extra Kaolin + & 7.0 & 5.0 & 5.5 & & 3.9 & 2.16 & & 0.5 & 1.14 & & 1.06 & 1.28 & 0.66 & 1.94 & & \\
\hline 5.3 & $11 / 19 / 200310: 10$ & $21: 50$ & 400 & & 4.5 & 3.2 & 3.6 & 0.83 & 3.7 & 2.05 & & 0.0 & 0.67 & 3.03 & 0.00 & 1.99 & 0.00 & 1.99 & & \\
\hline 5.4 & $11 / 20 / 200317: 33$ & $7: 38$ & 565 & & 5.7 & 4.0 & 4.6 & & & & & 1.1 & 0.54 & & 2.58 & & 2.15 & 2.15 & & \\
\hline 5.5 & $11 / 21 / 20031: 11$ & $1: 41$ & & & & & & & & & & 0.7 & & & 2.20 & & 1.77 & 1.77 & $\begin{array}{c}295 \\
101 \%\end{array}$ & \\
\hline $5.5 \mathrm{a}$ & $11 / 21 / 20032: 53$ & $5: 31$ & 630 & & & & & 000 & 00 & 000 & & 0.6 & 0.46 & 0.00 & 1.68 & 000 & 1.35 & 1.35 & stoich.) & \\
\hline $5.5 \mathrm{~b} *$ & $11 / 21 / 20038: 24$ & $1: 46$ & & Kaolin & & & 3 & & & & & 0.8 & & & 2.44 & & 1.96 & 1.96 & & 0 \\
\hline$\frac{5.5 \mathrm{c}}{5.5 \mathrm{~d}}$ & $\begin{array}{lll}11 / 21 / 2003 & 10: 10 \\
11 / 21 / 2003 & 11: 58\end{array}$ & $\frac{1: 48}{1: 05}$ & 450 & & 4.5 & 3.2 & 3.6 & & & & & 1.2 & 1.11 & & 3.76 & & 1.79 & 1.79 & & \\
\hline $5.5 \mathrm{e}^{* *}$ & $11 / 21 / 200313: 03$ & $0: 28$ & & & & & & & & & Type-1a & 15 & 100 & & 15 & & 20 & 2.34 & & \\
\hline 5.6 & $11 / 21 / 200313: 31$ & $2: 50$ & 384 & & & & & 0.20 & 0.9 & 0.50 & & 1.5 & 1.00 & 0.73 & $4.5 /$ & 0.37 & 2.34 & 2.71 & & \\
\hline
\end{tabular}

* 350 grams of iron oxide powder added. ** 400 grams of iron powder added $(<60 \mu \mathrm{m})$.

Assumes $13 \mathrm{wt} \%$ non-carbon in the Type- $1 \mathrm{a}$ and $-1 \mathrm{~b}$ carbons and $6 \mathrm{wt} \%$ non-carbon in the Type- 2 carbon.

H:ITHOR fy04\[THOR Mineral Test Map.xls] 


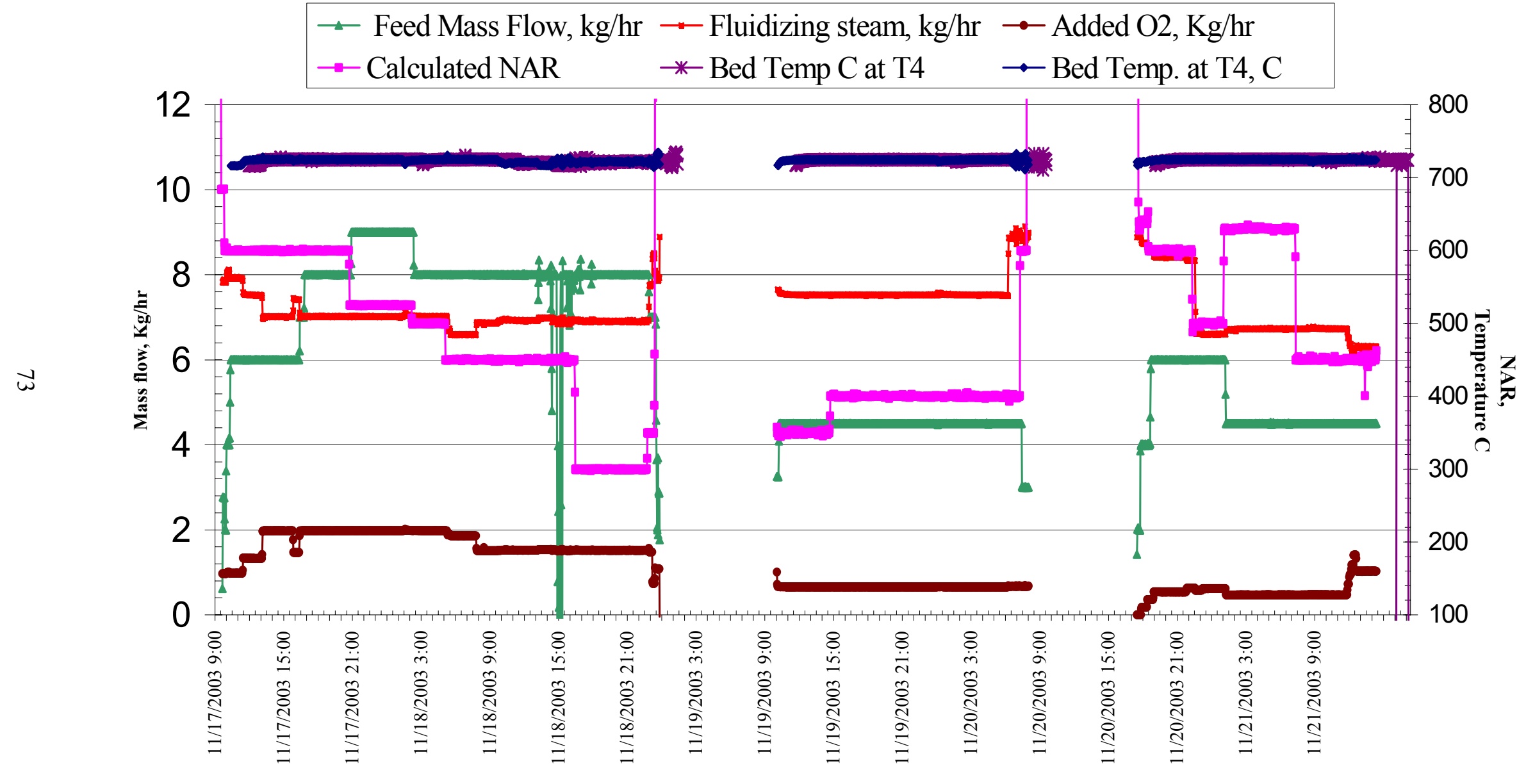

Figure 6.1-1. Feed simulant and fluidizing steam flow rates for the THOR mineralized test series. 


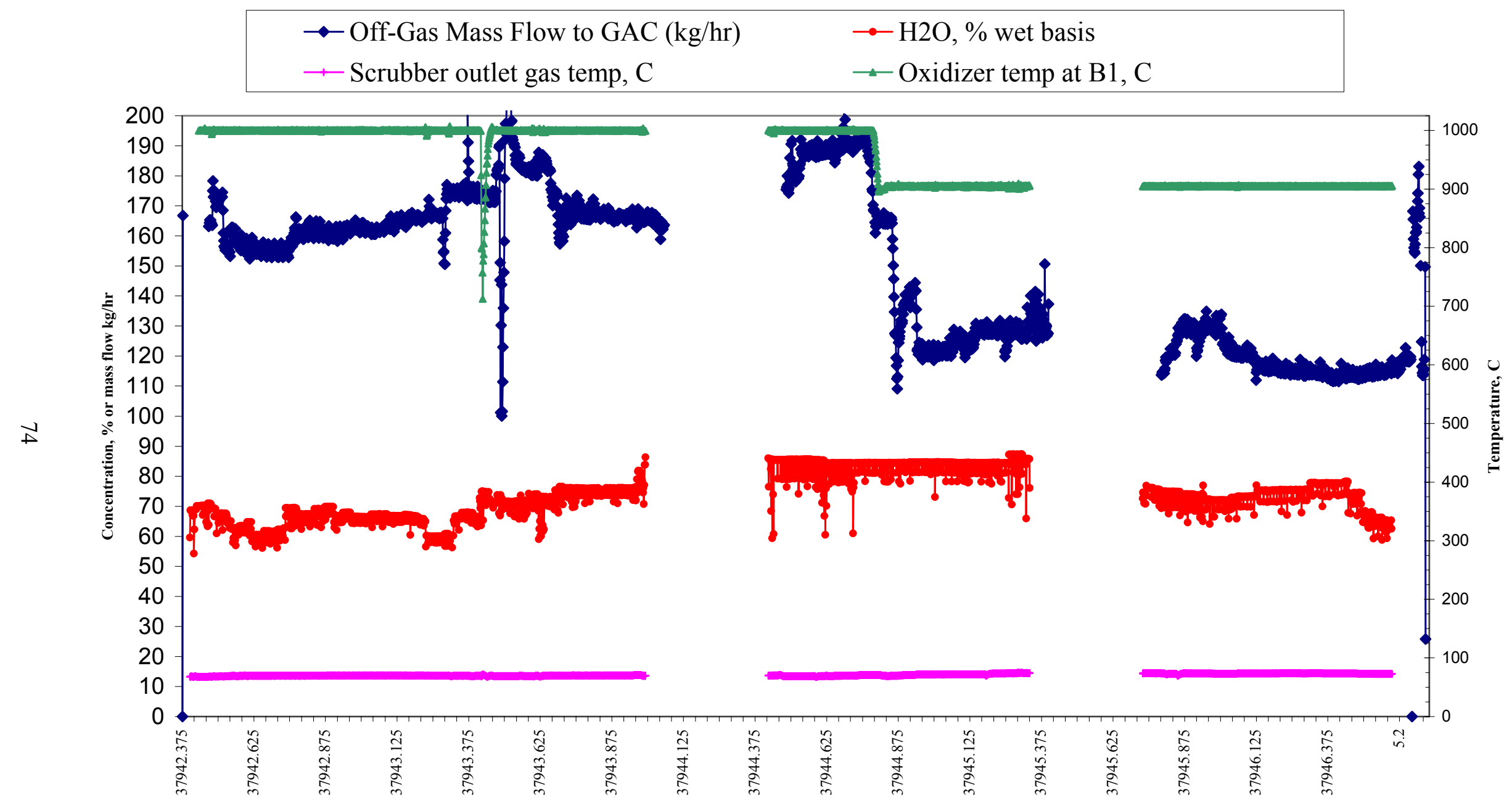

Figure 6.1-2. Selected key operating conditions for the THOR mineralized test series. 


\subsubsection{Bed Conditioning}

The 4.1 tests were intended to be a conditioning step with operating parameters that were expected to be adequate to ensure stable bed operation. Feed was brought on-line at $6 \mathrm{~kg} / \mathrm{hr}(4.3 \mathrm{~L} \mathrm{SBW}$ equivalent) with syrup flowing at $1.5 \mathrm{~kg} / \mathrm{hr}$ and Type- 2 activated carbon addition at about $1 \mathrm{~kg} / \mathrm{hr}$. The oxygen addition rate was $1.3 \mathrm{~kg} / \mathrm{hr}$, similar to the rate during the carbonate flow sheet tests. These conditions were selected because they matched the maximum SBW feed rate achieved in the January 2003 tests, and an average $76 \%$ stoichiometric excess of carbon was provided. In spite of the excess carbon, hydrogen generation was considerably lower than expected. $\mathrm{NO}_{\mathrm{x}}$ destruction was initially high at about $95 \%$. Carbon monoxide concentrations were also much higher than observed during the carbonate tests.

After about 75 minutes, the oxygen and activated carbon addition rates were increased, and syrup addition slightly decreased to ascertain the impact of additional oxygen on the hydrogen and $\mathrm{NO}_{\mathrm{x}}$ concentrations (Test 4.1a). No discernable impact was observed. About an hour later, the activated carbon addition rate was increased by half to $1.8 \mathrm{~kg} / \mathrm{hr}$ and held for nearly an hour without changing other parameters (Test 4.1b). Off-gas concentrations remained constant, except that $\mathrm{NO}_{\mathrm{x}}$ destruction decreased slightly, contrary to expectations.

The bottom thermocouple began to read higher than the other bed thermocouples, indicative of a significant carbon inventory in the bed. Oxygen was increased to $2 \mathrm{~kg} / \mathrm{hr}$, and carbon addition was held relatively constant along with the other parameters (Test 4.1c). These conditions were held for over 3 hours to see if $\mathrm{NO}_{\mathrm{x}}$ destruction would improve over time as the bed became "conditioned." Increasing the oxygen increased the carbon dioxide but had no influence on the hydrogen, methane, or total hydrocarbon production. $\mathrm{NO}_{\mathrm{x}}$ destruction stayed relatively constant at about $93 \%$.

There was no evidence that bed "conditioning" was occurring, as had been observed in the previous carbonate tests, which improved hydrogen production and $\mathrm{NO}_{\mathrm{x}}$ destruction, as the bed became coated with product. It was the general consensus that the potentially catalytically active metals contained in the SBW supernate were being bound chemically or physically in the mineral matrix, so that they were not available to facilitate either hydrogen production or $\mathrm{NO}_{\mathrm{x}}$ destruction.

\subsubsection{Feed Maximization Tests}

The feed rate maximization tests were started by increasing the SBW feed rate to $7 \mathrm{~kg} / \mathrm{hr}$ (Test 4.2). The syrup addition increased proportionately to maintain a constant mass flow ratio of 0.23 relative to the SBW slurry. The bottom thermocouple was reading about $15^{\circ} \mathrm{C}$ higher than the rest of the bed, so after 23 minutes, the feed rate was increased again (Test 4.3) to see if the added bed agitation from feed atomization and vaporization would bring the thermocouple more in line with the others. The carbon addition rate was reduced to $0.8 \mathrm{~kg} / \mathrm{hr}$ to reduce the accumulation of carbon in the bed.

Hydrogen generation remained lower than desired, and $\mathrm{NO}_{\mathrm{x}}$ destruction stayed relatively constant. Samples of the bed showed that the bed media were well coated with the product, and larger particles appeared to be activated carbon coated with the mineralized product. The coating would inhibit mass transport to and from the carbon, thereby reducing the carbons availability and effectiveness.

Drawing upon previous TTT experience that hard carbons, like the Type- 2 carbon, did not perform as well as softer carbons during mineralization trials, the decision was made to switch back to the Type- $1 \mathrm{~b}$ carbon. The thinking was that the lower-density carbons would be more likely to float on the bed, perhaps removing it somewhat from the feed zone, and that the mineral product would be less likely to adhere to the softer carbon. 
The switch to the Type-1b carbon was accomplished over a period of a few minutes and marked the start of Test $4.3 \mathrm{a}$. The addition rate of the Type- $1 \mathrm{~b}$ carbon was slightly higher $(1 \mathrm{~kg} / \mathrm{hr})$ than was last used with the Type- 2 carbon, but all other parameters were held constant. With the change in carbon, nearly every off-gas constituent concentration rose, except for carbon dioxide. Hydrogen generation improved almost imperceptibly, but $\mathrm{NO}_{\mathrm{x}}$ destruction decreased to less than $90 \%$.

The steam reformer outlet $\mathrm{NO}_{\mathrm{x}}$ measurements were made using an Ametek DUV analyzer and a California Analytical Instruments (CAI) chemiluminescent analyzer, which was rented and installed for this test because of interferences observed on the Ametek analyzer during the carbonate test series. With organic species filtration and air dilution, the CAI analyzer performed reliably, although the Ametek analyzer was still subject to interferences. Because of the calibrated validity of the CAI analyzer, all reported $\mathrm{NO}_{\mathrm{x}}$ values for the mineralized test series are based solely on the CAI analyzer.

Tests 4.4 and $4.4 \mathrm{a}$ involved increasing the feed rate to $9 \mathrm{~kg} / \mathrm{hr}$ of SBW slurry, with the same relative syrup addition mass ratio and decreasing the NAR from 600 to 525 to maintain a constant mass flow rate of atomizing gas. The increase in feed rate brought about an increase in $\mathrm{NO}_{\mathrm{x}}$ and hydrogen concentrations, while other constituents remained relatively constant. After nearly 40 minutes, the activated carbon addition rate was increased (Test 4.4a) to see if hydrogen generation and $\mathrm{NO}_{\mathrm{x}}$ destruction would improve. Hydrogen generation did improve a little, but $\mathrm{NO}_{\mathrm{x}}$ destruction decreased to about $70 \%$, contrary to expectations. Appreciable amounts of $\mathrm{NO}_{2}$ in addition to $\mathrm{NO}$ were observed. Test $4.4 \mathrm{a}$ conditions were held for nearly 5 hours with a combined SBW slurry and syrup addition rate of $11.1 \mathrm{~kg} / \mathrm{hr}$.

Test 4.5 was initiated when the SBW slurry feed rate was reduced to $8 \mathrm{~kg} / \mathrm{hr}$, and the syrup mass ratio increased from 0.23 to $0.45 \mathrm{~kg}$ syrup $/ \mathrm{kg}$ SBW slurry. This resulted in the total fluid addition rate of $11.6 \mathrm{~kg} / \mathrm{hr}$. NAR was adjusted down to 500 to keep the atomizing gas flow constant. All other parameters were held constant. The purpose was to demonstrate whether the feed rate could be maintained and to ascertain whether the carbon from the syrup is more available for reaction with the steam to produce hydrogen. Over the 3-hour test period, the methane and THC nearly tripled. Hydrogen and carbon monoxide rose slightly, and $\mathrm{NO}_{\mathrm{x}}$ destruction increased from about 70 to about $80 \%$.

\subsubsection{Reductant Optimization Tests}

From Test 4.5, it was apparent that syrup cannot be solely relied upon to reduce $\mathrm{NO}_{\mathrm{x}}$. For Test 5.1, syrup addition was stopped and the activated carbon addition rate was increased from 1.5 to $2.3 \mathrm{~kg} / \mathrm{hr}$. Overall, reductant stoichiometry was still just under $200 \%$. During the 2-hour test, an increase was observed in carbon dioxide emissions, and a significant reduction in methane and THC was observed. $\mathrm{NO}_{\mathrm{x}}$ declined somewhat, as did carbon monoxide. Hydrogen concentration was unchanged, in spite of a reduction in atomizing gas usage.

The bottom thermocouple in the bed was reading about $10^{\circ} \mathrm{C}$ above the other bed thermocouples at the end of Test 5.1, so the activated carbon addition rate and the oxygen addition rates were reduced for Test $5.1 \mathrm{a}$. The reductant stoichiometry was reduced to $151 \%$. The changes had no apparent effect on offgas constituents other than a slight decrease in carbon dioxide emissions.

Syrup was restarted, and the carbon addition rate reduced for Test 5.2, which lasted for 3.5 hours. Oxygen addition was decreased slightly, resulting in a reductant stoichiometry of $185 \%$. The hydrogen concentration increased modestly, but $\mathrm{NO}_{\mathrm{x}}$ destruction dropped from about 80 to about $70 \%$. THC and methane increased about 500 and $300 \%$, respectively. The rise in hydrocarbons was expected, but the drop in $\mathrm{NO}_{\mathrm{x}}$ destruction is inconsistent with previous results. 
Test 5.2a maintained all feed rates as constant as could be reasonably achieved, but the feed was switched to an iron-enhanced slurry $\left(265.4 \mathrm{gm}\right.$ of $\mathrm{Fe}\left(\mathrm{NO}_{3}\right)_{3} \cdot 9 \mathrm{H}_{2} \mathrm{O}$ in $18.14 \mathrm{~kg}$ of slurry). Entrained air from mixing in the iron nitrate resulted in difficulty in controlling and reading the mass flow during the test, which lasted over 3 hours. Hydrocarbon emissions showed a slight decrease, and $\mathrm{NO}_{\mathrm{x}}$ destruction increased again to about $80 \%$. All other off-gas constituents remained unchanged. The test indicates that potentially catalytically active metals in the SBW, such as iron, may be bound in the mineral phase and not available to catalyze gas-phase reactions or are insufficiently reduced to be effective.

Tests $5.2 \mathrm{~b}$ and $5.2 \mathrm{c}$ were normal slurry feed stock, from different tanks. Feed tanks were switched while an additional 54 grams of kaolin clay was added for each liter of the remaining slurry, because mineralization seemed to be less than expected. The silica that was added did not appear to be reactive, leaving some of the alkali metals un-mineralized and soluble. Switching back to a "normal" feed slurry (no extra iron nitrate) resulted in a decrease in $\mathrm{NO}_{\mathrm{x}}$ emissions and an increase in hydrocarbon emissions.

Test $5.2 \mathrm{~d}$ held the same processing conditions as the rest of the Test 5.2 series, except that the feed slurry had enhanced kaolin concentrations. Most of the off-gas species remained constant, although $\mathrm{NO}_{\mathrm{x}}$ destruction increased to about $87 \%$

Test 5.2e had slightly reduced SBW slurry, syrup, activated carbon, and oxygen addition rates. The total carbon-to-oxidizer ratio was held constant, but more of the carbon was supplied by syrup. The test was shortened ( $<1 \mathrm{hr}$ long) by indications that the bed was agglomerating. Anomalous bed pressure and temperature indications were caused by a large agglomeration that had formed in the reactor at the end of the 5.2 series of tests. The process was shut down for inspection and cleaning.

Post-test evaluations indicate that the presence of silica has contributed to or caused the bed agglomerations, as has occurred in other defluidizing agglomerations during the Phase 2 test series and during prior tests (Soelberg 2003a).

\subsubsection{Flow Sheet Demonstration Tests}

The reformer was reassembled with the ring gas distributor with the concurrence of TTT, because the ring distributor had been successfully used during the carbonate test series, and it was expected to give the most uniform gas distribution of the distributors on hand. A new alumina bed was charged, and the process was restarted without any activated carbon (Test 5.3). The SBW feed rate was low (averaging $3.6 \mathrm{~kg} / \mathrm{hr}$ ), and syrup addition was high $(3.7 \mathrm{~kg} / \mathrm{hr})$, resulting in $200 \%$ reductant stoichiometry. The philosophy for operation shifted from that of exploring possible reductant and feed combination to demonstrating stable operation and particle size control, and making a significant quantity of fully mineralized product. These process conditions were chosen after consultation with TTT and were maintained for nearly 22 hours until the bed instrumentation showed evidence of large agglomerate formation and defluidization.

The THC and methane numbers were very high, relative to what had been previously observed, which is consistent with the high syrup feed rate relative to SBW nitrates. Carbon dioxide concentrations were significantly lower than had been observed with process conditions with similar excess carbon stoichiometries. $\mathrm{NO}_{\mathrm{x}}$ destruction decreased from initial values of over 80 to about $55 \%$. This low $\mathrm{NO}_{\mathrm{x}}$ destruction may have been caused by gradually increasing defluidization. Filter blowbacks were inefficient. The filter catch appeared beige in color, indicating that very little carbon was carrying over. The resultant filter cake was relatively difficult to dislodge from the filter candles.

We believe that defluidization at the conclusion of Test 5.3 to have been caused by the Min-U-Sil silica that was still present in the feed slurry. Sample analysis of the agglomerations indicated that the agglomeration was enriched in silica. Therefore, a batch of SBW slurry was prepared using about 101\% 
stoichiometric kaolin clay without any silica, and used for the remainder of the demonstration tests. The agglomerated bed formed a mass, perched on the ring distributor, that had a hollow and somewhat cylindrical shape.

Test 5.4 began after the reformer was re-assembled. A TTT-style distributor was installed, rather than the ring distributor, because it would be less likely to form self-supporting masses (i.e., a hollow cylinder) should the bed begin to agglomerate. Recovered bed from Test 5.3 was used to provide a bed that was already coated with product for Test 5.4. For this test, no syrup was fed to the reactor. Activated carbon was fed at $1.1 \mathrm{~kg} / \mathrm{hr}$, which provided for $215 \%$ reductant stoichiometry. Without the presence of syrup, the THC and methane readings were very low. Carbon dioxide and carbon monoxide were at the lowest recordings during the week. Hydrogen was low, and $\mathrm{NO}_{\mathrm{x}}$ destruction increased from initial values below 60 to about $75 \%$. The slurry feed rate was $5.7 \mathrm{~kg} / \mathrm{hr}$. Filter blowbacks were more efficient because the filter cake dislodged relatively easily, but the quantity of fines increased because of carbon carryover. These conditions were held for nearly 8 hours. An increased quantity of unreacted carbon granules was found in the bed samples.

The activated carbon addition rate was decreased to $0.7 \mathrm{~kg} / \mathrm{hr}$, and the SBW slurry feed rate was reduced to $4.5 \mathrm{~kg} / \mathrm{hr}$ for Test 5.5. Oxygen addition was also reduced to $0.46 \mathrm{~kg} / \mathrm{hr}$. This resulted in $177 \%$ reductant stoichiometry. Most of the off-gas constituents remained constant, although $\mathrm{NO}_{\mathrm{x}}$ destruction decreased slightly. Test 5.5a had a lower NAR to atomize the feed and a slightly reduced carbon addition rate. The combined duration was over 7 hours. $\mathrm{NO}_{\mathrm{x}}$ destruction continued to drop to about $70 \%$.

Test 5.5b maintained process conditions from before. To determine if an iron catalyst would enhance hydrogen production and enhance $\mathrm{NO}_{\mathrm{x}}$ destruction, 350 grams of iron oxide granules were added through the carbon addition port. A short-duration increase in $\mathrm{NO}_{\mathrm{x}}$ destruction occurred, while all other off-gas constituent concentrations remained unchanged. The iron oxide addition did not improve system performance during the 2-hour test.

When the iron oxide did not improve performance, the performance of the Type- $1 \mathrm{~b}$ activated carbon was questioned. For Test 5.5c, the carbon additive was switched from Type $1 \mathrm{~b}$ to Type $1 \mathrm{a}$. The Type-1a carbon is more irregularly shaped than the other two carbons used in this series of tests and fed more inconsistently from the vibratory feeder. The addition rate was about $0.8 \mathrm{~kg} / \mathrm{hr}$, bringing the reductant stoichiometry up from 135 to $196 \%$. This condition was also held for nearly 2 hours, with no changes to the off-gas constituents other than a slight increase in carbon dioxide emissions. There was no demonstrable difference in the performance of the Type- $1 \mathrm{~b}$ and Type-1a carbons when mineralizing the SBW simulant, but this may have been because there was not sufficient time to establish representative inventories of carbon in the bed for each of the test conditions.

To ensure that the Type-1 a carbon inventory in the bed and the addition rate were adequate, the addition rate was increased by $50 \%$ to $1.2 \mathrm{~kg} / \mathrm{hr}$ for Test $5.5 \mathrm{~d}$. Oxygen addition was nearly doubled. The combined changes resulted in about $180 \%$ carbon stoichiometry. The only off-gas constituent that responded to the change was carbon dioxide. This test condition was held for 1 hour while preparations were made to add iron powder to the reformer via the carbon addition port.

Upon addition of 400 grams of iron powder (Test 5.5e), the $\mathrm{H}_{2}$ concentration immediately jumped from about $6.5 \%$ to over $9 \%$ (dry basis). $\mathrm{NO}_{\mathrm{x}}$ destruction rose from about 65 to $75 \%$. The effect was short lived, however, and the $\mathrm{H}_{2}$ and $\mathrm{NO}_{\mathrm{x}}$ returned to their previous levels in less than 10 minutes. The effectiveness of the iron powder was short lived because much of it was either (a) elutriated from the bed and past the cyclone to the filter, or (b) oxidized, making it ineffective as catalyst or participant in $\mathrm{NO}_{\mathrm{x}}$ reduction reactions. The iron powder particle size was only $60 \mu \mathrm{m}$, small enough for it to be quickly elutriated from the bed. However, it was dense enough to captured in the cyclone and recycled to the bed. 
The iron content in the bed, cyclone, and filter samples collected after the iron addition all increased, by 5 times, 40 times, and 5 times, respectively. The mass of iron collected in the filter fines (removed from the bed) was about $1 / 2$ of the iron added.

While about $1 / 2$ of the iron was eventually elutriated from the bed to the filter, the remaining iron apparently was oxidized, making it ineffective as a catalyst or participant in $\mathrm{NO}_{\mathrm{x}}$ reduction reactions. According to TTT experience, the iron is oxidized when reformer operating conditions are not sufficiently reducing to prevent oxidation of the iron. During Test $5.5 \mathrm{e}$, the carbon addition rate was $1.5 \mathrm{~kg} / \mathrm{hr}$, which yielded $234 \%$ total reductant stoichiometry. If the reformer conditions were made more reducing, or if iron addition were continuous, the capability of iron to facilitate $\mathrm{NO}_{\mathrm{x}}$ destruction could be improved. Since one of the objectives of the Phase 2 tests was to lower the amount of excess carbon in the solid products than was found in the products from the Phase 2 tests, the reducing potential of the reformer was not significantly raised during these tests.

About one-half hour after the iron powder addition, Test 5.6 was initiated. The syrup was restarted syrup at an addition rate of $0.9 \mathrm{~kg} / \mathrm{hr}$, which increased the reductant stoichiometry to about $270 \%$. Carbon dioxide concentrations increased in response to the change, but hydrogen did not. $\mathrm{NO}_{\mathrm{x}}$ destruction increased slightly.

During the course of the mineralizing tests, the process successfully operated for nearly 22 hours without activated carbon addition and, cumulatively, for over 24 hours without syrup addition. The reductant stoichiometry, relative to the nitrates and oxygen introduced to the reactor, ranged from 110 to $270 \%$. The hydrogen generation and $\mathrm{NO}_{\mathrm{x}}$ emissions did not respond to changes in excess carbon stoichiometry. Three activated carbons were tested, Type-1a, Type-1b, and Type-2. Three iron catalysts were also tried. These were dissolved iron nitrate, iron oxide granules, and iron powder. The only catalyst that showed any effectiveness was the iron powder. Min-U-Sil 5 silica was found to be insufficiently reactive to combine with available alkali and dissolved aluminum nitrate to form aluminosilicates (synthetic clay).

Tests 5.4 through 5.6, which used only the kaolin clay additive, had no agglomerations in the bed after nearly a day of operation, which suggests that the crystalline silica powder caused or at least contributed to the formation of agglomerates. These results suggest that operation with a clay-only additive can produce a mineralized product without defluidizing agglomerations.

Some minor deposits were found on the reformer wall opposite of the feed nozzle, which were thought to contribute to small clumps of product found in the bed product samples. The atomized feed appears to penetrate the mineralized product bed more readily than the denser carbonate bed, impacting on and causing clumps of product on the far wall of the reformer. This impaction of feed on the far wall is an artifact of this particular feed nozzle configuration and can be remedied in larger fluidized beds by controlling the bed density, or by reorienting or otherwise modifying the feed nozzle design or operation.

\subsection{Mineralized Test Solid Product Evaluations}

The feed solution, when sprayed into the bed, dries and undergoes evaporation, thermal decomposition, and other reactions that denitrate and devolatilize the feed constituents. The solid residual products of the steam reforming process either stay in the bed or elutriate from the bed with the off-gas, depending on operating conditions and properties of the bed media and solid products. If the solid products form relatively durable coatings on existing bed particles, then the products tend to stay in the bed. During continued operation, the bed mass would grow and would need to be removed. Most of the steam-reformed product would be in the form of bed media drained from the bed. 
If the solid products tend to form new, small particles, or fragile coatings on bed particles that readily break off the products, they would be easily entrained in the fluidizing gas and would tend to elutriate from the bed. This mode of operation would tend to leave the bed particles intact and result in a primary elutriated product captured in the cyclone and filter.

In practice, operating variations could include purposefully operating the fluidized bed to attrit bed particles for particle size control or to elutriate product. Alternatively, other operating modes could include recycling elutriated fines back to the fluidized bed to further treat elutriated fines or minimize the net amount of elutriated fines.

The product distribution can often be tailored by system design and operation to produce a bed product, elutriated product, or combination of the two. During the THOR Phase 2 tests, $100 \%$ of elutriated fines that were captured in the cyclone were recycled back to the fluidized bed. Some of elutriated fines passed through the cyclone and were captured on the sintered metal filters but not recycled back to the fluidized bed.

\subsubsection{Solid Product Distribution and Mass Balance Closure}

The solid product distribution and mass balance closure are shown in Table 6.2-1. The total input masses were the starting bed media, solid material from the reformed SBW feed, and the carbon additive. Total output masses were the bed product, the mass of the cyclone recycle material that was sampled, and the filters catch. The output bed product was the sum of the mass of bed removed at the end of the test, the mass of bed material in bed samples, and the mass of bed material removed (called excess bed) during the test series to maintain the design bed level as bed mass grew and became less dense.

Table 6.2-1. Solid product distribution and mass balance closure for the THOR mineral test series.

\begin{tabular}{|c|c|c|c|c|c|c|c|c|c|c|}
\hline \multirow[b]{3}{*}{ Date, time } & \multirow[b]{3}{*}{$\begin{array}{c}\text { Test } \\
\text { condition }\end{array}$} & \multicolumn{3}{|c|}{ Mass inputs, $\mathrm{kg}$} & \multicolumn{6}{|c|}{ Mass outputs, kg } \\
\hline & & \multirow[b]{2}{*}{$\begin{array}{l}\text { Bed material } \\
\text { added, } \mathrm{kg}(\mathrm{a})\end{array}$} & \multirow[b]{2}{*}{$\begin{array}{l}\text { Total solids } \\
\text { from SBW } \\
\text { feed, } \mathrm{kg} \mathrm{(a)}\end{array}$} & \multirow{2}{*}{$\begin{array}{l}\text { Estimated solid } \\
\text { residual from } \\
\text { solid carbon, } \mathrm{kg} \\
\text { (b) }\end{array}$} & \multicolumn{3}{|c|}{ Bed } & \multirow{2}{*}{$\begin{array}{c}\text { Cyclone } \\
\text { solids } \\
\text { sample } \\
\text { mass }\end{array}$} & \multicolumn{2}{|c|}{ Filter } \\
\hline & & & & & $\begin{array}{c}\text { Bed } \\
\text { removed at } \\
\text { test end }\end{array}$ & $\begin{array}{c}\text { Bed sample } \\
\text { mass }\end{array}$ & $\begin{array}{l}\text { Cumulative } \\
\text { excess bed }\end{array}$ & & $\begin{array}{l}\text { Filter solids } \\
\text { sample mass }\end{array}$ & $\begin{array}{c}\text { Filter solids } \\
\text { increment mass }\end{array}$ \\
\hline $11 / 16 / 0319: 58$ & Shutdown & 26.0 & & & \multirow{5}{*}{$\begin{array}{c}16.100 \\
8.900\end{array}$} & \multirow{5}{*}{0.064} & \multirow{5}{*}{3.200} & & \multirow{5}{*}{\multicolumn{2}{|c|}{1.300}} \\
\hline $11 / 19 / 035: 24$ & $5.2 \mathrm{~d}$ & \multirow[t]{2}{*}{26.0} & & & & & & & & \\
\hline $11 / 20 / 0312: 50$ & 5.3 & & & & & & & & & \\
\hline 11/20/03 16:02 & 5.3 & \multirow{2}{*}{\multicolumn{3}{|c|}{11.0}} & & & & & & \\
\hline $11 / 21 / 03 \quad 15: 40$ & 5.6 & & & & & & & & & \\
\hline \multicolumn{2}{|c|}{ Totals of individual streams } & 63.0 & 115.4 & 7.6 & 33.4 & 9.6 & 56.6 & 3.6 & 1.6 & 72.2 \\
\hline \multirow{2}{*}{\multicolumn{2}{|c|}{$\begin{array}{l}\text { Total bed or filter product } \\
\text { Total input or output }\end{array}$}} & \multirow{2}{*}{\multicolumn{3}{|c|}{186.1}} & \multicolumn{3}{|c|}{99.6} & & \multicolumn{2}{|c|}{73.8} \\
\hline & & & & & & 77.1 & & \\
\hline \multirow{2}{*}{\multicolumn{5}{|c|}{$\begin{array}{l}\text { Distribution of solids to bed product, wt } \%(\mathrm{c}) \\
\text { Mass balance closure, mass of output streams/ mass of input }\end{array}$}} & \multicolumn{3}{|c|}{38.1} & 2.9 & \multicolumn{2}{|c|}{59.0} \\
\hline & & & & & \multicolumn{6}{|c|}{0.95} \\
\hline
\end{tabular}

a. Total SBW solids was estimated from the calculated amount of solid product per liter of feed $(0.33-0.36 \mathrm{~kg} / \mathrm{L})$ and the total SBW feed volume of $343 \mathrm{~L}$ for the test.

b. The residual solid carbon was estimated using a weighted average of $3.7 \%$ inorganic in the carbons used, and assuming about $90 \mathrm{wt} \%$ of the elemental solid carbon was gasified.

c. Percentage of the total product mass in each of the three solid product streams. In this calculation the mass of the bed product stream was reduced by the mass of the virgin bed material that was fed to the reformer (first two bed material addtions only).

The bed turnover calculation is complicated because of the two shutdowns during the week. After the second shutdown, the prior bed media that contained some product was reused. Subtracting the mass of reused bed media, the total bed turnover was about of 2.3 . On average, up to $30 \%$ of the bed product was new solids from the simulant feed. 


\subsubsection{Bed Building and Product Elutriation}

One of the objectives of this testing was to obtain a stable bed in the steam reforming reactor. In stable operation, the bed mass, density, height, particle size, and product distribution would be controlled within acceptance limits. The product may be primarily elutriated from the bed, leaving the starting bed essentially intact, or the product may distribute partially or primarily to the bed product, eventually replacing the starting bed media. Under the first scenario, the starting bed provides the fluidized bed environment, acting as a catalyst or heat/mass transfer medium to facilitate the conversion of feed materials to products with little or no change to the starting bed. The entering feed forms new particles that elutriate from the bed or temporarily coat the bed particles with a layer that eventually spalls off and is elutriated. This process is dynamic in that the starting bed is continually gaining and losing mass as the feed materials enter, react, spall, and then fines are elutriated.

The solid product mass distribution between the bed product and filter fines indicates that a significant portion of the feed solids partitioned to the bed product. As the simulant feed was fed to the reformer, the feed solids tended to coat the bed particles rather than form separate small particles that would be elutriated from the bed. Bed media was periodically drained from the bed to maintain a target bed depth (indicated by continuous measurements fluidized bed density and bed height) of about 30-35 inches. As the bed particles grew in size, the bulk and particle densities decreased because of the larger particle sizes and the lower particle density of the mineralized product compared to the heavier starting alumina bed media. Figure 6.2-1 shows that as the bed height was maintained near the top of target range, the fluidized bed specific gravity decreased from about 1.96 to about 0.5 , almost a factor of 4 . These measurements were made using pressure taps located in the bed to measure the total fluidized bed pressure drop, and the fluidized bed pressure drop for a given 13-inch bed depth.

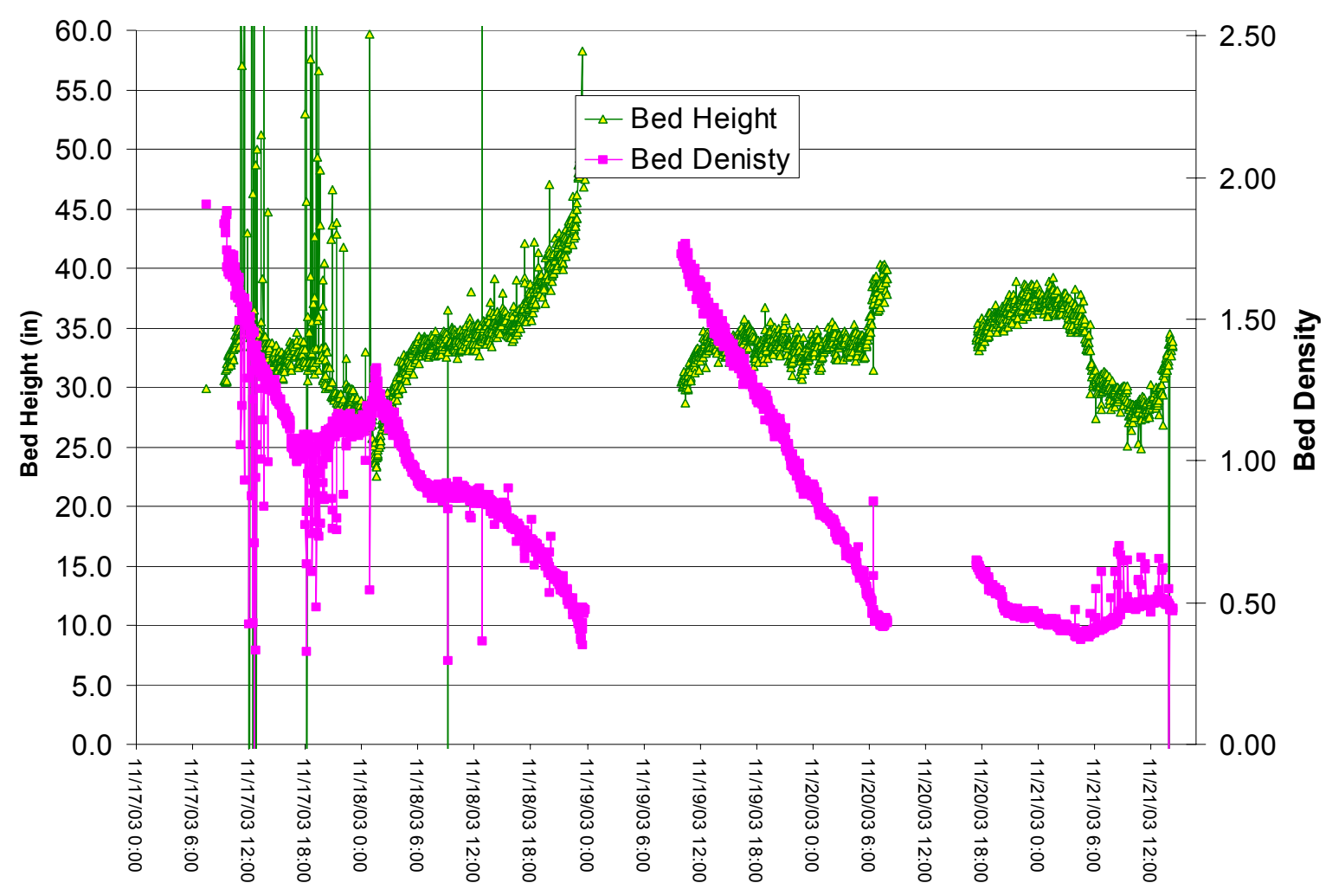

Figure 6.2-1. Continuously measured in situ bed depth and mass for the THOR mineral test series. 


\subsubsection{Solid Product Characterization and Particle Size}

6.2.3.1 Bed Product. Scanning electron micrographs (SEMs) of the solid bed product particles from the mineralized flowsheet are shown in Figure 6.2-1. The figure shows samples at four different values of cumulative feed (CF) and four different test conditions. The mineralized bed shows no growth in particles beyond the 0.5 - to $0.6-\mathrm{mm}$ size of the starting bed. The particles are not spherical, and do not have the spheroidal subparticles which were characteristic of the carbonate bed product.

The growth behavior of the bed particles for the mineralized flowsheet is illustrated in the traces of MMPD and HMPD in Figure 6.2-2. Consistent with the SEM photos, the figure indicates that the mean particle size is between 0.5 and $0.6 \mathrm{~mm}$ for the majority of the bed samples.

Bed particle size distributions are shown in Figure 6.2-3. Larger particle sizes did not grow significantly until roughly midway through the histogram in the "COT" direction. However, the COT scale in the figure is non-linear - the midway point actually represents the first half of the samples taken, not the first half of the run relative to the cumulative SBW fed. The midway point in the histogram thus represents the $10^{\text {th }}-11^{\text {th }}$ samples, which correspond to the $325 \mathrm{~kg} \mathrm{CF}$ mark in Figure 6.2-2, where the bed particle size began its oscillatory growth cycle. Thus, Figures 6.2-2 and 6.2-3 are consistent.

Additional insight into the dynamics of the bed during the mineralized test series is provided by the optical microscope photographs shown in Figure 6.2-4(a) and (b). The figure shows bed product particles at $141 \mathrm{~kg} \mathrm{CF}$ (Test Condition 4.5) and $371 \mathrm{~kg} \mathrm{CF}$ (Test Condition 5.3). The morphologies and sizes of the particles at these two points in the test are distinctly different, the latter of the two showing characteristics (namely increased size and spheroidal "bumps") that are reminiscent of, but not identical to, those of the carbonate flowsheet bed particles. A second significant difference is the presence in the first sample of carbon particles that are absent in the second sample (no solid carbon was fed during Test Condition 5.3). The solid carbon fed may account for the differences in the characteristics of the two bed product samples, though the physical mechanism is not yet understood.

In Figure 6.2-5 SEMs of the bed product are provided at 50x to 20,000x magnifications, with insets and scale bars. Comparison of these SEMs with those for the carbonate flowsheet yields both differences and similarities. At the smaller scales (2,000x and 20,000x magnification), subtle differences appear in the particle morphologies. The views at 2,000x indicate the mineralized particles to be more heterogeneous, coarser, and more angular in shape. The SEM for the mineralized product also indicates the presence of planar clay particles from the feed. At the 20,000x scale, the smallest particle sizes for the two flow sheets appear to be comparable, but, again, the mineralized particles appear less spherical, more angular, and give the impression of having been more nascent from the parent material, the latter being represented by the amorphous regions in the SEM view.

Individual particle densities and the bulk densities of the aggregated bed product are provided in Table 6.2-2. Sample numbers, test condition identifiers, and cumulative SBW simulant fed are also included. The bed product particle density and bulk densities decreased throughout the test. The bulk density, however, changed more dramatically than the particle density, dropping by a factor of more than two during the final $25 \%$ of the test, when stable operation was achieved during the final demonstration test. 


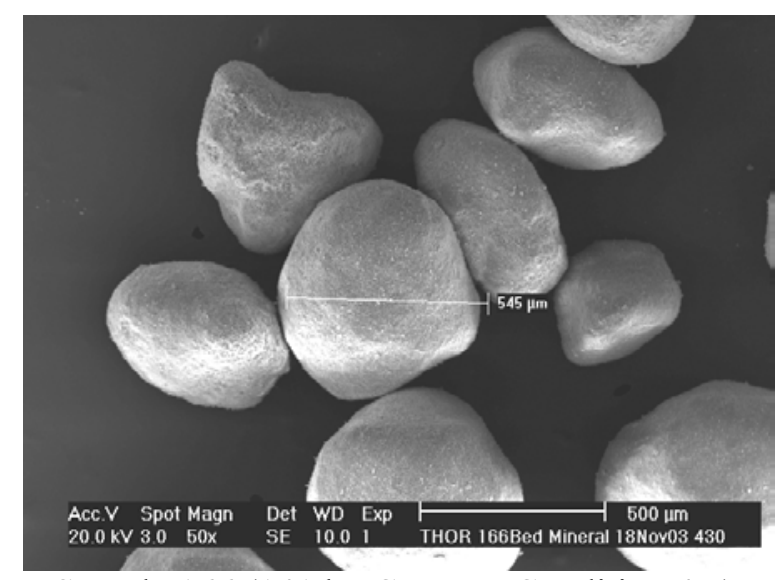

Sample 166 (141 kg CF, Test Condition 4.5)

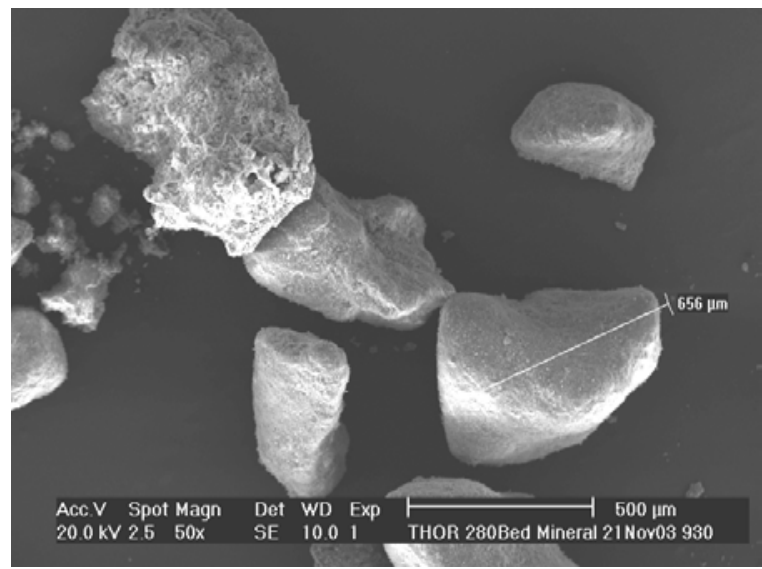

Sample 280 (473 kg CF, Test Condition 5.5b)

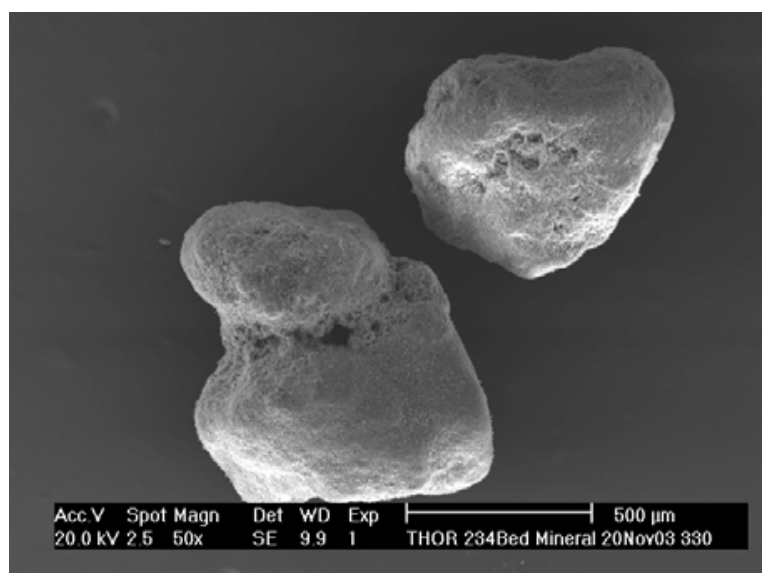

Sample 234 (371 kg CF, Test Condition 5.3)

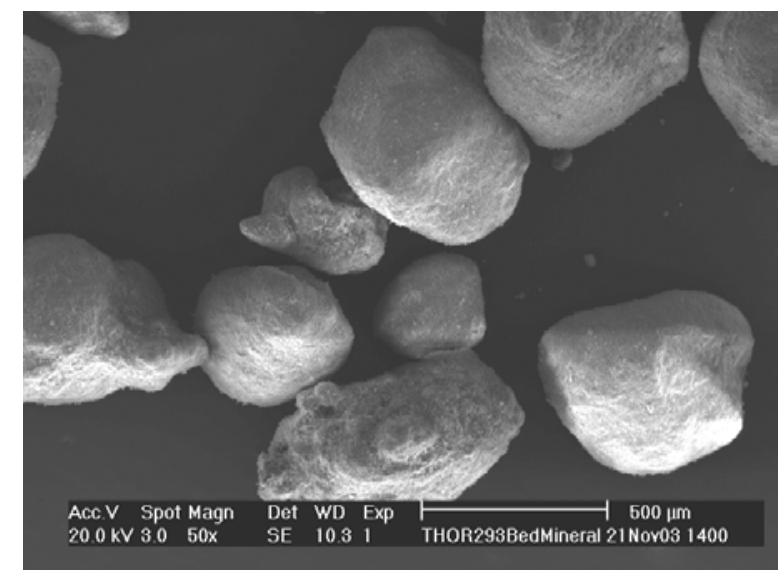

Sample 293 (493 kg CF, Test Condition 5.6)

Figure 6.2-1. SEMs of mineralized bed product at various cumulative feed amounts. 


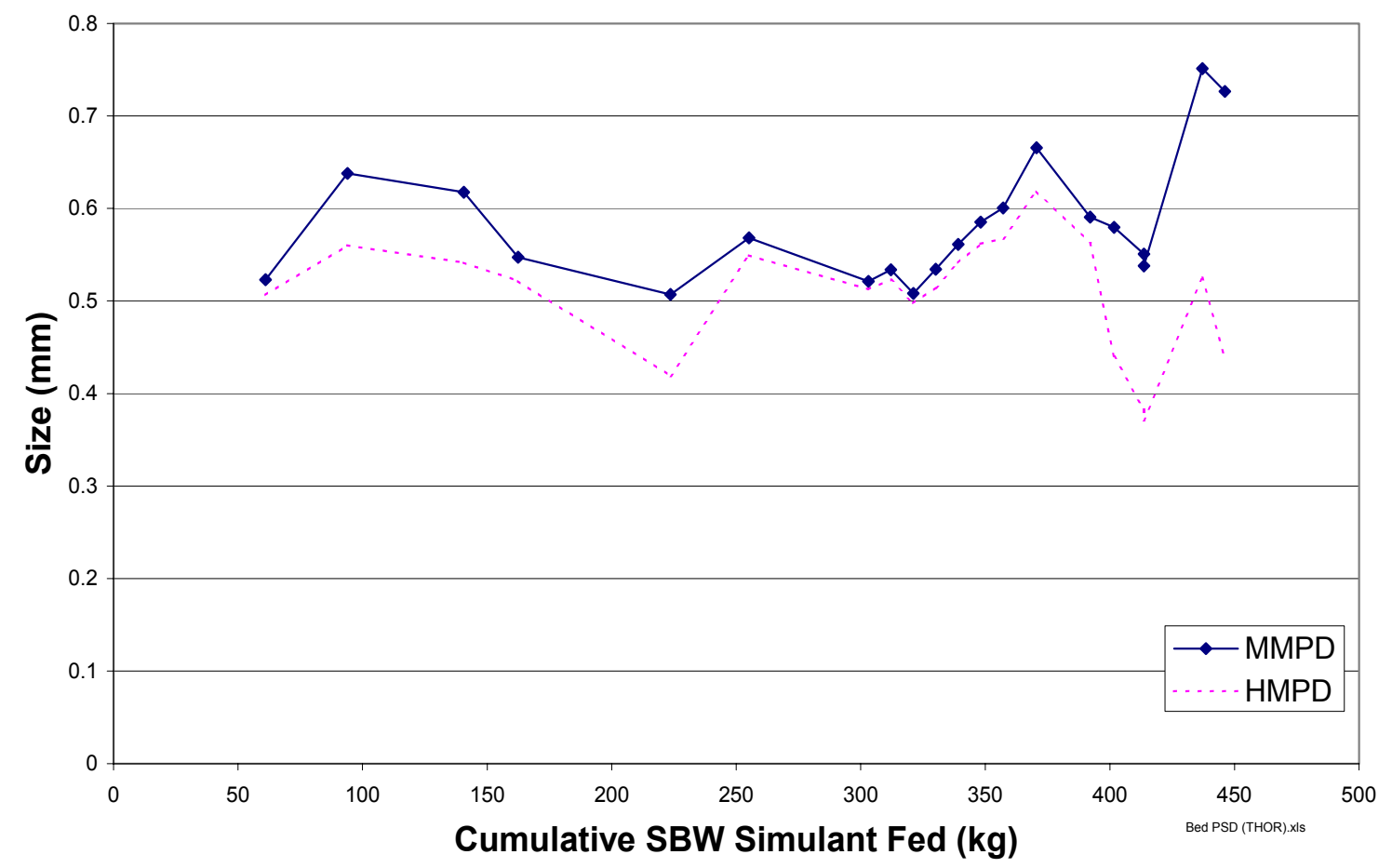

Figure 6.2-2. Mass and harmonic mean bed product particle diameter versus cumulative SBW fed.

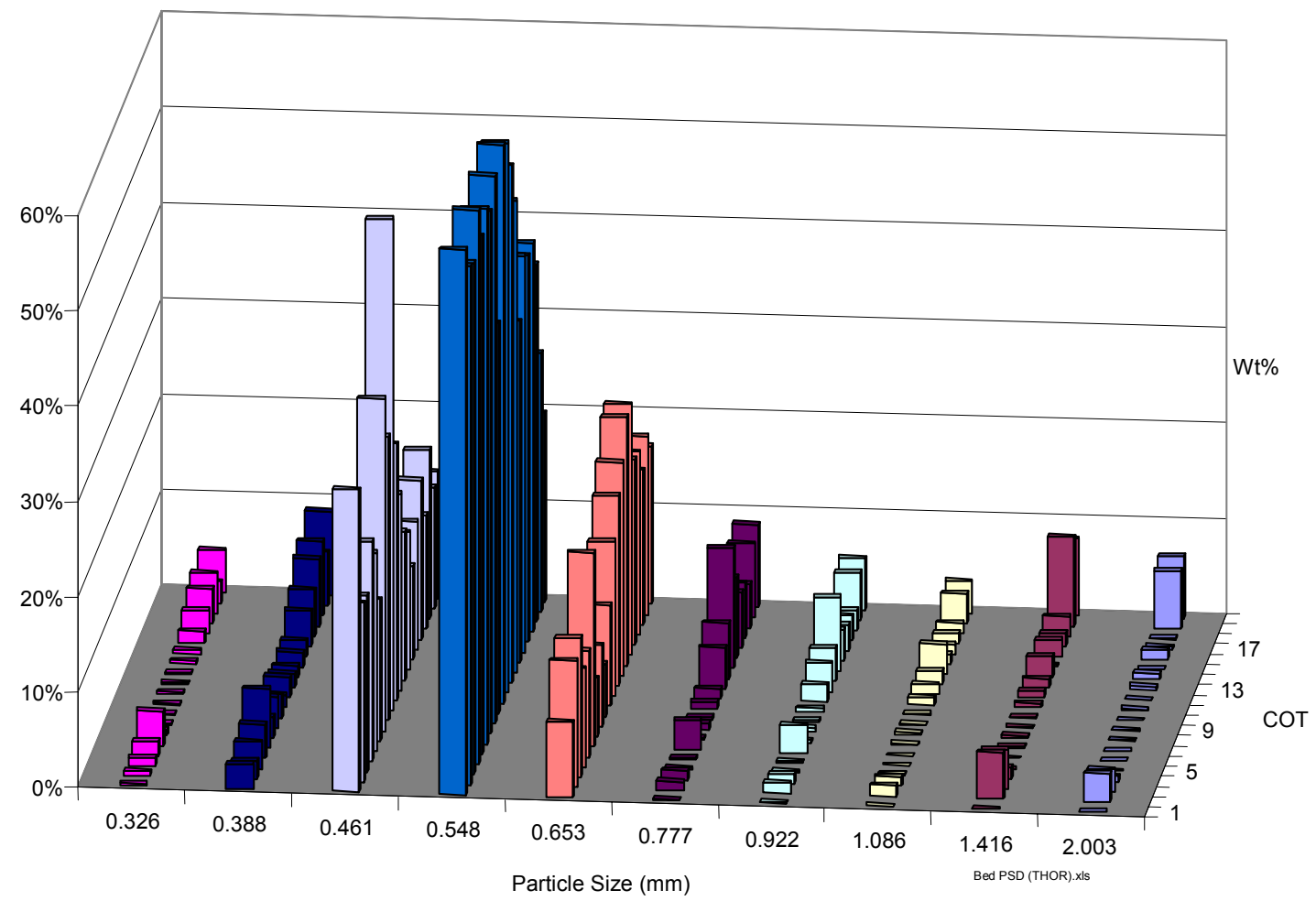

Figure 6.2-3. Mass fraction in various size ranges versus COT. (NOTE: COT axis is not linear. COT value indicates only chronological order in which samples were drawn through the run.) 


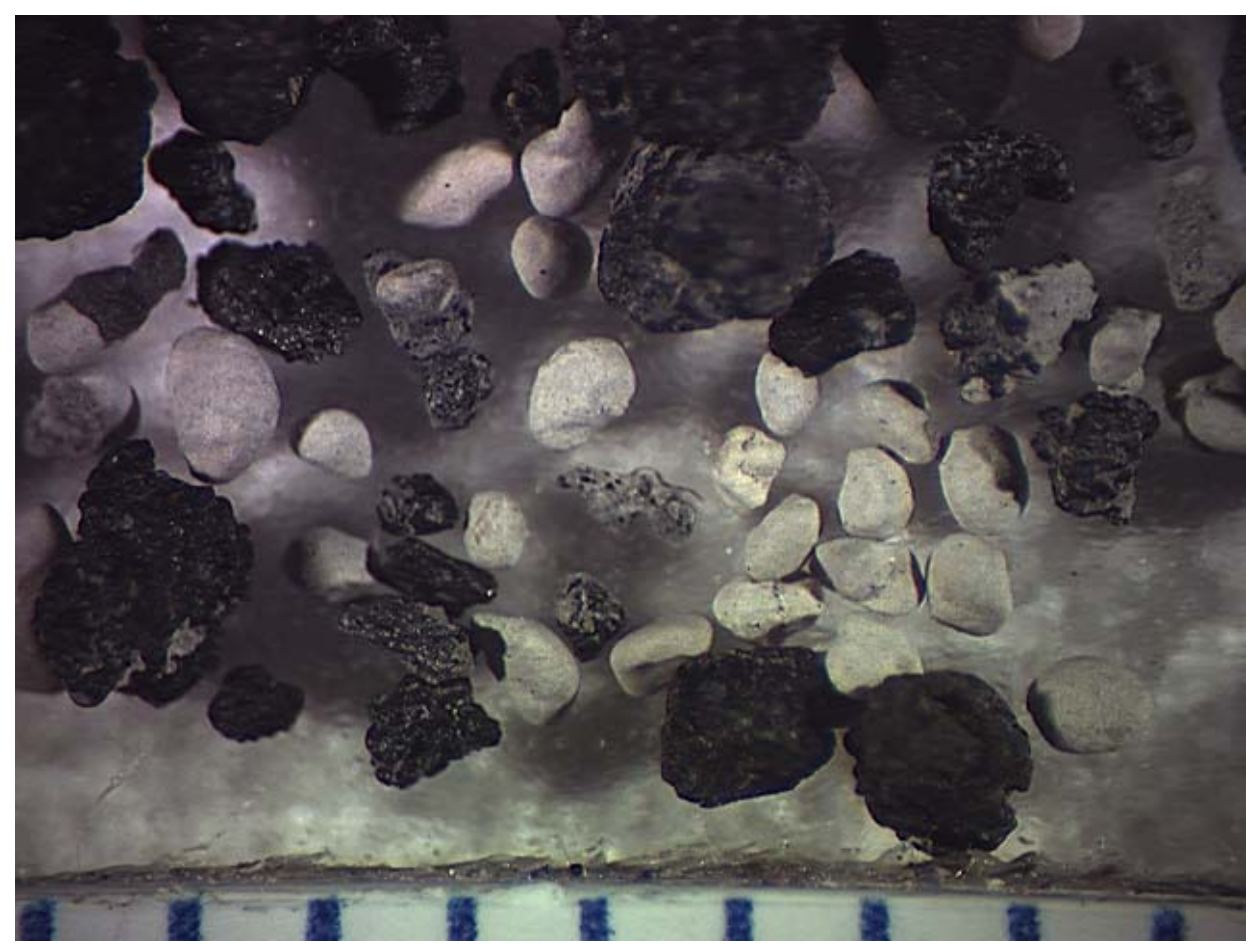

(a) Sample 166 (141 kg CF, Test Condition 4.5)

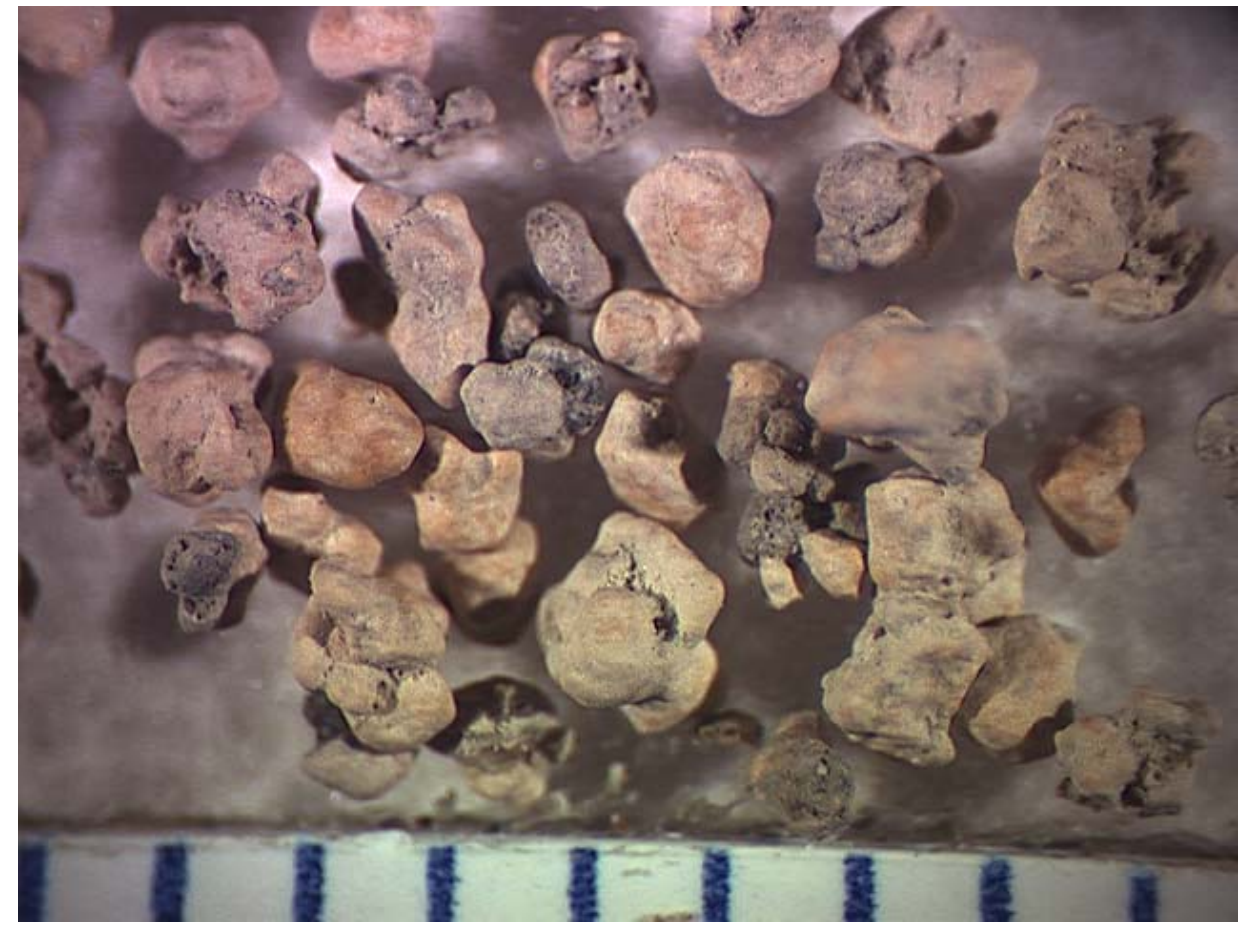

(b) Sample 234 (371 kg CF, Test Condition 5.3)

Figure 6.2-4. Optical microscope photographs of bed product particles from THOR mineralized flowsheet. Blue marks at left indicate scale (1 mm between marks). Note characteristically different shape and color of particles later in the run (b) compared with earlier (a). 

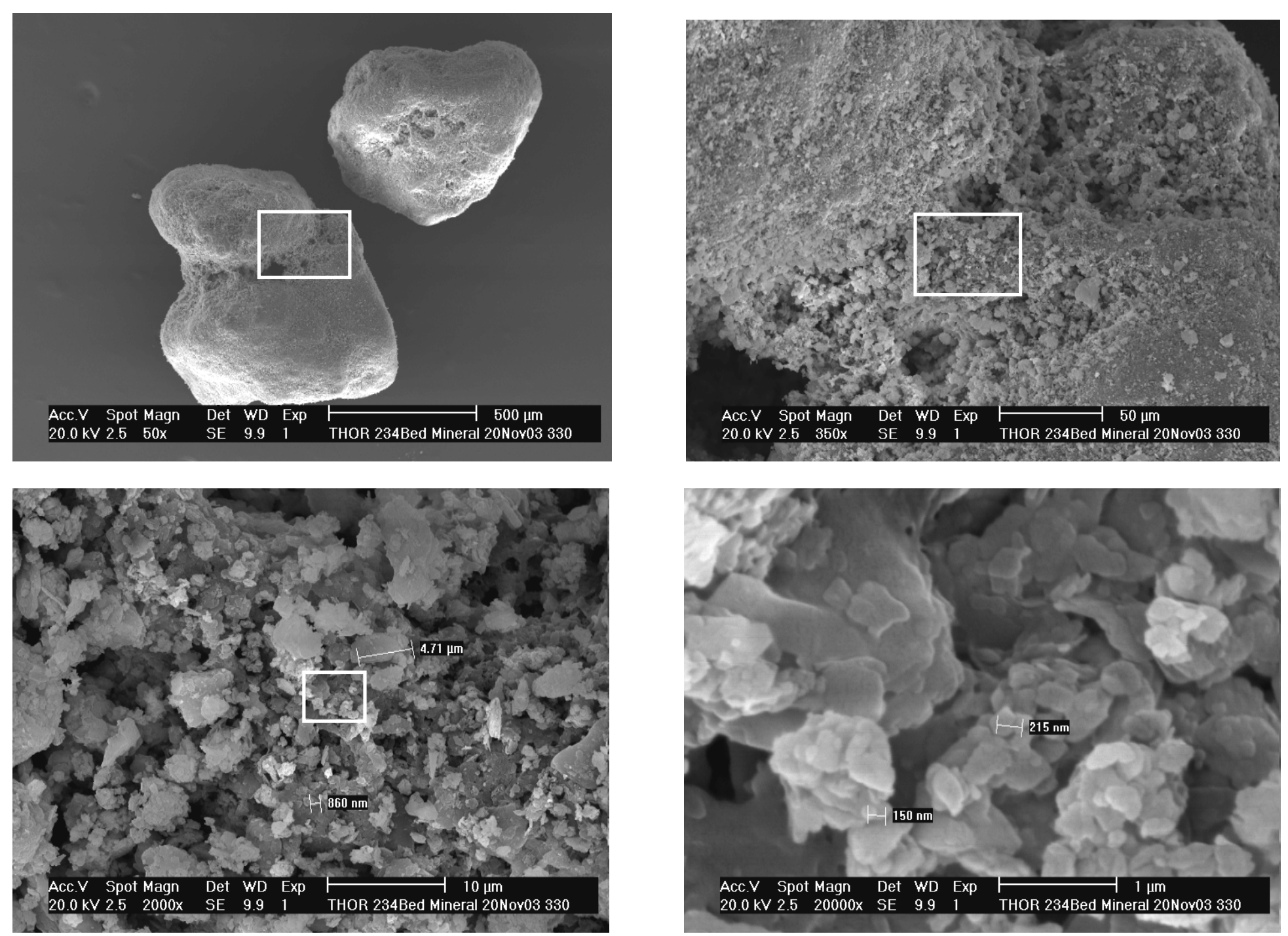

Figure 6.2-5. SEMs of THOR mineralized bed product, sample 234 (Test Condition 5.3). Scale decreases from left to right and top to bottom. Insets show field illustrated at next lower scale to right or below. 
Table 6.2-2. Bed product bulk and particle densities for THOR mineralized test series.

\begin{tabular}{|cccccc|}
\hline Sample & Date & Test Cond & $\begin{array}{c}\text { Cumulative SBW Fed } \\
(\mathrm{kg})\end{array}$ & $\begin{array}{c}\text { Particle Density } \\
(\mathrm{g} / \mathrm{cc})\end{array}$ & $\begin{array}{c}\text { Bulk Density } \\
(\mathrm{g} / \mathrm{cc})\end{array}$ \\
\hline 150 & $11 / 17 / 0314: 13$ & $4.1 \mathrm{c}$ & 25 & 3.33 & 1.96 \\
170 & $11 / 18 / 037: 15$ & $5.1 \mathrm{a}$ & 162 & 3.16 & 1.67 \\
206 & $11 / 19 / 0314: 30$ & 5.3 & 312 & 3.23 & 1.56 \\
277 & $11 / 21 / 037: 30$ & $5.5 \mathrm{a}$ & 464 & 2.42 & 0.65 \\
280 & $11 / 21 / 039: 30$ & $5.5 \mathrm{~b}$ & 473 & 2.4 & 0.705 \\
\hline
\end{tabular}

6.2.3.2 Cyclone and Filter Catches. SEMs of the solid cyclone and filter catches are shown in Figures 6.2-6 and 6.2-7. The figures for cyclone particles show both similarities and differences when compared with the corresponding SEMs for the carbonate flowsheet. The carbonate and mineralized samples are similar in that both show a broad spectrum of particle sizes and shapes. The largest particles seen in the 50x view for the mineralized flowsheet are larger those in the corresponding view for the carbonate flowsheet. However, in light of variety seen in both figures this difference is probably not representative. Significant differences in the SEMs at the smallest scale $(20,000 x$ magnification) are not evident.

The SEMs for the filter sample are very similar to the corresponding SEMs for the carbonate flowsheet. In particular, the smallest scale particles $(0.1$ to $1.0 \mu \mathrm{m})$ are comparable in both size and shape in both flow sheets.

Particle size distributions for the cyclone and filter catches were obtained using similar methods to those for the carbonate flowsheet samples. However, only one cyclone sample (Sample 165-Test Condition 4.5) was analyzed using the light scattering technique. The results of the measurement are shown in Figure 6.2-8 (solid curve). The PSD in this figure is strikingly different from the corresponding PSDs for the carbonate cyclone catch. First, the PSD in Figure 6.2-8 is unimodal. Second, the mean particle size is roughly $15 \mu \mathrm{m}$, considerably smaller than for the carbonate cyclone PSDs. In light of the difficulties experienced earlier with coagulation of carbonate cyclone particles in hexane, it is possible that the PSD in Figure 6.2-8 is anomalous. However, the lower mean particle size is consistent with the visual observation from the SEMs noted previously. As a crude check on the validity of the PSD, a manual counting of the particles in the upper right SEM of Figure 6.2-6 (350x magnification) was performed. The result of the manual count is shown in Figure 6.2-8 (dotted curve), together with the light scattering measurement. The manual count also suggests a peak about $15 \mu \mathrm{m}$, but also suggests higher peaks at larger particle sizes. Particles larger than $15 \mu \mathrm{m}$ are clearly indicated in the SEMs in Figure 6.2-8, so the light scattering measurement is not perfect. This may have been due to settling out of the larger particles before they could be counted. However, based on the data presented, it seems safe to state that the mean particle size for the cyclone catch is likely between 15 and $100 \mu \mathrm{m}$. 

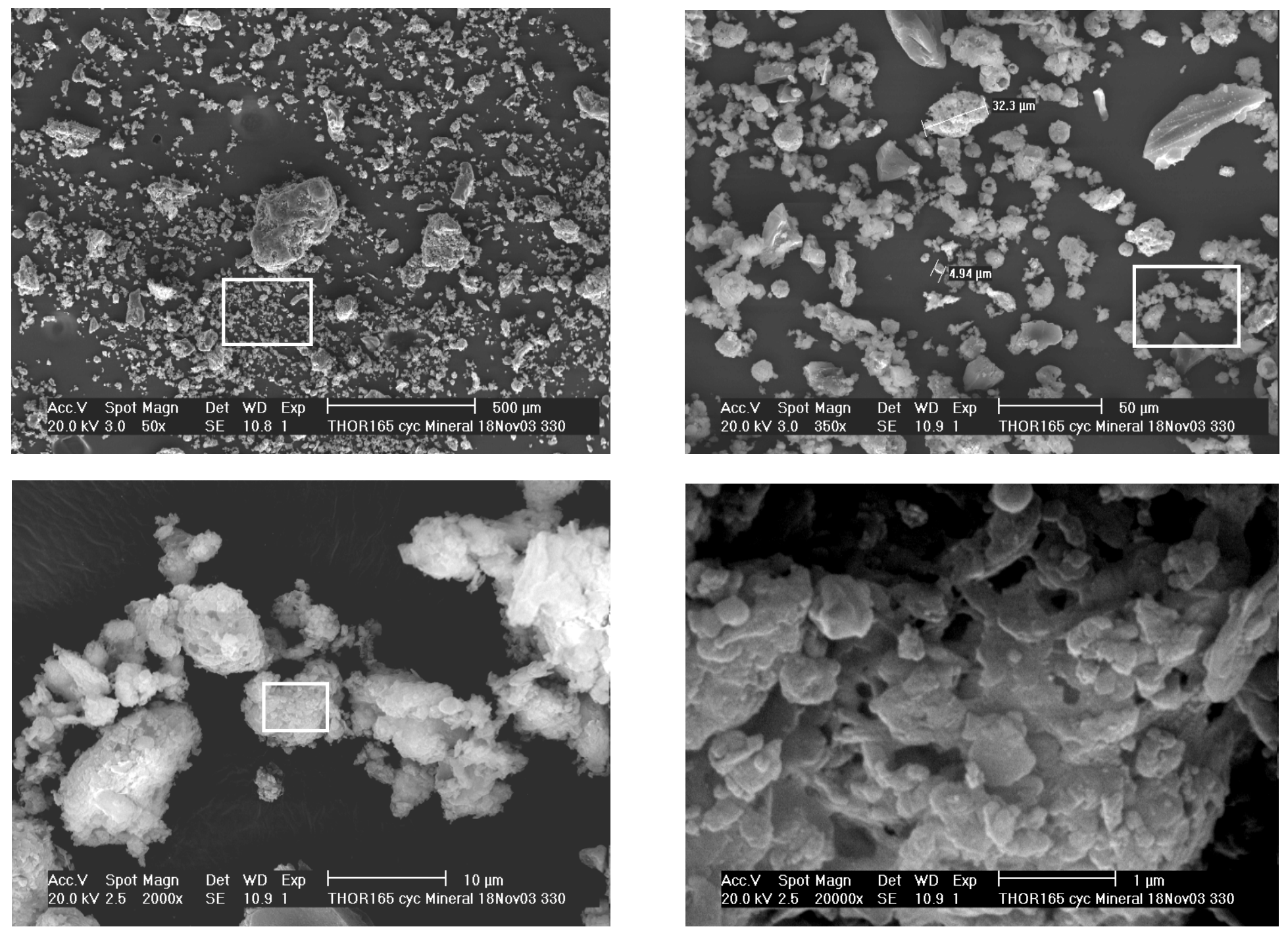

Figure 6.2-6. SEMs of THOR mineralized flowsheet cyclone catch, sample 165 (Test Condition 4.5). Scale decreases from left to right and top to bottom. Insets show field illustrated at next lower scale to right or below. 

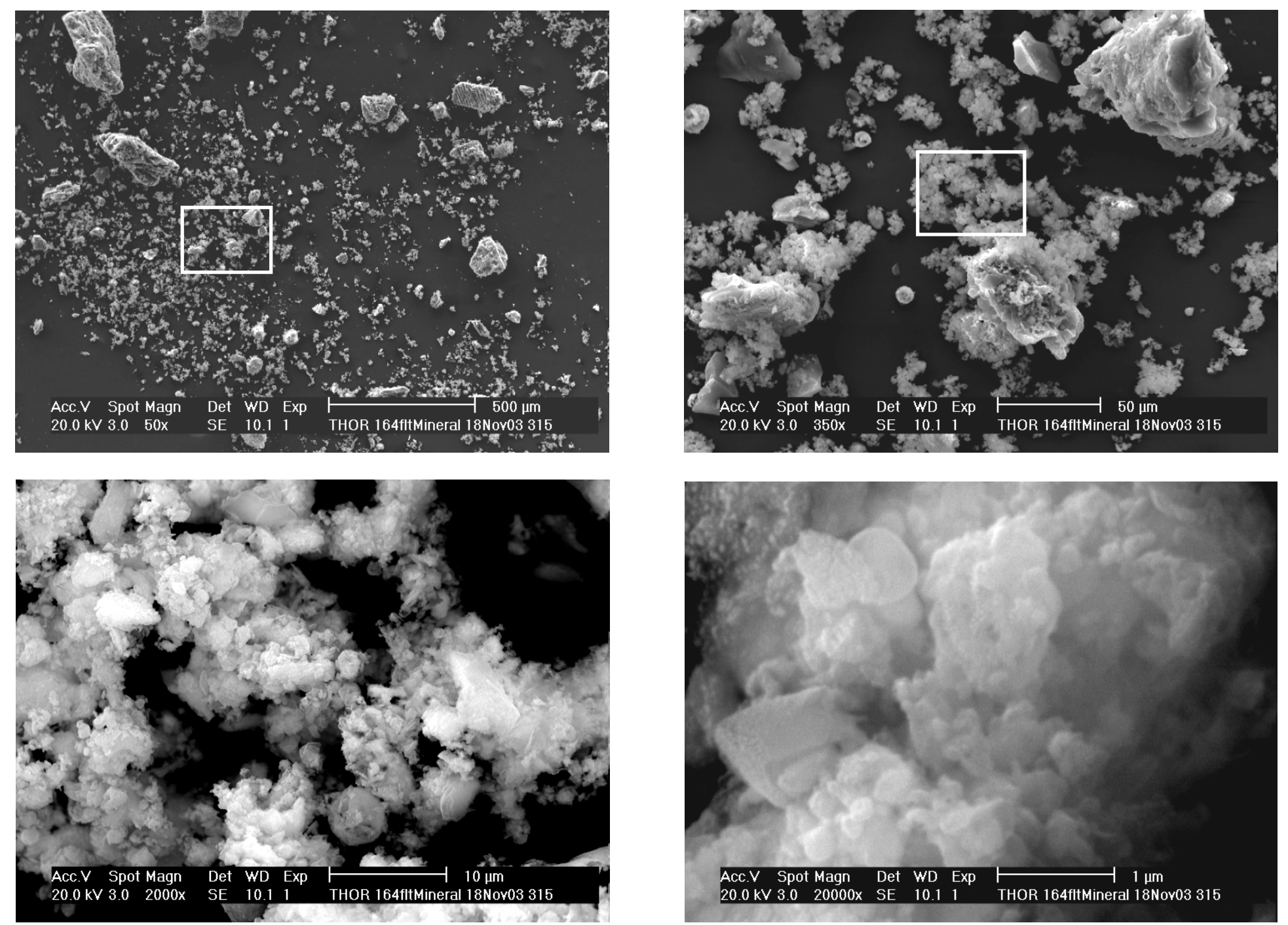

Figure 6.2-7. SEMs of THOR mineralized flowsheet filter catch, sample 164 (Test Condition 4.5). Scale decreases from left to right and top to bottom. Insets show field illustrated at next lower scale to right or below (the inset in the 2,000x SEM for the 20,000x SEM was not recognizable). 


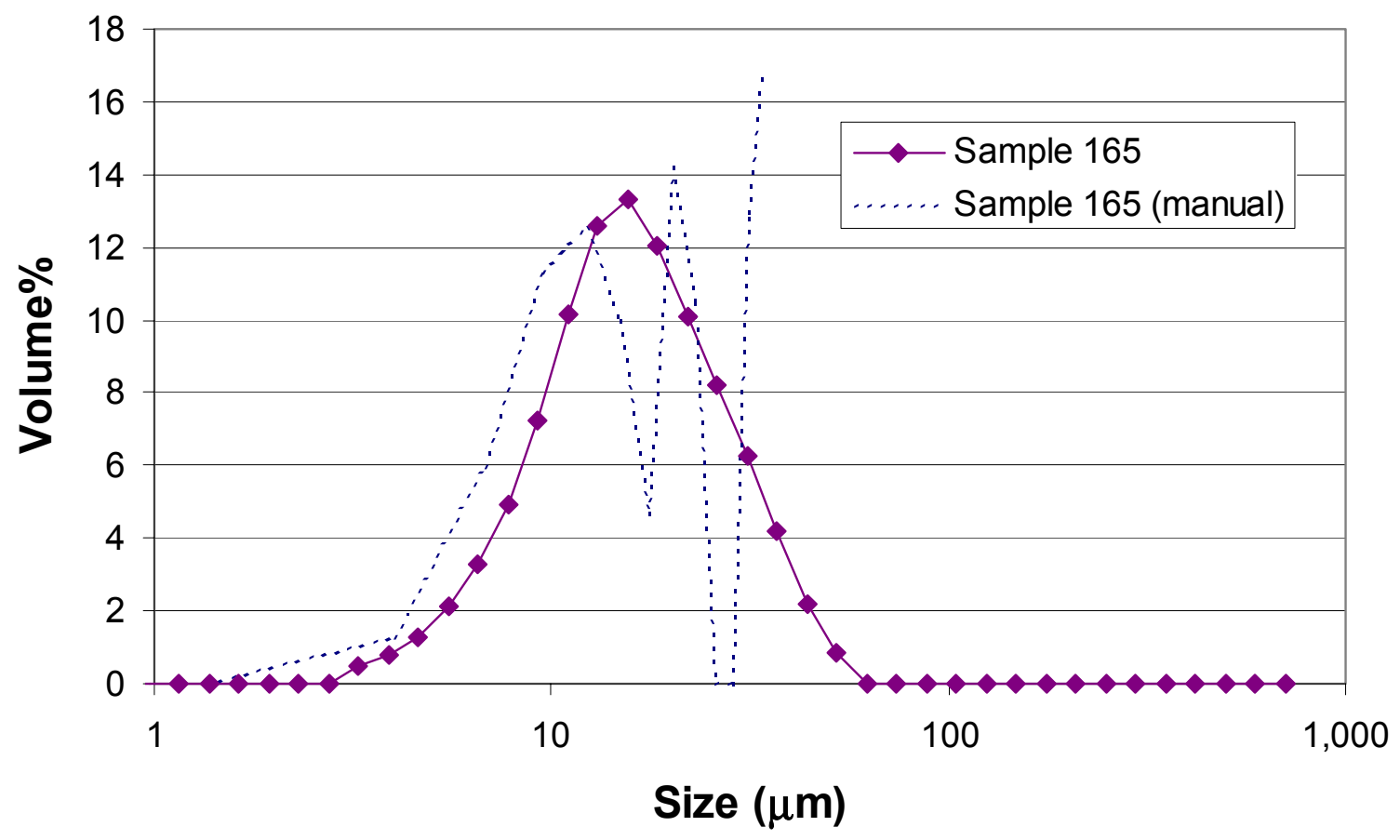

[Cyclone PSD Figures.xls]THOR

Figure 6.2-8. Cyclone catch differential PSD for the THOR mineralized test series.

An automated PSD determination for the filter catch was not made for the mineralized test series. However, a crude manual count was done for Sample 164 using the 20,000x SEM from Figure 2.6-7. The results, shown in Figure 6.2-9, indicate a small peak in the volume (mass) distribution between 0.2 and $0.6 \mu \mathrm{m}$, with larger peaks indicated at increasing particles sizes. The "sawtooth" nature of the PSD is an artifact of the limited number of particles counted (100-200), and the large particle peaks may represent composite particles that are actually agglomerations of smaller ones. However, the particles counted in the sub-0.6- $\mu \mathrm{m}$-size classes provide credible evidence of a minor peak in the mass distribution somewhere below $0.6 \mu \mathrm{m}$. This result is similar to that obtained for the carbonate flowsheet. The sizes of the smallest distinct particles could not be determined from the SEMs, but the smallest discernable particles were about $0.1 \mu \mathrm{m}$. In order to obtain an accurate accounting of the mass distribution at the smallest particle sizes, for design purposes it may be necessary to directly sample the gas stream going into the filter and size classify the aerosol using a suitable instrument (e.g., an electrostatic classifier).

Cyclone catch particle and bulk densities were not measured. Three measurements of these parameters for the filter catch are presented in Table 6.2-3. 


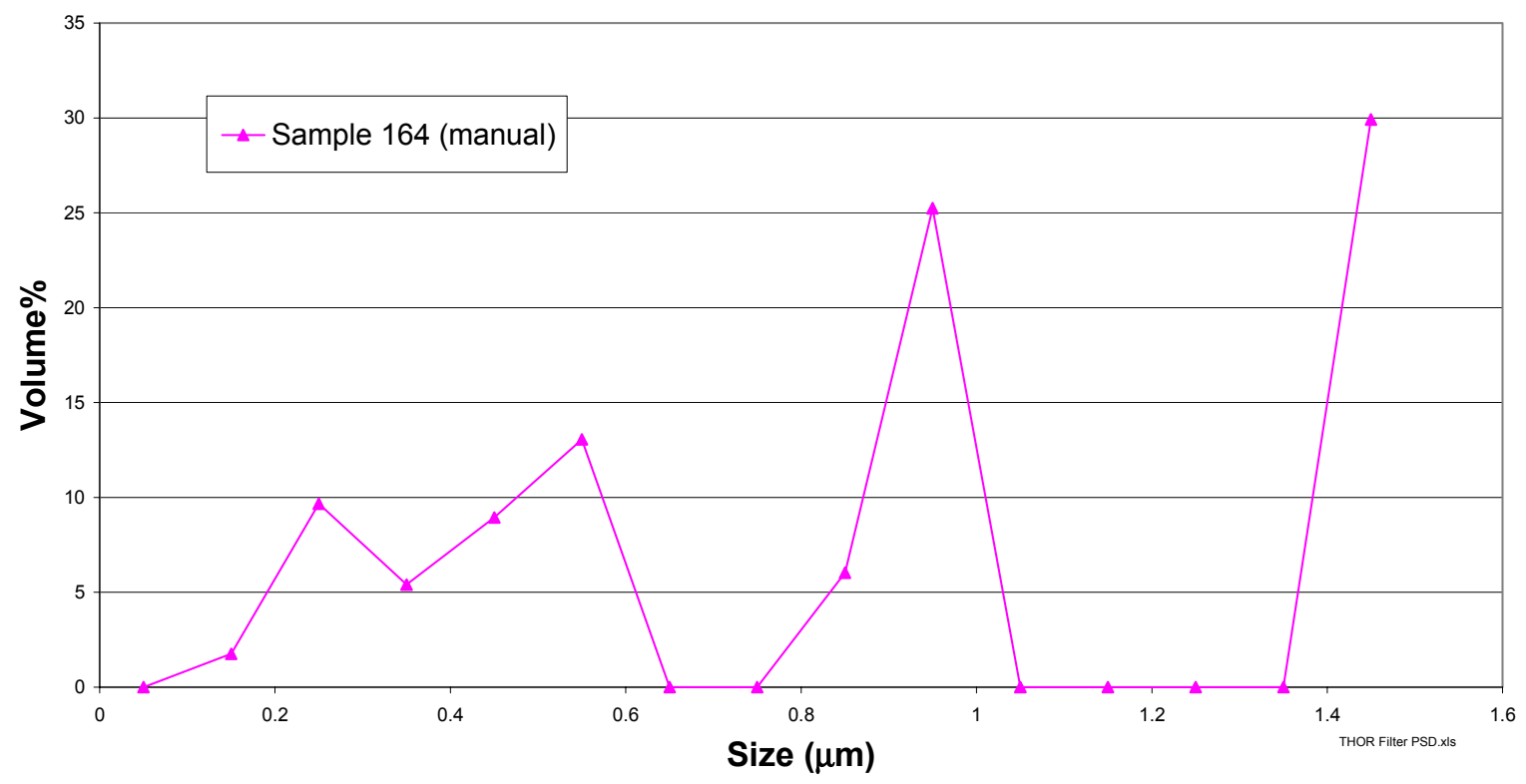

Figure 6.2-9. Filter catch differential PSD (obtained manually) for the THOR mineral test series.

Table 6.2-3. Filter catch bulk and particle densities for THOR mineral test series.

\begin{tabular}{|cccccc|}
\hline Sample & Date & Test Cond & $\begin{array}{c}\text { Cumulative SBW Fed } \\
(\mathrm{kg})\end{array}$ & $\begin{array}{c}\text { Particle Density } \\
(\mathrm{g} / \mathrm{cc})\end{array}$ & $\begin{array}{c}\text { Bulk Density } \\
(\mathrm{g} / \mathrm{cc})\end{array}$ \\
\hline 147 & $11 / 17 / 0315: 15$ & $4.1 \mathrm{c}$ & 32 & 2.71 & 0.5 wet \\
169 & $11 / 18 / 037: 15$ & $5.1 \mathrm{a}$ & 162 & 2.06 & $\begin{array}{c}0.31 \text { dry, } 0.53 \\
\text { hexane, } \\
204\end{array}$ \\
& $11 / 19 / 0314: 30$ & 5.3 & 312 & 2.56 & $\begin{array}{c}0.31 \text { dry, } 0.51 \\
\text { hexane }\end{array}$ \\
\hline
\end{tabular}

As in the case of the carbonate flowsheet, the cyclone catch for the mineralized flowsheet was recycled to the reformer to improve carbon utilization and minimize carbon in the final reformer products. The mass rate of recycle of the cyclone is tabulated below in Table 6.2-4. 
Table 6.2-4. Cyclone recycle rates for THOR mineralized flowsheet.

\begin{tabular}{|ccc|}
\hline Date & Test Cond & $\begin{array}{c}\text { Cyclone Product } \\
\text { Recycle } \\
(\mathrm{g} / \mathrm{hr})\end{array}$ \\
\hline $11 / 17 / 0315: 46$ & $4.1 \mathrm{~d}$ & 221 \\
$11 / 18 / 037: 32$ & $5.1 \mathrm{a}$ & 1,900 \\
$11 / 18 / 0311: 42$ & 5.2 & 970 \\
$11 / 18 / 0315: 38$ & $5.2 \mathrm{~b}$ & 724 \\
$11 / 19 / 0312: 50$ & 5.3 & 169 \\
$11 / 19 / 0314: 50$ & 5.3 & 528 \\
$11 / 19 / 0319: 10$ & 5.3 & 891 \\
$11 / 19 / 0320: 52$ & 5.3 & 750 \\
$11 / 19 / 0323: 54$ & 5.3 & 702 \\
$11 / 20 / 03 ~ 0: 54$ & 5.3 & 693 \\
$11 / 20 / 034: 04$ & 5.3 & 636 \\
$11 / 20 / 0319: 46$ & 5.4 & 1,479 \\
$11 / 20 / 0321: 20$ & 5.4 & 1,359 \\
$11 / 20 / 0323: 20$ & 5.4 & 1,587 \\
$11 / 21 / 03 ~ 2: 10$ & 5.5 & 1,464 \\
$11 / 21 / 03 ~ 3: 52$ & $5.5 \mathrm{a}$ & 1,238 \\
$11 / 21 / 035: 54$ & $5.5 \mathrm{a}$ & 1,215 \\
$11 / 21 / 037: 46$ & $5.5 \mathrm{a}$ & 1,175 \\
$11 / 21 / 03 ~ 9: 36$ & $5.5 \mathrm{~b}$ & 1,206 \\
$11 / 21 / 0311: 40$ & $5.5 \mathrm{c}$ & 1,251 \\
$11 / 21 / 0314: 16$ & 5.6 & 2,107 \\
\hline
\end{tabular}

[Auxilliary THOR data.xls]THOR cylone recycles 


\subsubsection{Mineralized Product Leach Tests}

Bed, cyclone, and filter samples from the mineralized testing were subjected to the EPA's Toxicity Characteristic Leaching Procedure (TCLP). Table 6.2-5 shows that all of the bed, cyclone, and filter samples easily passed TCLP limits. Of the metals included in the TCLP analysis, the feed simulant contained $\mathrm{Cr}, \mathrm{Ni}, \mathrm{Pb}$, and $\mathrm{Zn}$. $\mathrm{Cr}, \mathrm{Ni}$, and $\mathrm{Pb}$ were detected in the solid samples at high enough concentrations that would have caused the leachate to fail the TCLP limits if they significantly leached from the solid material. Except for $\mathrm{Ba}, \mathrm{Ni}$, and $\mathrm{Pb}$, all TCLP results were less than $1 \%$ of the regulatory limits. For $\mathrm{Ba}, \mathrm{Ni}$, and $\mathrm{Pb}$, the measured leachate concentrations ranged from non-detectable to a maximum of $8 \%$ of the regulatory limits. Even for the highest leach results, about $99.95 \%$ of the $\mathrm{Cr}$, $99.6 \%$ of the $\mathrm{Pb}, 98 \%$ of the $\mathrm{Ni}$, and $87 \%$ of the $\mathrm{Zn}$ was retained in the solid samples.

Product Consistency Test (PCT) leaches were performed on several bed, cyclone, and filter samples, using a modified PCT procedure developed for INEEL waste calcines. The results are still being evaluated and are not available for inclusion in this report.

\subsection{Process Effluent Compositions}

The solid and gaseous effluent compositions were determined at each effluent location. Samples of bed product, cyclone recycle, and filter catch collected both during test operations and at the end of the test series, were analyzed for the main constituents of the feed streams. The off-gas was characterized at two locations - at the outlet of the heated filter (upstream of the thermal oxidizer) and downstream of the oxidizer, wet scrubber and reheater.

\subsubsection{Solid Product Compositions}

The average product composition calculated from the SBW simulant composition is estimated in Table 6.3-1. This average composition excludes any residual alumina bed media or solid carbon. The table also shows the solid product rate and the rate of carbon used (regardless of whether the carbon comes from added sugar or added solid carbon) to form the carbonate product from the input feed solids. The product composition was estimated using simplifying assumptions based in part on chemical equilibrium composition calculations under representative steam reformer conditions using a commercial chemical equilibrium model (HSC Chemistry). The calculations included the major chemical species in the feed and expected to be potentially possible in the products (Taylor 2004). The equilibrium modeling did not account for some of the minor constituents, including $\mathrm{Cu}, \mathrm{Fe}, \mathrm{Ni}$, and $\mathrm{Pb}$, and some of the potential chloride, fluoride, phosphate, and sulfate species. Simplifying assumptions are listed in the table.

The bed product, cyclone recycle, and filter catch sample analyses are shown in Tables 6.3-2 and 6.3-3. The concentrations of primary simulant feed products $\left(\mathrm{CO}_{3}, \mathrm{~K}\right.$, and $\left.\mathrm{Na}\right)$ in the bed samples show a continuous trend of increasing amounts of simulant feed products. The amounts of these species in the bed product would continue to asymptotically approach the theoretically calculated concentrations for these species (down to $19 \% \mathrm{Al}$, and up to $19 \mathrm{wt} \% \mathrm{Si}, 2.1 \mathrm{wt} \% \mathrm{~K}$, and $13 \mathrm{wt} \% \mathrm{Na}$ ). The amounts several species in the bed near the end of the test series indicate that between $40-70 \%$ of the bed material was solids from the simulant feed rather than starting bed alumina.

The principal objective in formulating the THOR mineralized flowsheet was to produce a product that is insoluble (and presumably, non-leachable). Table 6.3-1 indicates that soluble carbonates constitute a much smaller fraction of the expected solid products for the mineralized flowsheet than was the case for the carbonate flowsheet (see Table 5-5). The measured solubilities for the mineralized bed, cyclone, and filter products are tabulated below in Table $6.3-3 \mathrm{a}$. The solubilities range from 0.8 to $4.0 \mathrm{wt} \%$, compared with corresponding values ranging from 22 to $64 \%$ for the carbonate flowsheet. 
Table 6.2-5. Results from TCLP testing of mineralized test bed, cyclone and filter products.

\begin{tabular}{|c|c|c|c|c|c|c|c|c|}
\hline \multirow[b]{3}{*}{ Element } & \multirow{3}{*}{$\begin{array}{l}\text { Reg. } \\
\text { Limit, } \\
\mathrm{mg} / \mathrm{L}\end{array}$} & \multicolumn{7}{|c|}{ Measured leachate concentr } \\
\hline & & THOR 166 & THOR 171 & THOR 234 & THOR 263 & THOR 293 & THOR 165 & THOR 172 \\
\hline & & BED & BED & BED & BED & BED & CYCLONE & CYCLONE \\
\hline \multirow{2}{*}{ Antimony } & \multirow{2}{*}{15} & $<0.039$ & k $\quad 0.039$ & $<\quad 0.039$ & 0.039 & 0.039 & k $\quad 0.039$ & $\begin{array}{ll}<\quad 0.039 \\
\end{array}$ \\
\hline & & $<\quad 0.3 \%$ & $0.3 \%$ & $<\quad 0.3 \%$ & $0.3 \%$ & $0.3 \%$ & $<\quad 0.3 \%$ & $0.3 \%$ \\
\hline \multirow{2}{*}{ Arsenic } & \multirow{2}{*}{5} & $<0.028$ & k 0.028 & $<0.028$ & 0.028 & $<0.028$ & $<\quad 0.028$ & 0.028 \\
\hline & & $<\quad 0.6 \%$ & $0.6 \%$ & $0.6 \%$ & $0.6 \%$ & $0.6 \%$ & $<\quad 0.6 \%$ & $0.6 \%$ \\
\hline \multirow{2}{*}{ Barium } & \multirow{2}{*}{100} & 0.415 & 0.298 & 1.789 & 2.710 & 0.481 & 0.139 & 0.393 \\
\hline & & $0.4 \%$ & $0.3 \%$ & $1.8 \%$ & $2.7 \%$ & $0.5 \%$ & $0.1 \%$ & $0.4 \%$ \\
\hline \multirow{2}{*}{ Beryllium } & \multirow{2}{*}{1} & 0.001 & < 0.001 & $\begin{array}{ll}<0.001 \\
\end{array}$ & 0.001 & $\begin{array}{ll}<\quad 0.001 \\
\end{array}$ & $\begin{array}{ll} & 0.001\end{array}$ & 0.001 \\
\hline & & 0.0 & 0.0 & 0.0 & 0.0 & 0.0 & 0.0 & 0.0 \\
\hline \multirow{2}{*}{ Cadmium } & \multirow{2}{*}{1} & $<\quad 0.004$ & k 0.004 & < $\quad 0.004$ & 0.004 & $<0.004$ & < $\quad 0.004$ & $\begin{array}{ll}<\quad 0.004 \\
\end{array}$ \\
\hline & & $<\quad 0.4 \%$ & $<\quad 0.4 \%$ & $<\quad 0.4 \%$ & $0.4 \%$ & $0.4 \%$ & $<\quad 0.4 \%$ & $0.4 \%$ \\
\hline \multirow{2}{*}{ Chromium } & \multirow{2}{*}{5} & 0.044 & 0.041 & 0.068 & 0.022 & 0.005 & 0.003 & 0.036 \\
\hline & & $0.9 \%$ & $0.8 \%$ & $1.4 \%$ & $0.4 \%$ & $0.1 \%$ & $0.1 \%$ & $0.7 \%$ \\
\hline \multirow{2}{*}{ Lead } & \multirow{2}{*}{5} & 0.098 & 0.122 & 0.197 & 0.263 & 0.063 & 0.031 & 0.026 \\
\hline & & $2.0 \%$ & $2.4 \%$ & $3.9 \%$ & $5.3 \%$ & $1.3 \%$ & $0.6 \%$ & $0.5 \%$ \\
\hline \multirow{2}{*}{ Nickel } & \multirow{2}{*}{20} & 0.431 & 0.352 & 0.049 & 0.125 & 0.248 & 0.220 & 1.634 \\
\hline & & $2.2 \%$ & $1.8 \%$ & $0.2 \%$ & $0.6 \%$ & $1.2 \%$ & $1.1 \%$ & $8.2 \%$ \\
\hline \multirow{2}{*}{ Selenium } & \multirow{2}{*}{5} & 0.029 & 0.029 & 0.029 & 0.029 & 0.029 & k $\quad 0.029$ & $<\quad 0.029$ \\
\hline & & $0.6 \%$ & $0.6 \%$ & $0.6 \%$ & $0.6 \%$ & $0.6 \%$ & $<\quad 0.6 \%$ & $0.6 \%$ \\
\hline \multirow{2}{*}{ Silver } & \multirow{2}{*}{5} & $<0.010$ & k 0.010 & $<\quad 0.010$ & 0.010 & 0.012 & < 0.010 & $\begin{array}{ll}<\quad 0.010 \\
\end{array}$ \\
\hline & & $<\quad 0.2 \%$ & $<\quad 0.2 \%$ & $<\quad 0.2 \%$ & $0.2 \%$ & $0.2 \%$ & $<\quad 0.2 \%$ & $0.2 \%$ \\
\hline \multirow{2}{*}{ Vanadium } & \multirow{2}{*}{24} & 0.027 & 0.034 & 0.061 & 0.063 & 0.114 & 0.026 & 0.020 \\
\hline & & $0.1 \%$ & $0.1 \%$ & $0.3 \%$ & $0.3 \%$ & $0.5 \%$ & $0.1 \%$ & $0.1 \%$ \\
\hline \multirow{2}{*}{ Zinc } & \multirow{2}{*}{250} & 0.544 & 0.274 & 2.221 & 1.603 & 0.656 & 0.695 & 0.782 \\
\hline & & $0.2 \%$ & $0.1 \%$ & $0.9 \%$ & $0.6 \%$ & $0.3 \%$ & $0.3 \%$ & $0.3 \%$ \\
\hline & & Concentr & $\begin{array}{r}\text { of metal } \\
\text { was }\end{array}$ & $\begin{array}{l}\text { in the solid } \\
\text { etained in th }\end{array}$ & $\begin{array}{l}\text { roducts (w } \\
\text { solid durit }\end{array}$ & $\begin{array}{l}\text { and the am } \\
\text { he TCLP te }\end{array}$ & $\begin{array}{l}\text { hount of those } \\
\text { sts (d) }\end{array}$ & metals that \\
\hline \multicolumn{2}{|l|}{ Chromium } & & & & $\begin{array}{r}0.02 \\
99.95 \%\end{array}$ & & & \\
\hline \multicolumn{2}{|l|}{ Lead } & & & & $\begin{array}{r}0.03 \\
99.56 \%\end{array}$ & & & \\
\hline Nickel & & & & & & & & $\begin{array}{r}0.032 \\
97.45 \%\end{array}$ \\
\hline Zinc & & & & $\begin{array}{r}0.009 \\
86.76 \% \\
\end{array}$ & & & & \\
\hline
\end{tabular}

\begin{tabular}{|c|c|c|c|c|c|c|c|}
\hline THOR 262 & THOR 294 & THOR 164 & THOR 173 & THOR 237 & THOR 261 & THOR 295 & Extractio \\
\hline C & & & IIL' & FILTER & FILTER & FILTER & Bla \\
\hline $\begin{array}{ll}k & 0.039 \\
\end{array}$ & $\begin{array}{ll}< & 0.039\end{array}$ & 0.0 & 0.039 & 0.039 & 0.039 & 0.039 & 0.039 \\
\hline < $\quad 0.3 \%$ & $0.3 \%$ & $0.3 \%$ & $0.3 \%$ & $0.3 \%$ & k & $3 \%$ & $0.3 \%$ \\
\hline $\begin{array}{ll}< & 0.028\end{array}$ & $\begin{array}{l}<\quad 0.028 \\
\end{array}$ & 0.028 & 0.028 & 0.028 & 0.028 & .028 & 0.028 \\
\hline $0.6 \%$ & $<\quad 0.6 \%$ & $0.6 \%$ & $0.6 \%$ & $0.6 \%$ & $\%$ & $0.6 \%$ & $0.6 \%$ \\
\hline 0.382 & 0.58 & 0.5 & 0.0 & 0.7 & 76 & & 0.025 \\
\hline $0.4 \%$ & 0. & 0 & 0.0 & $0.7 \%$ & $\%$ & $\%$ & $0.0 \%$ \\
\hline < 0.001 & $\begin{array}{ll}< & 0.001\end{array}$ & 0.001 & 0.001 & 0.001 & 0.001 & 1 & $\begin{array}{ll}k & 0.001\end{array}$ \\
\hline k & k & k & k & k & k & 0.0 & k \\
\hline \begin{tabular}{ll|}
$k$ & 0.004
\end{tabular} & $\begin{array}{ll}<\quad 0.004 \\
\end{array}$ & 0.004 & 0.0 & 0.004 & 04 & $\overline{54}$ & $\overline{0.004}$ \\
\hline < $\quad 0.4 \%$ & $<\quad 0.4 \%$ & < & $0_{0}$ & $0.4 \%$ & $\%$ & $\%$ & $0.4 \%$ \\
\hline 0.014 & 0.004 & $\begin{array}{l}<\quad 0.002 \\
\end{array}$ & $\begin{array}{ll}< & 0.0\end{array}$ & 0.008 & 0.002 & 02 & $\begin{array}{ll}<0.002 \\
\end{array}$ \\
\hline $0.3 \%$ & $0.1 \%$ & $0.0 \%$ & 0.0 & $0.2 \%$ & $.0 \%$ & $\%$ & $0.0 \%$ \\
\hline 75 & 032 & 0.0 & 0.022 & 80 & 56 & 22 & 0.022 \\
\hline $1.5 \%$ & & $<$ & 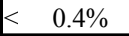 & $\%$ & $\%$ & & $0.4 \%$ \\
\hline & & & & & & & $<0.005$ \\
\hline 1. & & & & $\%$ & $\%$ & $\%$ & $0 \%$ \\
\hline 0.029 & $\begin{array}{ll}< & 0.029\end{array}$ & $\begin{array}{ll}< & 0.029\end{array}$ & \begin{tabular}{|l|}
$<\quad 0.029$ \\
\end{tabular} & 0.029 & 029 & 0.029 & $\begin{array}{ll}< & 0.029\end{array}$ \\
\hline $0.6 \%$ & $<\quad 0.6 \%$ & $0.6 \%$ & $0.6 \%$ & $0.6 \%$ & $0.6 \%$ & $0.6 \%$ & $0.6 \%$ \\
\hline 0.010 & $\begin{array}{l}k \quad 0.010 \\
\end{array}$ & $\begin{array}{l}<\quad 0.010 \\
\end{array}$ & $\begin{array}{l}<0.010 \\
\end{array}$ & $\begin{array}{l}k \quad 0.010 \\
\end{array}$ & 0.010 & 0.010 & 0.010 \\
\hline $0.2 \%$ & < $\quad 0.2 \%$ & $0.2 \%$ & $0.2 \%$ & $0.2 \%$ & $0.2 \%$ & $0.2 \%$ & $0.2 \%$ \\
\hline 0.0 & $\begin{array}{ll}< & 0.017\end{array}$ & 0.030 & 0,029 & $\begin{array}{ll}< & 0.017\end{array}$ & 0.027 & 0.022 & 0.017 \\
\hline $0.1 \%$ & < $\quad 0.1 \%$ & & 0 & $0.1 \%$ & $\%$ & $1 \%$ & < $\quad 0.1 \%$ \\
\hline 0.7 & & & 0.0 & 1.123 & 0.313 & 0.038 & $<0.055$ \\
\hline $0.3 \%$ & $0.2 \%$ & $0.4 \%$ & $0.0 \%$ & $0.4 \%$ & $0.1 \%$ & $0.0 \%$ & $0.0 \%$ \\
\hline
\end{tabular}

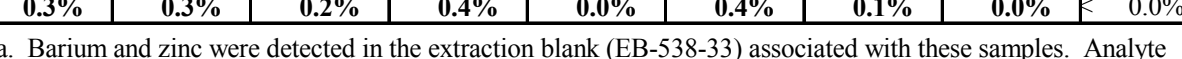
concentrations in the extraction blank may indicate a positive bias. The extraction blank result for barium is greater than $10 \%$ of the reported sample result in samples 4AA72, 4AA78, 4AA80, and 4AA81. The extraction blank result for zinc is greater than $10 \%$ of the reported sample result in samples 4AA67, 4AA68, 4AA76, 4AA78, 4AA80, and 4AA81.

b. The TCLP was was slightly modified for applicability to the mineralized product samples:

The filtered TCLP leachate was not digested prior to analysis by ICP-AES.

The sample size was less than $100 \mathrm{~g}$ because of the available sample size.

Because of sample size constraints the preliminary evaluation for extraction fluid type was not performed Extraction fluid \#2 was used for all extractions.

c. Detected values are bolded. The highest detected concentrations are highlighted in yellow. Three of the four highest detected values were detected in bed samples, not fines samples. 
Table 6.3-1. Calculated solid product distribution and composition based on chemical equilibrium calculations.

\begin{tabular}{|c|c|c|c|c|c|c|c|c|c|c|c|c|c|c|c|}
\hline \multirow[b]{2}{*}{ Test number } & & \multicolumn{4}{|c|}{ Elemental composition of solid product (a) } & \multicolumn{10}{|c|}{ Mass of solid product per liter of SBW simulant $(\mathrm{a}, \mathrm{b}, \mathrm{c}, \mathrm{d})$} \\
\hline & & $\begin{array}{l}4.1 \text { to } 5.2,5.2 \mathrm{~b}, \\
\text { and } 5.2 \mathrm{c}\end{array}$ & $5.2 \mathrm{a}$ & $5.2 \mathrm{~d}$ to 5.3 & 5.4 to 5.6 & $\begin{array}{l}4.1 \text { to } 5.2,5.2 \mathrm{~b}, \\
\text { and } 5.2 \mathrm{c}\end{array}$ & $5.2 \mathrm{a}$ & $5.2 \mathrm{~d}$ to 5.3 & 5.4 to 5.6 & \multirow{3}{*}{$\begin{array}{l}\text { Product } \\
\text { species }\end{array}$} & \multirow[b]{3}{*}{ Mole weight } & \begin{tabular}{|c}
4.1 to $5.2,5.2 \mathrm{~b}$, \\
and $5.2 \mathrm{c}$
\end{tabular} & $5.2 \mathrm{a}$ & $5.2 \mathrm{~d}$ to 5.3 & 5.4 to 5.6 \\
\hline \multirow[b]{2}{*}{ Component } & \multirow{2}{*}{$\begin{array}{c}\text { Mole } \\
\text { weight }\end{array}$} & $\begin{array}{c}\text { Supernate w/ Clay } \\
\& \mathrm{Si} \\
\end{array}$ & $\begin{array}{c}\text { w/ Clay, Si, } \\
\& \mathrm{Fe}\end{array}$ & $\begin{array}{c}\text { w/ Xtra Clay } \\
\& \mathrm{Si}\end{array}$ & $100 \%$ Clay & $\begin{array}{l}\text { Supernate w/ } \\
\text { Clay \& Si }\end{array}$ & $\begin{array}{c}\text { w/ Clay, } \mathrm{Si}, \\
\& \mathrm{Fe}\end{array}$ & $\begin{array}{c}\text { w/ Xtra } \\
\text { Clay \& Si }\end{array}$ & \multirow{2}{*}{$\begin{array}{c}100 \% \text { Clay } \\
\mathrm{gm} / \mathrm{L} \\
\end{array}$} & & & \multirow{2}{*}{$\begin{array}{l}\text { Supernate } \mathrm{w} / \\
\text { Clay \& Si } \\
\mathrm{gm} / \mathrm{L}\end{array}$} & \multirow[t]{2}{*}{$\begin{array}{l}\text { w/ Clay, Si, } \\
\qquad \mathrm{Fe} \\
\mathrm{gm} / \mathrm{L}\end{array}$} & \multirow{2}{*}{$\begin{array}{c}\mathrm{w} / \mathrm{Xtra} \\
\text { Clay \& Si } \\
\mathrm{gm} / \mathrm{L}\end{array}$} & \multirow{2}{*}{$\frac{100 \% \text { Clay }}{\mathrm{gm} / \mathrm{L}}$} \\
\hline & & Weight $\%$ & Weight $\%$ & Weight $\%$ & Weight \% & $\mathrm{gm} / \mathrm{L}$ & $\mathrm{gm} / \mathrm{L}$ & $\mathrm{gm} / \mathrm{L}$ & & & & & & & \\
\hline Acid & 1.01 & --- & --- & --- & --- & --- & --- & --- & --- & --- & --- & --- & --- & --- & $\overline{---}$ \\
\hline Aluminum & 26.98 & 19 & 18 & 20 & 21 & 60 & 60 & 70 & 72 & $\begin{array}{l}\mathrm{NaAlSiO} 4 \\
\mathrm{Al} 2 \mathrm{O} 3\end{array}$ & $\begin{array}{l}142.1 \\
102.0\end{array}$ & $\begin{array}{c}228 \\
0\end{array}$ & $\begin{array}{c}228 \\
0\end{array}$ & $\begin{array}{c}221 \\
0\end{array}$ & $\begin{array}{c}229 \\
26\end{array}$ \\
\hline Boron & 10.81 & 0.037 & 0.036 & 0.033 & 0.036 & 0.12 & 0.12 & 0.12 & 0.12 & $\mathrm{~B} 2 \mathrm{O} 3$ & 69.6 & 0.39 & 0.39 & 0.38 & 0.39 \\
\hline Calcium & 40.1 & 0.52 & 0.52 & 0.47 & 0.51 & 1.7 & 1.7 & 1.7 & 1.7 & $\mathrm{CaCO} 3$ & 100.1 & 4.26 & 4.26 & 4.14 & 4.26 \\
\hline Cesium & 132.9 & 0.12 & 0.12 & 0.11 & 0.12 & 0.39 & 0.39 & 0.38 & 0.39 & $\mathrm{Cs} 2 \mathrm{CO} 3$ & 325.8 & 0.48 & 0.48 & 0.46 & 0.48 \\
\hline Chromium & 52.0 & 0.048 & 0.048 & 0.043 & 0.047 & 0.16 & 0.16 & 0.15 & 0.16 & $\mathrm{Cr} 2 \mathrm{O} 3$ & 152.0 & 0.23 & 0.23 & 0.22 & 0.23 \\
\hline Copper & 63.5 & 0.012 & 0.012 & 0.011 & 0.012 & 0.040 & 0.040 & 0.039 & 0.040 & $\mathrm{CuO}$ & 79.5 & 0.050 & 0.050 & 0.049 & 0.050 \\
\hline Iron & 55.9 & 0.34 & 1.19 & 0.30 & 0.33 & 1.1 & 3.9 & 1.1 & 1.1 & $\mathrm{FeO}$ & 71.9 & 1.4 & 5.0 & 1.4 & 1.4 \\
\hline Lead & 207.2 & 0.076 & 0.075 & 0.068 & 0.074 & 0.25 & 0.25 & 0.24 & 0.25 & $\mathrm{PbO}$ & 223.2 & 0.27 & 0.27 & 0.26 & 0.27 \\
\hline Magnesium & 24.3 & 0.081 & 0.080 & 0.072 & 0.079 & 0.26 & 0.26 & 0.26 & 0.26 & $\mathrm{MgCO} 3$ & 84.3 & 0.91 & 0.91 & 0.89 & 0.91 \\
\hline Manganese & 54.9 & 0.21 & 0.21 & 0.19 & 0.21 & 0.70 & 0.70 & 0.68 & 0.70 & $\mathrm{MnCO} 3$ & 114.9 & 1.5 & 1.5 & 1.4 & 1.5 \\
\hline Mercury & 200.6 & --- & --- & --- & --- & --- & --- & --- & --- & --- & --- & --- & --- & --- & --- \\
\hline Nickel & 58.7 & 0.024 & 0.024 & 0.021 & 0.023 & 0.078 & 0.078 & 0.076 & 0.078 & $\mathrm{NiO}$ & 74.7 & 0.10 & 0.10 & 0.10 & 0.10 \\
\hline Potassium & 39.1 & 2.1 & 2.1 & 1.9 & 2.1 & 6.9 & 6.9 & 6.7 & 6.9 & KAlSiO4 & 158.2 & 28 & 28 & 27 & 28 \\
\hline \multirow[t]{4}{*}{ Rhenium } & 186.2 & 0.056 & 0.055 & 0.049 & 0.054 & 0.18 & 0.18 & 0.18 & 0.18 & Re2O3 & 420.4 & 0.20 & 0.20 & 0.20 & 0.20 \\
\hline & 28.1 & 19 & 19 & 20 & 17 & 63 & 63 & 73 & 58 & $\mathrm{SiO} 2$ & 60.1 & 0 & 0 & 0 & 0 \\
\hline & 23.0 & 13 & 13 & 12 & 13 & 43 & 43 & 42 & 43 & --- & --- & --- & --- & --- & --- \\
\hline & 65.4 & 0.019 & 0.019 & 0.017 & 0.019 & 0.062 & 0.062 & 0.060 & 0.062 & $\mathrm{ZnCO} 3$ & 150.7 & 0.14 & 0.14 & 0.14 & 0.14 \\
\hline Chloride & 35.5 & 0.29 & 0.29 & 0.26 & 0.29 & 0.96 & 0.96 & 0.93 & 0.96 & $\mathrm{NaCl}$ & 58.4 & 1.6 & 1.6 & 1.5 & 1.6 \\
\hline Fluoride & 19.0 & 0.12 & 0.12 & 0.11 & 0.12 & 0.41 & 0.41 & 0.39 & 0.41 & $\mathrm{NaF}$ & 42.0 & 0.9 & 0.9 & 0.9 & 0.9 \\
\hline Nitrate & 62.0 & --- & --- & --- & --- & --- & --- & --- & --- & --- & --- & --- & --- & --- & --- \\
\hline Phosphate & 95.0 & 0.76 & 0.75 & 0.68 & 0.74 & 2.5 & 2.5 & 2.4 & 2.5 & Na3PO4 & 163.9 & 4.3 & 4.3 & 4.1 & 4.3 \\
\hline Sulfate & 96.1 & 1.9 & 1.8 & 1.7 & 1.8 & 6.0 & 6.0 & 5.9 & 6.0 & $\mathrm{Na} 2 \mathrm{SO} 4$ & 142.0 & 8.9 & 8.9 & 8.7 & 8.9 \\
\hline Carbonate & 60.0 & 1.3 & 1.2 & 1.1 & 1.2 & & & & & A12Si2O5 & 190.1 & 44 & 44 & 82 & 25 \\
\hline Oxide & 16.0 & 41 & 41 & 41 & 41 & & & & & & & & & & \\
\hline Total & --- & 100.0 & 100.0 & 100.0 & 100.7 & 188 & 191 & 205 & 194 & Total & --- & 325 & 329 & 355 & 333 \\
\hline \multirow{3}{*}{\multicolumn{3}{|c|}{$\begin{array}{l}\mathrm{Na} \text { available after reaction with anions in feed } \\
\mathrm{Al}(\mathrm{Na}+\mathrm{K}) \text { molar ratio } \\
\mathrm{Si}(\mathrm{Na}+\mathrm{K}) \text { mole ratio }\end{array}$}} & & & & 37 & 37 & 36 & 37 & & & & & & \\
\hline & & & & & & 1.3 & 1.3 & 1.5 & 1.5 & & & & & & \\
\hline & & & & & & 1.3 & 1.3 & 1.5 & 1.1 & & & & & & \\
\hline
\end{tabular}

a. Not including any starting bed material or organic carbon, and assuming no volatilization except for water, acid, and nitrate.

b. Assume that $\mathrm{Na}$ reacts with anions in feed for produce $\mathrm{NaCl}, \mathrm{NaF}, \mathrm{Na} 3 \mathrm{PO} 4, \mathrm{Na} 2 \mathrm{SO} 4$; remaining $\mathrm{Na}$ is available to form nephelene with available $\mathrm{Al}$ and $\mathrm{Si}$.

c. Assume that nephelene (NaAlSiO4, also known as $\left.\mathrm{Na}_{2} \mathrm{O} * \mathrm{Al} 2 \mathrm{O} 3 *(\mathrm{SiO} 2) 2\right)$ is formed from available $\mathrm{Na}, \mathrm{Al}$, and $\mathrm{Si}$. Assume that $\mathrm{K}$ also reacts with available $\mathrm{Al}$ and $\mathrm{Si}$ to form $\mathrm{KAlSiO}$. Any remaining $\mathrm{Al}$ and $\mathrm{Si}$ forms Al2Si2O5; any excess $\mathrm{Al}$ forms $\mathrm{Al} 2 \mathrm{O} 3$.

d. Assume that remainder of cations produce either oxides or carbonates, consistent with a carbonate product. 
Table 6.3-2. Elemental composition of the bed product for the THOR mineral test series.

\begin{tabular}{|c|c|c|c|c|c|c|c|c|c|c|c|c|c|c|c|c|c|c|c|c|c|c|c|c|c|c|c|}
\hline \multirow[b]{2}{*}{ Sample } & \multirow[b]{2}{*}{ Sample date } & \multirow[b]{2}{*}{$\begin{array}{l}\text { Test } \\
\text { Cond }\end{array}$} & \multicolumn{25}{|c|}{ Measured concentrations, wt $\%$} \\
\hline & & & TOC & $\mathrm{CO}_{3}$ & $\mathrm{NO}_{3}$ & $\mathrm{PO}_{4}$ & $\mathrm{SO}_{4}$ & $\mathrm{Cl}$ & $\mathrm{F}$ & Al & $\mathrm{Ca}$ & $\mathrm{Cr}$ & Cs & $\mathrm{Cu}$ & $\mathrm{Fe}$ & $\mathrm{Hg}$ & K & $\mathrm{Mg}$ & $\mathrm{Mn}$ & $\mathrm{Na}$ & $\mathrm{Ni}$ & $\mathrm{Pb}$ & $\operatorname{Re}$ & $\mathrm{Si}$ & Sn & $\mathrm{Zn}$ & $\mathrm{Zr}$ \\
\hline 166 & $11 / 18 / 20034: 30$ & 4.5 & 5.1 & 0.04 & 0.006 & 0.117 & 0.021 & 0.007 & 0.01 & 2.95 & 0.204 & 0.01 & 0.003 & 0.00 & 0.195 & --- & 0.391 & 0.026 & 0.05 & 2.33 & 0.01 & 0.01 & 0.00 & 0.065 & -- & 0.007 & -- \\
\hline 171 & 11/18/2003 11:15 & 5.2 & 0.16 & 0.02 & 0.006 & 0.23 & 0.016 & 0.017 & 0.01 & 4.77 & 0.287 & 0.01 & 0.026 & 0.01 & 0.232 & -- & 0.709 & 0.042 & 0.071 & 3.6 & 0.01 & 0.02 & 0.01 & 0.025 & -- & .012 & - \\
\hline 234 & $11 / 20 / 20033: 30$ & 5.3 & 0 & 0.02 & 0.006 & 0.046 & 0.013 & 0.006 & 0.01 & 1.01 & 0.303 & 0.02 & 0.02 & 0.01 & 0.348 & -- & 1.11 & 0.045 & 0.075 & 7.27 & 0.01 & 0.03 & 0.01 & 0.018 & -- & 0.009 & -- \\
\hline 263 & $11 / 21 / 20031: 30$ & 5.5 & 7.8 & 0.02 & 0.006 & 0.245 & 0.012 & 0.022 & 0.01 & 9.48 & 0.306 & 0.02 & 0.042 & 0.01 & 0.304 & - & 1.31 & 0.048 & 0.077 & 6.84 & 0.01 & 0.03 & 0.03 & 0.022 & -- & 0.011 & --- \\
\hline 293 & $11 / 21 / 200314: 00$ & 5.6 & 5.4 & 0.02 & 0.007 & 0.194 & 0.205 & 0.037 & 0.01 & 12.8 & 0.734 & 0.03 & 0.019 & 0.01 & 1.66 & 0.000 & 2.02 & 0.089 & 0.138 & 8.87 & 0.01 & 0.05 & 0.01 & 0.013 & -- & 0.017 & -- \\
\hline \multicolumn{4}{|c|}{ Calculated product composition, wt $\%$} & 1.212 & --- & 0.727 & 1.785 & 0.283 & 0.12 & 19.53 & 0.503 & 0.05 & 0.115 & 0.012 & 0.337 & 0.000 & 2.038 & 0.078 & 0.206 & 12.59 & 0.023 & 0.073 & 0.053 & 19.3 & --- & 0.018 & -- \\
\hline \multicolumn{4}{|c|}{$\begin{array}{l}\text { Highest measured concentration as a percent of the } \\
\text { calculated product composition }\end{array}$} & 3.3 & & 33.69 & 11.48 & 12.91 & 5.446 & 65.52 & 145.9 & 58.94 & 37.01 & 112.1 & 492.7 & - & 99.13 & 114.2 & 67 & 70.44 & 56.67 & 69.99 & 57.26 & 0.339 & --- & 92.02 & -- \\
\hline
\end{tabular}

The feed constituents gradually increase in the bed product as the mass of starting bed in the fluidized bed is replaced by solid feed products.

[Master Analytical Data (ddt).xls]Master RFA (2)

Note 2: $\quad$ Parts of the mineralized product were suspected to be undissolved by the digestion procedure used by the analytical lab. This was confirmed after selected samples were re-analyzed using an aggressive digestion with HF and HNO3. Analysis of these samples gave Si concentrations 51 to 106 times the table values. The concentration of Al for sample 8 reported by the lab was only $\sim 0.45 \%$ of the theoretical value for virgin bed material.

Table 6.3-3. Elemental composition of the cyclone and filter catch samples for the THOR mineral test series.

\begin{tabular}{|c|c|c|c|c|c|c|c|c|c|c|c|c|c|c|c|c|c|c|c|c|c|c|c|c|c|c|c|}
\hline \multirow[b]{2}{*}{ Sample } & \multirow[b]{2}{*}{ Sample date } & \multirow[b]{2}{*}{$\begin{array}{l}\text { Test } \\
\text { Cond }\end{array}$} & \multicolumn{25}{|c|}{ Measured concentrations, wt $\%$} \\
\hline & & & TOC & $\mathrm{CO}_{3}$ & $\mathrm{NO}_{3}$ & $\mathrm{PO}_{4}$ & $\mathrm{SO}_{4}$ & $\mathrm{Cl}$ & $\mathrm{F}$ & $\mathrm{Al}$ & $\mathrm{Ca}$ & $\mathrm{Cr}$ & Cs & $\mathrm{Cu}$ & $\mathrm{Fe}$ & $\mathrm{Hg}$ & $\mathrm{K}$ & $\mathrm{Mg}$ & $\mathrm{Mn}$ & $\mathrm{Na}$ & $\mathrm{Ni}$ & $\mathrm{Pb}$ & $\operatorname{Re}$ & $\mathrm{Si}$ & $\mathrm{Sn}$ & $\mathrm{Zn}$ & $\mathrm{Zr}$ \\
\hline \multicolumn{28}{|c|}{ Cyclone samples } \\
\hline 165 & 11/18/2003 3:30 & 4.5 & --- & --- & 0.038 & 2.28 & 0.416 & 0.163 & 0.038 & 9.58 & 0.273 & 0.024 & 0.09 & 0.008 & 0.317 & --- & 1.44 & 0.054 & 0.077 & 8.61 & 0.017 & 0.048 & 0.043 & 0.024 & --- & 0.008 & --- \\
\hline 172 & 11/18/2003 11:15 & 5.2 & --- & --- & 0.041 & 2.07 & 0.239 & 0.202 & 0.041 & 9.68 & 0.292 & 0.024 & 0.103 & 0.008 & 0.319 & --- & 1.29 & 0.061 & 0.09 & 8.68 & 0.032 & 0.048 & 0.055 & 0.035 & --- & 0.01 & --- \\
\hline 239 & 11/20/2003 6:30 & 5.3 & --- & --- & 0.009 & 0.156 & 0.029 & 0.085 & 0.01 & 12.7 & 0.323 & 0.029 & 0.111 & 0.007 & 0.457 & --- & 1.42 & 0.07 & 0.102 & 8.17 & 0.024 & 0.051 & 0.044 & 0.027 & --- & 0.007 & --- \\
\hline 262 & 11/21/2003 1:30 & 5.5 & --- & --- & 0.041 & 1.49 & 0.085 & 0.067 & 0.041 & 11.6 & 0.313 & 0.025 & 0.078 & 0.01 & 0.435 & --- & 1.15 & 0.069 & 0.101 & 8.43 & 0.017 & 0.067 & 0.038 & 0.014 & -.- & 0.011 & -.- \\
\hline 294 & $11 / 21 / 200314: 00$ & 5.6 & 13.1 & 0.436 & 0.008 & 0.017 & 0.342 & 0.081 & 0.011 & 9.58 & 1.25 & 0.022 & 0.07 & 0.007 & 16.9 & $3 \mathrm{E}-05$ & 1.22 & 0.098 & 0.135 & 6.81 & 0.019 & 0.029 & 0.045 & 0.032 & --- & 0.01 & --- \\
\hline \multicolumn{3}{|c|}{ Cyclone averages } & 13.1 & 0.436 & 0.028 & 1.203 & 0.222 & 0.12 & 0.028 & 10.63 & 0.49 & 0.025 & 0.09 & 0.008 & 3.686 & $3 \mathrm{E}-05$ & 1.304 & 0.07 & 0.101 & 8.14 & 0.022 & 0.049 & 0.045 & 0.026 & --- & 0.009 & --- \\
\hline \multicolumn{28}{|c|}{ Filter samples } \\
\hline 164 & 11/18/2003 3:15 & 4.5 & 16.1 & 0.436 & 0.061 & 1.91 & 0.549 & 0.182 & 0.061 & 11.6 & 0.338 & 0.03 & 0.091 & 0.011 & 0.36 & -.- & 1.67 & 0.063 & 0.089 & 1.02 & 0.018 & 0.054 & 0.05 & 0.025 & -.- & 0.009 & --- \\
\hline 173 & 11/18/2003 11:15 & 5.2 & 15.6 & 0.743 & 0.061 & 1.91 & 0.549 & 0.182 & 0.061 & 12.7 & 0.422 & 0.038 & 0.11 & 0.011 & 0.406 & --- & 1.69 & 0.084 & 0.134 & 1.09 & 0.037 & 0.061 & 0.074 & 0.084 & --- & 0.011 & --- \\
\hline 237 & 11/20/2003 6:30 & 5.3 & 1.8 & 0.743 & 0.049 & 0.733 & 0.276 & 0.164 & 0.049 & 15.9 & 0.434 & 0.037 & 0.123 & 0.012 & 0.522 & --- & 1.86 & 0.088 & 0.133 & 10.3 & 0.02 & 0.08 & 0.059 & 0.057 & --- & 0.009 & --- \\
\hline 261 & 11/21/2003 1:30 & 5.5 & 24 & 1.049 & 0.049 & 0.733 & 0.276 & 0.164 & 0.049 & 13.7 & 0.44 & 0.032 & 0.082 & 0.01 & 0.494 & --- & 1.4 & 0.088 & 0.137 & 9.58 & 0.018 & 0.062 & 0.029 & 0.027 & --- & 0.011 & --- \\
\hline 295 & $11 / 21 / 200314: 00$ & 5.6 & 13.1 & 0.801 & 0.065 & 0.065 & 0.567 & 0.274 & 0.065 & 10.9 & 1.24 & 0.023 & 0.095 & 0.005 & 2.2 & $9 \mathrm{E}-05$ & 1.39 & 0.145 & 0.152 & 7.63 & 0.012 & 0.028 & 0.04 & 0.034 & --- & 0.008 & --- \\
\hline \multirow{2}{*}{\multicolumn{4}{|c|}{$\begin{array}{c}\text { Filter averages } \\
\text { Calculated product composition, } \mathrm{wt} \%\end{array}$}} & 0.754 & 0.057 & 1.07 & 0.443 & 0.193 & 0.057 & 12.96 & 0.575 & 0.032 & 0.1 & 0.01 & 0.796 & $9 \mathrm{E}-05$ & 1.602 & 0.093 & 0.129 & 5.924 & 0.021 & 0.057 & 0.05 & 0.046 & --- & 0.01 & --- \\
\hline & & & & 1.212 & --- & 0.727 & 1.785 & 0.283 & 0.12 & 19.53 & 0.503 & 0.046 & 0.115 & 0.012 & 0.337 & 0 & 2.038 & 0.078 & 0.206 & 12.59 & 0.023 & 0.073 & 0.053 & 19.3 & --- & 0.018 & --- \\
\hline \multicolumn{4}{|c|}{$\begin{array}{l}\text { Average cyclone concentration as a percent of the } \\
\text { calculated product composition }\end{array}$} & 35.99 & -- & 165.3 & 12.45 & 42.3 & 23.5 & 54.41 & 97.46 & 53.76 & 78.96 & 67.21 & 1094 & 0 & 63.99 & 90.7 & 49.09 & 64.64 & 94.41 & 67.07 & 84.37 & 0.137 & --- & 49.63 & --- \\
\hline \multicolumn{4}{|c|}{$\begin{array}{l}\text { Average filter concentration as a percent of the } \\
\text { calculated product composition }\end{array}$} & 62.24 & --- & 147.1 & 24.83 & 68.31 & 47.39 & 66.34 & 114.3 & 68.83 & 87.48 & 82.96 & 236.4 & 0 & 78.62 & 120.4 & 62.58 & 47.04 & 92.15 & 78.4 & 94.64 & 0.236 & --- & 52.58 & --- \\
\hline
\end{tabular}


Table 6.3-3a. Product solubilities for the THOR mineralized test series.

Bed Product

\begin{tabular}{|cccc|}
\hline Sample & Date & Test Cond & $\begin{array}{c}\text { Solubility } \\
(\mathrm{wt} \%)\end{array}$ \\
\hline 170 & $11 / 18 / 037: 15$ & $5.1 \mathrm{a}$ & 0.4 \\
171 & $11 / 18 / 0311: 15$ & 5.2 & 0.7 \\
206 & $11 / 19 / 0314: 30$ & 5.3 & 0.04 \\
234 & $11 / 20 / 033: 30$ & 5.3 & 0.3 \\
277 & $11 / 21 / 037: 30$ & $5.5 \mathrm{a}$ & 1.2 \\
280 & $11 / 21 / 039: 30$ & $5.5 \mathrm{~b}$ & 1.6 \\
293 & $11 / 21 / 0314: 00$ & 5.6 & 1.4 \\
\hline Average & & & 0.8 \\
\hline
\end{tabular}

Cyclone Catch

\begin{tabular}{|c|c|c|c|}
\hline \multicolumn{4}{|c|}{ Cyclone Catch } \\
\hline Sample & Date & Test Cond & $\begin{array}{c}\text { Solubility } \\
\text { (wt } \%)\end{array}$ \\
\hline 148 & $11 / 17 / 0315: 15$ & $4.1 \mathrm{c}$ & 6.6 \\
\hline
\end{tabular}

$4.1 \mathrm{c}$
Filter Catch

\begin{tabular}{|cccc|}
\hline \multicolumn{5}{c}{ Filter Catch } \\
Sample & Date & Test Cond & $\begin{array}{c}\text { Solubility } \\
(\mathrm{wt} \%)\end{array}$ \\
\hline 147 & $11 / 17 / 0315: 15$ & $4.1 \mathrm{c}$ & 8.2 \\
169 & $11 / 18 / 037: 15$ & $5.1 \mathrm{a}$ & 5.7 \\
204 & $11 / 19 / 0314: 30$ & 5.3 & 2.7 \\
228 & $11 / 20 / 030: 30$ & 5.3 & 2.3 \\
235 & $11 / 20 / 033: 30$ & 5.3 & 2.0 \\
276 & $11 / 21 / 037: 30$ & $5.5 \mathrm{a}$ & 3.3 \\
\hline Average & \multicolumn{4}{c}{} & 4.0 \\
\hline
\end{tabular}

[Auxilliary THOR data.xls]THOR solubilities 


\subsubsection{Scrub Solution and CEMS Condensate Compositions}

Samples of the scrub solution were collected and analyzed to indicate amounts of various species that were volatilized or elutriated out of the fluidized bed and also pass through the cyclone and heated filter to be captured in the wet scrubber. The scrub solution and CEMS condensate sample analyses are shown in Table 6.3-4.

The scrubber was designed with heat exchanger cooling to remove latent heat from the off-gas as the scrubber cools the hot off-gas to its dew point and performs acid gas and particulate matter scrubbing. By removing latent heat from the off-gas using the heat exchanger, the scrubber can be operated so that essentially no scrub water is evaporated and no moisture in the off-gas is condensed. The heat removal from the scrub solution is automatically controlled to maintain a relatively constant scrub water level in the scrub tank.

As the scrub solution volume remains constant at about 45 gallons, species scrubbed out of the offgas become enriched in the scrub solution. The scrub solution was not changed during the test series, so the ending composition of the scrub solution provides the total amounts of species scrubbed during the test series. The concentrations of key species, including $\mathrm{NO}_{3}, \mathrm{SO}_{4}, \mathrm{Cl}, \mathrm{F}$, and $\mathrm{Hg}$, all increased to a maximum at the end of the test series. In order to avoid complications that would be caused by added $\mathrm{NaOH}$ or other $\mathrm{pH}$-neutralizing caustic, none was added. The scrub solution became somewhat but not extremely acidic during the test series. The $\mathrm{pH}$ ranged as low as 2 . 
Table 6.3-4. Scrub solution and CEMS condensate composition for the THOR mineral test series.

\begin{tabular}{|c|c|c|c|c|c|c|c|c|c|c|c|}
\hline \multicolumn{3}{|c|}{ Scrub solution } & \multicolumn{9}{|c|}{ Measured concentrations } \\
\hline Sample & Sample date & $\begin{array}{l}\text { Test } \\
\text { Cond } \\
\end{array}$ & TOC & $\begin{array}{c}\text { Total } \\
\text { Carbon }\end{array}$ & $\mathrm{CO}_{3}$ & $\mathrm{NO}_{3}$ & $\mathrm{PO}_{4}$ & $\mathrm{SO}_{4}$ & $\mathrm{Cl}$ & $\mathrm{F}$ & $\mathrm{Hg}$ \\
\hline & & & $\mathrm{ug} / \mathrm{ml}$ & $\mathrm{ug} / \mathrm{ml}$ & --- & $\mathrm{ug} / \mathrm{ml}$ & --- & $\mathrm{ug} / \mathrm{ml}$ & $\mathrm{ug} / \mathrm{ml}$ & $\mathrm{ug} / \mathrm{ml}$ & $\mathrm{ug} / \mathrm{ml}$ \\
\hline 161 & 11/18/2003 3:15 & 4.5 & 1.1161 & 1.116059 & --- & 12.87 & --- & 112.6 & 11.98 & 24.81 & 0.037 \\
\hline 174 & 11/18/2003 11:15 & 5.2 & 0.8695 & 0.869524 & --- & 15.6 & --- & 184.8 & 22.69 & 43.39 & 0.522 \\
\hline 238 & 11/20/2003 6:30 & 5.3 & 3.5888 & 3.588844 & --- & 39.56 & --- & 590.8 & 216 & 61.69 & 1.636 \\
\hline 274 & 11/21/2003 7:30 & $5.5 a$ & 1.8601 & 1.860094 & --- & 54.76 & --- & 708.7 & 353.7 & 71.64 & 2.405 \\
\hline 290 & 11/21/2003 14:00 & 5.6 & 3.8368 & 3.836847 & --- & 61.24 & --- & 754.3 & 427.1 & 74.23 & 2.509 \\
\hline \multicolumn{3}{|c|}{ CEMS 1 condensate } & $\mathrm{wt} \%$ & $\begin{array}{l}-- \\
\end{array}$ & $\bar{M}$ & $\mathrm{ug} / \mathrm{ml}$ & --- & $\mathrm{ug} / \mathrm{ml}$ & $\mathrm{ug} / \mathrm{ml}$ & $\mathrm{ug} / \mathrm{ml}$ & $\begin{array}{l}-- \\
\end{array}$ \\
\hline 162 & 11/18/2003 3:15 & 4.5 & 0.0187 & --- & 0.494 & 3.348 & --- & 9.052 & 0.815 & 62.47 & --- \\
\hline 175 & 11/18/2003 11:15 & 5.2 & 0.0271 & --- & 0.57 & 8.666 & -- & 20.46 & 0.815 & 53.45 & -- \\
\hline 240 & 11/20/2003 6:30 & 5.3 & 0.0709 & --- & 0.324 & 20.49 & --- & 30.29 & 15.14 & 57.5 & --- \\
\hline 267 & $11 / 21 / 20033: 30$ & $5.5 a$ & 0.0059 & --- & 0.32 & 2.829 & --- & 320 & 2.685 & 40.25 & --- \\
\hline 291 & $11 / 21 / 200314: 00$ & 5.6 & 0.0038 & -- & 0.344 & 0.283 & -- & 158.4 & 4.165 & 21.35 & -- \\
\hline \multicolumn{3}{|c|}{ CEMS 2 condensate } & --- & $\overline{---}$ & $\overline{---}$ & $\mathrm{ug} / \mathrm{ml}$ & $\overline{---}$ & $\mathrm{ug} / \mathrm{ml}$ & $\mathrm{ug} / \mathrm{ml}$ & $\mathrm{ug} / \mathrm{ml}$ & $\begin{array}{l}-- \\
\end{array}$ \\
\hline 163 & 11/18/2003 3:15 & 4.5 & --- & --- & --- & 19.26 & -- & 34.45 & 0.215 & 1.259 & --- \\
\hline 176 & 11/18/2003 11:15 & 5.2 & --- & --- & --- & 17.19 & --- & 53.81 & 0.082 & 2.067 & --- \\
\hline 242 & $11 / 20 / 20036: 30$ & 5.3 & --- & --- & --- & 10.21 & --- & 74.38 & 0.655 & 5.135 & --- \\
\hline 268 & $11 / 21 / 20033: 30$ & $5.5 a$ & --- & --- & --- & 7.636 & --- & 56.21 & 0.648 & 3.915 & --- \\
\hline 292 & $11 / 21 / 200314: 00$ & 5.6 & --- & --- & --- & 8.977 & --- & 42.82 & 0.569 & 4.379 & --- \\
\hline
\end{tabular}


CEMS 1 measures the off-gas composition at the outlet of the heated filter and upstream of the thermal oxidizer. The off-gas at this location contains various incompletely oxidized gas species, including $\mathrm{CO}, \mathrm{CH}_{4}$, and other hydrocarbons that were not speciated during this test but were measured as total hydrocarbons (THC). Investigatory grab sample tests also showed the presence of $\mathrm{NH}_{3}$ and $\mathrm{HCN}$ in the off-gas at this location. The water condensate collected in the CEMS 1 condenser contains levels of water-soluble or condensable hydrocarbons, as well as other water-soluble or condensable species, including $\mathrm{NH}_{3}, \mathrm{HCN}, \mathrm{HCl}, \mathrm{HF}, \mathrm{SO}_{2}, \mathrm{H}_{3} \mathrm{PO}_{4}$, and $\mathrm{NO}_{2}$. The $\mathrm{CEM} 1$ condensate analysis indicates the presence of species in the off-gas that were not directly measured by CEMS 1 . The $\mathrm{CO}_{3}, \mathrm{NO}_{3}, \mathrm{SO}_{4}, \mathrm{Cl}$, and $\mathrm{F}$ were detected in the CEMS 1 condensate.

The CEMS 1 condensate analysis also indicates the amount of $\mathrm{NO}_{2}$ scrubbed in the condenser and thereby not detected by the CEM $1 \mathrm{NO}_{\mathrm{x}}$ analyzer. The nitrate in the condensate represents less than 2 ppm of the $\mathrm{NO}$ detected by the $\mathrm{NO}_{\mathrm{x}}$ analyzer, indicating that although some $\mathrm{NO}_{\mathrm{x}}$ was scrubbed in the CEMS 1 condensate, that amount was negligible compared to the amount of NO detected in the off-gas.

The CEMS 2 condensate could contain species that remain in the off-gas downstream of the thermal oxidizer and the wet scrubber. Levels of $\mathrm{SO}_{4}, \mathrm{Cl}$, and $\mathrm{F}$ were less than the levels of those species found in the CEMS 1 condensate.

\subsubsection{Off-gas Composition}

The CEMS 1 was used to measure the off-gas composition at the outlet of the heated filter (upstream of the thermal oxidizer) and downstream of the oxidizer. The CEMS 2 was used to measure the off-gas composition at operator-selectable locations at the inlet of the carbon bed or the outlet of any of the three stages of the carbon bed.

6.3.3.1 Off-gas Composition at the Steam Reformer Heated Filter Outlet. The average off-gas composition (wet basis) at the outlet of the heated filter is shown in Table 6.3-5 for each test condition. The wet basis composition was calculated from the dry, as-measured composition by (a) correcting for zero and span calibration error/drift and air dilution, and (b) normalizing the dry composition to a wet basis using the off-gas moisture content. The moisture content at the filter outlet location was not directly measured, but was calculated from the fluidized-bed input flow rates of fluidizing steam, evaporated water from the SBW and syrup feeds, and water from oxidation of the sugar in the syrup feed. The moisture content calculations are shown in water mass balance calculations.

The off-gas measurements were continuous, and recorded data-reduced in 2-minute averages. The 2-minute trend data are shown in Figure 6.3-1. The trends over time indicate graphically how the gas composition varied during the test series.

The 2-minute averages were averaged for each test condition. The various test conditions were of varying length, so the average composition for the test series is an average of all valid 2-minute data, equivalent to a time-weighted average of the test condition averages. The CEMS data were corrected for zero calibration error, zero drift, span calibration error, span drift, and interferences if the errors, drifts, and interferences were outside of acceptance limits. These corrections were done by the PLC when calibrations were done. The calibration data is summarized in Appendix B. 
Table 6.3-5. Off-gas Composition (wet basis) at the outlet of the heated filter for the THOR mineral test series.

\begin{tabular}{|c|c|c|c|c|c|c|c|c|c|c|c|c|c|}
\hline \multirow[b]{2}{*}{ Test } & \multicolumn{12}{|c|}{ Average composition for each test condition on a wet basis } & \multirow[b]{2}{*}{$\begin{array}{c}\text { Diluted } \\
\text { offgas } \\
\text { mole wt }\end{array}$} \\
\hline & $\mathrm{O}_{2}, \%$ & $\begin{array}{c}\mathrm{CO}_{2} \\
\%\end{array}$ & $\mathrm{CO}, \%$ & $\begin{array}{l}\text { Avg } \\
\text { NO, } \\
\text { ppm }\end{array}$ & $\begin{array}{l}\mathrm{NO}_{2}, \\
\mathrm{ppm}\end{array}$ & $\begin{array}{l}\mathrm{NO}_{\mathrm{x}}, \\
\mathrm{ppm}\end{array}$ & $\mathrm{H}_{2}, \%$ & $\begin{array}{l}\mathrm{CH}_{4}, \\
\text { ppm }\end{array}$ & $\begin{array}{l}\text { THC, } \\
\text { ppm }\end{array}$ & $\mathrm{H}_{2} \mathrm{O}, \%$ & $\begin{array}{c}\mathrm{N}_{2}, \\
\%\end{array}$ & $\begin{array}{c}\text { Total, } \\
\%\end{array}$ & \\
\hline 4 & 0.77 & --- & --- & -- & --- & -- & --- & -- & --- & --- & --- & --- & --- \\
\hline 4.1 & 0.58 & 8.29 & 0.84 & 2,616 & 122 & 2,739 & 1.8 & 206 & 646 & 67.0 & 21.5 & 100.0 & 22.2 \\
\hline $4.1 \mathrm{a}$ & 0.54 & 8.90 & 1.01 & 3,116 & 146 & 3,262 & 1.8 & 170 & 566 & 65.2 & 22.6 & 100.0 & 22.5 \\
\hline $4.1 \mathrm{~b}$ & 0.50 & 8.96 & 1.12 & 3,262 & 151 & 3,413 & 1.9 & 170 & 539 & 64.3 & 23.3 & 100.0 & 22.5 \\
\hline $4.1 \mathrm{c}$ & 0.44 & 10.83 & 1.36 & 2,600 & 121 & 2,721 & 1.9 & 162 & 488 & 61.7 & 23.7 & 100.0 & 23.1 \\
\hline $4.1 \mathrm{~d}$ & 0.40 & 9.91 & 1.29 & 1,086 & 51 & 1,137 & 2.0 & 173 & 490 & 63.3 & 23.1 & 100.0 & 22.7 \\
\hline 4.2 & 0.37 & 10.47 & 1.40 & 1,208 & 59 & 1,267 & 2.0 & 177 & 493 & 60.7 & 25.1 & 100.0 & 23.1 \\
\hline 4.3 & 0.34 & 10.45 & 1.46 & 1,274 & 65 & 1,340 & 2.0 & 187 & 530 & 60.6 & 25.2 & 100.0 & 23.1 \\
\hline $4.3 \mathrm{a}$ & 0.36 & 9.85 & 1.95 & 1,940 & 149 & 2,089 & 2.1 & 450 & 874 & 60.4 & 25.4 & 100.0 & 23.0 \\
\hline 4.4 & 0.39 & 9.70 & 2.14 & NA & 356 & 2,851 & 2.7 & 490 & 1,007 & 61.5 & 23.6 & 100.0 & 22.7 \\
\hline $4.4 \mathrm{a}$ & 0.37 & 9.77 & 2.33 & 3,101 & 1,295 & 4,396 & 3.1 & 511 & 1,067 & 61.5 & 22.9 & 100.0 & 22.6 \\
\hline 4.5 & 0.56 & 9.80 & 2.47 & 2,707 & 2,370 & 5,077 & 3.3 & 1,375 & 2,534 & 59.5 & 24.4 & 100.0 & 22.8 \\
\hline 5.1 & 0.43 & 11.61 & 1.89 & 2,465 & 2,347 & 4,812 & 3.2 & 650 & 757 & 66.3 & 16.6 & 100.0 & 22.4 \\
\hline $5.1 \mathrm{a}$ & 0.41 & 11.27 & 1.66 & 2,597 & 2,239 & 4,836 & 3.2 & 589 & 639 & 67.8 & 15.7 & 100.0 & 22.2 \\
\hline 5.2 & 0.40 & 10.19 & 2.18 & 2,178 & 1,650 & 3,827 & 3.7 & 1,896 & 3,500 & 59.1 & 24.4 & 100.0 & 22.8 \\
\hline $5.2 \mathrm{a}$ & 0.33 & 10.05 & 1.95 & 3,420 & 1,649 & 5,069 & 3.5 & 1,476 & 3,152 & 58.3 & 25.9 & 100.0 & 22.9 \\
\hline $5.2 b$ & 0.30 & 9.84 & 2.26 & 1,936 & 1,055 & 2,991 & 3.8 & 2,073 & 3,884 & 58.4 & 25.5 & 100.0 & 22.8 \\
\hline $5.2 \mathrm{c}$ & 0.30 & 11.56 & 2.33 & 2,319 & 1,027 & 3,346 & 3.8 & 2,382 & 3,810 & 63.5 & 18.4 & 100.0 & 22.5 \\
\hline $5.2 \mathrm{~d}$ & 0.32 & 11.25 & 2.57 & 2,102 & 977 & 3,079 & 4.0 & 2,271 & 3,888 & 63.3 & 19.0 & 100.0 & 22.4 \\
\hline Shutdor & & & & & & & & & & & & & \\
\hline 5.3 & 0.29 & 7.54 & 2.20 & 4,192 & 463 & 4,655 & 3.2 & 2,553 & 5,863 & 65.7 & 21.0 & 100.0 & 21.8 \\
\hline Shutdown & & & & & & & & & & & & & \\
\hline 5.4 & 0.28 & 6.28 & 1.13 & 5,226 & 327 & 5,554 & 2.9 & 456 & 543 & 70.3 & 19.1 & 100.0 & 21.2 \\
\hline 5.5 & 0.23 & 6.08 & 1.06 & 4,244 & 448 & 4,691 & 3.1 & 505 & 589 & 68.4 & 21.2 & 100.0 & 21.3 \\
\hline $5.5 \mathrm{a}$ & 0.23 & 5.85 & 0.97 & 4,390 & 512 & 4,903 & 2.9 & 327 & 406 & 68.8 & 21.3 & 100.0 & 21.3 \\
\hline $5.5 \mathrm{~b}$ & 0.26 & 5.97 & 1.01 & 5,076 & 422 & 5,498 & 2.7 & 250 & 330 & 71.4 & 18.7 & 100.0 & 21.1 \\
\hline $5.5 \mathrm{c}$ & 0.27 & 6.60 & 0.67 & 5,063 & 421 & 5,483 & 2.7 & 78 & 140 & 71.2 & 18.6 & 100.0 & 21.3 \\
\hline $5.5 \mathrm{~d}$ & 0.27 & 6.99 & 0.54 & 5,208 & 314 & 5,522 & 2.6 & 10 & 69 & 66.9 & 22.8 & 100.0 & 21.8 \\
\hline $5.5 \mathrm{e}$ & 0.23 & 7.02 & 0.39 & 4,009 & 484 & 4,492 & 2.8 & 15 & 80 & 66.4 & 23.1 & 100.0 & 21.8 \\
\hline 5.6 & 0.23 & 8.38 & 0.68 & 4,295 & 566 & 4,861 & 2.8 & 118 & 440 & 64.8 & 23.0 & 100.0 & 22.1 \\
\hline Average & 0.33 & 8.55 & 1.77 & 3,498 & 768 & 4,266 & 3.0 & 1,248 & 2,517 & 64.9 & 21.4 & 100.0 & 22.1 \\
\hline STD DEV & 0.1 & 2.0 & 0.7 & 1,364 & 699 & 1,318 & 0.6 & 1,034 & 2,369 & 4.6 & 4.2 & 0.0 & 0.7 \\
\hline
\end{tabular}

Notes:

1. The reported $\mathrm{CO}_{2}$ values are averages from both Nova analyzers. Data has been corrected for zero drift for each calibration period.

2. The reported $\mathrm{NO}, \mathrm{NO}_{2}$, and $\mathrm{NO}_{\mathrm{x}}$ values are from the CAI analyzer which was the more accurate of the $2 \mathrm{NO}_{\mathrm{x}}$ analyzers because it was not subject to interferences that the Ametek was subject to.

2. The final average is a weighted average of the test conditions, not a linear average. 

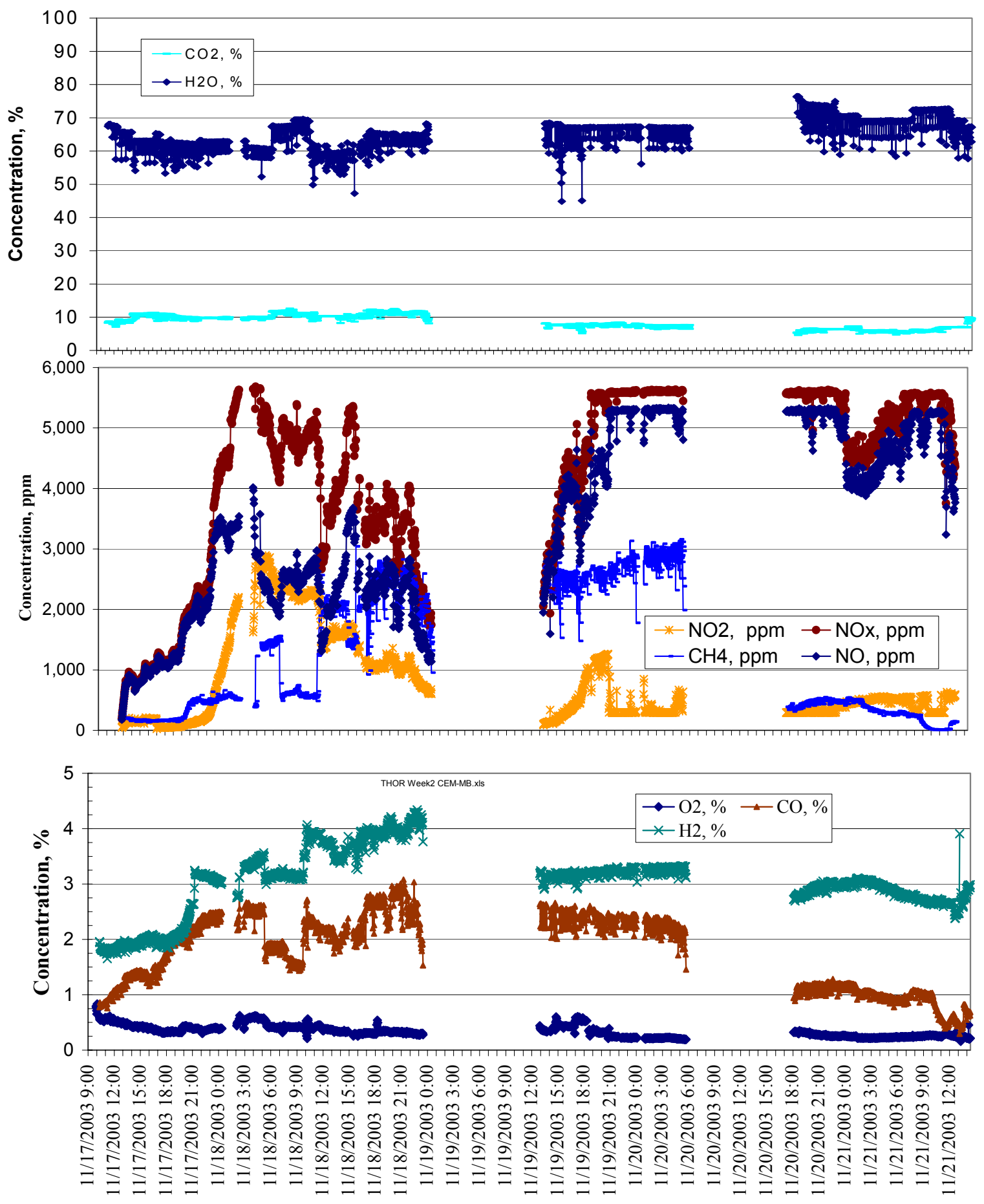

Figure 6.3-1. Wet-basis concentrations of $\mathrm{CH}_{4}, \mathrm{NO}, \mathrm{CO}_{2}, \mathrm{H}_{2} \mathrm{O}, \mathrm{O}_{2}, \mathrm{CO}$, THC, and $\mathrm{H}_{2}$ in the off-gas upstream of the oxidizer for the THOR mineral test series. 
Measuring the off-gas composition for this off-gas that contains not only moisture and acid gases, but also incompletely reacted hydrocarbons and other reduced gas species, is especially challenging for data quality. The wide range of hydrocarbons and other reduced gas species such as $\mathrm{HCN}$ and $\mathrm{NH}_{3}$ can interfere with measurement techniques that are industry standards worldwide for combustion gases. A corrective action that reduced the interference from condensable hydrocarbons on the CEMS was the addition of a charcoal filter in the CEMS. This filter, downstream of the condenser, eliminated some problems, such as the shift in the $\mathrm{CH}_{4}$ analyzer zero value. However, the carbon filter also sorbed $\mathrm{NO}_{x}$ for a short time after startup, invalidating the $\mathrm{NO}_{\mathrm{x}}$ data for that time.

The affects of these various interferences were further mitigated by frequent (daily or more often) calibrations during which calibration factors were recorded. When the calibration factors exceeded EPA acceptance criteria for air emission compliance monitoring, the data were adjusted during post-test data reduction.

All data were measured on a dry basis, after moisture in the off-gas was condensed. The dry-basis as-measured data (corrected for calibration error and interferences when applicable) was adjusted to a wet basis to provide results that represented the actual concentrations of the off-gas inside the system. The moisture content was determined by mass balance using the input steam reformer flow rates of gases, fluids, including the SBW simulant and the syrup, and accounting for water from oxidation of the reductants.

The wet-basis $\mathrm{O}_{2}$ concentration was measured between $0.2-1 \mathrm{vol} \%$. The measured level of free $\mathrm{O}_{2}$ does not indicate that there was much $\mathrm{O}_{2}$ in the steam reformer off-gas; instead, it indicates that there was a small amount of air in-leakage into the off-gas system or CEMS downstream of the steam reformer, where the gas temperature was cool enough to limit reactions of the in-leaked $\mathrm{O}_{2}$ with incompletely oxidized gas species such as $\mathrm{H}_{2}$ or $\mathrm{CH}_{4}$ in the steam reformer off-gas. Approximately this level of free $\mathrm{O}_{2}$ is typically detected in the test system at the outlet of the heated filter during system leak checks, when no source of $\mathrm{O}_{2}$ is fed to the system. A free $\mathrm{O}_{2}$ concentration of $0.5 \%$ represents an air leak of $2.5 \%$ of the initial steam reformer gas flow rate.

No zero, span, or interference corrections were necessary for the $\mathrm{O}_{2}$ measurements. In addition to the measured $\mathrm{O}_{2}$ levels that were due to small air in-leakage, a small amount of measured $\mathrm{O}_{2}$, perhaps $0.1-0.2 \%$, was due to $\mathrm{NO}_{\mathrm{x}}$ interference on the paramagnetic $\mathrm{O}_{2}$ measurement. While this interference is common, it is rarely corrected, and was not corrected in these tests because the interference was very small.

The Ametek $\mathrm{NO}_{\mathrm{x}}$ analyzer was configured to independently detect both $\mathrm{NO}$ and $\mathrm{NO}_{2}$ using dispersive ultraviolet (DUV) detection. While this analyzer is used reliably worldwide for combustion off-gas measurements, and is impervious to the kinds of interferences experienced by chemiluminescent detection used to measure $\mathrm{NO}_{\mathrm{x}}$ concentrations in the prior steam reformer tests (Marshall 2000a and Marshall 2000c), it still experienced interferences during the steam reforming tests. The levels of incompletely oxidized gas species, which were higher in the steam reformer off-gas than in off-gas from typical industrial combustion processes, caused a positive bias on the $\mathrm{NO}$ and $\mathrm{NO}_{2}$ measurements. The NO measurement was successfully corrected for this bias by subtracting a calibrated value of the interference from the as-measured $\mathrm{NO}$ values. The $\mathrm{NO}_{2}$ measurement was too strongly affected by the interference (compared to the expected $\mathrm{NO}_{2}$ values) and could not be corrected and still provide useable results. Because of this interference, no useable $\mathrm{NO}_{2}$ measurements were obtained during the carbonate test series at the filter outlet location.

The Ametek NO measurement also experienced zero drift during the tests, which was corrected using calibration data. Because of the magnitude of the zero and interference corrections, the accuracy of 
the corrected NO data is about $\pm 25-50 \%$ of the measured values, depending on the test period and the magnitude of the measured values.

While the Ametek $\mathrm{NO}_{\mathrm{x}}$ analyzer was operated during the mineral test series, a second $\mathrm{NO}_{\mathrm{x}}$ analyzer was also used. This CAI chemiluminescent analyzer was more impervious to the interferences experienced by the Ametek analyzer. All of the CEMS $1 \mathrm{NO}_{\mathrm{x}}$ and $\mathrm{NO}_{\mathrm{x}}$ destruction data for the mineral test series in this report are from the CAI analyzer alone. The CAI analyzer was operated with air dilution. The as-measured data were corrected for air dilution by the PLC.

$\mathrm{CO}_{2}$ was measured using two analyzers, an existing NOVA $\mathrm{CO}_{2} / \mathrm{H}_{2}$ analyzer and a NOVA $\mathrm{CO}_{2} / \mathrm{H}_{2}$ analyzer loaned by NOVA for the duration of the THOR tests. NOVA loaned the second analyzer because the existing analyzer failed to communicate with the PLC just before the THOR test series. The output of the existing analyzer was manually recorded; the output of the loaner analyzer was logged by the PLC and manually recorded. The output of the loaner analyzer exceeded the output range, so the only useable $\mathrm{CO}_{2}$ data from the loaner analyzer were the manually recorded data. The data used in this report are the average of the $\mathrm{CO}_{2}$ measurements from both analyzers.

$\mathrm{CO}_{2}$ measurements by the existing analyzer were corrected for a zero shift for which the analyzer could not be adjusted. No span or bias adjustments were made to the $\mathrm{CO}_{2}$ measurements from the existing analyzer. No adjustments were required for the loaner $\mathrm{CO}_{2}$ analyzer. The calibrations from both analyzers (after applicable adjustments) were within the EPA acceptance limits. The two analyzers typically agreed within $5 \%$ of the full-scale value of the analyzers. This resulted in a potential error of the measured values of about $\pm 20 \%$ of the reported values.

As with $\mathrm{CO}_{2}, \mathrm{H}_{2}$ was measured using the two NOVA $\mathrm{CO}_{2} / \mathrm{H}_{2}$ analyzers. The $\mathrm{H}_{2}$ data required no zero or span corrections, and the $\mathrm{CO}_{2}$ interference on the $\mathrm{H}_{2}$ reading was low enough that no correction was necessary. The $\mathrm{H}_{2}$ data from the two analyzers were averaged. Considering calibration errors of up to $10 \%$ of the full-scale values, the accuracy of the $\mathrm{H}_{2}$ readings was about $\pm 20 \%$ of the average reading.

The CO readings were accurate within EPA's acceptance criteria without any adjustments. The $\mathrm{CO}$ measurements were accurate to within about $\pm 10 \%$ of the measured readings.

The $\mathrm{CH}_{4}$ analyzer experienced no zero calibration error after the installation of the carbon filter in the CEMS 1. No zero or span corrections were necessary during the mineral test series.

6.3.3.2 Off-gas Composition Downstream of the Thermal Oxidizer and Scrubber. The average off-gas composition (wet basis) downstream of the thermal oxidizer and scrubber is shown in Table 6.3-6 for each test condition. All of the CEMS 2 measurements were made on a dry basis, after condensing off-gas moisture from the off-gas, except for the $\mathrm{O}_{2}$ measurement. The $\mathrm{O}_{2}$ measurement was made using a heated extractive $\mathrm{ZrO}_{2}$ electrochemical sensor, on a wet basis, for thermal oxidizer process control. Except for the $\mathrm{O}_{2}$ measurement, the wet basis composition was calculated from the dry, asmeasured composition by (a) correcting for zero and span calibration error/drift and (b) normalizing the dry composition to a wet basis using the off-gas moisture content. The $\mathrm{O}_{2}$ measurement required no calibration corrections and was measured on a wet basis. 
Table 6.3-6. Off-gas composition (wet basis) downstream of the oxidizer and scrubber for the THOR mineral test series.

\begin{tabular}{|c|c|c|c|c|c|c|c|c|c|c|c|}
\hline \multirow[b]{2}{*}{ Test condition } & \multicolumn{10}{|c|}{ Composition, wet basis } & \multirow[b]{2}{*}{$\begin{array}{c}\text { Off-gas } \\
\text { MW }\end{array}$} \\
\hline & $\mathrm{O}_{2}, \%$ & $\begin{array}{c}\mathrm{CO}_{2}, \\
\%\end{array}$ & $\begin{array}{l}\mathrm{CO}, \\
\mathrm{ppm}\end{array}$ & $\begin{array}{l}\mathrm{NO}, \\
\mathrm{ppm}\end{array}$ & $\begin{array}{l}\mathrm{NO}_{2}, \\
\text { ppm }\end{array}$ & $\begin{array}{l}\mathrm{NO}_{\mathrm{x}}, \\
\mathrm{ppm}\end{array}$ & $\begin{array}{c}\mathrm{H}_{2} \mathrm{O} \\
\%\end{array}$ & $\begin{array}{l}\mathrm{HCl}, \\
\mathrm{ppm}\end{array}$ & $\mathrm{N}_{2}, \%$ & $\begin{array}{c}\text { Total, } \\
\%\end{array}$ & \\
\hline 4 & 2.81 & 4.8 & 11.5 & 33 & 1 & 33 & 41.4 & 0.5 & 40.5 & 100.0 & 25.0 \\
\hline 4.1 & 2.38 & 5.0 & 8.2 & 171 & 4 & 174 & 43.1 & 0.5 & 41.3 & 100.0 & 24.6 \\
\hline 4.1a & 1.99 & 5.5 & 9.2 & 106 & 2 & 108 & 42.5 & 0.7 & 40.8 & 100.0 & 24.7 \\
\hline $4.1 b$ & 2.00 & 5.6 & 8.4 & 93 & 2 & 95 & 41.8 & 0.8 & 42.2 & 100.0 & 24.8 \\
\hline $4.1 \mathrm{c}$ & 2.00 & 5.9 & 8.0 & 86 & 2 & 88 & 42.5 & 0.8 & 41.6 & 100.0 & 24.8 \\
\hline $4.1 \mathrm{~d}$ & 2.00 & 5.7 & 8.4 & 84 & 2 & 86 & 42.7 & 0.7 & 41.3 & 100.0 & 24.7 \\
\hline 4.2 & 2.00 & 5.7 & 8.0 & 89 & 2 & 91 & 44.4 & 0.7 & 39.9 & 100.0 & 24.6 \\
\hline 4.3 & 2.00 & 5.6 & 8.1 & 95 & 2 & 97 & 45.3 & 0.8 & 38.9 & 100.0 & 24.4 \\
\hline $4.3 \mathrm{a}$ & 2.00 & 5.6 & 8.1 & 126 & 2 & 128 & 45.5 & 1.1 & 38.8 & 100.0 & 24.4 \\
\hline 4.4 & 2.00 & 5.7 & 6.8 & 200 & 4 & 203 & 45.3 & 0.9 & 40.3 & 100.0 & 24.5 \\
\hline $4.4 \mathrm{a}$ & 2.00 & 5.6 & 11.2 & 202 & 18 & 208 & 45.3 & 0.6 & 35.8 & 100.0 & 24.5 \\
\hline 4.5 & 2.00 & 5.6 & 6.3 & 197 & 14 & 203 & 46.0 & 0.6 & 40.1 & 100.0 & 24.4 \\
\hline 5.1 & 2.91 & 5.3 & 6.4 & 185 & 6 & 190 & 44.7 & 1.0 & 40.6 & 100.0 & 24.5 \\
\hline $5.1 \mathrm{a}$ & 3.00 & 5.4 & 8.8 & 179 & 8 & 187 & 41.7 & 1.2 & 41.1 & 100.0 & 24.8 \\
\hline 5.2 & 2.68 & 5.5 & 11.2 & 155 & 4 & 159 & 41.4 & 1.0 & 39.1 & 100.0 & 24.9 \\
\hline $5.2 \mathrm{a}$ & 2.45 & 5.6 & 12.4 & 182 & 2 & 184 & 41.5 & 0.6 & 38.0 & 100.0 & 24.8 \\
\hline $5.2 \mathrm{~b}$ & 2.25 & 5.5 & 11.5 & 163 & 2 & 165 & 44.1 & 0.5 & 36.6 & 100.0 & 24.6 \\
\hline $5.2 \mathrm{c}$ & 2.26 & 5.4 & 11.6 & 176 & 3 & 178 & 46.2 & 0.4 & 34.5 & 100.0 & 24.3 \\
\hline $5.2 \mathrm{~d}$ & 2.30 & 5.5 & 12.4 & 162 & 2 & 164 & 45.4 & 0.7 & 34.4 & 100.0 & 24.4 \\
\hline Shutdown & & & & & & & & & & & \\
\hline 5.3 & 2.40 & 4.6 & 7.7 & 236 & 8 & 235 & 46.4 & -0.1 & 38.9 & 100.0 & 24.2 \\
\hline Shutdown & & & & & & & & & & & \\
\hline 5.4 & 2.00 & 4.7 & 1.3 & 407 & 1 & 396 & 48.0 & 0.0 & 43.9 & 100.0 & 24.0 \\
\hline 5.5 & 2.00 & 4.8 & 3.8 & 136 & --- & 128 & 47.6 & 0.3 & 41.8 & 100.0 & 24.1 \\
\hline $5.5 \mathrm{a}$ & 2.00 & 4.8 & 3.6 & 201 & --- & 189 & 47.2 & 0.2 & 42.4 & 100.0 & 24.1 \\
\hline $5.5 b$ & 2.00 & 4.8 & 2.5 & 344 & --- & 327 & 47.4 & 0.1 & 43.3 & 100.0 & 24.1 \\
\hline $5.5 \mathrm{c}$ & 2.00 & 4.9 & 2.3 & 343 & --- & 328 & 47.4 & 0.1 & 43.5 & 100.0 & 24.1 \\
\hline $5.5 \mathrm{~d}$ & 2.00 & 5.1 & 2.0 & 386 & --- & 371 & 47.6 & 0.1 & 43.3 & 100.0 & 24.2 \\
\hline $5.5 \mathrm{e}$ & 2.00 & 5.0 & 3.1 & 152 & 0 & 144 & 47.8 & 0.2 & 42.2 & 100.0 & 24.1 \\
\hline 5.6 & 2.00 & 5.1 & 4.4 & 90 & --- & 85 & 47.9 & 0.1 & 40.6 & 100.0 & 24.1 \\
\hline Weighted average & 2.24 & $\overline{5.1}$ & 7.4 & 215 & 6 & 213 & 45.6 & 0.4 & 39.7 & 100.0 & 24.4 \\
\hline STD DEV & 0.4 & 0.6 & 7 & 117 & 7 & 115 & 2.5 & 0.5 & 6.6 & 0.0 & 0.3 \\
\hline
\end{tabular}

\begin{tabular}{|l|rrrrrr|}
\hline Dry, 7\% $\mathrm{O}_{2}$ basis & 11 & --- & --- & --- & --- & 0.6 \\
HWC MACT limit $\left(\right.$ dry, $\left.7 \% \mathrm{O}_{2}\right)$ & 100 & --- & --- & --- & --- & 21 \\
$\%$ of the HWC MACT limit & 11 & --- & --- & --- & --- & 3 \\
\hline
\end{tabular}

Notes: $\quad 1$. The $\mathrm{N}_{2}$ values were determined by difference.

cem2 wet/thor week2 cem-mb 
The moisture content downstream of the scrubber was not directly measured, but was calculated from a dew point calculation at the temperature and absolute pressure of the off-gas exiting the wet scrubber. The off-gas moisture content downstream of the scrubber is defined by the scrubber outlet gas dew point (except for any water aerosols that remain in the off-gas downstream of the mist eliminator, that could bias the moisture content upward slightly if they are evaporated in the reheater). The moisture content calculations are shown in water mass balance calculations.

The off-gas measurements were continuous and recorded in the data reduction database in 2-minute averages. The 2-minute averages were averaged for each test condition. The various test conditions were of varying length, so the average composition for the test series is an average of all valid 2-minute data, equivalent to a time-weighted average of the test condition averages.

The average CEM 2 measurements for $\mathrm{CO}$ and $\mathrm{HCl}$ were converted to a dry, $7 \% \mathrm{O}_{2}$ basis for comparison to the HWC MACT standards. The $\mathrm{CO}$ and $\mathrm{HCl}$ levels averaged about $1 / 10^{\text {th }}$ or less of the MACT limits.

\subsection{Fate of Feed Components}

Input and output mass balances were performed to determine the fate of feed components. Key calculations include (a) determination of nitrate and $\mathrm{NO}_{\mathrm{x}}$ destruction, (b) utilization of the organic reductants used to reduce $\mathrm{NO}_{\mathrm{x}}$, and (c) the fate of and mass balance closure for the main SBW simulant components $(\mathrm{Na}, \mathrm{Al}$, and $\mathrm{K})$, hazardous metals and radionuclide surrogates $(\mathrm{Cr}, \mathrm{Hg}, \mathrm{Pb}, \mathrm{Cs}$, and $\mathrm{Re}$ ), and anions in the SBW simulant.

\subsection{1 $\mathrm{NO}_{\mathrm{x}}$ Destruction}

As the SBW simulant and reductants are fed to the steam reformer, the nitrates react with the reductants under steam reformer conditions, converting the $\mathrm{N}$ in the nitrates to predominantly $\mathrm{N}_{2}$. Table 6.4-1 shows $\mathrm{NO}_{\mathrm{x}}$ destruction based on the amount of $\mathrm{NO}$ and $\mathrm{NO}_{2}$ in the off-gas compared to the amount of nitrate in the feed. $\mathrm{NO}_{\mathrm{x}}$ destruction trends during the test series are shown in Figure 6.4-1.

$\mathrm{NO}_{\mathrm{x}}$ destruction was calculated several ways. $\mathrm{NO}$ was determined at the steam reformer filter outlet off-gas based on the $\mathrm{NO}_{\mathrm{x}}$ measurements from the CAI NO analyzer. The $\mathrm{NO}_{\mathrm{x}}$ destruction calculations do not account for any $\mathrm{HCN}, \mathrm{N}_{2} \mathrm{O}, \mathrm{NH}_{3}$, or other reduced forms of nitrogen-bearing gas species.

$\mathrm{NO}_{\mathrm{x}}$ destruction was also determined for the entire steam reforming test system, using the NO and $\mathrm{NO}_{\mathrm{x}}$ measurements at the outlet of the thermal oxidizer. These $\mathrm{NO}_{\mathrm{x}}$ destruction values show how a representative complete, integrated system performs to destroy nitrates in the feed and $\mathrm{NO}_{\mathrm{x}}$ in the off-gas. 
Table 6.4-1. $\mathrm{NO}_{\mathrm{x}}$ destruction for the THOR mineral test series.

\begin{tabular}{|c|c|c|c|c|c|c|c|c|c|c|c|c|c|c|c|c|c|}
\hline \multirow[b]{2}{*}{ Test condition } & \multirow[b]{2}{*}{$\begin{array}{c}\text { Simulant } \\
\text { feedrate, } \\
1 / \mathrm{hr}\end{array}$} & \multirow[b]{2}{*}{$\begin{array}{c}\mathrm{NO}_{\mathrm{x}} \\
\text { feedrate, } \\
\text { scfm }\end{array}$} & \multicolumn{7}{|c|}{$\mathrm{NO}_{\mathrm{x}}$ destruction at the filter outlet } & \multicolumn{8}{|c|}{ NOx destruction downstream of the thermal oxidizer } \\
\hline & & & \begin{tabular}{|c}
$\begin{array}{c}\text { Off-gas flowrate at } \\
\text { the filter outlet, } \\
\text { wet scfm }\end{array}$ \\
\end{tabular} & $\begin{array}{r}\mathrm{NO}_{\mathrm{x}} \\
\text { MTEC, } \\
\text { wet ppm }\end{array}$ & $\begin{array}{l}\mathrm{NO}, \\
\mathrm{ppm}\end{array}$ & $\begin{array}{l}\mathrm{NO}_{2}, \\
\text { ppm }\end{array}$ & $\begin{array}{l}\mathrm{NO}_{\mathrm{x}} \\
\mathrm{ppm}\end{array}$ & $\begin{array}{l}\% \text { removal } \\
\text { from NO }\end{array}$ & $\begin{array}{l}\% \text { removal } \\
\text { from } \mathrm{NO}_{\mathrm{x}}\end{array}$ & $\begin{array}{c}\text { Off-gas } \\
\text { flowrate at the } \\
\text { carbon bed, wet } \\
\text { scfm }\end{array}$ & $\begin{array}{c}\text { NOx } \\
\text { MTEC, } \\
\text { wet ppm }\end{array}$ & $\begin{array}{c}\mathrm{NO} \text {, wet } \\
\mathrm{ppm}\end{array}$ & $\begin{array}{c}\mathrm{NO}_{2}, \\
\text { wet } \\
\text { ppm }\end{array}$ & $\begin{array}{c}\mathrm{NO}_{\mathrm{x}}, \\
\text { wet } \\
\mathrm{ppm} \\
\end{array}$ & $\begin{array}{c}\text { Total system } \\
\text { NO destruction, } \\
\%\end{array}$ & $\begin{array}{c}\text { Total system } \\
\text { NO }_{\mathbf{x}} \\
\text { destruction, \% }\end{array}$ & $\begin{array}{c}\mathrm{NO}_{\mathrm{x}} \\
\text { destruction by } \\
\text { thermal } \\
\text { oxidizer, } \%\end{array}$ \\
\hline 4 & 2.1 & 0.16 & 13.7 & 11,589 & --- & --- & --- & --- & --- & 95 & 1,689 & 33 & 1 & 33 & 97.7 & 97.7 & --- \\
\hline 4.1 & 4.2 & 0.24 & 14.5 & 16,184 & 799 & 146 & 835 & 95.1 & 94.9 & 95 & 2,507 & 166 & 4 & 169 & 93.3 & 93.2 & -40.5 \\
\hline $4.1 \mathrm{a}$ & 4.3 & 0.25 & 14.5 & 16,643 & 779 & 146 & 816 & 95.3 & 95.1 & 91 & 2,693 & 107 & 2 & 109 & 96.0 & 95.9 & 13.4 \\
\hline $4.1 \mathrm{~b}$ & 4.3 & 0.25 & 14.7 & 16,476 & 816 & 151 & 853 & 95.0 & 94.8 & 89 & 2,753 & 94 & 2 & 96 & 96.6 & 96.5 & 29.5 \\
\hline $4.1 \mathrm{c}$ & 4.3 & 0.25 & 14.6 & 16,519 & 1,049 & 121 & 1,098 & 93.6 & 93.3 & 88 & 2,775 & 86 & 2 & 88 & 96.9 & 96.8 & 50.2 \\
\hline $4.1 \mathrm{~d}$ & 4.3 & 0.25 & 14.7 & 16,428 & 1,086 & 51 & 1,137 & 93.4 & 93.1 & 88 & 2,778 & 84 & 2 & 86 & 97.0 & 96.9 & 53.2 \\
\hline 4.2 & 5.0 & 0.28 & 15.8 & 17,510 & 1,208 & 59 & 1,267 & 93.1 & 92.8 & 90 & 3,098 & 88 & 2 & 90 & 97.1 & 97.1 & 57.9 \\
\hline 4.3 & 5.8 & 0.33 & 16.9 & 19,022 & 1,274 & 65 & 1,340 & 93.3 & 93.0 & 93 & 3,493 & 95 & 2 & 96 & 97.3 & 97.2 & 58.8 \\
\hline $4.3 \mathrm{a}$ & 5.8 & 0.33 & 16.9 & 19,023 & 1,940 & 149 & 2,089 & 89.8 & 89.0 & 93 & 3,510 & 125 & 2 & 127 & 96.4 & 96.4 & 64.5 \\
\hline 4.4 & 6.4 & 0.36 & 17.4 & 20,369 & --- & --- & & --- & -- & 93 & 3,864 & 192 & 3 & 196 & 95.0 & 94.9 & --- \\
\hline $4.4 \mathrm{a}$ & 6.5 & 0.37 & 17.6 & 20,466 & 3,246 & 1,324 & 4,570 & 84.0 & 77.6 & 94 & 3,890 & 205 & 16 & 211 & 94.7 & 94.6 & 66.0 \\
\hline 4.5 & 5.8 & 0.33 & 18.9 & 17,073 & 1,980 & 2,202 & 4,182 & 86.7 & 71.2 & 97 & 3,368 & 203 & 10 & 208 & 94.0 & 93.8 & 53.7 \\
\hline 5.1 & 5.8 & 0.33 & 13.4 & 23,986 & 2,465 & 2,347 & 4,812 & 89.7 & 79.9 & 99 & 3,301 & 185 & 6 & 191 & 94.4 & 94.2 & 43.8 \\
\hline $5.1 \mathrm{a}$ & 5.8 & 0.33 & 13.2 & 24,341 & 2,597 & 2,239 & 4,836 & 89.3 & 80.1 & 99 & 3,302 & 178 & 8 & 186 & 94.6 & 94.4 & 47.3 \\
\hline 5.2 & 5.8 & 0.33 & 19.6 & 16,697 & 2,191 & 1,659 & 3,850 & 87.0 & 77.4 & 106 & 3,129 & 157 & 4 & 161 & 95.0 & 94.9 & 60.4 \\
\hline $5.2 \mathrm{a}$ & 6.1 & 0.35 & 20.5 & 16,543 & 3,420 & 1,649 & 5,069 & 79.3 & 69.3 & 104 & 3,304 & 186 & 2 & 188 & 94.4 & 94.3 & 72.6 \\
\hline $5.2 \mathrm{~b}$ & 5.7 & 0.25 & 19.1 & 16,559 & 2,374 & 1,136 & 3,510 & 85.6 & 78.7 & 98 & 3,260 & 178 & 2 & 180 & 94.5 & 94.5 & 61.6 \\
\hline $5.2 \mathrm{c}$ & 6.0 & 0.34 & 18.7 & 17,846 & 2,319 & 1,027 & 3,346 & 87.0 & 81.2 & 98 & 3,437 & 179 & 3 & 182 & 94.8 & 94.7 & 59.4 \\
\hline $\begin{array}{l}5.2 \mathrm{~d} \\
\text { Shutdown }\end{array}$ & 5.6 & 0.30 & 18.4 & 17,073 & 2,107 & 979 & 3,086 & 87.7 & 82.0 & 96 & 3,299 & 167 & 2 & 169 & 94.9 & 94.9 & 58.5 \\
\hline $\begin{array}{l}5.3 \\
\text { Shutdown }\end{array}$ & 3.2 & 0.18 & 15.5 & 11,476 & 4,515 & 460 & 4,975 & 61.1 & 57.2 & 88 & 2,136 & 256 & 6 & 255 & 88.0 & 88.0 & 69.1 \\
\hline 5.4 & 4.1 & 0.23 & 12.5 & 18,967 & 5,226 & 327 & 5,554 & 72.1 & 70.3 & 74 & 3,240 & 266 & 0 & 252 & 91.9 & 92.4 & 72.7 \\
\hline 5.5 & 3.3 & 0.19 & 10.7 & 17,301 & 4,244 & 448 & 4,691 & 75.5 & 72.9 & 68 & 2,755 & 140 & 0 & 131 & 94.9 & 95.3 & 80.7 \\
\hline $5.5 \mathrm{a}$ & 3.3 & 0.19 & 10.7 & 17,154 & 4,390 & 512 & 4,903 & 74.4 & 71.4 & 67 & 2,766 & 199 & 0 & 187 & 92.8 & 93.3 & 73.7 \\
\hline $5.5 \mathrm{~b}$ & 3.3 & 0.18 & 10.3 & 17,694 & 5,076 & 422 & 5,498 & 71.3 & 68.9 & 67 & 2,769 & 339 & 0 & 322 & 87.7 & 88.4 & 59.4 \\
\hline $5.5 \mathrm{c}$ & 3.3 & 0.18 & 10.3 & 17,642 & 5,063 & 421 & 5,483 & 71.3 & 68.9 & 67 & 2,754 & 344 & 0 & 329 & 87.5 & 88.0 & 58.4 \\
\hline $5.5 \mathrm{~d}$ & 3.3 & 0.18 & 10.4 & 17,406 & 5,208 & 314 & 5,522 & 70.0 & 68.2 & 67 & 2,728 & 384 & 0 & 369 & 85.9 & 86.5 & 54.9 \\
\hline $5.5 \mathrm{e}$ & 3.3 & 0.18 & 10.5 & 17,265 & 4,434 & 492 & 4,926 & 74.4 & 71.6 & 68 & 2,715 & 206 & 0 & 197 & 92.4 & 92.7 & 71.6 \\
\hline 5.6 & 3.3 & 0.18 & 11.6 & 15,753 & 4,295 & 566 & 4,861 & 72.7 & 69.1 & 70 & 2,645 & 97 & 0 & 92 & 96.3 & 96.5 & 87.3 \\
\hline Average & 4.4 & 0.22 & 15.1 & 16,323 & 3,408 & 777 & 4,179 & 78.0 & 73.6 & 87 & 2,914 & 203 & 4 & 201 & 92.6 & 92.6 & 55.3 \\
\hline STD DEV & 1.3 & 0.11 & 3.0 & 3,676 & 1,504 & 717 & 1,527 & 12.1 & 12.1 & 14 & 587 & 80 & 6 & 77 & 3.6 & 3.6 & 25 \\
\hline
\end{tabular}

1. The $\mathrm{NO}_{3}$ concentration in the simulant is $5.33 \mathrm{M}$. 


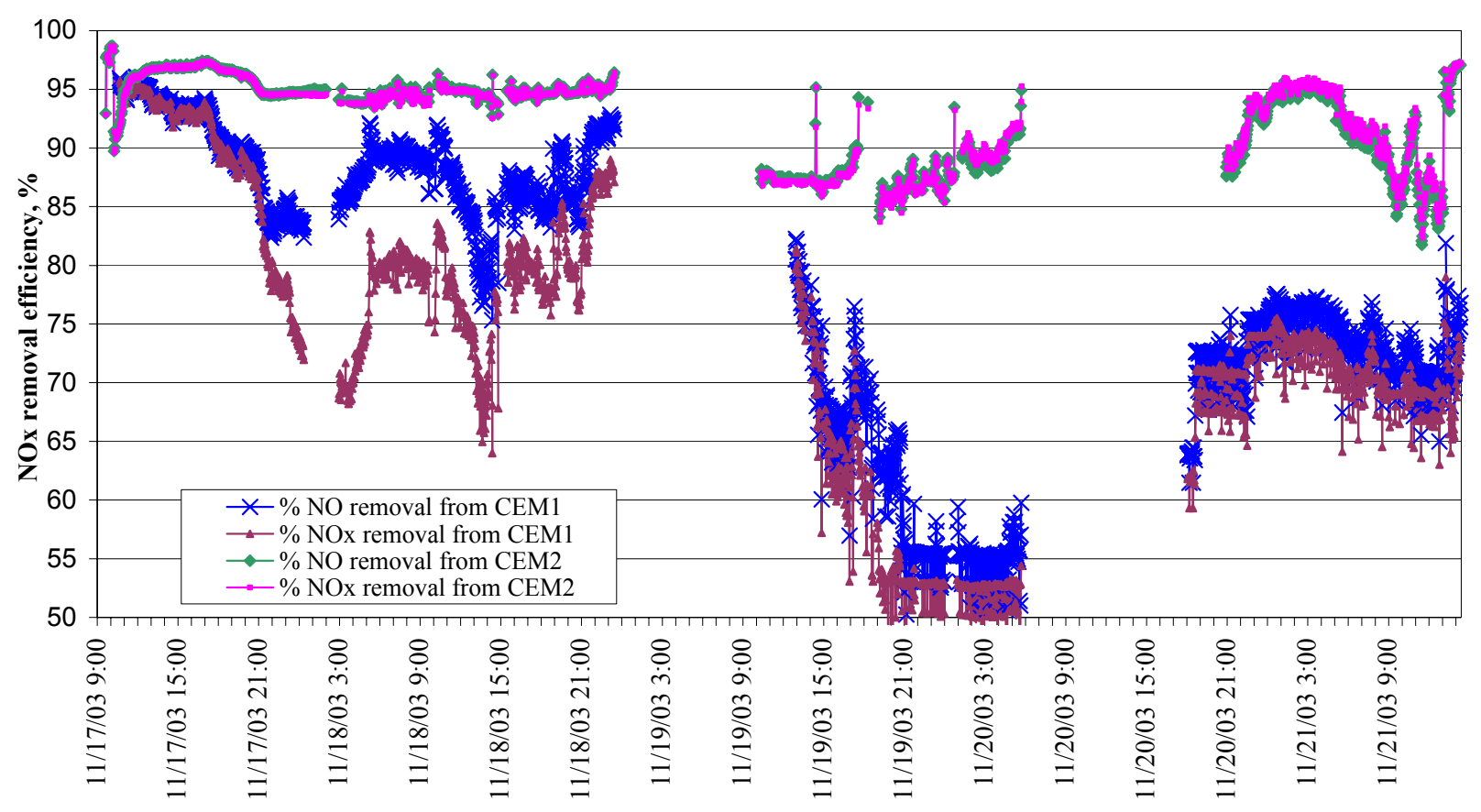

Figure 6.4-1. $\mathrm{NO}_{\mathrm{x}}$ destruction for the THOR mineral test series.

\subsubsection{Reductant Utilization}

Organic reductants used during this test series were sugar and solid carbon. During different test conditions, they were fed to the reformer in different proportions and with varying stoichiometric ratios with respect to nitrates in the SBW simulant and added $\mathrm{O}_{2}$. Carbon mass balance closure and distribution to the output streams are shown in Table 6.4-2.

Sources of carbon in the system were the sugar and the solid carbon additive. These reductants were heated (and thermally decomposed in the case of sugar) and reacted with sources of oxygen (nitrates, steam, and oxygen) in the steam reformer. While the stoichiometry was varied for different test conditions, the overall stoichiometry was always reductant-rich to encourage $\mathrm{NO}_{\mathrm{x}}$ destruction.

Most of the effluent carbon (about $86 \%$ ) was in the off-gas $\mathrm{CO}_{2}, \mathrm{CO}$, or THC. Only $14 \%$ of the carbon was found in the solid products, and a negligible amount was found in the wet scrubber. The total carbon in the solid products includes both organic carbon from unreacted reductants, and inorganic carbon in the form of $\mathrm{CO}_{3}$. Of the carbon found in the solid output streams, most was in the form of organic carbon in the filter fines. Smaller amounts were found as organic carbon in the bed, cyclone, and scrubber water outputs, and under $1 \%$ of the output carbon was attributed to inorganic carbonate in the solid products. 
Table 6.4-2. Carbon mass distribution and balance for the THOR mineralized test series.

\begin{tabular}{|c|c|c|c|c|c|c|c|c|c|c|c|}
\hline & \multicolumn{3}{|c|}{ Carbon mass inputs, $\mathrm{kg}$} & \multicolumn{7}{|c|}{ Carbon mass outputs, $\mathrm{kg}$} \\
\hline & & \multirow[b]{2}{*}{$\begin{array}{l}\text { From } \\
\text { syrup }\end{array}$} & \multirow[b]{2}{*}{$\begin{array}{l}\text { Total solid } \\
\text { carbon } \\
\text { additive }\end{array}$} & \multirow{2}{*}{$\begin{array}{c}\text { Estimated } \\
\text { carbon from } \\
\text { solid carbon } \\
\text { additive (a) }\end{array}$} & \multicolumn{3}{|c|}{ Solid outputs } & \multirow[b]{2}{*}{$\begin{array}{l}\text { Scrub } \\
\text { water }\end{array}$} & \multicolumn{3}{|c|}{\begin{tabular}{|l|l} 
Off-gas at the filter outlet \\
\end{tabular}} \\
\hline & & & & & $\begin{array}{c}\text { Bed } \\
\text { product }\end{array}$ & $\begin{array}{l}\text { Cyclone } \\
\text { samples }\end{array}$ & $\begin{array}{l}\text { Filter } \\
\text { catch }\end{array}$ & & $\mathrm{CO}_{2}$ & $\mathrm{CO}$ & $\mathrm{THC}$ \\
\hline \multirow[b]{2}{*}{$\begin{array}{l}\text { Totals of } \\
\text { individual } \\
\text { streams }\end{array}$} & $\begin{array}{l}\text { Total organic } \\
\text { (reduced) carbon } \\
\text { (TOC) }\end{array}$ & 42 & 58 & 56 & 2.1 & 0.5 & 11.0 & 0.0007 & 0.0 & 16.4 & 2.3 \\
\hline & $\begin{array}{l}\text { Total inorganic } \\
\text { (fully oxidized) } \\
\text { carbon (TIC) }\end{array}$ & 0 & 0 & 0 & 0.005 & 0.003 & 0.1 & 0.0 & 78.3 & 0.0 & 0.0 \\
\hline \multirow[b]{2}{*}{ Input/output } & TOC & \multicolumn{3}{|c|}{98} & \multicolumn{3}{|c|}{13.5} & 0.0007 & & 18.7 & \\
\hline & TIC & \multirow{2}{*}{\multicolumn{3}{|c|}{--- }} & \multicolumn{3}{|c|}{0.1} & & & 78 & \\
\hline \multicolumn{2}{|c|}{ Total input/output } & & & & \multicolumn{7}{|c|}{111} \\
\hline \multicolumn{5}{|c|}{$\begin{array}{l}\text { Total carbon mass balance closure, } \\
\% \text { (b) }\end{array}$} & \multicolumn{3}{|c|}{113} & & & & \\
\hline
\end{tabular}

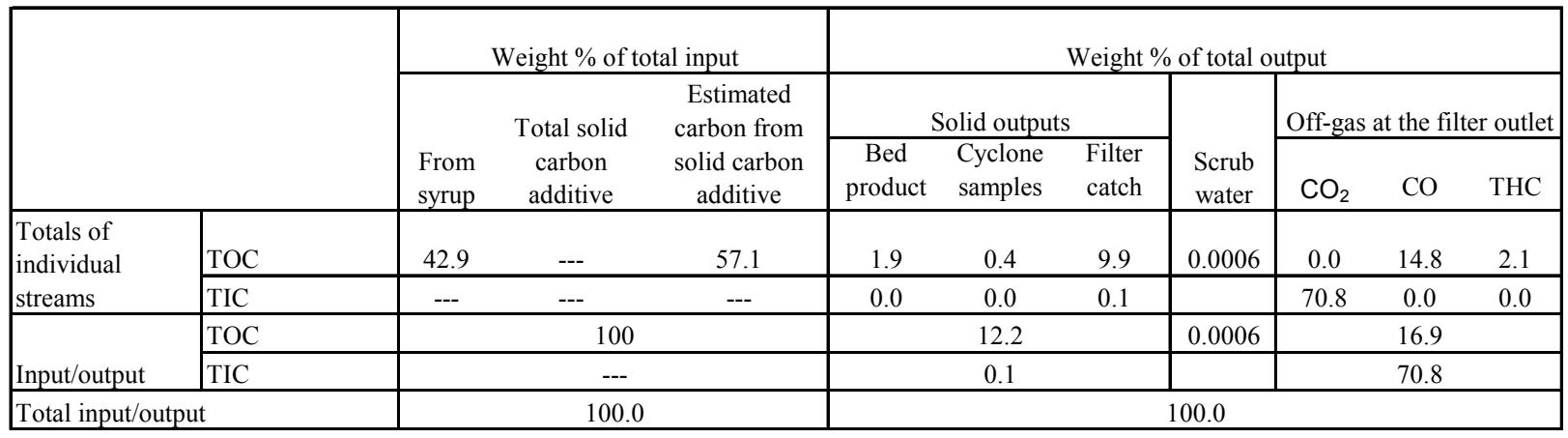

a. The carbon in the solid carbon additive was estimated assuming that about $3 \%$ of the carbon additive was inorganic.

b. Calculated based on the mass of the output stream divided by the total mass of all output streams.

[c balance for modem(ddt).xls]thor carb carbon MB

\subsubsection{Product Elemental Distribution and Mass Balance Closure}

The SBW simulant components, hazardous metals, radionuclide surrogates, and anions partition in different ways among the solid and gaseous effluents of the steam reformer. Species that are predominantly solid-phase at the operating conditions of the steam reformer are predominantly captured in the solid bed product or the elutriated fines. Species that tend to volatilize and thereby pass through the heated filter will tend to be scrubbed in the wet scrubber to the extent that they are condensible or watersoluble at the scrubber operating conditions. Species that pass through the heated filter and the wet scrubber may be captured in the carbon bed downstream of the wet scrubber, or pass on out the stack.

Input and output measurements and calculations were made in the current tests to determine the distribution of the feed constituents to the reformer products. The product distributions are shown in Table 6.4-3. The total solid mass (less the starting bed media) partitioned about $41 \%$ to the bed product (and cyclone solids, that are recycled back to the bed during operation), and about $59 \%$ to the filter fines. Partitioning of material to the scrub water was negligible. The total solids mass balance, at about $95 \%$ (not including the mass of input solid carbon that was gasified), shows that the mass of the total solids was accurately accounted for during the test series.

Species that appeared to partition relatively the same as the total solids to the bed product, filter fines, and off-gas were those that (a) partitioned between $40-70 \%$ to the combined bed product and cyclone recycle, and between $30-50 \%$ to the filter fines, and (b) had mass balance closure ratios of 1.0 \pm 0.4 . Those species included $\mathrm{Ca}, \mathrm{Cr}, \mathrm{Cu}, \mathrm{Fe}, \mathrm{K}, \mathrm{Mg}, \mathrm{Mn}, \mathrm{Na}, \mathrm{Si}$, and $\mathrm{Zn}$. 
Species that tend to be enriched in the elutriated solids, and then be captured in the cyclone recycle and filter fines, are those that have mass distributions to the bed less than about $40 \%$, mass distributions to the filter fines greater than about $50 \%$, and have mass balance closure ratios of about $1.0 \pm 0.4$. These species included $\mathrm{PO}_{4}, \mathrm{Cl}, \mathrm{Cs}, \mathrm{Ni}, \mathrm{Pb}$, and $\mathrm{Re}$.

Some species exhibited low mass balance closure ratios. These species either (a) tend to volatilize into a form (either a gas species or particulate matter (PM) too small to be captured in the heated filter) and are also not readily wet scrubbed, or (b) those that were difficult to solubilize during sample analysis, and so the sample analysis recoveries were low and did not accurately indicate the true concentrations of those species in the samples. $\mathrm{NO}_{3}$ and $\mathrm{Hg}$ are species with low mass balance closure ratios. Corroborating test results show that the $\mathrm{NO}_{3}$ was destroyed with an average efficiency of about $99.94 \%$. The small remaining amount of solid $\mathrm{NO}_{3}$ partitioned mainly to the filter fines, although lesser amounts were found in the bed product and the scrub water. The $\mathrm{Hg}$ was very volatile, and essentially $100 \%$ of the $\mathrm{Hg}$ partitioned to the off-gas, with only a small amount captured in the scrubber.

Some species had low enough mass balance closure ratios that the sample recovery during sample analysis is suspect. Those species were $\mathrm{SO}_{4}, \mathrm{~F}, \mathrm{Al}$, and $\mathrm{Si}$. While the low mass balance ratio for $\mathrm{SO}_{4}$ may have been because $\mathrm{SO}_{4}$ was converted to $\mathrm{SO}_{2}$ and not efficiently scrubbed in the scrubber, $\mathrm{Al}$ and $\mathrm{Si}$ are far less volatile and less likely to pass through the heated filter. The heated filter exhibited a total particulate capture efficiency of up to $100.0 \%$. The F could have formed HF and passed through the filter, but HF is readily soluble in even acidic scrub water, and was not detected there in large amounts.

The most reasonable explanation for the low mass balance closure ratios for $\mathrm{SO}_{4}, \mathrm{~F}, \mathrm{Al}$, and $\mathrm{Si}$ is low sample recoveries, due to dissolution procedures that were not sufficiently aggressive for insoluble mineral species formed in the reformer. Such species may also have bound some of the other cations and anions. This may be why mass balance closure ratios range between about 0.6 to 1.0 for several other species $(\mathrm{Cl}, \mathrm{Cr}, \mathrm{Cs}, \mathrm{Fe}, \mathrm{K}, \mathrm{Mn}, \mathrm{Na}, \mathrm{Pb}, \mathrm{Re}$, and $\mathrm{Zn})$. Even though the mass balance closure ratios are less than unity for these other species, the mass balance closure ratios are close enough to unity so that conclusions about the product distributions of these other species are reasonably valid. 
Table 6.4-3. Elemental distributions and mass balance closure for the THOR mineral test series.

\begin{tabular}{|c|c|c|c|c|c|c|c|c|c|c|c|c|c|c|c|c|c|c|c|c|c|c|c|c|}
\hline \multicolumn{25}{|c|}{ Mass, kg } \\
\hline & Total & $\mathrm{NO}_{3}$ & $\mathrm{PO}_{4}$ & $\mathrm{SO}_{4}$ & $\mathrm{Cl}$ & $\mathrm{F}$ & $\mathrm{Al}$ & $\mathrm{Ca}$ & $\mathrm{Cr}$ & Cs & $\mathrm{Cu}$ & $\mathrm{Fe}$ & $\mathrm{Hg}$ & $\mathrm{K}$ & $\mathrm{Mg}$ & $\mathrm{Mn}$ & $\mathrm{Na}$ & $\mathrm{Ni}$ & $\mathrm{Pb}$ & $\operatorname{Re}$ & $\mathrm{Si}$ & $\mathrm{Sn}$ & $\mathrm{Zn}$ & $\mathrm{Zr}$ \\
\hline \multicolumn{25}{|l|}{ Input streams: } \\
\hline Starting bed media & 63 & & 0.008 & 0.012 & 0.004 & 0.004 & 27.6 & 0.049 & 0.003 & 0.003 & 0.001 & 0.085 & 0 & 0.142 & 0.007 & 0.03 & 0.904 & 0.003 & 0.013 & 0.002 & 0.013 & $8 \mathrm{E}-05$ & 0.001 & 0.003 \\
\hline Feed solids & 123.1 & & 1.97 & 2.06 & 0.33 & 0.28 & 22.6 & 0.69 & 0.054 & 0.132 & 0.014 & 1.28 & 0.083 & 2.55 & 0.099 & 0.24 & 14.70 & 0.027 & 0.084 & 0.061 & 22.31 & 0.000 & 0.021 & 0.000 \\
\hline Total inputs & 186.1 & 101.35 & 1.97 & 2.08 & 0.33 & 0.28 & 50.2 & 0.74 & 0.057 & 0.135 & 0.015 & 1.36 & 0.083 & 2.69 & 0.106 & 0.27 & 15.60 & 0.030 & 0.097 & 0.063 & 22.32 & 0.000 & 0.023 & 0.003 \\
\hline $\begin{array}{l}\text { Output streams: } \\
\text { Bed product }\end{array}$ & 99.63 & 0.006 & 0.14 & 0.04 & 0.01 & 0.006 & 4.5 & 0.34 & 0.018 & 0.021 & 0.007 & 0.461 & 0.000 & 1.024 & 0.047 & 0.078 & 5.683 & 0.010 & 0.028 & 0.011 & 0.026 & 0.000 & 0.011 & 0.000 \\
\hline Cyclone samples & 3.64 & 0.00 & 0.03 & 0.01 & 0.00 & 0.00 & 0.4 & 0.03 & 0.001 & 0.003 & 0.000 & 0.33 & 0.000 & 0.05 & 0.003 & 0.00 & 0.28 & 0.001 & 0.001 & 0.002 & 0.001 & 0.000 & 0.000 & 0.000 \\
\hline Filter fines & 73.82 & 0.04 & 1.09 & 0.36 & 0.14 & 0.04 & 9.3 & 0.34 & 0.024 & 0.074 & 0.008 & 0.41 & 0.000 & 1.21 & 0.060 & 0.09 & 2.78 & 0.017 & 0.043 & 0.040 & 0.035 & 0.000 & 0.007 & 0.000 \\
\hline Scrub solids & 0.23 & 0.01 & 0.00 & 0.13 & 0.07 & 0.01 & 0.0 & 0.00 & 0.000 & 0.000 & 0.000 & 0.00 & 0.000 & 0.00 & 0.000 & 0.00 & 0.00 & 0.000 & 0.000 & 0.000 & 0.000 & 0.000 & 0.000 & 0.000 \\
\hline Total outputs & 177.3 & 0.06 & 1.26 & 0.54 & 0.23 & 0.06 & 14.2 & 0.71 & 0.043 & 0.097 & 0.015 & 1.20 & 0.001 & 2.28 & 0.110 & 0.17 & 8.73 & 0.028 & 0.072 & 0.053 & 0.062 & 0.000 & 0.018 & 0.000 \\
\hline
\end{tabular}

Elemental mass distribution, \% of mass in the output stream divided by total mass in the total of all output streams

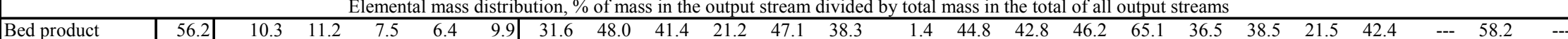

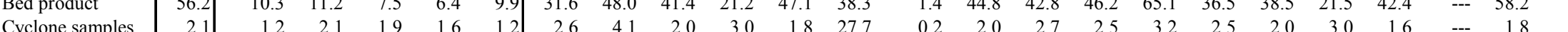

\begin{tabular}{l|r|rrrrrrrrrrrrrrrrrrrrrrrr} 
& \\
Cyclone samples & 2.1 & 1.2 & 2.1 & 1.9 & 1.6 & 1.2 & 2.6 & 4.1 & 2.0 & 3.0 & 1.8 & 27.7 & 0.2 & 2.0 & 2.7 & 2.5 & 3.2 & 2.5 & 2.0 & 3.0 & 1.6 & --- & 1.8 &
\end{tabular}

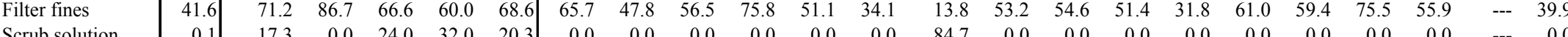

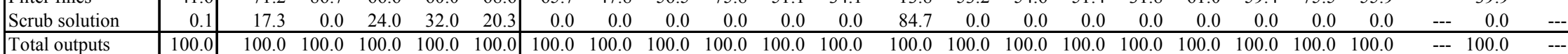

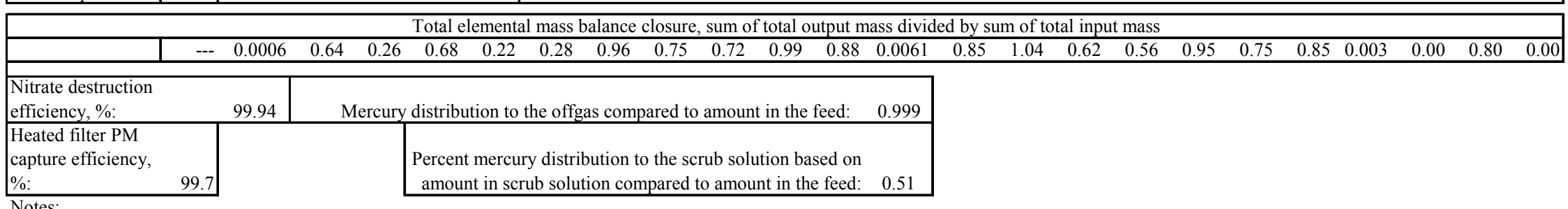

Notes:

1. Impurities of the starting bed media and in the solid carbon reductant are included.

2. The calculated total mass of feed solids is based on the theoretical product composition in Table 6.2-2.

3. The input mass of nitrate and $\mathrm{Hg}$ were included (even though the solid product calculations assumed that all $\mathrm{NO} 3$ and $\mathrm{Hg}$ would evolve to the offgas) in order to perform mass balance closure

calculations for these species.

4. The mass of any material (especially $\mathrm{Hg}$, and possibly some halides, $\mathrm{P}$, and $\mathrm{S}$ ) captured in the carbon bed is not included. This may be the cause for mass balance closures significantly less than 1.0 for some species $\left(\mathrm{PO}_{4}, \mathrm{SO}_{4}, \mathrm{Fe}\right.$, and $\left.\mathrm{Si}\right)$.

5. The mass balance closure calculations are based on the solid product masses and their measured compositions, together with the measured composition of the scrub liquor. Any elemental masses that leave the system in the offgas after passing through the cyclone, filter, and scrubber are not accounted for.

6. The volume of the scrub solution averaged 45 gallons. The total mass of undissolved and dissolved solids in the scrub solution is the sum of the elements and measured species, excluding any oxide mass.

7. The nitrate destruction efficiency is calculated from the total amount of output $\mathrm{NO}_{3}$ compared to the total input amount of $\mathrm{NO}_{3}$.

8. The heated filter particulate matter (PM) removal efficiency was estimated from the mass of solids captured in the wet scrubber compared the mass of filter fines; only the anions, Hg, and TOC were accounted for in the mass of captured scrubber solids.

9. The indicated mass balance closure for Si is only 0.0028. As discussed in Note 2 of Table 6.3-2 a second analysis of some samples indicated that the majority of the Si was not detected in the first sample analysis because of incomplete digestion of the Si species. The Si concentrations from the second analysis 50-100 times those reported in Table 6.3-2. Moreover, from the reported precision of the second analysis, the true concentration could have been higher still by another factor of six. Applying the implied range of correction factors (50x1 to 100x6) to 0.0028 the "true" mass balance

closure for Si would thus be $0.14-1.68$, which brackets the ideal value of 1.0 


\subsubsection{Off-gas Mercury Concentrations and Emissions Control}

Mercury is a unique hazardous metal because of its toxicity and its volatility. Expectations that essentially no $\mathrm{Hg}$ is retained in the solid bed product and filter catch are confirmed by sample analyses that show very low $\mathrm{Hg}$ levels in those products. The $\mathrm{Hg}$ in the SBW simulant feed quantitatively evolved to the steam reformer off-gas. Table 6.4-4 shows the speciation and concentrations of $\mathrm{Hg}$ as the off-gas passed through the wet scrubber and 3-stage carbon bed. This table also shows the mass balance closure and carbon bed sorption efficiency.

Measured mercury levels upstream of the wet scrubber averaged almost $6,000 \mu \mathrm{g} / \mathrm{m}^{3}$. Very little of the total mercury was scrubbed in the wet scrubber, because the mercury was almost entirely elemental mercury, which is not readily water-scrubbed. The total mercury removal efficiency of the carbon bed exceeded $99.8 \%$.

The carbon bed was designed with three stages in order to (a) show the potential loading capacity (mass of total $\mathrm{Hg}$ sorbed per mass of carbon sorbent) and (b) the potential total $\mathrm{Hg}$ removal efficiency from the steam reformer off-gas. These two objectives are mutually exclusive in discrete small-scale pilot tests. The theoretical sorption capacity for Nucon sulfur-impregnated carbon is up to $20 \mathrm{wt} \%$, so a carbon bed for discrete small-scale pilot tests would need to be too small to be appropriately designed according to vendor recommendations and design criteria for maximum superficial velocity, minimum residence time, and geometry (Soelberg 2003b).

The three-stage design enables both objectives to be accomplished. The first (3-inch deep) stage, while not designed with appropriate depth-to-diameter dimensions or residence time, has an appropriate superficial gas velocity and a small enough mass of carbon so that its capacity may be reached (defined by when breakthrough occurs) in a reasonable test duration. The Hg removal efficiency data confirm that the first stage is in fact not designed appropriately for high $\mathrm{Hg}$ removal efficiency. The first stage removed less than $89 \%$ of the total $\mathrm{Hg}$.

Breakthrough occurs when the outlet $\mathrm{Hg}$ levels start to increase from a relatively constant baseline level, asymptotically approaching the inlet level. By design, the first stage did not reach breakthrough during the THOR carbonate test series. The carbon capacity is at least the value shown for total $\mathrm{Hg}$ content in the carbon the time of the end of THOR mineral test series.

The combined first, second, and third stages have sufficient depth to meet vendor recommendations and design criteria. The Hg removal efficiency shown at the end of the second and third stages confirms that this bed design accomplishes very efficient $\mathrm{Hg}$ control. The $\mathrm{Hg}$ concentrations downstream of stages 2 and 3, corrected to a dry, $7 \% \mathrm{O}_{2}$ basis, are 1/4 or less of the HWC MACT limit. 
Table 6.4-4. Hg speciation, concentrations, mass balance closure, and carbon bed sorption efficiency for the THOR mineral test series.

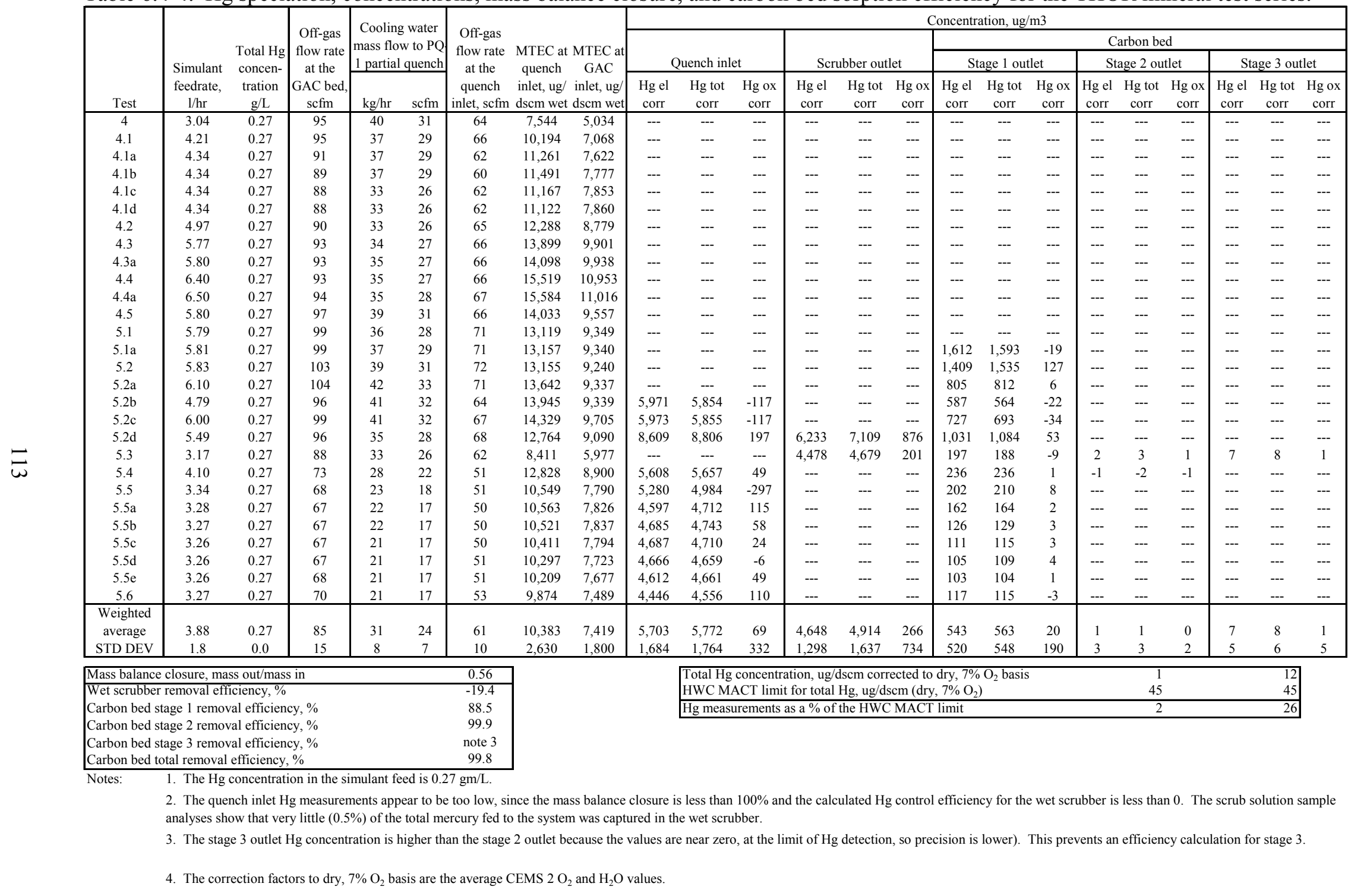




\section{SUMMARY AND CONCLUSIONS}

About one million gallons of acidic, hazardous, and radioactive sodium-bearing waste (SBW) is stored in stainless steel tanks at the Idaho Nuclear Technology and Engineering Center (INTEC), which is a major operating facility of the Idaho National Engineering and Environmental Laboratory (INEEL). This mixed waste was produced during nuclear fuel reprocessing activities that was halted in the 1990s, and remains after cessation of fluidized bed calcination that has already converted raffinate waste (also from nuclear fuel reprocessing) and much of the SBW into a more safely stored solid granule calcine form. Further treatment of the remaining SBW inventory is on hold pending a review and determination of the most appropriate treatment method. Steam reforming is a candidate technology being investigated for treatment of the SBW into a road ready waste form that can be shipped to the Waste Isolation Pilot Plant in New Mexico for interment.

A steam reforming technology patented by Studsvik, Inc., and licensed to THOR Treatment Technologies (TTT) was demonstrated on a WM-180 SBW simulant in January of 2003 using a Department of Energy-owned fluidized bed test system located at the Science Applications International Corporation (SAIC) Science and Technology Applications Research Center located in Idaho Falls, Idaho. This first phase of tests showed that SBW could be successfully converted into a solid alkali carbonate granule form without serious agglomeration, but the emphasis was on process viability and reliability rather than on production and optimization.

The THOR steam reforming process provides a thermal and reactive environment to (a) evaporate the liquid SBW simulant feed, producing a dry, granular solid product, and (b) destroy nitrates in the feed and $\mathrm{NO}_{\mathrm{x}}$ evolved from the nitrates. Organic reductants fed to the fluidized bed produce the overall chemically reducing environment with steam-reformed products, including hydrogen, methane, and reactive hydrocarbon free radicals that react with and destroy nitrates and $\mathrm{NO}_{\mathrm{x}}$.

Phase 2 tests were performed in November 2003 to evaluate the THOR process under a wider range of conditions. During the first test series, the process chemistry was designed to produce a sodium carbonate product similar to that of the January 2003 tests. The second test series was designed to produce a more leach-resistant, mineralized sodium aluminosilicate product. The tests also demonstrated the performance of MACT-compliant off-gas system.

\subsection{Emulation of the THOR Technology}

The fluidized bed test system was designed and built in 2002 to provide a test bed for evaluating steam reforming for SBW treatment. The system was designed to facilitate testing, with extensive process monitoring and controls. Some specific features such as the capability to add solid reductants were provided to emulate the THOR process. Some other features were not included, such as an internal cyclone or other proprietary or other specific hardware features unique to THOR or other candidate steam reforming technologies. To the extent possible, the January 2003 tests were designed to emulate the THOR technology based on recommendations from TTT.

TTT also participated in the Phase 2 tests to ensure that the tests emulated the primary features of the THOR technology to the extent possible. During test planning stages, TTT provided recommendations for test system modifications and helped determine test objectives. Under subcontract to the INEEL, TTT personnel observed the test series, provided consultation and recommendations during the tests, and provided an observation report to INEEL.

Before the Phase 2 tests, the test system was modified to better emulate some features of the THOR process design, and to include representative components of a full off-gas system that would be required 
for a thermal process, like steam reforming, to treat SBW and comply with the Hazardous Waste Combustor (HWC) Maximum Achievable Control Technology (MACT) standards. The prototype offgas system was based on a system design developed by the INEEL. This off-gas system does not accurately emulate the off-gas system that TTT has proposed for a full-scale test facility.

Steam, blended with a small amount of oxygen, was the fluidizing gas. A non-radioactive SBW simulant was atomized through a water-cooled nozzle into the fluidized bed. Nitrogen was the atomizing gas. The starting bed was dense alumina particles. Sugar dissolved in water was blended with the SBW simulant just before the feed nozzle. Solid activated carbon particles were fed through a separate access

port. Sugar and activated carbon were the reductants used during the carbonate and mineral test series to destroy $\mathrm{NO}_{\mathrm{x}}$, augment the heat input, and to generate the carbon dioxide needed to prevent bed agglomeration. The test objectives included varying the amounts of sugar and solid carbon additives and types of carbon to determine minimum reductant levels and types that still provide adequate $\mathrm{NO}_{\mathrm{x}}$ destruction. Kaolin and silica additives were tested during the mineral test series to produce a mineralized aluminosilicate product.

\subsection{Phase 2 Test Accomplishments, Conclusions, and Recommendations}

Table 7-1 summarizes the Phase 2 test objectives and accomplishments. All of the test objectives were accomplished. Several areas were identified for additional test operation or technology development/demonstration. These areas are:

- $\quad$ Control of the carbonate bed particle size growth by incorporation of a particle size management system to produce/introduce seed particles into the bed.

- Improving the mineralized product density

- Improving the reducing potential and $\mathrm{NO}_{\mathrm{x}}$ destruction while making a mineralized product

- Increasing retention of product in the bed particles and better solid carbon utilization by recycling more fines than were captured and recycled by the cyclone used during the test series

- Improved performance of key system components, including the gas distributor, the bed drain, and the feed nozzle

- $\quad$ Operation for longer times to demonstrate long-term performance

\subsection{Fluidized Bed Test System and Modifications}

The primary components of the test system included the reformer vessel, the product collection systems, the feed systems, the off-gas control system, and the process logic controller (PLC) system. The test system covered a footprint of about $40 \times 40$ feet. Equipment and piping were fabricated from 300 -series stainless steel, except for the reformer vessel, which was fabricated from Inconel $800 \mathrm{H}$. The system could be manually or automatically controlled using a process logic controller (PLC) system with multiple human-machine interface (HMI) stations. 
Table 7-1. Phase 2 test objectives and accomplishments.

\begin{tabular}{|c|c|}
\hline Test objective & Accomplishment \\
\hline $\begin{array}{l}\text { 1. Determine suitable fluidized-bed } \\
\text { operating parameters for the treating } \\
\text { simulated WM- } 180 \text { SBW supernate } \\
\text { and suspended solids that will: }\end{array}$ & Each of the components of this test objective was accomplished, as described below. \\
\hline $\begin{array}{l}\text { a. Reduce unreacted carbon in } \\
\text { the solid product to } \leq 10 \mathrm{wt} \%\end{array}$ & $\begin{array}{l}\text { Several levels of reductant stoichiometries were tested in order to minimize unreacted carbon in the solid } \\
\text { product. When no solid carbon additive was used, there was no unreacted carbon in the solid products. } \\
\text { Even when solid carbon reductant was used, the bed product from both the carbonate and mineralized test } \\
\text { series contained less than } 10 \mathrm{wt} \% \text { unreacted carbon. Unreacted carbon content of the filter fines varied } \\
\text { between } 0-53 \mathrm{wt} \% \text { when the feed rate of carbon reductant was varied. The amount of unreacted carbon in } \\
\text { the filter fines can be controlled to } \leq 20 \mathrm{wt} \% \text { by controlling the feed rate of carbon reductant. }\end{array}$ \\
\hline $\begin{array}{l}\text { b. Achieve } 90 \% \text { destruction of } \\
\mathrm{NO}_{\mathrm{x}} \text { off-gas emissions relative to } \\
\text { nitrates in the feed }\end{array}$ & $\begin{array}{l}\mathrm{NO}_{\mathrm{x}} \text { destruction averaged } 93 \%(99.64 \% \text { nitrate destruction) for the carbonate test and ranged from about } \\
65 \% \text { up to } 90 \%(99.64 \% \text { nitrate destruction) for the mineralized test. Based on results of the Phase } 2 \\
\text { tests, higher } \mathrm{NO}_{\mathrm{x}} \text { destruction is possible under more reducing conditions than were tested in the Phase } 2 \\
\text { tests. }\end{array}$ \\
\hline $\begin{array}{l}\text { c. Maintain a stable bed with } \\
\text { minimal addition of bed seed } \\
\text { particles }\end{array}$ & $\begin{array}{l}\text { No bed seed particle additions were used in the tests. Control of the carbonate bed particle size was not } \\
\text { accomplished during the tests. Additional operations are needed to develop and demonstrate the best of } \\
\text { several possible options for bed particle size control. Possible options include adding separate jet attrition } \\
\text { in the fluidized bed, adding bed seed particles, recycling more of the fines, or removing, attriting, and } \\
\text { reusing bed product. }\end{array}$ \\
\hline $\begin{array}{l}\text { d. Reduce or eliminate solid } \\
\text { catalyst addition }\end{array}$ & $\begin{array}{l}\text { Solid and dissolved catalysts were tested during the tests, but were not required to achieve acceptable } \mathrm{NO}_{\mathrm{x}} \\
\text { destruction. }\end{array}$ \\
\hline $\begin{array}{l}\text { e. Demonstrate a mineralizing } \\
\text { flow sheet }\end{array}$ & $\begin{array}{l}\text { The mineralized flow sheet was demonstrated during } 82 \text { hours of cumulative operation in three separate } \\
\text { test periods. During the first two test periods, bed agglomerations occurred that caused bed defluidization } \\
\text { and required process shut downs to remove the agglomerations. These agglomerations are thought to be } \\
\text { due to the use of silica as a mineralizing additive. After the silica was removed from the feed blend, the } \\
\text { process operated without defluidizing agglomerations. Kaolin alone provided product mineralization. The } \\
\text { tests showed that, with continued operation, the feed spray impacted on the far wall of the fluidized bed } \\
\text { vessel. This impaction caused local feed agglomeration that can be avoided by changing the orientation of } \\
\text { the feed nozzle, or using a larger diameter vessel. }\end{array}$ \\
\hline
\end{tabular}


Table 7-1. Phase 2 test objectives and accomplishments (continued).

f. Sustain the SBW processing $\quad$ The SBW simulant feed rate exceeded $4 \mathrm{~L} / \mathrm{hr}$ for both the carbonate and mineralized test series.

rate similar to or greater than

previous tests $(\geq 4 \mathrm{~L} / \mathrm{hr})$

2. Demonstrate Hazardous Waste Combustor (HWC) Maximum

Achievable Control Technology

(MACT) compliance:

a. Determine efficiency of the thermal oxidizer and characterize the outlet gas composition

Compliance to the HWC MACT standards was demonstrated by showing that $\mathrm{CO}, \mathrm{Hg}$, and $\mathrm{Cl}$ in the offgas complied with the HWC MACT standards.

b. Determine control efficiencies for $\mathrm{Hg}$ and $\mathrm{Cl}$ in the scrubber and carbon bed

c. Determine capacity of the GAC for $\mathrm{Hg}$ and leachability of $\mathrm{Hg}$ sorbed on the GAC

3. Determine the fate of feed constituents and additives including the halides, volatile heavy metals, cesium, etc.

The thermal oxidizer outlet off-gas composition was measured and showed sufficiently high efficiency to lower CO emissions to $1 / 10^{\text {th }}$ or less of the MACT standard for both the carbonate and mineralized test series.

System removal efficiencies for $\mathrm{Hg}$ ranged about $99.9 \%$, lowering the total $\mathrm{Hg}$ levels at the stack to $0-10$ $\mu \mathrm{g} / \mathrm{dscm}$ (dry, corrected to $7 \% \mathrm{O}_{2}$ ), less than $1 / 4^{\text {th }}$ of the MACT standard. $\mathrm{HCl}$ levels were essentially nondetectable, ranging under $0.5 \mathrm{ppm}\left(\mathrm{dry}, 7 \% \mathrm{O}_{2}\right)$, under $2 \%$ of the MACT standard. Mass balances show that almost all of the $\mathrm{Cl}$ was retained in the solid products for both the carbonate and mineral test series.

The Mersorb sulfur-impregnated activated carbon did not reach breakthrough during four test campaigns.

The highest $\mathrm{Hg}$ concentration, measured at the front of the carbon bed, exceeded $6 \mathrm{wt} \%$. Leachable $\mathrm{Hg}$ for this sample was $1.1 \mathrm{mg} / \mathrm{L}$, measured using the Toxicity Characteristic Leaching Procedure, and exceeded the TCLP limit of $0.2 \mathrm{mg} / \mathrm{L}$.

The fate of $\mathrm{NO}_{3}$, alkali metals, hazardous metals, radionuclide surrogates, halides and other anions, and organic reductants was rigorously determined. All feed constituents except $\mathrm{Hg}$ were quantitatively retained in the total solids (bed product and filter fines) during both the carbonate and mineral test series. Mass balance closure for some species including $\mathrm{SO}_{4}$ and $\mathrm{Cl}$ were low for the mineral test series, suggesting that these species in solid samples were not quantitatively solubilized for detection during laboratory analysis, because they were too tightly bound in the mineral product. Concentrations of these species in the scrub water indicate that at least $75-80 \%$ of the $\mathrm{SO}_{4}$ and $\mathrm{Cl}$ were retained in the solid material (bed product and elutriated fines).

4. Characterize solid product composition, quantity, and handling properties of all products and the leach resistance of the mineralized The solid products, quantity, and properties, including particle size, density, and leach resistance, were characterized for the mineralized product. Mineralized product pass the Toxicity Characteristic Leaching Procedure (TCLP) for $\mathrm{Pb}, \mathrm{Ni}, \mathrm{Zn}$, and $\mathrm{Cr}$. Even for the highest leach results, about $99.95 \%$ of the $\mathrm{Cr}$, $99.6 \%$ of the $\mathrm{Pb}, 98 \%$ of the $\mathrm{Ni}$, and $87 \%$ of the $\mathrm{Zn}$ was retained in the solid samples.

product. 
The main features of the fluidized bed vessel were the fluidized-bed section, the freeboard (particle disengaging) section, and the bottom gas distributor through which the fluidizing gas enters the vessel. The bed and freeboard sections were externally heated with electrical resistance heaters for temperature control. The fluidized-bed section was 6 inches in diameter and 30 inches tall. The freeboard section was 12 inches in diameter and 60 inches high. Numerous ports in the bed and freeboard sections enabled access for input streams and process instrumentation.

Several modifications were made to the reformer vessel before the Phase 2 tests to improve operation and data quality. These modifications were (a) relocation of several thermocouples to reduce pressure port plugging, (b) relocation of the lower pressure port to the distributor where it was less prone to plug, and (c) installation of an active bed sample drain. The gas distributor was also evaluated and changed if necessary, based on the expected fluidizing gas flow rate, to optimize gas pressure drop and gas distribution at the bottom of the fluidized bed.

Product fines and process gases exited the freeboard section and passed through a heated, 5-inchdiameter cyclone separator to remove most of the particles in excess of $15 \mu \mathrm{m}$. The off-gas was subsequently filtered in a heated filter vessel containing seven 2.5-inch-diameter, 24-inch-long, sinteredmetal filters with a nominal pore size of $2 \mu \mathrm{m}$.

Following TTT recommendations, the cyclone system was modified to continuously recycle fines captured in the cyclone back to the fluidized bed. This eliminated the separate cyclone catch product, reutilized unreacted solid carbon reductant, and returned product fines back to the bed for incorporation into the bed product. By operating the cyclone recycle auger in reverse, the cyclone recycle rate was measured, and real-time cyclone catch samples were collected for analysis.

Filter fines were collected continuously in a separate product drum located below the filter vessel. A sample spoon was installed before the Phase 2 tests to obtain real-time filter catch samples.

The liquid feed system included the 800-liter simulant hold/makeup tank, two 200-liter day-tanks, and solid additive feed systems. All three tanks were equipped with variable speed agitators and a recirculation/transfer pump to ensure that the solutions were fully mixed and undissolved solids remained suspended and uniformly blended. The liquid feed system was modified before the Phase 2 tests to enable simultaneous metering of two separate liquid feeds, so that simulant and liquid reductant blend ratios could be easily varied and to mimic how a full-scale treatment facility might be operated. The two feed streams were combined just before being atomized in the feed nozzle. The liquid feed nozzle was a water-cooled, gas-atomizing liquid spray nozzle.

Following recommendations from TTT, the solid reductant feed system was modified for better controllability and to reduce pressure fluctuations of the fluidized bed. The auger feed system was replaced with a vibratory feeder recommended by TTT to reduce particle attrition of the solid reductant in the feed system. Unlike the weight-loss feeder, however, the vibratory feeder had to be manually controlled and adjusted because it lacked feed back on carbon depletion in the hopper. Operators made periodic mass discharge rate checks and kept a record of the masses of carbons added to or removed from the feeder.

Just before the Phase 2 tests, the off-gas system was upgraded with new equipment to emulate a complete off-gas system capable of meeting air emission limits of the HWC MACT standards. The offgas system downstream of the heated filter included a natural gas-fired thermal oxidizer, water-spray partial quench vessel, venturi scrubber, mist eliminator, electric reheater, and 3-stage carbon bed. An air eductor induced draft through the entire system, diluted the off-gas, and vented the air-off-gas blend to the SAIC STAR Center stack. 


\subsection{Carbonate Test Series Results and Conclusions}

Process conditions of the carbonate test series were designed to produce an alkali carbonate product. Several different test conditions were performed to evaluate different reductants, provide operating time for process stabilization and bed building, determine maximum and optimum simulant feed rates, and to vary the reductant stoichiometry. All of the carbonate tests were conducted at a nominal bed temperature of $670^{\circ} \mathrm{C}$. Test results and conclusions are summarized below:

All carbonate tests produced a uniform, high-density sodium carbonate product with no agglomerations. However, during initial reductant evaluation tests, before the start of simulant feeding, starting bed media agglomeration occurred. This defluidizing agglomeration was not due to operation or chemistry of the simulant steam reforming process. Instead, it was thought to be due to a soft coating that formed on the bed media from silicon and phosphorus oxides that came from the carbon additive. When the actual simulant feed tests were started, this agglomeration did not occur, presumably because there was sufficient mass of new product to prevent high enough concentrations of Si and P compounds.

The cumulative operating time exceeded 78 hours. The maximum sustained total liquid feed rate exceeded $10 \mathrm{~kg} / \mathrm{hr}$.

The catalytically active metals in the SBW appear to facilitate $\mathrm{NO}_{\mathrm{x}}$ destruction when a carbonate product is produced. Added catalysts were not needed to achieve the desired $\mathrm{NO}_{\mathrm{x}}$ destruction.

Tests show that the use of sugar and the solid carbon reductant together marginally improved $\mathrm{NO}_{\mathrm{x}}$ destruction over using either sugar or a solid carbon reductant alone. A single, relatively short test indicated that Type- 2 carbon contributed to higher $\mathrm{NO}_{\mathrm{x}}$ destruction than Type- $1 \mathrm{~b}$ carbon. All of the reductant evaluation tests were relatively short. A longer test operating time for stabilizing the inventory of carbon in the bed is recommended to more conclusively determine if one reductant is significantly better than another reductant.

Control of bed particle size growth was not achieved. When the average bed particle size reached about $1 \mathrm{~mm}$ (doubling the $0.5-\mathrm{mm}$ starting bed particle size), the simulant feed rate was stopped, and the NAR was increased to try attriting the bed particles. After almost 5 hours of bed attrition, the average bed particle size decreased only slightly.

Operation while feeding a simulant that contained simulated tank heel solids was demonstrated.

The bed turned over about 1.0 times during the test, as feed solids were retained in the bed and starting bed particles grew in mass and size. About $53 \%$ of the solids in the feed partitioned to the bed product, and the remainder, about $47 \%$, partitioned to the filter fines. Only $0.1 \%$ of the input mass was collected in the scrub water.

As the bed particles grew in size and mass, the particle density and bulk density decreased from about $3.6 \mathrm{~g} / \mathrm{mL}$ and $2.2 \mathrm{~g} / \mathrm{mL}$, respectively (for the starting alumina bed media), to about $2.7 \mathrm{~g} / \mathrm{mL}$ and $1.2 \mathrm{~g} / \mathrm{mL}$, respectively, at the end of the test series.

The filter fines were less dense than the bed product. The filter fines particle density was about $3 \mathrm{~g} / \mathrm{mL}$, and the bulk density was about $0.3 \mathrm{gm} / \mathrm{mL}$. The sizes of individual filter fines particles ranged predominantly between under $1 \mu \mathrm{m}$ up to about $10 \mu \mathrm{m}$, but many of the smaller particles were agglomerated into larger particles. 
The concentrations of the primary simulant feed products $\left(\mathrm{CO}_{3}, \mathrm{~K}\right.$, and $\left.\mathrm{Na}\right)$ in the bed samples show a continuous trend of increasing amounts of simulant feed products. The amounts of these species in the bed product would continue to asymptotically approach the theoretically calculated concentrations for these species (up to $29 \mathrm{wt} \% \mathrm{CO}_{3}, 5.2 \mathrm{wt} \% \mathrm{~K}$, and $30 \mathrm{wt} \% \mathrm{Na}$ ). The amounts of these species measured in the bed product indicate that between $39-76 \%$ of the bed material was solids from the simulant feed rather than starting bed alumina.

The total organic carbon content of the filter fines decreased from above $50 \mathrm{wt} \%$ near the start of the test series (thought to be due to higher-than-intended solid carbon feed rates near the start of the test series) to about $8 \%$ near the end of the test series. Unreacted carbon in the fines can be reduced to within the goal of $\leq 10 \mathrm{wt} \%$ while maintaining adequate $\mathrm{NO}_{\mathrm{x}}$ destruction.

The wet-basis steam reformer off-gas contained over 60 volume $\% \mathrm{H}_{2} \mathrm{O}$ and under $30 \% \mathrm{~N}_{2} . \mathrm{CO}_{2}$ levels averaged about $6 \%, \mathrm{H}_{2}$ averaged about $4 \%$, and $\mathrm{CO}$ averaged about $1 \% . \mathrm{CH}_{4}$ and total hydrocarbons (THC) ranged about $0.2 \%$, and NO averaged about $1,600 \mathrm{ppm}$.

The wet-basis off-gas downstream of the thermal oxidizer and wet scrubber was fully oxidized, averaging about 8 ppm $\mathrm{CO}$. NO averaged $88 \mathrm{ppm}$, and $\mathrm{NO}_{\mathrm{x}}$ levels averaged $92 \mathrm{ppm}$. $\mathrm{HCl}$ was essentially not detected, with a reported concentration of $0.3 \mathrm{ppm}$. Total $\mathrm{Hg}$ levels averaged about $14,000 \mu \mathrm{g} / \mathrm{m}^{3}$ (wet basis) at the inlet to the partial quench (upstream of the wet scrubber). Oxidized $\mathrm{Hg}$ was only about $2 \%$ of the total $\mathrm{Hg}$. Downstream of the wet scrubber and carbon bed, the total $\mathrm{Hg}$ concentration was reduced to an average of $4 \mu \mathrm{g} / \mathrm{m}^{3}$ (wet basis). On a dry, $7 \% \mathrm{O}_{2}$ basis, the final $\mathrm{CO}, \mathrm{HCl}$, and $\mathrm{Hg}$ levels averaged about $1 / 10^{\text {th }}$ or less of the MACT limits.

The steam reformer $\mathrm{NO}_{\mathrm{x}}$ destruction (based on the steam reformer outlet $\mathrm{NO}$ measurements) averaged about $93 \% . \mathrm{NO}_{3}$ destruction averaged $99.96 \% . \mathrm{NO}_{\mathrm{x}}$ destruction for the entire steam reforming test system, using the $\mathrm{NO}$ and $\mathrm{NO}_{\mathrm{x}}$ measurements at the outlet of the thermal oxidizer, ranged between 93-97\%.

$\mathrm{PO}_{4}, \mathrm{SO}_{4}, \mathrm{Cl}, \mathrm{F}, \mathrm{Cs}, \mathrm{Cu}, \mathrm{K}, \mathrm{Ni}, \mathrm{Pb}, \mathrm{Re}, \mathrm{Sn}$, and $\mathrm{Zn}$ partitioned disproportionately to the filter fines instead of the bed product. Even though these species favored partitioning to the filter fines, they were nearly all quantitatively captured in the total solid mass that includes both the bed product and filter fines. One hundred percent of the $\mathrm{Cs}$ and $\mathrm{Re}$ (radionuclide surrogates) and $100.0 \%$ of the $\mathrm{Pb}$ and $\mathrm{K}$ partitioned to total solids.

Mercury partitioned quantitatively to the off-gas. Consistent with expectations, essentially all of the off-gas $\mathrm{Hg}$ was measured in the form of elemental $\mathrm{Hg}$ downstream of the thermal oxidizer. Only a fraction (about $0.18 \%$ ) of the total $\mathrm{Hg}$ was scrubbed in the wet scrubber, according to the amount of $\mathrm{Hg}$ detected in the scrub water. The total mercury was efficiently (over $99.9 \%$ on average) removed from the off-gas by the carbon bed.

\subsection{Mineralized Test Series Results and Conclusions}

Conditions of the mineralized test series were designed to produce a sodium aluminum silicate product. Kaolin clay $\left(\mathrm{Al}_{2} \mathrm{Si}_{2} \mathrm{O}_{5}(\mathrm{OH})_{4}\right)$ and (in the first two test periods) silica $\left(\mathrm{SiO}_{2}\right.$, procured as Min-USil 5 microfine crystalline silica), were added to provide about $100 \%$ stoichiometry to combine with Al, $\mathrm{Na}$, and $\mathrm{K}$ in the simulant to produce $\mathrm{NaAlSiO}_{4}$ (nepheline) and $\mathrm{KAlSiO}_{4}$. The kaolin and Min-U-Sil additives were slurried with the SBW simulant in the day tanks before feeding into the reformer.

As in the carbonate test series, steam (blended with a small amount of oxygen) was the fluidizing gas. The non-radioactive SBW simulant (slurried with mineralizing additives) was atomized through a 
water-cooled nozzle into the fluidized bed. Nitrogen was the atomizing gas. The starting bed was dense alumina particles. Sucrose dissolved in water and solid activated carbon granules were reductants. The sugar syrup was separately metered and blended with the SBW simulant slurry in the reformer feed system. The solid carbon reductant was added via a vibrator feeder. While the levels of syrup and carbon reductant were varied during the tests, the total stoichiometry for total reductants and total oxidants always exceeded 1, ranging between 1.1 and 2.7.

All of the mineralization tests were conducted at a nominal bed temperature of $725^{\circ} \mathrm{C}$. Hydrogen levels were lower than expected, and $\mathrm{NO}_{\mathrm{x}}$ levels were higher. $\mathrm{NO}_{\mathrm{x}}$ destruction ranged between about 65 $95 \%$.

During the feed maximization tests, the simulant slurry feed rate was progressively increased from 6 to $9 \mathrm{~kg} / \mathrm{hr}$, and the syrup feed rate was progressively increased to $3.6 \mathrm{~kg} / \mathrm{hr}$.

Three candidate carbons (Type-1a,Type-1b, and Type-2) were evaluated. None performed significantly better than the other two for $\mathrm{NO}_{\mathrm{x}}$ destruction. Tests showed that the use of sugar and the solid carbon reductant together marginally improved $\mathrm{NO}_{\mathrm{x}}$ destruction over using either sugar or a solid carbon reductant alone, and carbon alone reduced $\mathrm{NO}_{\mathrm{x}}$ better than sugar alone, at least for some of the test series.

Three types of iron-based catalysts were tested. Iron nitrate added to the simulant feed did not improve $\mathrm{NO}_{\mathrm{x}}$ destruction. Iron oxide granules added to the fluidized bed did not improve $\mathrm{NO}_{\mathrm{x}}$ destruction. Iron powder added to the bed resulted in an immediate but short-duration increase in $\mathrm{NO}_{\mathrm{x}}$ destruction. The temporary higher $\mathrm{NO}_{\mathrm{x}}$ reduction provided by the introduction of iron powder suggests that the bed is not sufficiently reducing to convert the iron oxides to an active catalytic oxidation state. Experience in a similar test by Studsvik demonstrated that it is necessary to maintain a minimum inventory of carbon in the bed. If the carbon inventory in the bed is too low, the iron oxide is not catalytically active. Higher carbon levels may make the iron catalysts more effective if higher $\mathrm{NO}_{\mathrm{x}}$ destruction is required.

Two types of agglomerations occurred: those that cause bed defluidization (which need to be avoided), and those that cause small agglomerations that are removed with bed product (which are common and not usually problematic). Two defluidizing agglomerations occurred during the first two test periods when silica was present in the simulant as a mineralization additive together with the kaolin clay. The silica additive is thought to be a cause of these two agglomerations, as the agglomerations had a high silica content. No defluidizing agglomerations occurred during the third test period, when kaolin only, without any added silica, was the mineralizing additive.

Some small agglomerations occurred during the third test period. These agglomerations are related to the feed spray. After many hours of operation, the fluidized bed density decreased significantly, allowing inertia of the atomized slurry feed to carry feed spray through the mass of fluidized bed, impacting and forming a deposit/agglomerate on the far wall, which periodically dislodged and accumulated in the reformer vessel bottom forming a small quantity of pencil stub type agglomerations. This waste feed nozzle type agglomeration can be eliminated by reorienting the injector vertically within the bed to prevent impact of waste feed on the vessel wall. This type of waste feed injector-related wall deposit is not an issue in larger production scale reformers.

About $41 \%$ of the solid product partitioned to the combined bed product and recycled cyclone solids. About 59\% partitioned to the filter fines, including unreacted carbon fines. The total mass balance closure ratio of 0.95 indicates good recovery of the expected mass of solid material, even though 
the mass balance was complicated by two shutdowns caused by the silica-related bed agglomeration events. The bed turnover was about of 2.3 .

The bed particle size remained under relative control during the test series, but the bulk density of the bed media decreased by about 3 times. Toxicity Characteristic Leaching Procedure (TCLP) analyses of bed, cyclone and filter samples showed that all of these solids passed TCLP requirements at levels between 0 and $8 \%$ of the regulatory limits. Sufficient amounts of $\mathrm{Cr}, \mathrm{Ni}, \mathrm{Pb}$, and $\mathrm{Zn}$ were present in the samples to show that between 87 to and $99.95 \%$ of those metals were not leached.

The concentrations of primary simulant feed products $\left(\mathrm{CO}_{3}, \mathrm{~K}\right.$, and $\left.\mathrm{Na}\right)$ in the bed samples show a continuous trend of increasing amounts of simulant feed products. The amounts of these species in the bed product would continue to asymptotically approach the theoretically calculated concentrations for these species (down to $19 \% \mathrm{Al}$, and up to $19 \mathrm{wt} \% \mathrm{Si}, 2.1 \mathrm{wt} \% \mathrm{~K}$, and $13 \mathrm{wt} \% \mathrm{Na}$ ). The amounts of several species in the bed near the end of the test series indicate that between $40-70 \%$ of the bed material was solids from the simulant feed rather than starting bed alumina.

Scrub water samples show that no feed components except for the $\mathrm{Hg}$ and small amounts of $\mathrm{SO}_{4}$, $\mathrm{Cl}$, and $\mathrm{F}$ volatilized or elutriated out of the fluidized bed and also passed through the cyclone and heated filter to be captured in the wet scrubber. All other feed components were quantitatively captured in the bed product or the filter fines.

The wet-basis steam reformer off-gas contained over 60 vol $\% \mathrm{H}_{2} \mathrm{O}$ and about $20 \% \mathrm{~N}_{2} . \mathrm{CO}_{2}$ levels averaged about $9 \%, \mathrm{H}_{2}$ averaged $3 \%$, and $\mathrm{CO}$ averaged $2 \%$. Average $\mathrm{CH}_{4}$ and total hydrocarbons (THC) ranged between $0.1 \%$ and $0.3 \%$. NO averaged about $3.500 \mathrm{ppm}$, and total $\mathrm{NO}_{\mathrm{x}}$ levels averaged about 4,300 ppm.

The wet-basis off-gas downstream of the thermal oxidizer and wet scrubber was fully oxidized, averaging about $7 \mathrm{ppm} \mathrm{CO}$. $\mathrm{NO}$ and $\mathrm{NO}_{\mathrm{x}}$ levels averaged about $200 \mathrm{ppm}$. $\mathrm{HCl}$ was essentially not detected with a reported concentration of $0.4 \mathrm{ppm}$. Total $\mathrm{Hg}$ levels averaged about $6,000 \mu \mathrm{g} / \mathrm{m}^{3}$ (wet basis) at the inlet to the partial quench (upstream of the wet scrubber). Oxidized $\mathrm{Hg}$ was only about $1 \%$ of the total $\mathrm{Hg}$. Downstream of the wet scrubber and carbon bed, the total $\mathrm{Hg}$ concentration was reduced to $1-8 \mu \mathrm{g} / \mathrm{m}^{3}$ (wet basis). On a dry, $7 \% \mathrm{O}_{2}$ basis, the final $\mathrm{CO}, \mathrm{HCl}$, and $\mathrm{Hg}$ levels averaged less than $1 / 10$ to $1 / 4$ of the MACT limits.

The steam reformer $\mathrm{NO}_{\mathrm{x}}$ destruction (based on the steam reformer outlet $\mathrm{NO}$ measurements) averaged about $74 \% . \mathrm{NO}_{3}$ destruction averaged $99.94 \% . \mathrm{NO}_{\mathrm{x}}$ destruction for the entire steam reforming test system, using the $\mathrm{NO}$ and $\mathrm{NO}_{\mathrm{x}}$ measurements at the outlet of the thermal oxidizer, averaged $93 \%$. During this test, $\mathrm{NO}_{\mathrm{x}}$ was reduced in the thermal oxidizer, at an average efficiency of about $60 \%$.

Species that were enriched more in the filter fines than the bed product were $\mathrm{PO}_{4}, \mathrm{SO}_{4}, \mathrm{Cl}, \mathrm{F}, \mathrm{Cs}$, and Re. Even though concentrations of these species were proportionately higher in the filter fines, they were nearly all quantitatively captured in the total solid mass that includes both the bed product and filter fines. One hundred percent of the $\mathrm{Cs}$ and $\mathrm{Re}$, (radionuclide surrogates), and $100.0 \%$ of the $\mathrm{PO}_{4}$ partitioned to the total solids.

Mercury partitioned quantitatively to the off-gas. Consistent with expectations, essentially all of the off-gas $\mathrm{Hg}$ was measured in the form of elemental $\mathrm{Hg}$ downstream of the thermal oxidizer. Only a fraction (about $0.5 \%$ ) of the total $\mathrm{Hg}$ was scrubbed in the wet scrubber, according to the amount of $\mathrm{Hg}$ detected in the scrub water. The total mercury was efficiently (over $99.8 \%$ on average) removed from the off-gas by the carbon bed. 


\section{REFERENCES}

Barnes, C. M., 2001, Feed Composition for the Sodium-Bearing Waste Treatment Process, INEEL/EXT2000-01378, Rev. 1, July.

EPA 2002, "Determination of Sulfur Dioxide Emissions, from Stationary Sources (Instrumental Analysis Procedure)," 40 CFR 60 Appendix A, Method 6C.

INEEL, 2003, SRS Tank 48 Steam Reforming Demonstration Test Plan, final draft internal INEEL report, July.

Magrini-Bair, Kimberly, Stefan Czernik, et al., 2002, "Fluidizable Catalyts for Producing Hydrogen by Steam Reforming Biomass Pyrolysis Liquids," NREL/CP-610-32405, Proceedings of the 2002 U.S. DOE Hydrogen Program Review.

Marshall, D. W., N. R. Soelberg, and K.M. Shaber, 2003a, THOR Bench-scale Steam Reforming Demonstration, INEEL/EXT-03-00437, May.

Marshall, D. W., N. R. Soelberg, and G. L. Anderson, 2003b, SBW Test Plan: Fluidized Bed Steam Reforming - THOR Process Optimization Tests (FY04), internal INEEL report, November 10.

Marshall, D.W. and N. R. Soelberg, 2003c, TWR Bench-Scale Steam Reforming Demonstration, INEEL/EXT-03-00436, May.

Ogden, Joan M., 2002, Review of Small Stationary Reformers for Hydrogen Production, IEA/H2/TR$02 / 002$.

Rowley, Debbie, 2003, personal communication to Nick Soelberg, 16 July.

SAIC 2003, Steam Reformer Operating Instructions, SAIC-SR-OI-01, Rev. 2, January.

St. Michel, Curtis, 2003, System Description, Fluidized Bed Steam Reformer Data Acquisition and Controls, internal INEEL report, December.

Soelberg, Nick, Doug Marshall, Steve Bates, and Duane Siemer, 2003a, SRS Tank $48 H$ Waste Steam Reforming Proof-of-Concept Test Results, INEEL/EXT-03-01118, September 15.

Soelberg, Nick, 2003b, Off-gas Mercury Control for the Idaho Tank Farm Project-Calcination with MACT Upgrade SBW Treatment Alternative, INEEL EDF-3292, Revision 0, February.

Taylor, Dean, 2004, HSC Calculations for Steam Reforming Optimization Tests, unpublished INEEL report, January. 
Appendix A

\section{Operating Conditions}


Table A-1. Process mass flow rates and conditions for the THOR carbonate test series.

\begin{tabular}{|c|c|c|c|c|c|c|c|c|c|c|c|c|c|c|c|c|c|c|c|c|}
\hline Test & $\begin{array}{c}\text { Off-gas } \\
\text { flow at } \\
\text { carbon } \\
\text { bed, } \\
\mathrm{kg} / \mathrm{hr} \\
\end{array}$ & $\begin{array}{l}\text { Sim. } \\
\text { feed } \\
\text { flow, } \\
\mathrm{kg} / \mathrm{hr} \\
\end{array}$ & $\begin{array}{c}\text { Fluidizing } \\
\text { steam } \\
\text { flowrate, } \\
\mathrm{kg} / \mathrm{hr} \\
\end{array}$ & \begin{tabular}{|c|}
$\mathrm{O}_{2}$ flow \\
rate, \\
$\mathrm{kg} / \mathrm{hr}$ \\
\end{tabular} & $\begin{array}{c}\text { Total } \mathrm{N}_{2} \\
\text { flow } \\
\text { rate, } \\
\mathrm{kg} / \mathrm{hr}\end{array}$ & \begin{tabular}{|c} 
Solid C \\
feed \\
rate, \\
$\mathrm{kg} / \mathrm{hr}$ \\
\end{tabular} & \begin{tabular}{|c|} 
Total gas \\
input to \\
system, \\
$\mathrm{kg} / \mathrm{hr}$ \\
\end{tabular} & $\begin{array}{c}\begin{array}{c}\text { System } \\
\text { gas mass } \\
\text { balance } \\
\text { closure } \\
\text { ratio }\end{array} \\
\end{array}$ & $\begin{array}{c}\mathrm{H}_{2} \mathrm{O} \text { at } \\
\text { filter } \\
\text { outle, } \\
\text { wet } \% \\
\end{array}$ & \begin{tabular}{|c|} 
Calc \\
NAR \\
(a) \\
\end{tabular} & $\begin{array}{l}\text { PLC } \\
\text { NAR } \\
\text { (a) }\end{array}$ & \begin{tabular}{|c} 
SR Bed \\
Temp \\
Control \\
Point at \\
T4, C \\
\end{tabular} & \begin{tabular}{|c} 
SR Wall \\
Temp \\
Control \\
Point at \\
T19, C \\
\end{tabular} & \begin{tabular}{|c} 
Fluiding \\
gas T, H-1 \\
super \\
heater out, \\
C \\
\end{tabular} & $\mid \begin{array}{c}\text { Oxidizer } \\
\text { temp in B- } \\
1 \mathrm{C} \\
\end{array}$ & $\begin{array}{c}\text { Oxidizer } \\
\text { temp at B } \\
1 \mathrm{C} \\
\end{array}$ & $\left\{\begin{array}{c}\text { Oxidizer B } \\
1 \text { fuel flow } \\
\text { rate } \mathrm{kg} / \mathrm{hr}\end{array}\right.$ & $\begin{array}{l}\text { Oxidizer } \\
\text { air flow to } \\
\text { B-1 } 1 \mathrm{~kg} / \mathrm{hr}\end{array}$ & $\begin{array}{c}\text { Air flow } \\
\text { rate to } \\
\text { oxidizerkg } \\
/ \mathrm{hr}\end{array}$ & $\begin{array}{c}\text { Sim. feed } \\
\text { density } \\
\mathrm{gm} / \mathrm{cc}\end{array}$ \\
\hline Tag number & & $\left|\begin{array}{c}\text { SR1_F } \\
1 \text { A_VA } \\
\text { L }\end{array}\right|$ & H1 F PV & $\begin{array}{c}\text { SR1_F } \\
3 \_K G \\
H\end{array}$ & $\begin{array}{c}\text { V1_F1__ } \\
\text { VAL }\end{array}$ & & $\begin{array}{c}\text { TOTAL } \\
\text { GAS_M } \\
\text { ASS_IN } \\
\text { SYS }\end{array}$ & $\begin{array}{c}\text { OFFGAS } \\
\text { MASS_- } \\
\text { RATIO }\end{array}$ & & & NAR & $\begin{array}{c}\text { SR1_T4_ } \\
\text { VAL }\end{array}$ & $\begin{array}{c}\text { SR1_T9 } \\
\text { VAL }\end{array}$ & $\underset{\text { L }}{\mathrm{H} 2 \text { T_VA }}$ & $\underset{A L}{B 1 \_T 1 \_V}$ & $\underset{\text { AL }}{\text { B1_T2_V }}$ & $\underset{\text { AL }}{\text { B1_F1_V }}$ & $\underset{\text { AL }}{\text { B1_F2_V }}$ & $\underset{\text { AL }}{\text { B1_F3_V }}$ & $\left|\begin{array}{c}\text { SR1_D1A } \\
\text { VAL }\end{array}\right|$ \\
\hline 0.5 & 214 & 5.30 & 8.45 & $\begin{array}{ll}1.49 \\
\end{array}$ & 9.10 & 1.08 & 190 & 1.13 & 59.9 & \begin{tabular}{|l|}
466 \\
\end{tabular} & 500 & 670 & 683 & 728 & 1,000 & 920 & 4.88 & 97.7 & 18.0 & 1.27 \\
\hline 1.1 & 213 & 5.41 & 8.45 & 1.49 & 9.18 & 1.08 & 188 & 1.13 & 59.9 & 466 & 500 & 670 & 679 & 729 & 1,000 & 920 & 4.72 & 94.4 & 20.4 & 1.27 \\
\hline 2.1 & 217 & 6.00 & 8.46 & 1.49 & 10.04 & 0.00 & 192 & 1.13 & 65.8 & 466 & 500 & 670 & 679 & 726 & 1,000 & 921 & 4.65 & 92.9 & 22.7 & 1.27 \\
\hline 2.2 & 216 & 6.00 & 8.45 & 1.49 & 9.88 & 0.54 & 190 & 1.13 & 62.7 & \begin{tabular}{|l|}
466 \\
\end{tabular} & 500 & 670 & 679 & 730 & 1,000 & 921 & 4.58 & 91.6 & 23.4 & 1.27 \\
\hline 2.3 & 217 & 6.00 & 8.45 & 1.49 & 9.59 & 1.38 & 189 & 1.15 & 58.4 & \begin{tabular}{|l|}
466 \\
\end{tabular} & 500 & 670 & 678 & 730 & 1,000 & 920 & 4.56 & 91.2 & 23.1 & 1.27 \\
\hline 2.4 & 216 & 6.00 & 8.45 & $\begin{array}{ll}1.49 \\
\end{array}$ & 9.15 & 0.37 & 191 & 1.13 & 64.9 & \begin{tabular}{|l|}
466 \\
\end{tabular} & 500 & 670 & 679 & 730 & 1,000 & 920 & 4.88 & 97.5 & 18.4 & 1.27 \\
\hline 2.5 & 217 & 6.00 & 8.45 & 1.49 & 9.12 & 0.36 & 191 & 1.14 & 65.0 & 466 & 500 & 670 & 680 & 732 & 1,000 & 920 & 4.96 & 98.9 & 16.9 & 1.27 \\
\hline 2.6 & 220 & 6.00 & 8.46 & $\begin{array}{ll}1.49 \\
\end{array}$ & 9.41 & 0.34 & 196 & 1.13 & 64.8 & \begin{tabular}{|l|}
466 \\
\end{tabular} & 500 & 669 & 680 & 736 & 1,000 & 923 & 5.14 & 100.8 & 16.6 & 1.27 \\
\hline 2.7 & 222 & 5.81 & 8.45 & 1.49 & 9.37 & 1.18 & 196 & 1.13 & 60.0 & \begin{tabular}{|l|}
466 \\
\end{tabular} & 500 & 670 & 678 & 736 & 1,000 & 923 & 5.09 & 100.6 & 17.2 & 1.27 \\
\hline 2.8 & 220 & 6.00 & 8.45 & 1.49 & 9.12 & 0.73 & 192 & 1.15 & 62.7 & \begin{tabular}{|l|}
466 \\
\end{tabular} & 500 & 670 & 674 & 736 & 1,000 & 920 & 4.89 & 97.9 & 18.5 & 1.27 \\
\hline 2.9 & 218 & 6.00 & 8.45 & 1.49 & 8.98 & 0.60 & 193 & 1.13 & 63.7 & \begin{tabular}{|l|}
466 \\
\end{tabular} & 500 & 670 & 674 & 735 & 1,000 & 923 & 5.07 & $\begin{array}{l}101.3 \\
\end{array}$ & 16.0 & 1.27 \\
\hline 2.10 . & 224 & 6.00 & 8.62 & 1.32 & 9.06 & 0.53 & 205 & 1.10 & 64.4 & \begin{tabular}{|l|}
466 \\
\end{tabular} & 500 & 668 & 672 & 732 & 1,000 & 921 & 5.07 & 100.8 & 17.0 & 1.27 \\
\hline 2.11 & 226 & 5.21 & 9.78 & 1.23 & 10.29 & 0.66 & 202 & 1.12 & 62.6 & \begin{tabular}{|l|}
649 \\
\end{tabular} & 697 & 668 & 671 & 722 & 1,000 & 920 & 5.07 & 100.0 & 17.5 & 1.27 \\
\hline 2.12 & 202 & 4.99 & 11.01 & 1.26 & 11.64 & 0.61 & 178 & 1.14 & 62.3 & \begin{tabular}{|l|}
756 \\
\end{tabular} & 812 & 667 & 670 & 711 & 1,000 & 919 & 4.64 & 92.8 & 6.9 & 1.27 \\
\hline $2.13 \mathrm{a}$ & 206 & 4.50 & 13.57 & 1.26 & 11.30 & 0.56 & 180 & 1.15 & 65.8 & \begin{tabular}{|l|}
891 \\
\end{tabular} & 957 & 666 & 667 & 689 & 1,000 & 925 & 4.80 & 96.0 & 6.5 & 1.27 \\
\hline $2.13 b$ & 211 & 4.50 & 13.54 & $\begin{array}{ll}1.18 \\
\end{array}$ & 13.11 & 0.72 & 184 & 1.14 & 62.8 & \begin{tabular}{|l|}
886 \\
\end{tabular} & 951 & 669 & 668 & 730 & 1,000 & 924 & 4.79 & 95.7 & 7.6 & 1.27 \\
\hline 3.1 & 200 & 2.56 & 13.82 & 1.04 & 11.71 & 0.74 & 173 & 1.16 & 63.1 & \begin{tabular}{|l|l}
1726 \\
\end{tabular} & 1,853 & 669 & 667 & 728 & 1,000 & 920 & 4.65 & 93.0 & 6.2 & 1.27 \\
\hline 3.2 & 201 & 1.62 & 16.25 & 1.22 & 11.70 & 0.96 & 171 & 1.18 & 64.4 & \begin{tabular}{|l|l}
2184 \\
\end{tabular} & 2,344 & 669 & 666 & 702 & 990 & 914 & 4.67 & 93.3 & 4.0 & 1.27 \\
\hline 3.3 & 197 & 4.00 & 16.25 & 1.22 & 12.06 & 1.02 & 167 & 1.18 & 65.1 & \begin{tabular}{|l|}
1071 \\
\end{tabular} & 1,150 & 669 & 664 & 702 & 950 & 874 & 4.15 & 83.1 & 9.2 & 1.27 \\
\hline 3.4 & 200 & 4.00 & 16.29 & 1.23 & 12.30 & 0.92 & 169 & 1.19 & 65.4 & \begin{tabular}{|l}
1071 \\
\end{tabular} & 1,149 & 668 & 663 & 702 & 950 & 872 & 4.19 & 83.8 & 9.6 & 1.25 \\
\hline S.1 & 201 & 4.00 & 16.32 & 1.23 & 12.82 & 1.22 & 170 & 1.18 & 63.5 & \begin{tabular}{|l|}
1070 \\
\end{tabular} & 1,149 & 667 & 662 & 701 & 950 & 872 & 4.18 & 83.6 & 10.5 & 1.24 \\
\hline S.2 & 193 & 4.00 & 16.26 & 1.22 & 10.46 & 1.49 & 161 & 1.20 & 64.8 & \begin{tabular}{|l|l}
1071 \\
\end{tabular} & 1,149 & 669 & 662 & 700 & 950 & 872 & 4.16 & 83.3 & 8.3 & 1.24 \\
\hline S.3 & 206 & 4.00 & 16.24 & 1.22 & 9.87 & 1.80 & 181 & 1.14 & 64.0 & \begin{tabular}{|l|}
1071 \\
\end{tabular} & 1,150 & 670 & 662 & 700 & 994 & 917 & 4.82 & 95.0 & 8.2 & 1.24 \\
\hline & & & & & & & & & & & & & & & & & & & & \\
\hline $\begin{array}{c}\text { Overall } \\
\text { Average }\end{array}$ & 211 & 4.82 & 11.27 & 1.31 & 10.59 & 0.80 & 185 & 1.14 & 63.0 & 796 & 854 & 669 & 672 & 721 & 993 & 915 & 4.77 & 95.0 & 12.8 & 1.27 \\
\hline STD DEV & 11.1 & 1.22 & 2.99 & 0.15 & 2.28 & 0 & 13 & 0.03 & 2.7 & 473 & 507 & 2 & 9 & 13 & 17 & 16 & 0.30 & 5.55 & 5.86 & 0.01 \\
\hline
\end{tabular}

a. NAR is calculated from as measured liters of gases per measured liters of feeds. 
Table A-2. Process volume flow rates for the THOR carbonate test series.

\begin{tabular}{|c|c|c|c|c|c|c|c|c|c|c|c|c|c|}
\hline Test & $\begin{array}{c}\text { Off-Gas } \\
\text { Flow to } \\
\text { GAC, } \\
\mathrm{kg} / \mathrm{hr} \\
\end{array}$ & \begin{tabular}{|c|} 
Off-Gas \\
Flow to \\
GAC Inlet, \\
scfm \\
\end{tabular} & $\begin{array}{l}\text { Off-Gas } \\
\text { Flow to } \\
\text { Oxidizer } \\
\text { inlet, scfm } \\
\text { (a) }\end{array}$ & $\begin{array}{c}\text { Simulant } \\
\text { feedrate, } \\
\mathrm{kg} / \mathrm{hr}\end{array}$ & \begin{tabular}{|c|} 
Water \\
Flow in \\
Simulant \\
Feed, $\mathrm{kg} / \mathrm{hr}$
\end{tabular} & $\begin{array}{c}\mathrm{H}_{2} \mathrm{O} \text { from } \\
\text { Syrup, } \\
\mathrm{kg} / \mathrm{hr}\end{array}$ & $\begin{array}{c}\mathrm{CO}_{2} \text { from } \\
\text { sugar in } \\
\text { simulant, } \\
\mathrm{kg} / \mathrm{hr}\end{array}$ & $\begin{array}{l}\text { Total } \\
\mathrm{H}_{2} \mathrm{O} \\
\mathrm{kg} / \mathrm{hr}\end{array}$ & $\begin{array}{l}\text { Total } \\
\mathrm{H}_{2} \mathrm{O} \\
\text { scfm }\end{array}$ & $\begin{array}{c}\text { Total } \mathrm{N}_{2} \\
\text { flowrate, } \\
\text { scfm }\end{array}$ & $\begin{array}{l}\text { Total } \\
\mathrm{CO}_{2} \\
\text { scfm } \\
\end{array}$ & $\begin{array}{c}\text { Scrubber } \\
\text { outlet gas } \\
\text { pressure, } \\
\text { psia }\end{array}$ & $\begin{array}{c}\text { Scrubber } \\
\text { outlet gas } \\
\text { temp, C } \\
\end{array}$ \\
\hline Tag number & & $\frac{\mathrm{AJ} 1 \_\mathrm{F} 1 \_\mathrm{SC}}{\mathrm{FM}}$ & & \begin{tabular}{|c|} 
SR1_F1A \\
H2O_K \\
GH \\
\end{tabular} & $\begin{array}{c}\text { SR1_F1A_ } \\
\text { H2O_KG } \\
\text { H }\end{array}$ & \begin{tabular}{|c|} 
SYRUP_F \\
D_TO_H2 \\
O_KGH
\end{tabular} & \begin{tabular}{|c|} 
SYRUP_F \\
D_TO_C \\
O2_KGH
\end{tabular} & $\begin{array}{c}\text { TOT }_{-} \\
\text {MASS } \\
\text { IN } \\
\end{array}$ & & & & $\begin{array}{c}\text { T7_P_VA } \\
\text { L }\end{array}$ & $\begin{array}{c}\mathrm{T} 7 \mathrm{~T}_{-} \text {-VA } \\
\mathrm{L}\end{array}$ \\
\hline 0.5 & 214 & 122 & 19.2 & 5.30 & 3.05 & 2.69 & 2.97 & 14.7 & 11.5 & 4.59 & 4.6 & 9.86 & 68 \\
\hline 1.1 & 213 & 121 & 19.4 & 5.41 & 3.12 & 2.75 & 3.03 & 14.8 & 11.6 & 4.63 & 4.6 & 9.83 & 68 \\
\hline 2.1 & 217 & 123 & 18.5 & 6.00 & 3.46 & 3.04 & 3.36 & 15.5 & 12.1 & 5.06 & 5.1 & 9.93 & 68 \\
\hline 2.2 & 216 & 122 & 19.4 & 6.00 & 3.46 & 3.04 & 3.36 & 15.5 & 12.1 & 4.98 & 5.0 & 9.90 & 68 \\
\hline 2.3 & 217 & 123 & 20.8 & 6.00 & 3.46 & 3.04 & 3.36 & 15.5 & 12.1 & 4.84 & 4.8 & 9.95 & 69 \\
\hline 2.4 & 216 & 123 & 18.7 & 6.00 & 3.46 & 3.04 & 3.36 & 15.5 & 12.1 & 4.62 & 4.6 & 9.94 & 68 \\
\hline 2.5 & 217 & 123 & 18.7 & 6.00 & 3.46 & 3.04 & 3.36 & 15.5 & 12.1 & 4.60 & 4.6 & 9.97 & 69 \\
\hline 2.6 & 220 & 126 & 19.5 & 6.00 & 3.47 & 3.67 & 4.05 & 16.1 & 12.6 & 4.74 & 4.7 & 10.07 & 69 \\
\hline 2.7 & 222 & 126 & 21.1 & 5.81 & 3.35 & 3.78 & 4.18 & 16.1 & 12.6 & 4.72 & 4.7 & 10.11 & 69 \\
\hline 2.8 & 220 & 125 & 19.4 & 6.00 & 3.47 & 3.04 & 3.36 & 15.5 & 12.1 & 4.60 & 4.6 & 10.06 & 69 \\
\hline 2.9 & 218 & 123 & 19.0 & 6.00 & 3.45 & 3.04 & 3.36 & 15.5 & 12.1 & 4.53 & 4.5 & 9.99 & 68 \\
\hline 2.10 & 224 & 130 & 19.5 & 6.00 & 3.45 & 3.42 & 3.78 & 16.0 & 12.6 & 4.57 & 4.6 & 10.20 & 70 \\
\hline 2.11 & 226 & 131 & 20.4 & 5.21 & 3.00 & 3.00 & 3.32 & 16.2 & 12.7 & 5.19 & 5.2 & 10.22 & 70 \\
\hline 2.12 & 202 & 116 & 21.7 & 4.99 & 2.88 & 2.87 & 3.17 & 17.2 & 13.5 & 5.87 & 5.9 & 9.97 & 69 \\
\hline $2.13 a$ & 206 & 117 & 22.8 & 4.50 & 2.58 & 2.62 & 2.90 & 19.2 & 15.0 & 5.70 & 5.7 & 9.92 & 69 \\
\hline $2.13 b$ & 211 & 120 & 24.2 & 4.50 & 2.58 & 2.73 & 3.02 & 19.3 & 15.1 & 6.61 & 6.6 & 9.80 & 69 \\
\hline 3.1 & 200 & 114 & 21.7 & 2.56 & 1.56 & 1.86 & 2.06 & 17.5 & 13.7 & 5.91 & 5.9 & 9.72 & 68 \\
\hline 3.2 & 201 & 115 & 23.0 & 1.62 & 1.07 & 1.38 & 1.52 & 18.9 & 14.8 & 5.90 & 5.9 & 9.74 & 69 \\
\hline 3.3 & 197 & 114 & 25.6 & 4.00 & 2.31 & 2.31 & 2.55 & 21.2 & 16.6 & 6.08 & 6.1 & 9.59 & 69 \\
\hline 3.4 & 200 & 116 & 25.6 & 4.00 & 2.34 & 2.30 & 2.55 & 21.3 & 16.7 & 6.20 & 6.2 & 9.50 & 69 \\
\hline S.1 & 201 & 115 & 26.4 & 4.00 & 2.35 & 2.30 & 2.55 & 21.3 & 16.7 & 6.46 & 6.5 & 9.47 & 68 \\
\hline S.2 & 193 & 111 & 24.6 & 4.00 & 2.35 & 1.35 & 1.49 & 20.3 & 15.9 & 5.27 & 5.3 & 9.30 & 67 \\
\hline S.4 & 206 & 118 & 24.3 & 4.00 & 2.35 & 0.83 & 0.92 & 19.8 & 15.5 & 4.98 & 5.0 & 9.71 & 69 \\
\hline Overall Average & 211 & 121 & 21.4 & 4.82 & 2.80 & 2.65 & 2.93 & 17.2 & 13.4 & 5.34 & 5.3 & 9.90 & 69 \\
\hline STD DEV & 11.1 & 6.5 & 2.6 & 1.22 & 0.66 & 0.74 & 0.82 & 2.2 & 1.8 & 1.15 & 1.1 & 0.25 & 1 \\
\hline
\end{tabular}

a. This included $\mathrm{H} 2 \mathrm{O}$, and $\mathrm{CO} 2$ from the syrup, $\mathrm{H} 2 \mathrm{O}$ and $\mathrm{N} 2$ (assuming 100\% conversion from NO3) from the feed, fluidizing gases, minus the gases from carbon required to produce product carbonate, corrected based on post-test coriolis meter zero calibration. 
Table A-3. Process mass flow rates and conditions for THOR mineralized test series.

\begin{tabular}{|c|c|c|c|c|c|c|c|c|c|c|c|c|c|c|c|c|c|c|c|c|c|c|c|}
\hline & \begin{tabular}{|c|} 
Off-Gas \\
Flow to \\
Carbon \\
Bed \\
$\mathrm{kg} / \mathrm{hr}$ \\
\end{tabular} & \begin{tabular}{|c} 
Sim. \\
Feed \\
Flow, \\
L/hr \\
\end{tabular} & \begin{tabular}{|c|} 
Sim. \\
Feed \\
Flow, \\
$\mathrm{kg} / \mathrm{hr}$ \\
\end{tabular} & \begin{tabular}{|c} 
Fluidizing \\
steam \\
flowrate, \\
$\mathrm{kg} / \mathrm{hr}$
\end{tabular} & \begin{tabular}{|c|}
$\mathrm{O}_{2}$ \\
flow \\
rate, \\
$\mathrm{kg} / \mathrm{hr}$ \\
\end{tabular} & \begin{tabular}{|c|} 
Total \\
$\mathrm{N}_{2}$ flow \\
rate, \\
$\mathrm{kg} / \mathrm{hr}$ \\
\end{tabular} & \begin{tabular}{|c|} 
Solid \\
C feed \\
rate, \\
$\mathrm{kg} / \mathrm{hr}$ \\
\end{tabular} & \begin{tabular}{|c} 
Total \\
Gas \\
Input to \\
System \\
$\mathrm{kg} / \mathrm{hr}$ \\
\end{tabular} & \begin{tabular}{|c|} 
System \\
gas mass \\
balance \\
closure \\
\end{tabular} & $\begin{array}{c}\mathrm{H}_{2} \mathrm{O} \text { at } \\
\text { filter } \\
\text { out, \% }\end{array}$ & \begin{tabular}{|c|} 
Calc \\
NAR \\
(a) \\
\end{tabular} & $\begin{array}{l}\text { PLC } \\
\text { NAR } \\
\end{array}$ & \begin{tabular}{|c|} 
SR Bed \\
Temp \\
Control \\
Point at \\
T4, C \\
\end{tabular} & \begin{tabular}{|c|} 
SR Wall \\
Temp \\
Control \\
Point at \\
T19, C \\
\end{tabular} & 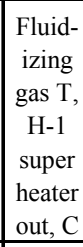 & $\begin{array}{l}\text { Oxidizer } \\
\text { temp in } \\
\text { B-1, C } \\
\end{array}$ & \begin{tabular}{|c|} 
Oxidizer \\
temp at \\
B-1 \\
output C \\
\end{tabular} & $\begin{array}{c}\text { Oxidizer } \\
\text { B-1 fuel } \\
\text { flow rate } \\
\mathrm{kg} / \mathrm{hr} \\
\end{array}$ & \begin{tabular}{|c} 
Oxidizer \\
air flow \\
to \\
burner B \\
$1 \mathrm{~kg} / \mathrm{hr}$ \\
\end{tabular} & $\begin{array}{l}\text { Air flow } \\
\text { rate to } \\
\text { oxidizer } \\
\mathrm{kg} / \mathrm{hr}\end{array}$ & \begin{tabular}{|c|} 
Sim. \\
Feed \\
density \\
gm/cc \\
\end{tabular} & \begin{tabular}{|c} 
Syrup \\
density \\
gm/cc \\
\end{tabular} & \begin{tabular}{|c} 
Syrup \\
feed \\
rate \\
$\mathrm{kg} / \mathrm{hr}$ \\
\end{tabular} \\
\hline Test & & $\begin{array}{l}\text { SR1_ } \\
\text { F1A_ } \\
\text { VFR }\end{array}$ & \begin{tabular}{|c} 
SR1_F \\
$1 \mathrm{~A} \_\mathrm{V}$ \\
$\mathrm{AL}$
\end{tabular} & H1_F_PV & $\begin{array}{c}\text { SR1_- } \\
\text { F3_K } \\
\text { GH }\end{array}$ & $\begin{array}{l}\text { V1_F } \\
\text { VAL }\end{array}$ & & \begin{tabular}{|c|} 
TOTAL \\
GAS \\
MASS_I \\
N_SYS \\
\end{tabular} & $\begin{array}{c}\text { OFFGA } \\
\text { S_MAS } \\
\text { S_RATI } \\
\text { O }\end{array}$ & & & NAR & $\begin{array}{c}\text { SR1_T4 } \\
\text { VAL }\end{array}$ & $\begin{array}{c}\text { SR1_T9 } \\
\text { VAL }\end{array}$ & $\begin{array}{l}\mathrm{H} 2 \_\mathrm{T} \\
\text { VAL }\end{array}$ & $\begin{array}{c}\text { B1_T1_ } \\
\text { VAL }\end{array}$ & $\begin{array}{c}\text { B1_T2 } \\
\text { VAL }\end{array}$ & $\begin{array}{c}\text { B1_F1_ } \\
\text { VAL }\end{array}$ & $\begin{array}{c}\text { B1_F2 } \\
\text { VAL }\end{array}$ & $\begin{array}{c}\text { B1_F3_- } \\
\text { VAL }\end{array}$ & $\begin{array}{l}\text { SR1_D1 } \\
\text { A_VAL }\end{array}$ & $\begin{array}{l}\text { SR1_D1 } \\
\text { C_VAL }\end{array}$ & $\begin{array}{c}\text { SR1_F } \\
1 C_{-} \mathrm{V} \\
\mathrm{AL}\end{array}$ \\
\hline 4 & 168 & 2.89 & \begin{tabular}{|l|}
2.88 \\
\end{tabular} & 7.91 & 0.98 & 8.35 & 1.27 & 175 & 0.964 & 64.6 & 651 & --- & --- & --- & --- & --- & --- & NA & $\mathrm{NA}$ & NA & --- & --- & \begin{tabular}{|l|}
0.92 \\
\end{tabular} \\
\hline 4.1 & 166 & 4.21 & 5.75 & 7.94 & 0.98 & 8.53 & 1.20 & 168 & 0.987 & 67.0 & 600 & 716 & 716 & 780 & 772 & 1,000 & 919 & 4.84 & 101.0 & 0.8 & 1.38 & 1.26 & 1.41 \\
\hline $4.1 \mathrm{a}$ & 159 & 4.34 & 6.00 & 7.56 & 1.30 & 8.64 & 1.20 & 163 & 0.976 & 65.2 & 600 & 723 & 723 & 775 & 775 & 1,000 & 916 & 4.81 & 87.5 & 10.0 & 1.38 & 1.26 & 1.38 \\
\hline $4.1 \mathrm{~b}$ & 156 & 4.34 & 6.00 & 7.52 & 1.33 & 8.89 & 1.33 & 160 & 0.976 & 64.3 & 600 & 724 & 724 & 772 & 776 & 1,000 & 915 & 4.69 & 84.4 & 11.0 & 1.38 & 1.26 & 1.38 \\
\hline $4.1 \mathrm{c}$ & 155 & 4.34 & 6.00 & 7.01 & 1.97 & 8.87 & 1.60 & 155 & 1.001 & 61.7 & 600 & 725 & 725 & 746 & 779 & 1,000 & 914 & 4.58 & 82.4 & 10.9 & 1.38 & 1.26 & 1.38 \\
\hline $4.1 \mathrm{~d}$ & 154 & 4.34 & 6.00 & 7.38 & 1.51 & 8.96 & 1.91 & 154 & 1.003 & 63.3 & 600 & 724 & 724 & 758 & 778 & 1,000 & 914 & 4.56 & 82.1 & 11.0 & 1.38 & 1.26 & 1.38 \\
\hline 4.2 & 157 & 4.97 & 6.86 & 7.05 & 1.93 & 9.83 & $\begin{array}{ll}1.87 \\
\end{array}$ & 156 & 1.007 & 60.7 & 600 & 725 & 725 & 752 & 778 & 1,000 & 915 & 4.56 & 82.0 & 11.5 & 1.38 & 1.26 & 1.58 \\
\hline 4.3 & 161 & 5.77 & 7.97 & 7.02 & 1.98 & 10.52 & 1.76 & 161 & 1.002 & 60.6 & 600 & 725 & 725 & 756 & 780 & 1,000 & 918 & 4.62 & 83.2 & 12.1 & 1.38 & 1.26 & 1.83 \\
\hline $4.3 \mathrm{a}$ & 161 & 5.80 & 8.00 & 7.02 & 1.98 & 10.51 & 0.93 & 161 & 0.998 & 60.4 & 597 & 725 & 725 & 758 & 780 & 1,000 & 919 & 4.56 & 82.2 & 12.7 & 1.38 & 1.26 & 1.84 \\
\hline 4.4 & 161 & 6.40 & 8.85 & 7.02 & 1.98 & 10.26 & 0.94 & 162 & 0.998 & 61.5 & 525 & 724 & 724 & 763 & 780 & 1,000 & 920 & 4.56 & 82.1 & 12.7 & 1.38 & 1.26 & 2.04 \\
\hline $4.4 \mathrm{a}$ & 163 & \begin{tabular}{|l|}
6.50 \\
\end{tabular} & 9.00 & 7.02 & 1.98 & 10.16 & 1.27 & 162 & 1.003 & 61.3 & 525 & 724 & 724 & 765 & 780 & 1,000 & 920 & 4.60 & 82.8 & 12.5 & 1.39 & 1.26 & 2.07 \\
\hline 4.5 & 166 & 5.80 & 8.04 & 7.02 & \begin{tabular}{|l|}
1.98 \\
\end{tabular} & 10.40 & 1.34 & 170 & 0.981 & 59.5 & 498 & 724 & 724 & 770 & 780 & 1,000 & 917 & 4.52 & 81.4 & 14.9 & 1.38 & 1.26 & 3.54 \\
\hline 5.1 & 172 & \begin{tabular}{|l|}
5.79 \\
\end{tabular} & 8.00 & 6.62 & \begin{tabular}{|l|}
1.87 \\
\end{tabular} & 8.01 & 2.01 & 168 & 1.019 & 66.3 & 450 & 725 & 725 & 748 & 782 & 1,000 & 917 & 4.82 & 95.6 & 10.7 & 1.38 & 1.26 & 0.10 \\
\hline $5.1 \mathrm{a}$ & 174 & \begin{tabular}{|l}
5.81 \\
\end{tabular} & 8.00 & 6.79 & \begin{tabular}{|l|}
1.60 \\
\end{tabular} & 7.92 & 1.51 & 171 & 1.019 & 67.8 & \begin{tabular}{|l|}
450 \\
\end{tabular} & 725 & 725 & 752 & 781 & 1,000 & 919 & 4.90 & 98.1 & 10.6 & 1.38 & 1.25 & 0.00 \\
\hline 5.2 & 181 & \begin{tabular}{|l|}
5.83 \\
\end{tabular} & 7.99 & 6.92 & \begin{tabular}{|l|}
1.52 \\
\end{tabular} & 10.91 & 0.69 & 184 & 0.981 & 59.1 & \begin{tabular}{|l|}
450 \\
\end{tabular} & 721 & 721 & 776 & 780 & 977 & 901 & 4.67 & 95.1 & 14.7 & 1.37 & 1.26 & 4.15 \\
\hline $5.2 \mathrm{a}$ & 183 & \begin{tabular}{|l}
6.10 \\
\end{tabular} & 7.92 & 6.98 & \begin{tabular}{|l|}
1.53 \\
\end{tabular} & 11.64 & 0.63 & 187 & 0.979 & 58.3 & 450 & 717 & 717 & 778 & 780 & 1,000 & 922 & & 96.9 & 11.3 & 1.30 & 1.26 & 4.48 \\
\hline $5.2 \mathrm{~b}$ & 168 & \begin{tabular}{|l|}
4.79 \\
\end{tabular} & 6.49 & 6 & \begin{tabular}{|l|}
1.52 \\
\end{tabular} & \begin{tabular}{|l|}
10.08 \\
\end{tabular} & 0.71 & 175 & 0.956 & 58.4 & 440 & 721 & 721 & 771 & 780 & 1,000 & 918 & 4.58 & 82.5 & 17.9 & 1.37 & 1.25 & 4.35 \\
\hline $5.2 \mathrm{c}$ & 169 & \begin{tabular}{|l|}
6.00 \\
\end{tabular} & 8.01 & 6.93 & \begin{tabular}{|l|}
1.52 \\
\end{tabular} & 8.89 & 0.72 & 175 & 0.966 & 63.5 & \begin{tabular}{|l|}
300 \\
\end{tabular} & 720 & 720 & 776 & 781 & 1,000 & 920 & 4.62 & 83.1 & 17.9 & 1.34 & 1.26 & 4.48 \\
\hline $5.2 \mathrm{~d}$ & 166 & \begin{tabular}{|l|}
5.49 \\
\end{tabular} & 7.67 & 7.06 & 1.46 & 8.57 & 0.66 & 168 & 0.990 & 63.4 & \begin{tabular}{|l|}
335 \\
\end{tabular} & 722 & 722 & 774 & 780 & 1,000 & 919 & 4.55 & 82.7 & 17.3 & 1.40 & 1.26 & 4.24 \\
\hline \multicolumn{2}{|c|}{ Shutdown } & & & & & & & & & & & & & & & & & & & & & & \\
\hline 5.3 & 150 & 3.18 & 4.45 & 7.64 & \begin{tabular}{|l|}
0.66 \\
\end{tabular} & 7.80 & 0.00 & 147 & 1.024 & 65.8 & 398 & 724 & 724 & 766 & 844 & 944 & 858 & 3.90 & 74.0 & 11.8 & 1.40 & 1.26 & 3.70 \\
\hline \multicolumn{2}{|c|}{ Shutdown } & & & & & & & & & & & & & & & & & & & & & & \\
\hline 5.4 & 125 & 4.09 & 5.61 & 7.87 & 0.50 & 8.00 & 0.92 & 122 & 1.027 & 70.6 & 581 & 724 & 724 & 765 & 778 & 905 & 811 & 3.50 & 62.9 & 7.3 & 1.37 & 1.26 & 0.00 \\
\hline 5.5 & 117 & 3.34 & 4.62 & 6.70 & \begin{tabular}{|l|}
0.48 \\
\end{tabular} & 7.14 & 0.65 & 111 & 1.049 & 68.4 & \begin{tabular}{|l|}
630 \\
\end{tabular} & 725 & 725 & 760 & 784 & 905 & 807 & 3.40 & 61.3 & 6. & 1.38 & 1.26 & 0.00 \\
\hline $5.5 \mathrm{a}$ & 114 & 3.28 & 4.50 & & \begin{tabular}{|l|}
0.47 \\
\end{tabular} & 7.07 & 0.48 & 110 & 1.041 & 68.8 & 595 & 725 & 725 & 757 & 784 & 905 & 806 & 24 & 612 & & 1.37 & 1.26 & 0.00 \\
\hline $5.5 \mathrm{~b}$ & 114 & 3.27 & 4.50 & 6.74 & \begin{tabular}{|l|}
0.47 \\
\end{tabular} & 6.50 & 0.47 & 109 & 1.046 & 71.4 & 450 & 724 & 724 & 756 & 783 & 905 & 805 & 3.40 & 61.2 & 6.1 & 1.38 & 1.26 & 0.00 \\
\hline $5.5 \mathrm{c}$ & 114 & 3.26 & 4.50 & 6.73 & 0.47 & 6.60 & 0.62 & 108 & 1.052 & 71.2 & \begin{tabular}{|l|}
450 \\
\end{tabular} & 724 & 724 & 758 & 783 & 905 & 805 & 3.42 & 61.5 & 5.8 & 1.38 & 1.26 & 0.00 \\
\hline $5.5 \mathrm{~d}$ & 115 & 3.26 & 4.50 & 6.29 & \begin{tabular}{|l|}
1.04 \\
\end{tabular} & 6.75 & 1.04 & 109 & 1.057 & 66.9 & \begin{tabular}{|l|}
450 \\
\end{tabular} & 725 & 725 & 744 & 783 & 905 & 805 & 3.43 & 61.7 & 5.8 & 1.38 & 1.26 & 0.00 \\
\hline $5.5 \mathrm{e}$ & 116 & 3.26 & 4.50 & 6.30 & 1.03 & 6.84 & 1.15 & 109 & 1.061 & 66.4 & 448 & 724 & 724 & 744 & 784 & 905 & 806 & 3.41 & 61.5 & 6.2 & 1.38 & 1.26 & 0.00 \\
\hline 5.6 & 119 & \begin{tabular}{|l}
3.27 \\
\end{tabular} & 4.50 & 6.31 & \begin{tabular}{|l|}
1.03 \\
\end{tabular} & 7.23 & 1.28 & 112 & 1.066 & 64.8 & 45 & 724 & 7 & 75 & 784 & 905 & 807 & 3.42 & 61. & 6.8 & 1.38 & 1.26 & 0.84 \\
\hline & & & & & & & & & & & & & & & & & & & & & & & \\
\hline Avg & 150 & 4.38 & 6.04 & 7.22 & 1.11 & 8.49 & 0.72 & 148 & 1.013 & 65.0 & 480 & 724 & 724 & 764 & 798 & 959 & 872 & 4.12 & 76.7 & 11.2 & 1.39 & 1.26 & 1.83 \\
\hline std dev & 25.8 & 1.29 & 1.8 & 0.6 & 0.6 & 1.7 & 0.6 & 28.0 & 0.034 & 4.7 & \begin{tabular}{|l|}
119 \\
\end{tabular} & 2 & 2 & 9 & 28 & 48 & 54 & 0.70 & 13.0 & 6.1 & 0.02 & 0.00 & 1.81 \\
\hline
\end{tabular}


Table A-4. Process volume flow rates for THOR mineralized test series.

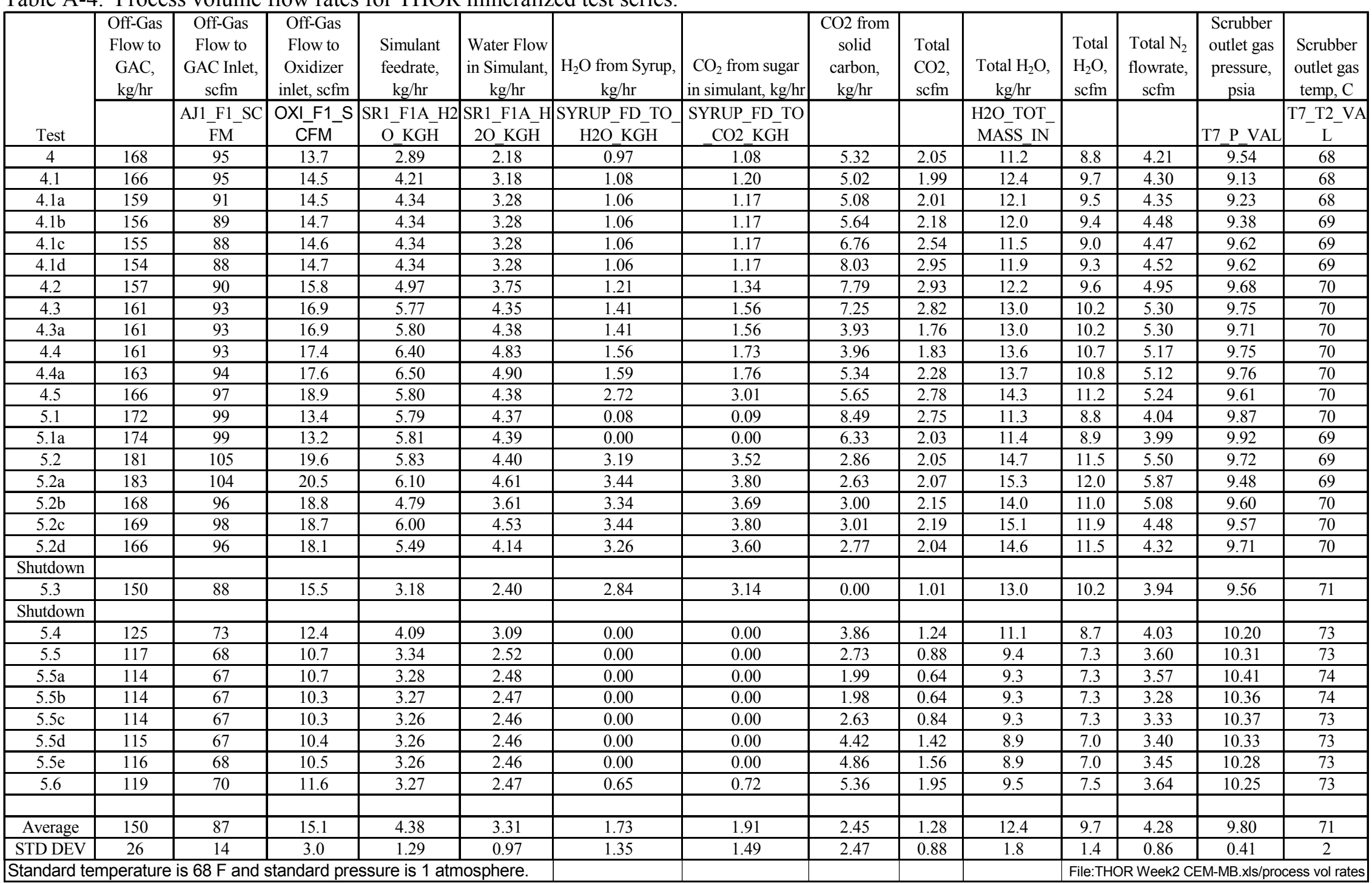


Appendix B

CEMS Calibrations 
Table B-1. CEMS1 calibration results for the THOR carbonate and mineralized test series.

\begin{tabular}{|c|c|c|c|c|c|c|c|c|c|c|c|c|c|c|c|c|c|c|c|}
\hline & \multicolumn{4}{|c|}{ Servomex $\mathrm{O} 2$} & \multicolumn{6}{|c|}{ AMETEK NO } & \multicolumn{4}{|c|}{ Existing NOVA CO2 } & \multicolumn{4}{|c|}{ Existing NOVA H2 } \\
\hline & & $\mathrm{FS}=$ & 25.00 & & & & & $\mathrm{FS}=$ & 5,000 & & & $\mathrm{FS}=$ & 100 & & & $\mathrm{FS}=$ & 20 & & \\
\hline Date & Time & Pre-Zero & $\begin{array}{l}\text { Post- } \\
\text { Zero }\end{array}$ & $\begin{array}{l}\text { Pre- } \\
\text { Span }\end{array}$ & $\begin{array}{l}\text { Post- } \\
\text { Span }\end{array}$ & $\begin{array}{c}\text { Pre-Zero } \\
\text { Val }\end{array}$ & $\begin{array}{c}\text { Zero drift } \\
\text { per } \\
\text { minute, } \\
\text { ppm } / \mathrm{min}\end{array}$ & Pre-Zero & $\begin{array}{l}\text { Post- } \\
\text { Zero }\end{array}$ & $\begin{array}{l}\text { Pre- } \\
\text { Span }\end{array}$ & $\begin{array}{l}\text { Post- } \\
\text { Span }\end{array}$ & $\begin{array}{l}\text { Pre- } \\
\text { Zero }\end{array}$ & $\begin{array}{l}\text { Post- } \\
\text { Zero }\end{array}$ & Pre-Span & $\begin{array}{l}\text { Post- } \\
\text { Span }\end{array}$ & $\begin{array}{l}\text { Pre- } \\
\text { Zero }\end{array}$ & $\begin{array}{l}\text { Post- } \\
\text { Zero }\end{array}$ & $\begin{array}{l}\text { Pre- } \\
\text { Span }\end{array}$ & $\begin{array}{l}\text { Post- } \\
\text { Span }\end{array}$ \\
\hline 10-Nov-03 & $23: 50$ & --- & --- & --- & --- & --- & --- & --- & --- & --- & --- & --- & --- & --- & --- & --- & --- & --- & --- \\
\hline 10-Nov-03 & $23: 50$ & 0.00 & 0.00 & -- & --- & -3 & --- & -0.07 & -0.01 & -4.07 & --- & 5.00 & -- & --- & -- & 1.15 & --- & --- & --- \\
\hline 13-Nov-03 & $0: 50$ & --- & --- & --- & --- & --- & -- & --- & --- & --- & --- & --- & --- & --- & --- & --- & --- & --- & --- \\
\hline 13-Nov-03 & $0: 50$ & 0.24 & --- & -0.64 & --- & $-3,899$ & -1.00 & -77.98 & 0.00 & 0.00 & 0.18 & 7.40 & 6.31 & --- & --- & 2.05 & 1.80 & --- & --- \\
\hline 13-Nov-03 & $1: 25$ & -- & --- & -- & -- & --- & --- & --- & --- & --- & --- & --- & -- & --- & -- & --- & --- & --- & --- \\
\hline 13-Nov-03 & $1: 25$ & --- & --- & --- & --- & -180 & -5.14 & -3.60 & 0.00 & 1.84 & --- & & --- & --- & --- & --- & --- & --- & --- \\
\hline 13-Nov-03 & $7: 55$ & --- & --- & --- & --- & --- & --- & --- & --- & -- & --- & --- & --- & --- & --- & --- & --- & --- & --- \\
\hline 13-Nov-03 & $7: 55$ & 0.00 & --- & -0.56 & --- & $-1,135$ & -2.52 & -22.70 & -0.24 & --- & 3.34 & 7.17 & 7.16 & --- & --- & 1.85 & 1.80 & -5.14 & --- \\
\hline 13-Nov-03 & $7: 56$ & -- & --- & --- & --- & --- & --- & -- & --- & --- & -- & --- & --- & --- & --- & --- & --- & --- & --- \\
\hline 13-Nov-03 & $7: 56$ & 0.00 & --- & 0.56 & --- & --- & --- & --- & --- & --- & --- & --- & --- & --- & --- & --- & --- & --- & --- \\
\hline 13-Nov-03 & 19:16 & --- & --- & -- & --- & --- & --- & --- & --- & -- & --- & --- & --- & --- & --- & --- & --- & --- & --- \\
\hline 13-Nov-03 & 19:16 & 0.40 & 0.00 & -- & --- & --- & --- & --- & -- & --- & --- & 7.00 & 6.60 & --- & -- & 3.00 & 2.50 & --- & --- \\
\hline 14-Nov-03 & $7: 00$ & -- & -- & -- & -- & --- & --- & --- & --- & -- & --- & -- & -- & --- & -- & --- & --- & --- & --- \\
\hline 14-Nov-03 & $7: 00$ & 0.24 & 0.24 & -0.24 & --- & -953 & -0.68 & -19.06 & -0.24 & --- & 2.74 & --- & --- & --- & --- & --- & --- & --- & --- \\
\hline 14-Nov-03 & $11: 46$ & -- & -- & --- & -- & --- & -- & --- & --- & -- & --- & -- & --- & --- & --- & --- & --- & --- & --- \\
\hline 14-Nov-03 & $11: 46$ & -- & --- & --- & --- & $-1,200$ & -4.15 & -24.00 & -0.31 & --- & --- & 7.50 & -- & --- & --- & -2.00 & --- & --- & --- \\
\hline 14-Nov-03 & $\begin{array}{ll}14: 30 \\
\end{array}$ & -- & -- & --- & -- & --- & --- & --- & --- & --- & -- & -- & -- & $-\cdots$ & --- & -- & -- & --- & --- \\
\hline 14-Nov-03 & $14: 30$ & 0.80 & 0.36 & --- & --- & -165 & --- & -3.30 & --- & 3.10 & -4.10 & 6.80 & 6.40 & -1.90 & --- & -6.00 & -2.00 & --- & --- \\
\hline 14-Nov-03 & $14: 50$ & --- & -- & --- & --- & --- & --- & --- & --- & -- & --- & -- & -- & --- & --- & -- & -- & --- & --- \\
\hline 14-Nov-03 & $14: 50$ & 0.36 & --- & -1.16 & --- & -619 & -3.35 & -12.38 & --- & --- & --- & 7.00 & 7.20 & --- & --- & -2.00 & -3.00 & --- & --- \\
\hline 14-Nov-03 & $15: 50$ & --- & -- & - & -- & --- & --- & --- & --- & -- & -- & --- & --- & --- & --- & --- & --- & --- & --- \\
\hline 14-Nov-03 & $15: 50$ & --- & --- & --- & --- & --- & --- & --- & --- & --- & --- & 6.70 & 6.50 & --- & --- & -3.00 & --- & \begin{tabular}{|l|}
-9.50 \\
\end{tabular} & -4.50 \\
\hline 17-Nov-03 & $0: 20$ & --- & --- & --- & --- & --- & --- & --- & --- & --- & --- & --- & --- & --- & --- & --- & --- & --- & --- \\
\hline 17-Nov-03 & $0: 20$ & --- & --- & --- & --- & -974 & --- & -19.48 & 0.12 & --- & -0.18 & 9.60 & --- & -0.10 & --- & 5.50 & --- & 0.00 & --- \\
\hline 17-Nov-03 & $7: 00$ & --- & --- & --- & --- & --- & --- & --- & -- & --- & --- & --- & --- & --- & --- & --- & --- & --- & --- \\
\hline 17-Nov-03 & $7: 00$ & 0.84 & 0.04 & --- & --- & --- & --- & --- & 0.05 & --- & -0.18 & 7.00 & 7.00 & -1.40 & --- & -4.00 & --- & -5.00 & 4.00 \\
\hline 19-Nov-03 & $0: 20$ & --- & --- & --- & --- & --- & --- & --- & --- & --- & --- & --- & --- & --- & --- & --- & --- & --- & --- \\
\hline 19-Nov-03 & $0: 20$ & 0.00 & 0.40 & $\begin{array}{l}-1.28 \\
\end{array}$ & --- & -56 & --- & -1.12 & -0.34 & -2.00 & 0.48 & 14.40 & 14.30 & 4.60 & 0.10 & 8.00 & 8.00 & \begin{tabular}{|l|}
-1.00 \\
\end{tabular} & -0.50 \\
\hline 19-Nov-03 & $10: 13$ & -- & -- & -- & -- & --- & --- & --- & --- & -- & --- & -- & -- & --- & --- & --- & -- & --- & --- \\
\hline 19-Nov-03 & 10:13 & 0.04 & --- & -- & --- & 21 & --- & 0.42 & 0.25 & --- & --- & 12.30 & --- & --- & --- & 5.50 & --- & --- & --- \\
\hline 19-Nov-03 & $11: 50$ & -- & -- & -- & -- & --- & --- & -- & --- & --- & -- & -- & -- & --- & --- & -- & -- & -- & --- \\
\hline 19-Nov-03 & $11: 50$ & -0.04 & --- & -- & --- & $-1,136$ & -0.37 & -22.71 & 0.06 & --- & 0.10 & 13.50 & --- & --- & --- & 7.00 & --- & --- & --- \\
\hline 19-Nov-03 & 23:50 & --- & -- & --- & -- & --- & --- & --- & --- & --- & --- & --- & --- & --- & --- & --- & --- & --- & --- \\
\hline 19-Nov-03 & $23: 50$ & -0.04 & --- & -2.36 & --- & -500 & -0.70 & -10.00 & 0.00 & $-\ldots$ & -2.10 & 13.50 & --- & 1.10 & $-\ldots$ & 8.00 & --- & 0.50 & --- \\
\hline $20-$ Nov-03 & $8: 15$ & -- & -- & --- & -- & --- & -- & -- & --- & --- & -- & -- & -- & --- & --- & -- & --- & --- & --- \\
\hline $20-$ Nov-03 & $8: 15$ & -0.28 & --- & --- & --- & $-1,136$ & -2.25 & -22.71 & -0.27 & --- & 0.19 & 12.40 & --- & --- & --- & 6.00 & --- & --- & --- \\
\hline $21-$ Nov-03 & $14: 30$ & --- & --- & --- & --- & --- & --- & --- & --- & --- & --- & --- & --- & --- & --- & --- & --- & --- & --- \\
\hline 21-Nov-03 & $14: 30$ & 0.40 & --- & -2.80 & --- & 350 & --- & 7.00 & --- & -1.86 & --- & 13.60 & --- & -0.10 & --- & 8.00 & --- & \begin{tabular}{|l|}
-1.00 \\
\end{tabular} & --- \\
\hline & & --- & -- & --- & -- & --- & -- & --- & --- & --- & -- & --- & --- & --- & --- & --- & --- & --- & --- \\
\hline & & --- & --- & --- & --- & --- & --- & --- & --- & --- & --- & --- & --- & --- & --- & --- & --- & --- & $\begin{array}{l}--- \\
\end{array}$ \\
\hline $\begin{array}{l}\text { Average calib } \\
\text { error }\end{array}$ & & 0.20 & 0.17 & -1.06 & -- & -772.30 & -2.24 & -15.45 & -0.07 & -0.50 & 0.05 & 9.43 & 7.68 & 0.37 & 0.10 & 3.06 & 1.52 & -3.02 & -0.33 \\
\hline $\begin{array}{l}\text { Maximum cal } \\
\text { error }\end{array}$ & ration & 0.84 & 0.40 & 0.56 & 0.00 & 350.00 & -0.37 & 7.00 & 0.25 & 3.10 & 3.34 & 14.40 & 14.30 & 4.60 & 0.10 & 12.90 & 8.00 & 0.50 & 4.00 \\
\hline $\begin{array}{l}\text { Minimum cali } \\
\text { error }\end{array}$ & ration & -0.28 & 0.00 & -2.80 & 0.00 & -3899 & -5.14 & -77.98 & -0.34 & -4.07 & -4.10 & 5.00 & 6.31 & -1.90 & 0.10 & -6.00 & -3.00 & -9.50 & -4.50 \\
\hline $\begin{array}{l}\text { Adjsut data fo } \\
\text { error or dilutic }\end{array}$ & zero cal & ibration & no & & & & Yes - corre & ect NOx d & -2.2 & NO $p$ & inute & ce last cal & Yes & -7.0814 & $\%$ averag & week 1 & No 2 & zero cor & ect \\
\hline Adjust data fo & span ca & libration & & & & & & & & & & & & & $\%$ ave & reek 2 & & & \\
\hline error? & & & no & & & & & & no & & & & & -12.04 & & & Nos & span cor & rect \\
\hline Correct for bi & & & & & & & & & & & & & No & & & & & & \\
\hline
\end{tabular}


Table B-1. CEMS1 calibration results for the THOR carbonate and mineralized test series (continued).

\begin{tabular}{|c|c|c|c|c|c|c|c|c|c|c|c|c|c|c|c|c|c|}
\hline & \multicolumn{4}{|c|}{ LOANER NOVA CO2 } & \multicolumn{4}{|c|}{ LOANER NOVA H2 } & \multicolumn{4}{|c|}{$\mathrm{CAICO}$} & \multicolumn{4}{|c|}{$\mathrm{CAI} \mathrm{CH} 4$} \\
\hline & & $\mathrm{FS}=$ & 100.00 & & & $F S=$ & 20 & & & $\mathrm{FS}=$ & 10 & & & $\mathrm{FS}=$ & 50,000 & & \\
\hline Date & Time & Pre-Zero & $\begin{array}{l}\text { Post- } \\
\text { Zero }\end{array}$ & Pre-Span & $\begin{array}{l}\text { Post- } \\
\text { Span }\end{array}$ & Pre-Zero & Post-Zero & $\begin{array}{l}\text { Pre- } \\
\text { Span }\end{array}$ & $\begin{array}{l}\text { Post- } \\
\text { Span }\end{array}$ & $\begin{array}{l}\text { Pre- } \\
\text { Zero }\end{array}$ & Post-Zero & $\begin{array}{l}\text { Pre- } \\
\text { Span }\end{array}$ & $\begin{array}{l}\text { Post- } \\
\text { Span }\end{array}$ & $\begin{array}{l}\text { Pre- } \\
\text { Zero }\end{array}$ & Post-Zero & $\begin{array}{l}\text { Pre- } \\
\text { Span }\end{array}$ & $\begin{array}{l}\text { Post- } \\
\text { Span }\end{array}$ \\
\hline $10-$ Nov-03 & $23: 50$ & -- & -- & -- & -- & -- & -- & -- & -- & -- & -- & -- & -- & -- & -- & -- & -- \\
\hline 10-Nov-03 & $23: 50$ & -- & --- & --- & --- & -- & -- & --- & -- & 0.00 & --- & 0.40 & -- & 3.34 & -- & -0.06 & -- \\
\hline 13-Nov-03 & $0: 50$ & --- & --- & --- & --- & --- & --- & --- & --- & --- & --- & --- & --- & -- & --- & --- & --- \\
\hline 13-Nov-03 & $0: 50$ & --- & --- & --- & --- & --- & --- & --- & --- & 2.70 & 0.00 & $-\ldots$ & $\ldots$ & 14.06 & 13.80 & --- & --- \\
\hline 13-Nov-03 & $1: 25$ & -- & -- & -- & --- & -- & --- & --- & -- & -- & -- & --- & -- & -- & --- & -- & --- \\
\hline 13-Nov-03 & $1: 25$ & --- & --- & --- & --- & -- & --- & --- & --- & 0.000 & --- & -0.50 & -- & -- & -- & -- & --- \\
\hline 13-Nov-03 & $7: 55$ & --- & --- & $-\ldots$ & --- & --- & --- & --- & --- & --- & --- & --- & -- & --- & --- & --- & --- \\
\hline 13-Nov-03 & $7: 55$ & -- & --- & --- & --- & -- & -- & -- & --- & 5.60 & 0.00 & -6.70 & 0.00 & - & -- & -- & -- \\
\hline 13-Nov-03 & $7: 56$ & -- & --- & --- & -- & -- & -- & -- & -- & --- & -- & -- & -- & -- & -- & -- & -- \\
\hline 13-Nov-03 & $7: 56$ & --- & --- & --- & --- & --- & --- & --- & --- & --- & --- & --- & --- & --- & --- & --- & --- \\
\hline 13-Nov-03 & $19: 16$ & --- & --- & -- & --- & -- & --- & -- & -- & --- & -- & --- & -- & --- & --- & -- & -- \\
\hline 13-Nov-03 & $19: 16$ & 0.10 & 0.00 & -- & -- & 5.50 & 0.00 & -- & -- & 3.20 & 0.00 & --- & -- & 16.00 & 16.00 & -- & -- \\
\hline 14-Nov-03 & $7: 00$ & -- & -- & -- & -- & -- & -- & -- & -- & -- & -- & -- & -- & -- & -- & -- & -- \\
\hline 14-Nov-03 & $7: 00$ & --- & 0.00 & --- & -0.60 & --- & 0.00 & --- & -30.00 & 7.90 & 0.00 & -9.80 & -1.10 & 0.00 & --- & --- & --- \\
\hline 14-Nov-03 & $11: 46$ & --- & --- & --- & --- & --- & --- & -- & --- & --- & --- & --- & --- & -- & --- & --- & --- \\
\hline 14-Nov-03 & $11: 46$ & -- & --- & -- & -- & -2.00 & -- & -- & -- & 5.70 & -- & -- & -- & -- & -- & -- & -- \\
\hline 14-Nov-03 & $14: 30$ & -- & -- & -- & -- & -- & -- & -- & - & -- & -- & -- & -- & -- & -- & -- & -- \\
\hline 14-Nov-03 & $14: 30$ & 0.40 & 0.30 & 2.20 & --- & -26.00 & -16.00 & --- & --- & 7.20 & 5.10 & -4.80 & --- & 2.15 & 2.13 & -- & --- \\
\hline 14-Nov-03 & $14: 50$ & --- & --- & --- & --- & -- & --- & -- & -- & --- & --- & --- & --- & --- & -- & -- & --- \\
\hline 14-Nov-03 & $14: 50$ & 0.60 & -- & -- & -- & -3.50 & -- & -- & -- & 5.60 & 5.40 & -- & -- & -- & -- & -- & -- \\
\hline 14-Nov-03 & $15: 50$ & --- & --- & --- & --- & --- & --- & --- & --- & $-\ldots$ & --- & --- & -- & --- & --- & --- & --- \\
\hline 14-Nov-03 & $15: 50$ & 0.60 & 0.00 & -- & --- & -5.50 & -- & -32.00 & -0.50 & -- & -- & --- & -- & -- & -- & -- & --- \\
\hline 17-Nov-03 & $0: 20$ & -- & -- & -- & -- & -- & -- & -- & -- & -- & -- & -- & -- & -- & -- & -- & -- \\
\hline 17-Nov-03 & $0: 20$ & -0.10 & --- & 0.40 & 0.10 & 28.50 & -- & -- & --- & 2.00 & 0.00 & -1.90 & 0.00 & -0.30 & 0.00 & $\begin{array}{l}-0.06 \\
\end{array}$ & --- \\
\hline 17-Nov-03 & $7: 00$ & --- & --- & -- & --- & --- & --- & --- & --- & --- & --- & --- & --- & --- & --- & --- & --- \\
\hline 17-Nov-03 & $7: 00$ & 0.80 & 0.03 & -0.23 & -- & -- & -- & -- & --- & -2.40 & 0.00 & -0.10 & 0.10 & 0.22 & 0.01 & -2.11 & -0.66 \\
\hline 19-Nov-03 & $0: 20$ & -- & -- & -- & -- & -- & -- & -- & -- & -- & -- & -- & -- & -- & -- & -- & -- \\
\hline 19-Nov-03 & $0: 20$ & 0.00 & -0.18 & -0.20 & 0.68 & 28.50 & 28.60 & -25.50 & -25.60 & 0.00 & 0.00 & -0.10 & --- & 0.03 & 0.01 & -0.45 & --- \\
\hline 19-Nov-03 & $10: 13$ & -- & --- & --- & --- & -- & -- & -- & --- & --- & -- & --- & -- & -- & -- & -- & --- \\
\hline 19-Nov-03 & $10: 13$ & -- & -- & -- & -- & -- & -- & -- & -- & 0.50 & 0.00 & -- & -- & 0.05 & -- & -- & -- \\
\hline 19-Nov-03 & $11: 50$ & -- & --- & --- & -- & -- & -- & -- & -- & -- & -- & -- & -- & -- & -- & --- & -- \\
\hline 19-Nov-03 & $11: 50$ & --- & --- & --- & 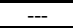 & - & -- & --- & --- & -0.20 & -- & --- & -- & 0.07 & -- & -- & -- \\
\hline 19-Nov-03 & $23: 50$ & -- & -- & -- & -- & -- & -- & -- & -- & -- & -- & -- & -- & -- & -- & -- & -- \\
\hline 19-Nov-03 & $23: 50$ & -0.20 & -- & 1.70 & -0.20 & 28.50 & -- & -26.00 & -- & 0.00 & -- & -2.00 & 0.00 & 0.00 & 0.00 & -0.69 & -- \\
\hline 20 -Nov-03 & $8: 15$ & --- & --- & --- & --- & --- & --- & --- & --- & --- & --- & --- & --- & -- & --- & -- & --- \\
\hline $20-N o v-03$ & $8: 15$ & --- & --- & --- & --- & --- & --- & --- & --- & -0.60 & --- & --- & -- & 0.01 & -- & -- & --- \\
\hline 21-Nov-03 & $14: 30$ & -- & -- & -- & -- & -- & --- & -- & -- & -- & -- & -- & -- & -- & -- & -- & -- \\
\hline 21-Nov-03 & $14: 30$ & -0.30 & -- & -0.70 & -- & 28.50 & -- & -6.00 & -- & -0.40 & -- & 0.60 & -- & 0.00 & -- & -0.73 & -- \\
\hline & & --- & --- & --- & --- & --- & --- & --- & --- & --- & --- & --- & --- & --- & --- & --- & --- \\
\hline & & --- & --- & -- & -- & -- & -- & -- & -- & --- & -- & --- & -- & -- & -- & --- & -- \\
\hline Average calib & $n$ error & -0.30 & 0.02 & 0.96 & 0.00 & 7.59 & 2.10 & -13.42 & -9.12 & 2.16 & 1.05 & -2.49 & -0.20 & 2.74 & 4.56 & -0.68 & -0.66 \\
\hline Maximum cali & on error & 0.80 & 0.30 & 4.50 & 0.68 & 28.50 & 28.60 & 10.00 & 10.50 & 7.90 & 5.40 & 0.60 & 0.10 & 16.00 & 16.00 & -0.06 & -0.66 \\
\hline Minimum calit & on error & -5.20 & -0.18 & -0.70 & -0.60 & -26.00 & -16.00 & -32.00 & -30.00 & -2.40 & 0.00 & -9.80 & -1.10 & -0.30 & 0.00 & -2.11 & -0.66 \\
\hline Adjsut data fo & o calibra & ion error o & dilution? & No zero & adjust for & wk 1 - avg & zero respo & nse was & -3.88 & & no & & & ro correct & $-4,537.50$ & $\mathrm{ppm}$ & \\
\hline $\begin{array}{l}\text { Adjust data fo } \\
\text { Correct for bia }\end{array}$ & an calibr & $\begin{array}{l}\text { tion error? } \\
\text { No span }\end{array}$ & adjust for $w$ & $\begin{array}{r}\text { Yes ze } \\
\text { week } 1 \mathrm{bec}\end{array}$ & $\begin{array}{l}\mathrm{o} \text { adjust } \\
\text { ause ave }\end{array}$ & $\begin{array}{l}\text { veek } 2 . \text { A } \\
\text { age span } \\
\text { Yes span }\end{array}$ & $\begin{array}{l}\text { vg zero cor } \\
\text { error }=\text {. C } \\
\text { adjust for }\end{array}$ & $\begin{array}{r}\text { ection is: } \\
\text { AF }=1.17 \\
1.53 \\
\end{array}$ & $\begin{array}{r}-5.7 \\
-6.1 \\
\text { for week }\end{array}$ & & no & & & $\begin{array}{l}\text { no zero c } \\
\text { no span }\end{array}$ & $\begin{array}{l}\text { correction for } \\
\text { correction }\end{array}$ & week 2 & \\
\hline
\end{tabular}


Table B-1. CEMS1 calibration results for the THOR carbonate and mineralized test series (continued).

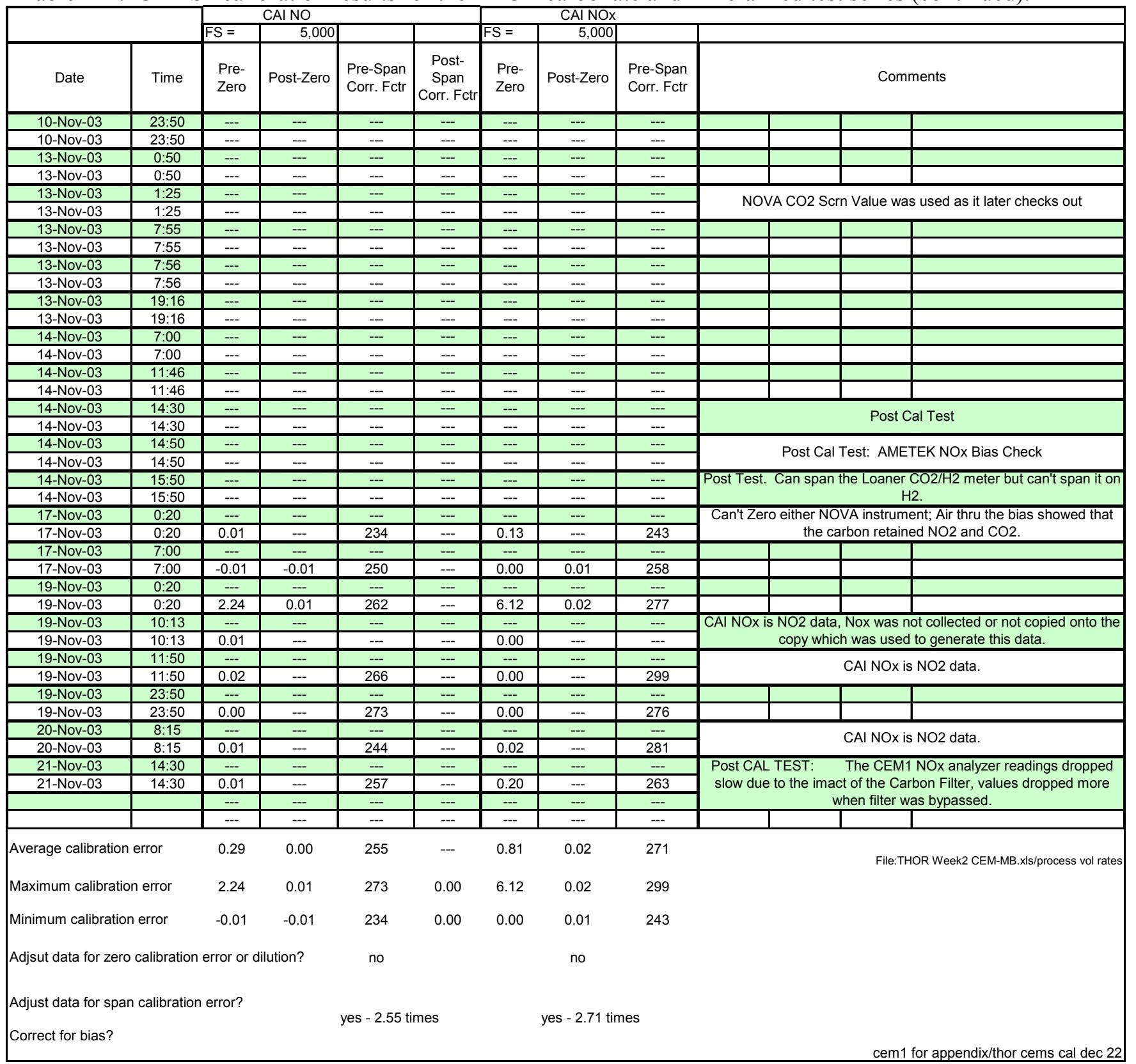


Table B-2. CEMS2 calibration results for the THOR carbonate and mineralized test series.

\begin{tabular}{|c|c|c|c|c|c|c|c|c|c|c|c|c|c|c|c|c|c|}
\hline & \multicolumn{4}{|c|}{ TECO HCl } & \multicolumn{4}{|c|}{ CAl CO2 } & \multicolumn{4}{|c|}{ CAI CO } & \multicolumn{4}{|c|}{ TECO NO } \\
\hline & & FS $=$ & 100 & & & $\mathrm{FS}=$ & 100 & & & $\mathrm{FS}=$ & 500 & & & $\mathrm{FS}=$ & 5000 & & \\
\hline Date & Time & Pre-Zero & Post-Zero & Pre-Span & Post-Span & \begin{tabular}{|l|} 
Pre-Zero \\
\end{tabular} & \begin{tabular}{|l|} 
Post-Zero \\
\end{tabular} & \begin{tabular}{|l|} 
Pre-Span \\
\end{tabular} & Post-Span & Pre-Zero & Post-Zero & Pre-Span & Post-Span & Pre-Zero & Post-Zero & \begin{tabular}{|l|} 
Pre-Span \\
\end{tabular} & Post-Span \\
\hline 10-Nov-03 & $12: 00$ & --- & --- & --- & --- & --- & --- & --- & --- & --- & --- & --- & --- & -- & --- & --- & --- \\
\hline 10-Nov-03 & 12:00 & 5.71 & -- & -- & -- & 0.13 & 0.04 & 0.93 & -- & 0.01 & 0.40 & -0.01 & -- & -- & -- & -- & -- \\
\hline $11-$ Nov-03 & $4: 20$ & --- & --- & --- & --- & --- & --- & --- & --- & --- & --- & --- & --- & --- & --- & --- & --- \\
\hline 11-Nov-03 & $4: 20$ & 6.30 & -0.04 & -16.04 & 0.31 & 0.04 & -- & 0.01 & -- & -1.52 & -- & 13.32 & 1.52 & -- & --- & --- & -- \\
\hline 12-Nov-03 & $10: 20$ & -- & -- & -- & -- & -- & --- & -- & --- & -- & --- & -- & --- & --- & --- & --- & --- \\
\hline $12-N o v-03$ & $10: 20$ & 1.59 & -0.23 & 1.51 & 0.28 & -0.10 & 0.00 & 0.86 & --- & 2.26 & 0.00 & -2.66 & --- & --- & --- & --- & --- \\
\hline 13-Nov-03 & $1: 25$ & --- & -- & --- & -- & --- & -- & -- & -- & -- & -- & -- & -- & -- & -- & -- & -- \\
\hline 13-Nov-03 & $1: 25$ & --- & --- & --- & -- & --- & --- & --- & --- & --- & --- & --- & --- & --- & --- & -- & --- \\
\hline 13-Nov-03 & 19:16 & --- & -- & --- & --- & -- & --- & -- & -- & -- & -- & -- & -- & -- & -- & -- & -- \\
\hline 13-Nov-03 & 19:16 & -0.02 & -- & -- & --- & -0.10 & 0.00 & --- & -- & -3.60 & 0.00 & -- & -- & 0.02 & 0.00 & -2.36 & 0.00 \\
\hline 14-Nov-03 & $3: 00$ & - & -- & -- & -- & -- & -- & -- & -- & -- & -- & -- & -- & -- & -- & -- & -- \\
\hline 14-Nov-03 & $3: 00$ & --- & --- & -- & --- & --- & --- & --- & --- & -- & --- & --- & --- & 0.02 & 0.00 & 0.26 & 0.00 \\
\hline 14-Nov-03 & $7: 00$ & --- & --- & --- & --- & --- & --- & --- & --- & --- & $\overline{---}$ & --- & --- & -- & --- & --- & -- \\
\hline 14-Nov-03 & $7: 00$ & --- & --- & --- & --- & --- & --- & --- & --- & --- & --- & --- & --- & --- & --- & --- & --- \\
\hline 14-Nov-03 & $13: 45$ & --- & -- & --- & -- & --- & --- & --- & --- & -- & --- & --- & --- & --- & --- & --- & --- \\
\hline \begin{tabular}{|c|}
$14-N o v-03$ \\
\end{tabular} & $13: 45$ & 0.70 & --- & -- & -- & 7.40 & --- & --- & -- & 2.00 & - & -- & --- & 1.06 & -- & -- & -- \\
\hline 14-Nov-03 & $14: 30$ & -- & --- & --- & --- & -- & --- & --- & --- & - & --- & --- & --- & -- & --- & --- & --- \\
\hline 14-Nov-03 & $14: 30$ & 0.80 & 0.80 & -- & --- & 0.04 & 0.04 & 0.11 & --- & 3.00 & 0.60 & -4.20 & -- & 0.00 & -- & -0.22 & --- \\
\hline 14-Nov-03 & $14: 50$ & --- & -- & -- & -- & -- & -- & -- & -- & -- & --- & -- & -- & -- & -- & --- & -- \\
\hline 14-Nov-03 & $14: 50$ & -- & --- & --- & --- & --- & --- & --- & --- & --- & -- & -- & --- & -- & --- & --- & --- \\
\hline 14-Nov-03 & $17: 23$ & -- & -- & -- & -- & -- & --- & -- & -- & -- & --- & -- & -- & -- & --- & --- & --- \\
\hline 14-Nov-03 & $17: 23$ & --- & --- & -- & --- & --- & --- & --- & --- & --- & -- & --- & -- & -0.01 & 0.00 & 0.41 & 0.00 \\
\hline 14-Nov-03 & $17: 23$ & -- & --- & --- & --- & -- & --- & --- & --- & --- & -- & --- & --- & --- & --- & --- & --- \\
\hline 14-Nov-03 & $17: 23$ & --- & --- & -- & --- & --- & --- & --- & --- & - & -- & --- & --- & -- & --- & --- & --- \\
\hline 17-Nov-03 & $0: 20$ & --- & -- & --- & --- & --- & --- & --- & --- & --- & --- & --- & --- & --- & --- & --- & -- \\
\hline 17-Nov-03 & $0: 20$ & --- & --- & --- & --- & --- & --- & --- & --- & --- & --- & --- & --- & --- & --- & --- & --- \\
\hline $17-\mathrm{Nov}-03$ & $7: 00$ & --- & --- & --- & --- & --- & --- & --- & --- & --- & --- & --- & --- & $\overline{---}$ & --- & --- & --- \\
\hline 17-Nov-03 & $7: 00$ & 2.67 & -0.10 & --- & --- & 0.04 & 0.04 & -0.48 & 0.02 & 2.56 & 0.10 & -9.56 & -2.90 & 0.00 & 0.00 & 0.00 & 0.04 \\
\hline $19-$ Nov-03 & $0: 20$ & --- & --- & --- & --- & --- & --- & --- & -- & --- & --- & -- & - & -- & -- & -- & -- \\
\hline 19-Nov-03 & $0: 20$ & 2.00 & 0.03 & -- & -- & 0.30 & 0.00 & 0.60 & 0.00 & 2.60 & 0.00 & -4.80 & -- & 0.00 & --- & -0.24 & -0.24 \\
\hline 19-Nov-03 & $23: 50$ & -- & -- & --- & --- & --- & -- & -- & -- & --- & --- & -- & --- & -- & --- & --- & -- \\
\hline 19-Nov-03 & $23: 50$ & 0.75 & 0.03 & -- & --- & -0.20 & 0.00 & -0.20 & --- & 1.00 & 0.00 & -4.60 & --- & 0.00 & 0.00 & 0.00 & -- \\
\hline $21-\mathrm{Nov}-03$ & $14: 30$ & --- & -- & -- & -- & --- & -- & --- & --- & --- & --- & -- & --- & -- & -- & --- & -- \\
\hline \begin{tabular}{|l|}
$21-N o v-03$ \\
\end{tabular} & $14: 30$ & -0.40 & --- & -- & --- & 0.13 & --- & -0.13 & --- & 0.40 & --- & 0.00 & --- & 0.00 & --- & 0.06 & -- \\
\hline Average calit & tion error & 2.01 & 0.08 & -7.27 & 0.30 & 0.77 & 0.02 & 0.21 & 0.01 & 0.87 & 0.16 & -1.56 & -0.69 & 0.12 & 0.00 & -0.26 & -0.04 \\
\hline $\begin{array}{l}\text { Maximum ca } \\
\text { error }\end{array}$ & ration & 6.30 & 0.80 & 1.51 & 0.31 & 7.40 & 0.04 & 0.93 & 0.02 & 3.00 & 0.60 & 13.32 & 1.52 & 1.06 & 0.00 & 0.41 & 0.04 \\
\hline $\begin{array}{l}\text { Minimum cal } \\
\text { error }\end{array}$ & ation & -0.40 & -0.23 & -16.04 & 0.28 & -0.20 & 0.00 & -0.48 & 0.00 & -3.60 & 0.00 & -9.56 & -2.90 & -0.01 & 0.00 & -2.36 & -0.24 \\
\hline $\begin{array}{l}\text { Adjust data } \\
\text { error or diluti }\end{array}$ & $\begin{array}{l}\text { zero calib } \\
?\end{array}$ & ration & & & no & & & & no & & & & no & & & & no \\
\hline $\begin{array}{l}\text { Adjust data } \mathrm{f} \\
\text { calibration er } \\
\text { Need to corr } \\
\text { bias? }\end{array}$ & & & & & no & & & & no & & & & no & & & & no \\
\hline
\end{tabular}


Table B-2. CEMS2 calibration results for the THOR carbonate and mineralized test series (continued).

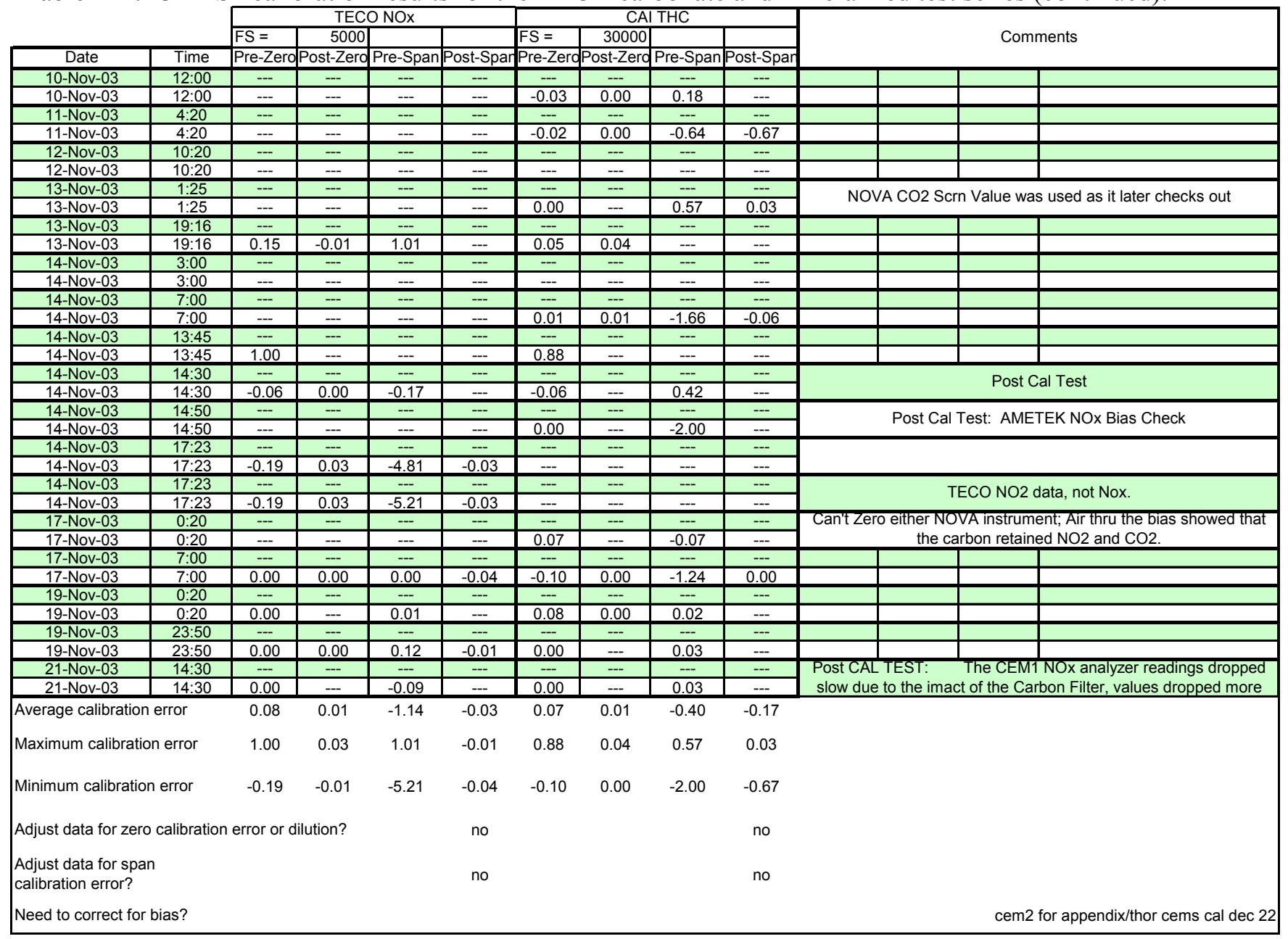




\section{Appendix C \\ Quality Assurance/Quality Control Activities and Results}




\section{Appendix C}

\section{Quality Assurance/Quality Control Activities and Results}

Several different quality assurance/quality control (QA/QC) activities have been performed for this test series to characterize the quality of the test data and to ensure sufficient data quality to meet the data quality objectives. QA/QC activities have been grouped as either qualitative or quantitative. Qualitative QA parameters are comparability and representativeness.

\section{C-1. DATA QUALITY OBJECTIVES}

Data quality objectives include qualitative and quantitative objectives that define the QA/QC activities for this test series. Data from this test are to be used in engineering and feasibility evaluations of steam reforming technology and to demonstrate off-gas treatment technologies. The data are not intended for treatment facility design or operation. As such, the data are not collected to be quality-controlled data. The QA/QC activities have been defined to characterize the quality of the test data and to ensure sufficient data quality to meet the data quality objectives.

\section{C-1.1 Qualitative QA/QC Activities}

Several activities were performed to characterize and ensure representativeness and comparability of test data. Representativeness is a measure to which sample data accurately and precisely represent the average properties being measured. Comparability is the determination that one data set can be compared to another. These qualitative characteristics involve all aspects of the work, including preparation for sampling, sampling, sample handling, analytical method performance, data validation, and reporting of results. Comparability and representativeness in this project were achieved by the following:

- Appropriate planning and calibrations

- Documentation of all laboratory data, general observations, and details of the activities in a Laboratory Record Books (LRBs), data entry sheets, and electronic data logs

- $\quad$ Collecting samples and making measurements from specific approved locations in the steam reformer system

- Using standard procedures for calibrations where possible

- Using sampling and analytical procedures based on standard methods where possible

- Documenting all necessary deviations from standard procedures, sample preparation methods, or analytical methods

- Using standard procedures or procedures that are developed for this test program that are checked for accuracy for all data reductions and emissions calculations.

\section{C-1.2 Quantitative QA/QC Activities}

Quantitative QA/QC activities include calibrations and other measurements that quantify data precision and accuracy. Precision is a measure of the agreement among individual measurements of the same parameter under similar conditions. Accuracy is the degree of agreement of a measurement with a true or known value. 
Key process control, safety-related, and off-gas characterization instruments and the data collection loops were calibrated for reliability and data quality. Results of the calibrations are shown in Table C-1. Calibration procedures and records are maintained in the project files. The accuracy of the process instrumentation and software has also been demonstrated in prior steam reforming tests (Marshall 2003a, Marshall 2003c, Soelberg 2003a).

The CEMS accuracy, calibrations, and quality assurance checks are discussed in Sections 5 and 6. The calibration results are summarized in Appendix B.

Many samples were collected and analyzed for this test series. Several QA/QC activities were performed to characterize and ensure sample analysis precision and accuracy. Results of these QA/QC activities are shown in Table $\mathrm{C}-2$.

\section{C-1.3 Sample Handling And Custody}

Gaseous, liquid, and solid samples were collected for analysis in this test program. New sample containers were used that were appropriate to the sample matrix. Sample containers were kept in a clean environment, in original shipping boxes, and covered, until needed.

All samples were labeled with a unique identifying number and with other information that describes the sample to field, shipping, and laboratory personnel. The label identified the unique sample number, project name, sample description, sample date and time, and sampler name or initials. The sample description will include the location of sample collection and the sample matrix. This same information along with any additional detail information, including sample volume or weight, requests for analysis, and chain of custody information, were recorded in a sample log and on request for analysis/chain of custody (RFA/COC) forms.

Samples were transported according to INEEL requirements. Samples that were not hazardous were not Department of Transportation (DOT) regulated, and were freely transported by test team personnel using a government vehicle (Rowley 2003). Samples that were hazardous were regulated by DOT. DOT provides a "Materials of Trade Exception" (49CFR173.6), which allowed transport by test team personnel by meeting shipping requirements that included (a) securing the samples in an outer container, so that there would not be breakage, leakage, or spillage during transportation, (b) securing the container in a government vehicle, and (c) properly labeling the samples.

\section{C-1.4 Data Reduction, Review, Validation and Reporting}

Key process data and CEMS data were recorded manually on data sheets and recorded automatically in electronic data files. The electronic data files were imported into spreadsheet formats for data reduction and presentation. Onsite data reduction will be performed to the extent possible. Process data from the PLC was incorporated with CEMS data and available sample analysis data to characterize the process inputs, outputs, operating conditions.

The CEMS data reductions included:

- Calculation of instantaneous and average off-gas composition

- Calculation of CEMS zero and span drifts

- $\quad$ Correction of CEMS data for calculated drift if zero or span drift exceeds acceptance limits

- $\quad$ Correction of CEMS data for any dilutions

- Calculation of concentrations on a representative basis (such as wet or dry basis). 
Table C-1. Calibrated instrument accuracies for the fluidized bed test system.

\begin{tabular}{|c|c|c|c|c|}
\hline Tag Name & Description & Manufacturer & Technology & Accuracy \\
\hline AJ1_F1_VAL & Off-Gas Mass Flow to GAC (kg/hr) & Micro Motion & Coriolis & $+\underline{+0.044 \%}$ \\
\hline AJ1_P2_VAL & Off-gas Pressure at Reheater RH-2 Discharge (PSIA) & Rosemount & Capacitive & $0.2 \%$ Span \\
\hline AJ1_T1_VAL & Off-Gas Temperature at GAC Inlet (oC) & Idaho Lab & Type K & $\pm 2.2^{\circ} \mathrm{C}$ \\
\hline B1_A1_O2 & Raw Oxygen Concentration at B-1 Oxidizer Discharge (Wet Basis) (\%) & Ametek & Zirconium Oxide & $+0.75 \%$ (measured) \\
\hline B1_F1_VAL & Natural Gas Mass Flow to B-1 Burner (kg/hr) & Micro Motion & Coriolis & $+0.044 \%$ \\
\hline B1_F2_VAL & Air Mass Flow to B-1 Burner $(\mathrm{kg} / \mathrm{hr})$ & Micro Motion & Coriolis & $+0.044 \%$ \\
\hline B1_F3_VAL & Air Mass Flow to B-1 Oxidizer $(\mathrm{kg} / \mathrm{hr})$ & Micro Motion & Coriolis & $+0.044 \%$ \\
\hline B1_F4_VAL & Cooling Water Mass Flow to B-1 Oxidizer $(\mathrm{kg} / \mathrm{hr})$ & Micro Motion & Coriolis & $+0.044 \%$ \\
\hline B1_T1_VAL & Temperature in B-1 Oxidizer $(\operatorname{deg} \mathrm{C})$ & Idaho Lab & Type K & $\pm 2.2^{\circ} \mathrm{C}$ \\
\hline B1_T2_VAL & Temperature at B-1 Oxidizer Discharge $(\operatorname{deg} C)$ & Idaho Lab & Type K & $\pm 2.2^{\circ} \mathrm{C}$ \\
\hline C1_PD_VAL & Differential Pressure Across C-1 Cyclone (inH2O) & Rosemount & DP Cell & $0.25 \%$ Span \\
\hline C1_T1_VAL & Off-gas Temperature at C-1 Cyclone Inlet (oC) & Idaho Lab & Type K & $\pm 2.2^{\circ} \mathrm{C}$ \\
\hline C1_T2_VAL & Off-gas Temperature in C-1 Cyclone (oC) & Idaho Lab & Type K & $\pm 2.2^{\circ} \mathrm{C}$ \\
\hline C1_T3_VAL & Off-gas Temperature at $\mathrm{C}-1$ Cyclone Discharge $(\mathrm{oC})$ & Idaho Lab & Type K & $\pm 2.2^{\circ} \mathrm{C}$ \\
\hline EVS1_F2_VAL & Scrub Solution Volume Flow to EVS-1 Scrubber $(1 / \mathrm{hr})$ & Yokogawa & Mag. & $0.25 \%$ of Span \\
\hline EVS1_PD1_VAL & Differential Pressure Across EVS-1 Scrubber (inH2O) & Rosemount & DP Cell & $0.2 \%$ Span \\
\hline F1_PD_VAL & Differential Pressure Across F-1 Filter Vessel (inH2O) & Rosemount & DP Cell & $.25 \%$ Span \\
\hline F1_T1_VAL & Off-gas Temperature in F-1 Filter Vessel (oC) & Idaho Lab & Type K & $\pm 2.2^{\circ} \mathrm{C}$ \\
\hline $\mathrm{F} 1{ }^{-} \mathrm{T} 2 \_\mathrm{V}$ VAL & Off-gas Temperature at F-1 Filter Vessel Discharge (oC) & Idaho Lab & Type K & $\pm 2.2^{\circ} \mathrm{C}$ \\
\hline GACE1_PD_VAL & Differential Pressure Across GAC (inH2O) & DWYER & DP Cell & $2 \%$ of Scale \\
\hline GAC1_T_VAL & Temperature 1 in GAC (oC) & Idaho Lab & Type K & $\pm 2.2^{\circ} \mathrm{C}$ \\
\hline GAC1_T2_VAL & Temperature 2 in GAC $(\mathrm{oC})$ & Idaho Lab & Type K & $\pm 2.2^{\circ} \mathrm{C}$ \\
\hline H1_F_PV & Steam Mass Flow to Fluidized Bed (kg/hr) & Rosemount & Mass ProPlate & $1 \%$ Range \\
\hline H1_F2_PV & Fluidizing Gas Mass Flow to Fluidized Bed $(\mathrm{kg} / \mathrm{hr})$ & Micro Motion & Coriolis & $+0.044 \%$ \\
\hline H1_T1_VAL & Process Gas Temperature at H-1 Superheater Inlet (oC) & Rosemount & Mass ProPlate & $\pm .56^{\circ} \mathrm{C}$ \\
\hline $\mathrm{H} 1 \_\mathrm{T} 2 \_\mathrm{V} A \mathrm{~L}$ & Process Gas Temperature at H-1 Superheater Discharge (oC) & Idaho Lab & Type R & $\pm 2.2^{\circ} \mathrm{C}$ \\
\hline H1_T2B_Val & Pipe Temperature in H-1 Superheater (oC) & Idaho Lab & Type K & $\pm 2.2^{\circ} \mathrm{C}$ \\
\hline $\mathrm{H} 2-\mathrm{T}$ T_VALL & Process Gas Temperature at $\mathrm{H}-1$ Superheater Discharge $(\mathrm{oC})$ & Idaho Lab & Type R & $\pm 2.2^{\circ} \mathrm{C}$ \\
\hline $\mathrm{H} 2 \_\mathrm{TB} \_\mathrm{Val}$ & Pipe Temperature in $\mathrm{H}-2$ Superheater $(\mathrm{oC})$ & Idaho Lab & Type R & $\pm 2.2^{\circ} \mathrm{C}$ \\
\hline H3_T1_VAL & Pipe Temperature in $\mathrm{H}-3$ Superheater $(\mathrm{oC})$ & Idaho Lab & Type R & $\pm 2.2^{\circ} \mathrm{C}$ \\
\hline H3_T2_VAL & Process Gas Temperature at $\mathrm{H}-3$ Superheater Discharge $(\mathrm{oC})$ & Idaho Lab & Type K & $\pm 2.2^{\circ} \mathrm{C}$ \\
\hline H4_T1_VAL & Pipe Temperature in $\mathrm{H}-4$ Superheater $(\mathrm{oC})$ & Idaho Lab & Type R & $\pm 2.2^{\circ} \mathrm{C}$ \\
\hline $\mathrm{H} 4 \_\mathrm{T} 2 \_\mathrm{V}$ VAL & Process Gas Temperature at $\mathrm{H}-4$ Superheater Discharge $(\mathrm{oC})$ & Idaho Lab & Type R & $\pm 2.2^{\circ} \mathrm{C}$ \\
\hline MĒ1_PD1_VAL & Differential Pressure across the Mist Eliminator (inH2O) & Rosemount & DP Cell & $0.25 \%$ Span \\
\hline PQ1_F1_VAL & Cooling Water Mass Flow to PQ-1 Partial Quench $(\mathrm{kg} / \mathrm{hr})$ & Micro Motion & Coriolis & $+0.044 \%$ \\
\hline PQ1_PD1_VAL & Differential Pressure Across PQ-1 Partial Quench (in $\mathrm{H} 2 \mathrm{O}$ ) & Rosemount & DP Cell & $\overline{0.25} \%$ Span \\
\hline PQ1_T1_V̄ VAL & Temperature at PQ-1 Partial Quench Discharge (deg C) & Idaho Lab & Type K & $\pm 2.2^{\circ} \mathrm{C}$ \\
\hline SR1_D1A_VAL & Simulant Feed Density $(\mathrm{gm} / \mathrm{cc})$ & Micro Motion & Coriolis & $+0.044 \%$ \\
\hline SR1_D1C_VAL & Reductant Feed Density (gm/cc) & Micro Motion & Coriolis & $\overline{+0} .044 \%$ \\
\hline SR1_F1A_VAL & Simulant Feed Mass Flow to Fluidized Bed $(\mathrm{kg} / \mathrm{hr})$ & Micro Motion & Coriolis & $+0.044 \%$ \\
\hline SR1_F1B_KGH & Atomizing Calculated Mass Flow Rate Based on Raw Value from MFC & Brooks & Thermal Anem & $1 \%$ of Setpoint \\
\hline SR1_F1C_VAL & Reductant Feed Mass Flow to Fluidized Bed $(\mathrm{kg} / \mathrm{hr})$ & Micro Motion & Coriolis & $+0.044 \%$ \\
\hline SR1_F2_KGGH & O2 to Distributer Plate Calculated Mass Flow Rate Based on Raw Value from MFC (THOR) & Brooks & Thermal Anem & $1 \%$ of Setpoint \\
\hline SR1_F3_KGH & Atomizing O2 Calculated Mass Flow Rate Based on Raw Value from MFC & Brooks & Thermal Anem & $1 \%$ of Setpoint \\
\hline SR1_P1_VAL & Pressure at Bottom of Fluidized Bed (PSIA) & Rosemount & Capacitive & $0.2 \%$ Span \\
\hline SR1_PD1_VAL & Differential Pressure Across Distributor Plate (inH2O) & Rosemount & DP Cell & $0.25 \%$ of Span \\
\hline SR1_PD2_VAL & Differential Pressure Across Lower 13 in of Fluidized Bed (Density) (inH2O) & Rosemount & DP Cell & $0.25 \%$ of Span \\
\hline SR1_PD3_VAL & Differential Pressure Across Fluidized Bed (inH2O) & Rosemount & DP Cell & $0.25 \%$ of Span \\
\hline SR1_T11_VAL & Wall Temperature of Upper Disengaging Section (oC) & Idaho Lab & Type K & $\pm 2.2^{\circ} \mathrm{C}$ \\
\hline SR1_T12_VAL & Wall Temperature of Mid Disengaging Section (oC) & Idaho Lab & Type K & $\pm 2.2^{\circ} \mathrm{C}$ \\
\hline SR1_T13_VAL & Wall Temperature of Lower Disengaging Section (oC) & Idaho Lab & Type K & $\pm 2.2^{\circ} \mathrm{C}$ \\
\hline SR1_T15_VAL & Cooling Water Jacket Temperature on Feed Nozzle (oC) & Idaho Lab & Type K & $\pm 2.2^{\circ} \mathrm{C}$ \\
\hline SR1_T19_VAL & Wall Temperature of Upper Fluidized Bed (oC) & Idaho Lab & Type K & $\pm 2.2^{\circ} \mathrm{C}$ \\
\hline SR1_T2_VAL & Bed Temperature at Bottom of Fluidized Bed (oC) & Idaho Lab & Type K & $\pm 2.2^{\circ} \mathrm{C}$ \\
\hline SR1_T20_VAL & Wall Temperature of Lower Fluidized Bed (oC) & Idaho Lab & Type K & $\pm 2.2^{\circ} \mathrm{C}$ \\
\hline SR1_T3_VAL & Bed Temperature at 5 in Fluidized Bed Height (oC) & Idaho Lab & Type K & $\pm 2.2^{\circ} \mathrm{C}$ \\
\hline SR1_T4_VAL & Bed Temperature at 11 in Fluidized Bed Height (oC) & Idaho Lab & Type K & $\pm 2.2^{\circ} \mathrm{C}$ \\
\hline SR1_T5_VAL & Bed Temperature at 17in Fluidized Bed Height (oC) & Idaho Lab & Type K & $\pm 2.2^{\circ} \mathrm{C}$ \\
\hline SR1_T6_VAL & Bed Temperature at 23in Fluidized Bed Height (oC) & Idaho Lab & Type K & $\pm 2.2^{\circ} \mathrm{C}$ \\
\hline SR1_T7_VAL & Off-gas Temperature in Lower Disengaging Section $(\mathrm{oC})$ & Idaho Lab & Type K & $\pm 2.2^{\circ} \mathrm{C}$ \\
\hline SR1_T8_VAL & Off-gas Temperature in Mid Disengaging Section (oC) & Idaho Lab & Type K & $\pm 2.2^{\circ} \mathrm{C}$ \\
\hline SR1_T9_VAL & Off-gas Temperature in Upper Disengaging Section (oC) & Idaho Lab & Type K & $\pm 2.2^{\circ} \mathrm{C}$ \\
\hline T7_P_VAL & Vapor Space Pressure in T-7 Tank (PSIA) & Rosemount & Capacitive & $0.2 \%$ Span \\
\hline T7_T1_VAL & Scrub Solution Temperature in T-7 Tank (oC) & Idaho Lab & Type K & $\pm 2.2^{\circ} \mathrm{C}$ \\
\hline T7_T2_VAL & Off-gas Temperature at Tank T-7 Discharge (oC) & Idaho Lab & Type K & $\pm 2.2^{\circ} \mathrm{C}$ \\
\hline V1_F1_VAL & Gas Supply Mass Flow at System Inlet (kg/hr) & Micro Motion & Coriolis & $+\underline{0.044 \%}$ \\
\hline
\end{tabular}


Table C-2. Precision, accuracy, and detection limits for critical laboratory measurements.

\begin{tabular}{|c|c|c|c|c|c|c|c|c|}
\hline \multicolumn{2}{|c|}{\begin{tabular}{|l|} 
\\
Measurement \\
\end{tabular}} & $\begin{array}{l}\text { Method } \\
\text { (a) }\end{array}$ & $\begin{array}{l}\text { Detection } \\
\text { Limits, } \\
\mathrm{mg} / \mathrm{kg} \text { or } \\
\mathrm{mg} / \mathrm{L}\end{array}$ & $\begin{array}{c}\text { Precision , \% } \\
\text { RPD for } \\
\text { Duplicate } \\
\text { Analyses (b) } \\
\end{array}$ & $\begin{array}{c}\text { Accuracy, \% } \\
\text { Error of } \\
\text { CCV }\end{array}$ & $\begin{array}{c}\text { Matrix Spike, } \\
\% \text { recovery }\end{array}$ & $\begin{array}{c}\text { TCLP } \\
\text { Detection } \\
\text { Limits, } \mathrm{mg} / \mathrm{L} \\
\end{array}$ & $\begin{array}{c}\text { TCLP } \\
\text { Matrix Spike } \\
\text { (\% recovery) }\end{array}$ \\
\hline \multirow{2}{*}{ Nitrate } & $\mathrm{NO}_{2}$ & \multirow{2}{*}{ IC } & 0.059 & & $1.4 \pm 3.2$ & 102 & & \\
\hline & $\mathrm{NO}_{3}$ & & 0.300 & & $3.7 \pm 3.7$ & 104 & & \\
\hline Carbon & TOC & PUO-IM & & 55.0 & & & & \\
\hline \multirow{29}{*}{ Elemental } & $\mathrm{Ag}$ & ICP-AES & & & & & 0.0096 & 77 \\
\hline & $\mathrm{Al}$ & ICP-AES & 0.071 & 3.30 & $3.5 \pm 0.5$ & 101 & & \\
\hline & As & ICP-AES & & & & & 0.0282 & 100 \\
\hline & B & ICP-AES & 0.042 & & $-5.0 \pm 0.7$ & 104 & & \\
\hline & $\mathrm{Ba}$ & ICP-AES & & & & & & 99.0 \\
\hline & $\mathrm{Be}$ & ICP-AES & & & & & 0.0012 & 100 \\
\hline & $\mathrm{Ca}$ & ICP-AES & 0.021 & 1.75 & $-0.2 \pm 0.9$ & 95.3 & & \\
\hline & $\mathrm{Cd}$ & ICP-AES & & & & & 0.0036 & 99.4 \\
\hline & Cs & ICP-MS & 0.054 & 0.17 & $-4.0+0.4$ & 111 & & \\
\hline & $\mathrm{Cr}$ & ICP-AES & 0.010 & 6.87 & $-0.4 \pm 0.4$ & 103 & 0.0018 & 99.3 \\
\hline & $\mathrm{Cu}$ & ICP-AES & 0.014 & 1.90 & $-2.3 \pm 0.5$ & 101 & & \\
\hline & $\mathrm{Fe}$ & ICP-AES & 0.006 & 14.8 & $-2.5 \pm 0.7$ & 98.9 & & \\
\hline & $\mathrm{Hg}$ & CVAA & 0.010 & 9.37 & & 96.9 & 0.0005 & \\
\hline & $\mathrm{K}$ & ICP-AES & 0.167 & 4.35 & $-6.3 \pm 2.1$ & 96.2 & & \\
\hline & $\mathrm{Mg}$ & ICP-AES & 0.003 & 2.80 & $4.0 \pm 0.1$ & 100 & & \\
\hline & $\mathrm{Mn}$ & ICP-AES & 0.003 & 2.30 & $-0.1 \pm 0.5$ & 97.5 & & \\
\hline & $\mathrm{Na}$ & ICP-AES & 0.068 & 3.75 & $-3.8+2.4$ & 97.8 & & \\
\hline & $\mathrm{Ni}$ & ICP-AES & 0.007 & 4.52 & $-3.1 \pm 0.5$ & 99.3 & 0.0048 & 97.5 \\
\hline & $\mathrm{Pb}$ & ICP-AES & 0.059 & 1.72 & $7.8 \pm 0.7$ & 102 & 0.0222 & 96.9 \\
\hline & $\mathrm{Re}$ & ICP-MS & 0.300 & 0.23 & $-5.9 \pm 0.6$ & 102 & 0.0198 & 103 \\
\hline & $\mathrm{S}$ & ICP-AES & 0.037 & 0.40 & & 102 & & \\
\hline & $\mathrm{Sb}$ & ICP-AES & & & & & 0.0390 & 100 \\
\hline & $\mathrm{Se}$ & ICP-AES & & & & & 0.0294 & 101 \\
\hline & $\mathrm{Si}$ & ICP-AES & 0.053 & 47.0 & $4.6 \pm 1.6$ & 100 & & \\
\hline & $\mathrm{Sn}$ & ICP-AES & 0.022 & 1.30 & $9.3 \pm 0.7$ & 94.2 & & \\
\hline & $\mathrm{Tl}$ & ICP-AES & & & & & 0.0294 & 99 \\
\hline & $\mathrm{V}$ & ICP-AES & & & & & 0.0168 & 100 \\
\hline & $\mathrm{Zn}$ & ICP-AES & 0.005 & 13.3 & $-2.2+0.4$ & 100 & & 100 \\
\hline & $\mathrm{Zr}$ & ICP-AES & 0.009 & 10.5 & $5.1 \pm 0.3$ & 71.8 & & \\
\hline \multirow{3}{*}{ Anions } & $\mathrm{Cl}$ & \multirow{3}{*}{ IC } & 0.082 & 4.1 & $2.4 \pm 2.4$ & 102 & & \\
\hline & $\mathrm{F}$ & & 0.092 & 14.8 & $-0.6+2.8$ & 103 & & \\
\hline & $\mathrm{SO}_{4}$ & & 0.293 & 5.8 & $2.7 \pm 2.4$ & 99.7 & & \\
\hline
\end{tabular}

a. Ion Chromatography (IC), Persulfate-Ultraviolet Oxidation/Combustion-Infrared method 5310B/C (PUO-IM), Inductively Coupled Plasma Atomic Emission Spectroscopy (ICP-AES), Cold Vapor Atomic Absorption (CVAA)

b. $\mathrm{RPD}=$ Relative percent difference $=2 \times$ (Measurement $2-$ Measurement 1$) /($ Measurement $1+$ Measurement 2$) \times 100 \%$

Goal for precision is $+5 \%$ relative percent difference (RPD).

Goal for accuracy is $\pm 20 \%$ error for continuing calibration verifications (CCVs).

Goal for accuracy is $100 \pm 20 \%$ for Matrix spike recovery

All calculations in the PLC and in data reduction spreadsheets were validated by limited sampling of hand calculations and by limited comparisons to other validated results from prior tests.

Laboratory data were flagged if conditions during analysis such as proximity to detection limits or full-scale values, interferences, or blank values cause the data to be suspect. 


\section{C-1.5 Internal Quality Control Checks and Specific Routine Procedures for Quality Assurance}

Internal quality control checks for this project included quality assurance/quality control (QA/QC) samples, calibration checks, equipment maintenance and handling, and protocols or procedures specified in each of the sampling and analysis methods.

QA/QC samples included blank and duplicate samples. Duplicate samples were used to indicate analytical precision.

Test system and sampling equipment was inspected when it was used for functionality, cleanliness, wear, corrosion, or other issues that could affect its performance for this test program. The CEMS operations included routine inspections and maintenance of all components, leak checks, zero and span calibrations, linearity checks, bias checks, interference checks, drift checks, sample gas flow rate and pressure monitoring and control, dilution checks, and temperature monitoring and control. Test personnel used laboratory notebooks and data sheets to maintain orderly and well-documented records of the test program. 